\title{
ADAPTIVE COLLABORATIVE MANAGEMENT IN FOREST LANDSCAPES
}

VILLAGERS, BUREAUCRATS AND CIVIL SOCIETY

Edited by

Carol J. Pierce Colfer, Ravi Prabhu, and Anne M. Larson 
This is a thought-provoking and engaging book about how a global initiative on adaptive collaborative management has helped transform the lives of both rural community members and researchers. It provides an inspiring account of the enormous power of shared learning experiences. What makes the book stand out to me are the personal reflections by the authors, especially when it comes to the many struggles involved in creating and sustaining this innovative initiative.

Krister Andersson, Professor of Political Science and Director, The Center for the Governance of Natural Resources, University of Colorado at Boulder, USA

This book explores the critical role researchers and development practitioners have in promoting collaboration and reflexive learning. A reminder that engagement should not be taken for granted, chapters offer insightful approaches to unpack what collaboration is really about and why it is needed to advance transformative development outcomes. Drawing on a comprehensive set of situations that span diverse geographies and topics, the book provides insightful perspectives to address emerging challenges in natural resources governance.

Iliana Monterroso Ibarra, Scientist, Co-Coordinator of Gender and Social Inclusion Research, CIFOR, Guatemala City, Guatemala

What a privilege to share these authors' quest to apply appealing concepts: Learn by doing and adjust. Work alongside groups you support. Listen to diverse perspectives. Recognize disparities. Their amazing exploration shows those concepts' huge promise and complexity. Few final answers, but tons of wisdom. Well worth the ride.

David Kaimowitz, Manager of the Farm and Forest Facility at the UN Food and Agriculture Organization, and CIFOR's second Director General

This book provides a unique and rare reflection on a multi-year learning programme on adaptive collaborative management. The cases engage a reader as a co-learner in the evolution of the participatory action research approach and its outcomes. The honest reflection of the authors reveals the quality of implementation and their own development in these processes. A great read, with lots of lessons for anyone engaging in complex natural resource management interventions!

Jürgen Hagmann, Institute for People, Innovation and Change in Organisations 
Building adaptive and collaborative capacity requires ability to learn by and learn from doing, seeking long-run improvements over time; it demands inclusivity while turning participation on its head. This book demystifies the processes for researchers and the communities they engage alike, while highlighting the value of emergent outcomes on the Research - Action continuum.

Nadarajah Sriskandarajah, Professor of Environmental Communication (Emeritus), Swedish University of Agricultural Sciences, Uppsala, Sweden

This collection by three leading scientists in the world of natural resource governance demonstrates brilliantly the potential and impact of adaptive collaborative management - as a means to advance sustainability and democracy, to co-produce knowledge and practice, and to strengthen governance processes. Its insights will be of interest to students, professors, and researchers and to scholars and decision makers alike.

Arun Agarwal, Professor, SEAS, University of Michigan, Ann Arbor, USA

A timely reminder about the untapped potential of exploring theories about practice in environmental governance. At once illuminating in its genealogy and rich for its empirical applications across tropical forest regions in Asia, Africa, and Latin America, this book provides both a window into praxis and a menu for those driven by collaborative interests in addressing pressing environmental challenges at a landscape scale. It is both rich empirically and unique for its generalizability, catching readers up with important dimensions of thinking around gender, justice, and representation in ACM. With all the hype around participatory approaches and knowledge co-production in both research initiatives and development projects, this book reminds readers how to easily avoid classic mistakes and shows what it takes to nurture better participatory process to achieve more meaningful outcomes in environmental governance.

Micah Fisher, Assistant Professor, Department of Urban and Regional Planning, University of Hawaii, Honolulu, USA

ACM has evolved over the past couple of decades and has demonstrated its worth as a multidisciplinary participatory approach in achieving practical, social and research outcomes. This volume brings together researchers, many of whom have been involved in ACM since its inception, to reflect on their experiences in applying ACM and participatory action research in a wide range of complex natural resource management settings. It is a valuable addition to the research and development literature.

Don Gilmour, Chair of ACM International Steering Committee from 2000, and Adjunct Associate Professor, Forest Research Institute, University of the Sunshine Coast, Queensland, Australia 


\section{Adaptive Collaborative Management in Forest Landscapes}

This book examines the value of adaptive collaborative management for facilitating learning and collaboration with local communities and beyond, utilizing detailed studies of forest landscapes and communities.

Many forest management proposals are based on top-down strategies, such as the Million Tree Initiatives, Forest Landscape Restoration (FLR) and REDD+, often neglecting local communities. In the context of the climate crisis, it is imperative that local peoples and communities are an integral part of all decisions relating to resource management. Rather than being seen as beneficiaries or people to be safeguarded, they should be seen as full partners, and adaptive collaborative management is an approach that prioritizes the rights and roles of communities alongside the need to address the environmental crisis. The volume presents detailed case studies and real-life examples from across the globe, promoting and prioritizing the voices of women and scholars and practitioners from the Global South who are often under-represented. Providing concrete examples of ways that a bottom-up approach can function to enhance development sustainably via its practitioners and far beyond the locale in which they initially worked, this volume demonstrates the lasting utility of approaches like adaptive collaborative management that emphasize local control, inclusiveness and local creativity in management.

This book will be of great interest to students, scholars and practitioners working in the fields of conservation, forest management, community development and natural resource management and development studies more broadly.

Carol J. Pierce Colfer is currently a Senior Associate at the Center for International Forestry Research (CIFOR) and Visiting Scholar at Cornell University's Southeast Asia Program, Ithaca, New York, USA. She is the author/editor of numerous books, including Masculinities in Forests (Routledge, 2020), The Earthscan Reader on Gender and Forests (Routledge, 2017) and Gender and Forests (Routledge, 2016).

Ravi Prabhu is a Forester with 30 years of international experience. He began his international career with CIFOR and has been with World Agroforestry (ICRAF) since 2012 and is the Deputy Director General-Research. Since January 2020, he is also the Director of Innovation, Investment and Impact at CIFOR-ICRAF. He won the Queen's Award for Forestry in 2005, presented by HM Queen Elizabeth II.

Anne M. Larson has been a Principal Scientist at the Center for International Forestry Research (CIFOR) since 2012. She is currently the Team Leader for Equal Opportunities, Gender, Justice and Tenure at CIFOR and also co-coordinates the Governance of Natural Resources flagship of the Policies, Institutions and Markets (PIM) CGIAR Research Program. Anne serves on the Council of the International Land Coalition (ILC) and the board of directors of the Rights and Resources Initiative (RRI). 


\title{
The Earthscan Forest Library
}

\section{Series Editorial Advisers:}

John L. Innes, University of British Columbia, Canada; John Parrotta, US Forest Service - Research \& Development, USA; Jeffrey Sayer, University of British Columbia, Canada; and Carol J. Pierce Colfer, Center for International Forestry Research, USA.

This series brings together a wide collection of volumes addressing diverse aspects of forests and forestry and draws on a range of disciplinary perspectives. It is aimed at undergraduate and postgraduate students, researchers, professionals, policy-makers and concerned members of civil society.

\section{Forest Ecosystem Management and Timber Production}

Divergence and Resource Use Resilience

Russell Warman

\author{
A New Era for Collaborative Forest Management \\ Policy and Practice insights from the Collaborative Forest Landscape \\ Restoration Program \\ Edited by William Butler and Courtney Schultz
}

Forest Conservation and Sustainability in Indonesia

A Political Economy Study of International Governance Failure

Maxton Bernice-Lee

\author{
Masculinities in Forests \\ Representations of Diversity \\ Carol J. Pierce Colfer
}

\author{
Adaptive Collaborative Management in Forest Landscapes \\ Villagers, Bureaucrats and Civil Society \\ Edited by Carol J. Pierce Colfer, Ravi Prabhu, and Anne M. Larson
}

For more information about this series, please visit: http://www.routledge .com/books/series/ECTEFL 


\section{Adaptive Collaborative Management in Forest Landscapes}

Villagers, Bureaucrats and Civil Society

Edited by Carol J. Pierce Colfer, Ravi Prabhu, and Anne M. Larson 
First published 2022

by Routledge

2 Park Square, Milton Park, Abingdon, Oxon OX14 4RN

and by Routledge

605 Third Avenue, New York, NY 10158

Routledge is an imprint of the Taylor \& Francis Group, an informa business

(C) 2022 selection and editorial matter, Carol J. Pierce Colfer, Ravi Prabhu, and Anne M. Larson; individual chapters, the contributors

The right of Carol J. Pierce Colfer, Ravi Prabhu, and Anne M. Larson to be identified as the authors of the editorial material, and of the authors for their individual chapters, has been asserted in accordance with sections 77 and 78 of the Copyright, Designs and Patents Act 1988.

The Open Access version of this book, available at www.taylorfrancis.com, has been made available under a Creative Commons Attribution-Non Commercial-No Derivatives 4.0 license.

Trademark notice: Product or corporate names may be trademarks or registered trademarks, and are used only for identification and explanation without intent to infringe.

British Library Cataloguing-in-Publication Data

A catalogue record for this book is available from the British Library

Library of Congress Cataloging-in-Publication Data

Names: Colfer, Carol J. Pierce, editor. | Prabhu, Ravi, editor. |

Larson, Anne M., editor.

Title: Adaptive collaborative management in forest landscapes: villagers, bureaucrats and civil society/edited by Carol J. Pierce Colfer, Ravi

Prabhu, and Anne M. Larson.

Description: Abingdon, Oxon; New York, NY: Routledge, 2022. |

Series: The Earthscan forest library | Includes bibliographical references and index.

Identifiers: LCCN 2021027508 (print) | LCCN 2021027509 (ebook)

Subjects: LCSH: Forest landscape management. | Landscape protection. |

Forest management. | Forestry and community. | Sustainable forestry.

Classification: LCC SD387.L35 A33 2022 (print) | LCC SD387.L35 (ebook) |

DDC 333.76-dc23

LC record available at https://lccn.loc.gov/2021027508

LC ebook record available at https://lccn.loc.gov/2021027509

ISBN: 978-1-032-05367-7 (hbk)

ISBN: 978-1-032-05368-4 (pbk)

ISBN: 978-1-003-19725-6 (ebk)

DOI: $10.4324 / 9781003197256$

Typeset in Bembo

by Deanta Global Publishing Services, Chennai, India 
This book is dedicated to the memory of Dr Esther Mwangi, a colleague who died prematurely and contributed significantly to the research presented in a number of the chapters in this book. 


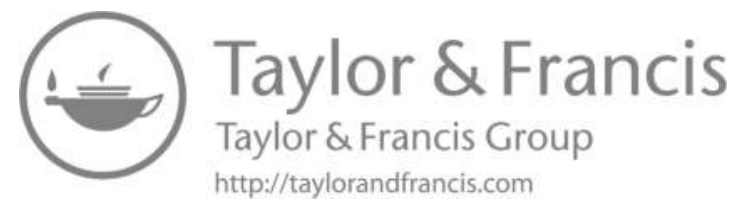




\section{Contents}

List of boxes, figures and tables

Foreword xiii

Acknowledgements xvi

Contributors xvii

Glossary and Abbreviations xxii

1 Adaptive collaborative management: Experiential and theoretical forebearers

CAROL J. PIERCE COLFER, RAVI PRABHU, AND ANNE M. LARSON

2 Local people's perspectives on action learning: Impressions from the Amazon

JAMES JOHNSON AND BENNO POKORNY

3 Researcher collaboration complexities in participatory action research: Zambian experiences

T. MUTIMUKURU-MARAVANYIKA, E. MADZUDZO AND M. M. SONGE

4 Gender and adaptive collaborative management in forested Ugandan landscapes

ALLAN BOMUHANGI, ABWOLI YABEZI BANANA, JIMMY BUSHOBOROZI, CONCEPTA MUKASA, ALICE TIBAZALIKA AND ESTHER MWANGI

5 Strengthening women's tenure rights and participation in community forestry in central Uganda

CONCEPTA MUKASA, ALICE TIBAZALIKA, ABWOLI YABEZI BANANA, ESTHER MWANGI AND TENDAYI MUTIMUKURU-MARAVANYIKA

6 Capacity building for ACM: Lessons learned from training in distinct contexts 
x Contents

7 Learning from adaptive collaborative management:

A participatory tool to support adaptive and reflective learning in multi-stakeholder forums

JUAN PABLO SARMIENTO BARLETTI

8 How does adaptive collaborative management leverage changes in power? Insights from social theory

CYNTHIA McDOUGALL AND HEMANT OJHA

9 Can activist engagements have research outcomes?: The case of $\mathrm{ACM}$ and participatory action research

ROBERT FISHER AND WILLIAM JACKSON

10 Circles and spirals

RAVI PRABHU, ANNE M. LARSON AND CAROL J. PIERCE COLFER

Index 


\section{List of boxes, figures and tables}

\section{Boxes}

1.1 Adaptive collaboration management - defined (from Colfer 2005a, 4)

3.1 A story that shows a lack of understanding by researchers of reasons to collaborate

$\begin{array}{lll}3.2 & \text { Researcher conflict due to different backgrounds } & 75\end{array}$

$\begin{array}{lll}8.1 & \text { Equity and CBNRM } & 191\end{array}$

10.1 Elements of the SHARED approach 250

$\begin{array}{lll}10.2 & \text { A global paradigm shift } & 254\end{array}$

\section{Figures}

2.1 Chronological overview of the reported activities. 34

3.1 Map showing the Barotse Floodplain. 64

3.2 Expected linkages between the global, Lusaka and Barotse
Hub researchers.

$\begin{array}{llr}4.1 & \text { Study sites. } & 89\end{array}$

$\begin{array}{lll}5.1 & \text { Participatory action research process. } & 108\end{array}$

5.2 Lake Victoria Crescent covering the initial study districts
of Mpigi, Masaka and Rakai.

$\begin{array}{lll}5.3 & \text { Framework of implementation of ACM activities. } & 115\end{array}$

$\begin{array}{lll}7.1 & \text { Sample completed reflection sheet. } & 175\end{array}$

$\begin{array}{ll}8.1 & 188\end{array}$

10.1 Map of Kenya, showing Turkana County. 248

10.2 The phases of the SHARED Framework. 249 


\section{Tables}

3.1 Examples of factors that make NRM and agricultural systems complex

$\begin{array}{lll}3.2 & \text { Levels of collaboration and their characteristics } & 67\end{array}$

$\begin{array}{lll}3.3 & \text { Summary of dreams from the communities } & 73\end{array}$

4.1 Study areas (sites with ACM indicated by *) 90

4.2 Demographic characteristics of the respondents 91

4.3 Participation of women in forest management activities in ACM and non-ACM sites 94

4.4 Men's and women's perceptions of the quality of their own participation in forest management activities

4.5 Factors that determine women's participation in forest management in ACM vs. non-ACM sites

4.6 Factors that determine men's participation in forest management in ACM vs. non-ACM sites

4.7 Forest products harvested by women and men in ACM and non-ACM sites 99

4.8 Perceptions on availability/abundance of forest resources $\quad 100$

4.9 Gender dimensions of forest product and income use 101

$\begin{array}{lll}5.1 & \text { Selected study sites (see also Table 4.1) } & 111\end{array}$

$\begin{array}{ll}5.2 & \text { Attendance per community } \\ 5.3 & 113\end{array}$

5.3 Number of trees planted by men and women user group members, four years after the facilitation of ACM processes in 2015

5.4 Leadership in ACM groups in $2016 \quad 120$

5.5 Women's leadership roles in ACM groups in $2020 \quad 121$

$\begin{array}{lll}\text { 5.6 Status of ACM group activities in } 2020 & 125\end{array}$

7.1 MSF case studies in CIFOR's research (table by Nicole Heise) 164

$\begin{array}{lll}7.2 & \text { Research-based indicators } & 173\end{array}$

$\begin{array}{ll}7.3 \text { "Local” indicators } & 174\end{array}$ 


\title{
Foreword
}

\author{
Jeff Sayer
}

Forests that for generations had been managed by the communities who lived in and around them are now the subject of actions by global conventions, multi-national companies and environmental activists. Forests are now expected to provide multiple goods and services whose nature and extent are constantly changing. Forest management has to adapt to changing external environments and changing demands - it has to deal with constantly moving targets. There is competition between the claims of the relatively small number of local stakeholders and a growing number of more distant "global citizens" with expectations for forests. These competing claims can only be effectively reconciled through intensified collaboration among all actors. We now have a cacophony of claims and counterclaims in an environment where attention spans have shortened and institutional memories are fading. Activists pursue the latest silver bullet solution to the world's forest issues, and donors want problems solved within the time span of their ever-shortening funding cycles. Experts fly in and fly out and prescribe instant solutions. Emotions and opinions have more influence than evidence. Social media and academic publications allow advocates to exert an influence that is beyond their competence - too few people have "skin in the game." Forests are subject to "whack a mole" interventions where the latest bright idea gains centre stage for a brief time before attention shifts to another silver bullet solution.

We are all bombarded with information relevant to decision making on forests. Trying to keep pace with the new material is like trying to drink from a fire hose. It often seems that people's opinions on forest issues are inversely correlated with their knowledge. People who advocate for simple solutions usually don't fully understand the complexity of the issues. There is an obsession with fighting threats and a lack of interest in long-term scenarios.

My enthusiasm for this book stems from the fact that it runs counter to these concerns. The authors of all of the chapters are people who do have "skin in the game"; they have all spent long periods in the field seeking better outcomes for local people and their environments, and they all know how difficult it is to achieve this. The authors have extensive experience from some of the world's most contested forest landscapes, and they know that they are always dealing with wicked problems. There is no single "right" answer to 
forest trade-offs; forest management is always challenged by the need to adapt to changing pressures and demands and by the need to ensure collaboration among a diversity of actors with claims on forest lands. The chapters in this book bring together decades of practical learning from a wide diversity of situations.

The book does not lead us to a simple recipe for adaptive collaborative management, and if it had done so it would have failed in its ambition. There is rarely any simple recipe that can solve forest conflicts. The book allows us to benefit from the long-term learning of accomplished scientists who have studied these issues together with local and global actors.

The concepts underlying ACM have been evolving over three decades and are gradually having an influence on the institutions that govern forest landscapes. The authors of this book have been central to that movement and have quietly nudged it in the direction of greater inclusivity. They are part of a process that has pushed forestry institutions away from their historical "command and control" view of forest management towards approaches that allow the emergence of governance systems that will broaden and sustain the range of benefits that societies obtain from forests. Government forestry institutions and the international agencies that support them have not been good at adapting forest management to deal with changing pressures and opportunities, nor at achieving the partnerships and collaborations that are essential to optimal forest outcomes. These institutions have not been good at learning; rather they have been locked into historically determined models of forest management. This is not only true of formal forestry institutions, but even activists have not been good at adapting and collaborating, and many have tended to be "single issue fanatics" who have been expert at shutting out any competing understandings of the issues around forests. The world has been limited in its ability to go beyond simplistic metrics such as areas deforested, the extent of old growth or primary forests, mean annual increment and annual allowable cut. All of these metrics derive from a narrow view of the world of forests and of the expectations of civil society. Fisher and Jackson in Chapter 9 of this volume argue that even activists have to learn and adapt.

Formal institutions and especially aid agencies have been wedded to the idea that multi-stakeholder fora should play a determining role in forest governance - yet Sarmiento Barletti in Chapter 7 explores the difficulties of making these fora work effectively. The importance of gender-disaggregated decision making on forests is explored in Chapters 4 and 5 by Bomuhangi et al. and Mukasa and colleagues, respectively, from Uganda - this is a subject that still requires a lot more investigation and where tricky trade-offs and long entrenched power dynamics have to be addressed.

Participation is a mantra of forest institutions that is challenged in Chapter 7 by Sarmiento Barletti, who points out that nobody argues against participation, but there are issues around who participates, how do they participate and how do we avoid tokenism. Saxena, cited in Chapter 7, coined the aphorism "You participate - but we manage." Forestry institutions have often 
been highly selective in what they have decentralized and how much control they have retained at the centre.

ACM requires deep engagement with local people. MutimukuruMaravanyika, Madzudzo, and Songe explore the difficulties of engaging people in research in such complex environments from their experience in the Miombo forests of Zambia. Johnson and Pokorny report on similar experiences in the Amazon. All of the authors are both scientists and practitioners, and the chapters in this book combine to present a wealth of real-world learning.

Forestry institutions are changing, and Colfer, Prabhu and Larson have been at the centre of changes that have permeated thinking and practice on decentralized forest management over three decades. Colfer and Prabhu introduced the concept of ACM to the international forestry narrative in the 1990s. The term ACM embraces a diversity of practices that engage a broad range of actors in decision making on forests - it is not a simple formula. ACM has accompanied a broad tendency to move the locus of decision making on forests away from the centre and towards the periphery. This decentralizing process allows for forest management to be adapted to local contexts, and every context is different. Conditions are constantly changing, and so are the demands that society places on forest landscapes; so the process of adaptation is continuous. Achieving better outcomes requires changing the behaviour of all the actors whose decisions determine the fate of forests. The intensity of collaboration among actors has to increase. Collaborative management requires that some actors, particularly state forest agencies, forfeit power, and greater responsibility has to be assumed by actors who are embedded in the landscapes. The science database, "Academia," recorded a total of 2475 published papers on ACM when accessed in April 2021. The authors of this volume have been involved in much of this work and have certainly inspired the entire ACM movement. They have been responsible for a quantum shift in the ways forest management happens today.

We need diverse and sustained benefit flows from forest landscapes to meet development and environmental goals. Forestry and civil society environmental institutions will need to expand their competencies to deal with the multiplicity of contexts within which the world's forests need to be managed. The lessons of decades of experience of ACM encompassed in this book will provide a rich resource for professionals and for building institutions. Global targets for forests to meet climate change, biodiversity, desertification and other goals will only be achieved if the management of all the world's forests is much better adapted to local contexts and is driven by collaboration among the numerous stakeholders concerned. The work of Colfer, Prabhu, Larson and their colleagues, brought together in this volume, should serve to inspire and inform all those who seek sustainable futures for our forests. 


\section{Acknowledgements}

We wish to acknowledge the support of our respective programmes and institutions: the two Consultative Group on International Agricultural Research (CGIAR) programmes, "Policies, Institutions and Markets" (PIM) and "Forest, Trees and Agroforestry" (FTA); the Center for International Forestry Research, World Agroforestry and Cornell University (especially the Southeast Asia Program), have provided us with a variety of in-kind resources. We are grateful as well to all the authors who have contributed to this collection, all of whom have made their contributions without a specific budget being allocated for this work, and similarly, to the 20 anonymous volunteer reviewers (and two known ones). We also appreciate the efforts of the staff at Earthscan, Hannah Ferguson, John Baddeley and Nancy Antony for their consistently cooperative and encouraging words of wisdom and help throughout the publication process. Our biggest debt of gratitude goes to the communities - at various scales - who have contributed their time and effort in the adaptive collaborative management efforts described herein. We have all learned a great deal about the ACM process, among other things, from them, and hope that their efforts can have broader impacts among this book's readers. 


\section{Contributors}

Abwoli Y. Banana is a Professor in the Department of Forestry, Biodiversity and Tourism, School of Forestry, Environment and Geographical Sciences, Makerere University. Although with a background in wood science and technology, Banana has a wide experience in teaching and research in the fields of community forestry and in institutions that affect access and utilization of forestry resources in Eastern Africa. Over the decades, he has worked closely with scientists in CIFOR on forest tenure and gender in forestry management.

Allan Bomuhangi is currently a Climate Change Adaptation Specialist with the United Nations Environment Program - Technical University of Denmark (UNEP-DTU) partnership. His interests are in gender, climate change adaptation, forest management reforms and land property rights.

Jimmy Bushoborozi is a Graduate Student pursuing an MSc in Agribusiness Management at the Department of Agribusiness and Natural Resources Economics, Makerere University, Kampala, Uganda. He has worked with research projects focusing on sustainable land management, forest governance and value addition in semi-arid cereal crops. Bushoborozi also works with Hinterland Consults Ltd - an agricultural-based research organization.

Carol J. Pierce Colfer is an Anthropologist who has, since joining CIFOR in 1994, specialized in collaborative approaches, gender, health, governance and sustainable management of forests. She has extensive ethnographic experience in the United States, the Middle East and Indonesia and in international comparative research, mainly in the tropics. She is currently a Senior Associate with CIFOR and a Visiting Scholar in Cornell University's Southeast Asia Program.

Peter Cronkleton is a Senior Scientist (Anthropologist) at CIFOR and has worked as a researcher and development practitioner in Latin America and Africa for more than 23 years. Cronkleton is a specialist in community forestry, forest governance, tenure and policy reform, sustainable livelihoods and participatory approaches for development. He is currently based in Peru. 
Kristen Evans is a Research Consultant at CIFOR. She has worked as a CIFOR researcher since 2004 on projects in Bolivia, Nicaragua, Vietnam and Ghana, primarily as a field team trainer and workshop facilitator in participatory methods such as ACM. She has a background in social science and biochemistry. She writes plays and puppet shows and raises chickens with her daughter.

Robert (Bob) Fisher is an Anthropologist who has worked extensively in community forestry and natural resource management in a number of countries in Asia and Africa, particularly Nepal, Thailand and Papua New Guinea. He was heavily involved in action research at the University of Western Sydney, Hawkesbury, between 1991 and 1996, and was Deputy Director of the Regional Community Forestry Training Center in Bangkok (1997-2001). He is currently a Senior Lecturer in Human Geography at the University of Sydney and a Senior Research Fellow at the University of the Sunshine Coast in Australia.

William (Bill) Jackson is an Environmental Consultant with over 40 years' experience in conservation and community management of natural resources. He is currently an adjunct Professor at the University of the Sunshine Coast. He has worked on community management of natural resources in Nepal, Africa, Latin America and elsewhere in Asia. His PhD used an action research approach. He was the chief author for the Australia State of Environment Report 2016 and has held positions of Chief Executive of Parks Victoria and Deputy Director General of the International Union for Conservation of Nature (IUCN).

James M. Johnson, an independent researcher, has a background in agriculture and forestry. He has worked in community forestry and integrated land management across the Amazon region, largely in Bolivia, where he lives with his family, running a small farm, putting theory into practice while linking with policy and decision-making processes.

Anne M. Larson has been a Principal Scientist at CIFOR since 2012. She is currently the Team Leader for Equal Opportunities, Gender, Justice and Tenure there and also co-coordinates the Governance of Natural Resources flagship of the Policies, Institutions and Markets (PIM) CGIAR Research Program. She was based in Lima, Peru, until 2019 and is now located in Washington, DC. Larson serves on the Council of the International Land Coalition (ILC), the board of directors of the Rights and Resources Initiative (RRI) and the CGIAR Gender Platform Management Committee.

Elias Madzudzo is a Lecturer in the Sociology of Development and Migration at Great Zimbabwe University. He has applied participatory action research in research in development projects in the Communal Area Management Programme for Indigenous Resources (Zimbabwe); Fodder Innovation Project (Nigeria); Research into Use Project (Malawi); the Strengthening 
Aquatic Resource Governance Project and the Aquatic Agricultural Systems Programme (Zambia). Madzudzo's research interests include innovation studies, natural resources governance and ethnicity.

Cynthia McDougall was the Team Leader for the ACM research in Nepal while at CIFOR; she subsequently led the gender research theme at WorldFish, and now, the Stockholm Environment Institute's Gender, Environment and Development team. She is an Interdisciplinary Social Scientist with over 20 years of experience in gender and social equity, food security and natural resource governance. Her particular interest is in mixed methods, participatory action research and gender transformative approaches and how these can leverage scalable shifts towards empowerment, equality, poverty reduction, food and nutrition security and sustainability.

Concepta M. Mukasa is a Programme Manager for Forestry and Environment in the Association of Uganda Professional Women in Agriculture and Environment (NGO) in Uganda. She is the holder of a masters in agroforestry and BSc forestry degrees from Makerere University Kampala. She has a postgraduate diploma in Forestry for Rural Development from ITC in the Netherlands. She has co-authored a number of infobriefs on community forestry and gender with CIFOR.

Tendayi Mutimukuru-Maravanyika is a Lecturer at Great Zimbabwe University, Masvingo, Zimbabwe. She is a natural resources management expert with several years of experience in designing and implementing participatory action research projects in forestry, fisheries and agriculture to deal with real-life challenges faced by African rural communities. She has worked in several African Countries including Zimbabwe, Zambia, Ghana, Ethiopia and Uganda.

Esther Mwangi (deceased, 2019) was an environmentalist, public policy expert and scholar, with an interest in understanding how equity and inclusion influence livelihoods and conservation outcomes of forestry resources. She worked for CIFOR. From 2014, Mwangi was both the team leader for the CIFOR Nairobi Hub and a Principal Scientist with the Equal Opportunities, Gender, Justice and Tenure team (formerly the Forests and Governance Program). Together with Anne Larson, she led a comparative study on gender and tenure in Uganda and Nicaragua and "Securing Tenure Rights for Forest-Dependent Communities: A Global Comparative Study of Design and Implementation of Tenure Reform." These two projects demonstrate the comprehensive and systematic approach to research for which she was best known.

Hemant Ojha is Associate Professor for the University of Canberra and a Principal Advisor for a Sydney-based research and development consulting firm, the Institute for Study and Development Worldwide (IFSD). From his early work in Himalayan South Asia, Ojha has worked progressively 
across Asia and the Pacific as well as in parts of Africa, with a strong focus on climate change, water security and natural resource management. With his cross-disciplinary educational background in natural and social sciences, he champions locally based action research and multi-scalar political economic analysis for positive impacts on climate resilience and sustainable development. He has taught at Australian universities with a focus on postgraduate student supervision and has conducted research in Asia and Africa on a range of environmental governance issues. His books have been published by Routledge and Cambridge, and he writes actively in both academic and public media. He has also advised and consulted for a number of international development institutions.

Benno Pokorny, a Professor for Rural Development at the Faculty of Environment and Natural Resources at the University of Freiburg (currently with GIZ [Deutsche Gesellschaft für Internationale Zusammenarbeit] in Brazil), focuses on the question of whether and how natural resources in tropical and subtropical regions can be used effectively for sustainable local development for and with local resource users.

Ravi Prabhu is a Forester with 30 years of international experience. He began his international career with CIFOR and has been with World Agroforestry (ICRAF) since 2012 and is the Deputy Director General-Research. Since January 2020, he is also the Director of Innovation, Investment and Impact at CIFOR-ICRAF. He won the Queen's Award for Forestry in 2005, presented by HM Queen Elizabeth II.

Juan Pablo Sarmiento Barletti is a Peruvian Social Anthropologist at CIFOR in Lima, Peru. He has worked with Indigenous Amazonian societies for the past 15 years, carrying out collaborative research examining their experiences of natural resource extraction ventures and climate change initiatives implemented in their ancestral territories, and related experiences of rights violations and socio-environmental injustice. Before joining CIFOR, Sarmiento Barletti held posts at the universities of Durham, St Andrews and Sussex in the UK.

Jeff Sayer is Professor of Forest Conservation in the Department of Forest and Conservation Sciences, Faculty of Forestry, at the University of British Columbia. He was CIFOR's first Director General and held that office when our original ACM research was being planned and conducted. He has a long history of global involvement in conservation, ecology, and related policy issues, as well as considerable field experience.

Mwansa M. Songe is a Zambian Veterinary Pathologist, specializing in aquatic medicine. She is currently employed as a Veterinary Research Officer concerned with fish health at the Central Veterinary Research Institute in Zambia. Her work encompasses surveillance, management and control of fish diseases. Songe has previously worked in small 
animal practice, academia and international research institutions within the CGIAR. Current interests and activities include an aquatic animal health strategy for Zambia, mainstreaming aquatic biosecurity, emergency preparedness and contingency planning for aquatic animal diseases in Zambia and the region.

Alice Eunice Tibazalika holds MSc and BSc (Agriculture) degrees from Makerere University and postgraduate diplomas in management and in nutrition. She is working with the Association of Uganda Professional Women in Agriculture and Environment (AUPWAE), as a Capacity Development Officer, working on agriculture, gender and environment, and has participated in CIFOR projects. 


\section{Glossary and Abbreviations}

AAS Aquatic Agricultural Systems programme in the Barotse Floodplain in western Zambia - a participatory action research programme

ACM Adaptive collaborative management; an approach whereby people who have interests in a natural resource agree to act together to plan, observe and learn from the implementation of their plans while recognizing that plans often fail to achieve their stated objectives. It is characterized by conscious efforts among such groups to communicate, collaborate, negotiate, resolve conflicts and seek out opportunities to learn collectively about the impacts of their actions

action research Research carried out by a team encompassing a professional action researcher and members of an organization or community seeking to improve their situation. AR promotes broad participation in the research process and supports action leading to a more just or satisfying situation for the stakeholders (adapted from Lewin 1998, p. 4)

agency The human actor's ability to learn, reflect and choose actions, even in the face of structural constraints

ALITAS A Bolivian NGO working on veterinary issues

Anlo Beach A fishing community in Ghana

AR Action research

auto-appraisal A structured assessment of local conditions, needs and opportunities, carried out by teams of community members trained as facilitators rather than by external technicians

Baganda Most common ethnic group in Uganda ACM sites (Chapter 5)

Barotse A floodplain in Zambia

Bioversity A CGIAR research centre situated in Rome, focusing on biodiversity

BOLFOR USAID's Bolivian Sustainable Forest Management Project (mid-1990s-mid-2000s)

bolivianos Bolivian currency

Bonn Challenge The challenge to bring 150 million hectares of degraded and deforested landscapes into restoration by 2020 and 350 million hectares by 2030 
C\&I Criteria and indicators

CAM Collaborative adaptive management - a similar approach to ACM, with a greater emphasis on the United States

campesino A farmer, in Spanish; peasant

CAPRI A CGIAR multi-centre programme on Collective Action and Property Rights

CARE International A non-governmental organization

Cedro In Bolivia, Cedro includes a number of species that belong to the genus Cedrela spp., especially Credrela odorata

CFM Collaborative Forest Management (Uganda)

CFP Community forest organization, Bolivia

CFR Central Forest Reserve (Uganda)

CGIAR Consultative Group of International Agricultural Research

chaco Crop land, Bolivia

CIDP County Integrated Development Plan (in Kenya, a government planning instrument)

CIFOR Center for International Forestry Research

co-generation (of knowledge) A process whereby a team or individual works together with another(s) to analyse and learn together

CRP Collaborative research programme

DDPI East Kalimantan's Provincial Council on Climate Change (Dewan Daerah Perubahan Iklim), Indonesia

decentralization A process whereby authority (and sometimes budget) is moved from a more central institution to a more peripheral or lower bureaucratic level

DFID Department for International Development, UK

DGIS Ministry of Foreign Affairs of the Netherlands

DoF Department of Forest, Nepal

doxa Bourdieu's (1998) concept: "a particular point of view, the point of view of the dominant, which presents and imposes itself as a universal point of view" (p. 57)

DTI Design Techniques Implementation (a team in the Africa Regreening project)

empowerment A process in which people denied the ability to make strategic life choices acquire the ability to do so.

ethnographic Research informed by long-term involvement, observation, communication and systematic study in the communities of interest

extractive research Data taken from communities with little or no feedback of information or direct benefit to them

facilitation A crucial function within ACM to encourage and support an equitable interchange of ideas among stakeholders, including shared and/ or complementary decision making, and to move the iterative process forwards

FECOFUN A network of community forest user groups (Nepal) 
FLORES Forest Land Oriented Resource Envisioning System - a simulation system designed for forest contexts (initially at CIFOR, led by Jerry Vanclay)

ForLive Action research project in Bolivia

FPIC Free, Prior and Informed Consent

FSR\&D Farming Systems Research and Development

FSSD Forest Sector Support Department (Uganda)

GEF Global Environment Facility; established in 1992 to help tackle the Earth's most pressing environmental problems

gender "Gender [is] a sociocultural system that organizes the practices and relationships that play out among humans, and between humans and their environment, infusing them with power and meaning that refers symbolically to sex and sexuality" (Paulson 2016, pp. 1-2; or see Chapter 8. fn 3)

GoU Government of Uganda

governance Ways and institutions through which people/groups express their interests, exercise rights and obligations and mediate differences

GPS Global positioning system

ha Hectare

hacienda Cattle ranch, Bolivia

How are we doing? A participatory tool for use in multi-stakeholder forums to help monitor progress towards the group's goals (Chapter 7)

ILRI International Livestock Research Institute

inclusivity Ensuring that all relevant individuals are "at the table" and have an equitable voice

indicators Actions, results, feelings, etc. monitored to assess progress towards goals that have been chosen (can complement or replace reflexivity)

Ingeniero Professional agricultural technicians receive the university title of ingeniero agronomo, which is abbreviated to Ing.

INRA National Institute of Agrarian Reform (Instituto Nacional de Reforma Agraria), responsible for defining land rights and granting titles, Bolivia

institutions A framework of rules for achieving particular social or economic goals; organizations refer to the specific structural forms of such institutions

interdisciplinary Coordination among disciplines in problem formulation, analysis and interpretation, characterized by mutual acceptance and understanding, SOMETIMES applying other disciplines' methods and approaches; Interdisciplinary research may lead to new questions and methods

interpretivist A view of the world as subjective - a result of human interpretation and construction

iterative reflection Cycles or loops where conscious phases of group reflection are interspersed with information collection and analysis

IUCN International Union for the Conservation of Nature

IWMI International Water Management Institute 
learning loops Process of planning, action and reflection (here, in support of natural resource management)

LDD Land Degradation Dynamics (a geospatial analysis team in Africa Regreening)

LLS Livelihoods and Landscapes Strategy (an IUCN program)

Mafungautsi A state forest in Zimbabwe where ACM was conducted in the early 2000s

M\&E Monitoring and evaluation

management Management is to an organization or sector (like forestry) what governance is to society at large (see "governance")

MBO Management by objectives

MEL Monitoring, Evaluation and Learning (more narrowly, a project team in Africa Regreening)

motacu Thatch from Attalea phalerata, a palm

MOU Memorandum of Understanding

MSF Multi-stakeholder forum; also called multi-stakeholder platforms

multi-disciplinary People from different disciplines collaborate to address a jointly identified problem, interpret results, from the perspective of one dominant discipline

multi-stakeholder forum Purposely organized interactive process that brings together a range of stakeholders to participate in dialogue, decision making and/or implementation regarding actions seeking to address a problem they hold in common or to achieve a goal for their common benefit

NAFP Nepal Australia Forestry Project

NFA National Forestry Authority, Uganda

NFTP National Forest and Tree Planting, Uganda

NGO Non-governmental organization

Nitlapan Institute of Research and Development of the Central American University of Nicaragua

NTFP Non-timber forest product

Nuevo Horizonte Fictitious community where participatory action research was carried out in Bolivia (Chapter 2)

panchayat Local government, Nepal

PAR Participatory action research; a process of systematic inquiry that is collective, collaborative, self-reflective and undertaken by participants seeking to answer questions about real life concerns to improve their wellbeing

Pedro Martinez Fictitious farmer collaborating in participatory action research efforts, Bolivia (Chapter 2)

positivist A world view in which the world is seen as objectively "out there" to be investigated, without researchers themselves being part of it

power Refers to the ability to act, including influencing and controlling events and people. Socially, one can differentiate power over, power to and power with. ACM seeks the latter two 
PROMETE An NGO, Bolivia

Proyecto Pollito A project dealing with chickens, Bolivia

RACCN Nicaragua's Northern Caribbean Autonomous Region

Realist Synthesis Review A method allowing for the systematic, comparative analysis of how contexts affect an initiative's outcome, revealing "what works, for whom, in what circumstances, and why"

REDD+ Reducing Emissions from Deforestation, forest Degradation and the role of conservation, sustainable management of forests and enhancement of forest carbon stocks in developing countries -- intended to contribute to addressing climate change

reflexivity A process whereby a team or individual examines and assesses the progress they have made towards a previously identified goal; it involves a researcher turning the investigative lens towards themselves by explicitly examining how their research agenda, assumptions, beliefs and emotions influenced the outcome of a research process; can be complemented with use of indicators

restoration Usually reforesting a degraded area; sometimes planting trees in an area without them

RnD Research in Development, Zambia

scenarios Images (within ACM) of desirable (and undesirable) futures developed together by collaborating groups

SDG Sustainable Development Goal; a set of 17 global goals designed, together, to address human and environmental wellbeing by 2030

SERNANP Protected Areas Service, Peru

SHARED Stakeholder approach to risk, informed and evidence-based decision making

Social capital Networks of mutually beneficial relationships among people who live and work in a particular society, contributing to society's functioning

Srta. Seniorita, an unmarried woman or girl, Bolivia

stakeholder An individual with an interest in a topic of interest (e.g., in forest management)

strategic research Research midway between applied and academic research; research with significant utility for policymakers and other users, but more theoretically sophisticated than much applied research

Superintendencia Forestal Forest Service, Bolivia

systemic Recognizing interconnections and feedbacks among parts (e.g., of a culture, an institution, a habitat)

T\&S Travel and Subsistence, Zambia

TCO Spanish acronym for Tierra Comunitario de Origen or Indigenous Community Land, Bolivia

transdisciplinary Research problems are jointly formulated by all team researchers, with collaborators accepting and adapting new methods, analysis and interpretation that span multiple disciplines

UH University of Hawaii in Honolulu, Hawaii, USA 
UNICEF United Nations International Children's Emergency Fund

USAID United State Agency for International Development

UWS-H University of Western Sydney, Hawkesbury

visioning A process during which participants imagine the futures they would like to see/realize

WAFFI West African Forest-Farm Interface project, Ghana (also in Burkina Faso)

wicked problems Problems with many interdependent and dynamic factors making them difficult to solve, requiring a deep understanding of the stakeholders and contexts involved as well as innovative approaches. Relevant factors may be incomplete, in flux and difficult to define

WorldFish A One CGIAR research centre focusing on aquatic food systems, with its headquarters in Penang, Malaysia. 


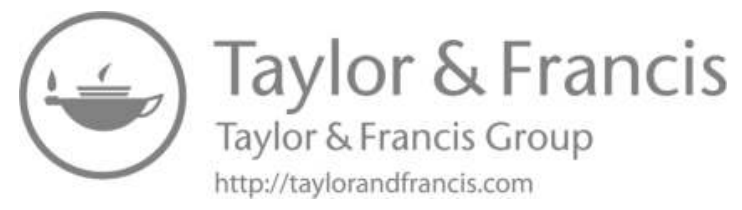




\title{
1 Adaptive collaborative management
}

\section{Experiential and theoretical forebearers}

\author{
Carol J. Pierce Colfer, Ravi Prabhu, \\ and Anne M. Larson
}

\section{Introduction}

We begin this book with these observations about forests and natural resource management, which have become widely accepted in recent years:

- We are dealing with "wicked problems."1

- Life's problems (human and otherwise) are interconnected and systemic and can rarely be solved through reductionist or unilinear approaches.

- Sustained involvement of and shared decision making with local communities are key.

- Inclusivity is desirable and probably necessary if we hope for peace and prosperity overall.

- Actors - in communities, the wider social context, and the environment have differing amounts of power and different agendas; these influence the human capacity and freedom to act.

With these observations in mind, we have brought together a cadre of 22 researchers - the authors of this book - from a wide variety of fields and countries, ${ }^{2}$ representing decades of experience working collaboratively with communities around the world. They have produced this treasure trove of examples and guidance on adaptive collaborative management - designed to move us forwards to learn from what has gone before (just as we encourage communities to do in their own adaptive processes).

Adaptive collaborative management (or ACM) is an approach in which shared learning, experimentation, and adaptation are key principles, as are inclusivity and shared decision making at various levels - all of which will become clear in the pages to follow (see Box 1.1 for a preview). These contributing authors, who responded with alacrity and enthusiasm to our May 2020 invitation to contribute, move us all forwards in our understanding of:

- The ways local communities often experience ACM efforts;

- Processes that encourage gender and tenurial inclusivity in forest restoration;

- Constructive ways that disciplinary misunderstandings can be managed; 
2 Carol J. Pierce Colfer et al.

- The training needed for communities, teams, and other stakeholders in how to do ACM;

- The functioning and improvement of multi-stakeholder forums;

- The significance and management of power in adaptive collaborative processes; and

- $\quad$ ACM as research and/or action. ${ }^{3}$

\section{BOX 1.1 ADAPTIVE COLLABORATION MANAGEMENT - DEFINED (FROM COLFER 2005A, 4)}

Adaptive collaborative management, in our usage, is a value-adding approach whereby people who have interests in a forest agree to act together to plan, observe, and learn from the implementation of their plans while recognizing that plans often fail to achieve their stated objectives. ACM is characterized by conscious efforts among such groups to communicate, collaborate, negotiate, and seek out opportunities to learn collectively about the impacts of their action.

The lessons from this approach are useful not only for researchers who choose to adopt an ACM approach specifically, but also for any initiative that contemplates engaging with communities and that accepts the observations that open this chapter - whether the goals are forest landscape restoration, climate adaptation or mitigation, improved management of extractive industries, biodiversity conservation, nature-based solutions, and/or much more.

\section{Justification for the ACM approach}

One central idea in our initial conceptualization of ACM (beginning 1998) was that success in any such effort over the long term would mean that local people were both willing and empowered to sustain them. We recognized the frequency with which all action stops on a project once the funding disappears. That led us to conclude that continually counting on donors - so frequently the case - to sustain conservation/development efforts made no sense. We hoped that genuine and shared local analysis, planning, monitoring, and reflection could render plans and actions more appropriate - and thus more acceptable and sustainable - for local environmental and social needs.

Another central idea was a concern for equity: how could we fashion conservation/development efforts in such a way that women, marginalized ethnic groups, and 'the poor' might participate and benefit at least as much as outsiders or elites?

Still another justification was the recognition that each place is unique, and that therefore standardized solutions were not going to apply universally. In 
terms of research, could we develop mechanisms or methods that would allow practitioners and policy and other decision makers to analyse and learn about local contexts themselves and respond to them appropriately, constructively, and cooperatively? We also believed that, from an action or practice perspective, facilitating social learning processes might build on and strengthen local people's abilities to learn from their own experiences, adapt to changing conditions more effectively and resiliently, and enhance their power to influence change.

Our version of $\mathrm{ACM}^{4}$ initially inspired work at the community and forest management unit level in 11 mainly tropical countries for periods ranging from two to six years (2000-2006). ${ }^{5}$ These time spans were far shorter than we felt we needed, but donors were not prone, in those days, to grant longer-term funding. We'd estimated 10-15 years as the likely period of time this approach would require to really take hold - a time period recognized in 2010 in the US Collaborative Forest Landscape Restoration Program, which shares many features with ACM (e.g., Butler and Schultz 2019).

Later, in the mid-2000s, we took these ideas to other contexts, striving to adapt them to broader scales. We built on the work of Tsing (2005), Vayda (1983), and later Ojha et al. (2016); each of whom showed the mutual interactions among scales, demonstrating its relevance for action. In Indonesia, we worked in Jambi, Sumatra, at both the village and district (kabupaten) level, incorporating a more substantial governance component into our work with the CAPRI (Collective Action and Property Rights) programme. ${ }^{6}$ Shortly thereafter, we attempted the same approach in a Landscape Mosaics programme that included sites in five countries, ${ }^{7}$ combining village and landscapelevel efforts, with a greater focus on environmental management. Principles of ACM were also built into restoration projects that went beyond the edge of the forest into agriculture, with very promising results (discussed further in Chapters 4, 5, and 10).

This book will provide much more information about the ACM processes we experienced. But in this chapter, we go back in time to ACM's precursors. We approach this as a conversation among the three co-authors, as we revisit the theories and observations that influenced our fashioning of ACM. We hope to bring the reader along this journey back in time, thereby clarifying some of the understandings that underlie our approach.

We recognized from the beginning that we were not inventing an entirely new "beast." Rather, we were putting existing knowledge together in a way rarely done at that time. " $[\mathrm{F}]$ ar more often than not, what we call beginnings are fulfillments of things set in motion a long time ago" (Gail Godwin, novelist 1999, p. 3). The principles we accepted, and on which we based ACM, are reflected in the six approaches summarized in (Marald et al. 2017), among others: the ecosystem approach, the ecosystem-based approach, resilience thinking, the social-ecological systems framework, the ecosystem services approach, and reflexive governance. The literature on ACM, however, tends to be more explicit than these about ways to implement these principles with communities and with equity firmly in mind and practice. 


\section{Our paths to ACM}

In this section, we differentiate ourselves to show the variety of backgrounds and experiences that initially contributed to the development of ACM (Colfer, Prabhu), and in its more recent iteration (Larson), we highlight where we converge and diverge in our understandings and practice.

It all began when Prabhu, a forester, was hired by the Center for International Forestry Research (CIFOR) in 1994 to lead a project that aimed to develop criteria and indicators (C\&I) to inform fledgling efforts on forest certification and develop a sound scientific basis in support of the credibility of these efforts. Within months of taking up the responsibility in Bogor, Indonesia, he realized that he needed the skills, training, and experience of a social scientist who understood how local communities interacted with forests around the world. He turned to Colfer to help test and develop indicators for social aspects of sustainability. By the year 2000, this work had spawned a network of efforts around the world, such that the C\&I team at CIFOR (Prabhu, Colfer, and others) felt the time had come to take the next steps and let others continue with the momentum that had been generated.

For Prabhu, this came with the challenge, articulated by CIFOR administrators, to formulate and pitch the next funded project. His journey to ACM began with C\&I and the quest for sustainability, which he saw as predicated on equity and innovation/learning (which in turn were related to decision making). His training as a forester helped him to look to the longer term. The C\&I project had been globally controversial, and Prabhu remembers being sometimes viciously criticized - as different certification bodies competed for preeminence (a political context we strove to avoid).

His experience in that project taught him how important the creation of shared experience was in providing a platform on which analysis and decisions could be based. It was in the creation of these shared experiences and the nonpartisan evidence that was thrown up in the process that the C\&I project was able to bring around influential parties who had previously been so critical. This left a deep impression.

Prabhu's interest in how indicators could be used began to change. The C\&I project had focused on indicators' uses as assessment tools. But he was concluding that, in fact, C\&I seemed to work best when used by those who had developed them to make their own decisions. These ideas had emerged as the team audited a forest enterprise in Kalimantan (Indonesian Borneo), testing three certification schemes produced by professional certification companies. It was becoming clear that certification pathways alone were too limited a use of indicators in decision making. While CIFOR had concentrated on the local level ("Forest Management Unit") C\&I, others had been focusing on national and global C\&I as tools for analysis, reporting, and communication. But how all this - the development of excellent C\&I - could actually affect decisions, attitudes, and behaviours remained unclear. He was interested in whether transformational learning actually resulted. Who learned? How? And with what effect? 
The opportunity to frame the first ACM project - at that time still called "adaptive co-management," came as a result of conversations that Prabhu had at the Asian Development Bank, which was interested in funding a project with CIFOR in three Asian countries. This was to be based on the theoretical framework of adaptive management that Buzz Hollings, Carl Walters, and others had developed, but inspired by discussions that Prabhu had with Colfer, Wollenberg and NC Saxena. Saxena had written the "Saga of Participatory Forest Management" (1997) during a short sabbatical at CIFOR and had influenced Prabhu's thinking on the dangers of the formalization of participatory processes and elite capture.

At this time, another team at CIFOR had started approaching the topic from a different angle -Lini Wollenberg and Louise Buck (see e.g., Buck et al. 2001; Wollenberg, Anderson, and Edmunds 2001b; Wollenberg, Edmunds, and Buck 2000; Wollenberg et al. 2001a). Prabhu remembers Buck as having initially used the term "collaborative."

Colfer, a cultural anthropologist, meanwhile, joined Prabhu at CIFOR in late 1994 and continued working full time until 2009 and part time after that. As with other jobs, she'd had to learn the world views of her colleagues, the ways foresters and others involved in forests saw the world, their professional customs. CIFOR was unusual within the forestry world for its focus on policies and people, interest in multiple scales (including community or forest management unit level), and commitment to interdisciplinarity and teamwork, all of which were attractive and congenial for her. However, there remained strong biases in favour of quantitative and experimental methods, the search for generalizability, and quantified impact assessment (less to her liking). ${ }^{10}$ There was also a requirement to do comparative research, which was new to her.

She worked first on Prabhu's C\&I project. Her first role was to develop the C\&I that could monitor improvements in human well-being in forest concessions. The C\&I teams conducted month-long fieldwork in Côte d'Ivoire, Brazil, Indonesia and the United States. Colfer was initially sceptical about the reliability of what we could learn in one month, but each team worked with local researchers to fill knowledge gaps. A second phase involved developing social science methods to assess these C\&I quickly, as would be needed for certification of the sustainability of forest management in any given concession (see the nine volumes in CIFOR 1999). Again, local partners were knowledgeable about the areas CIFOR teams knew less about.

Throughout all this, Colfer and Prabhu developed an excellent working relationship. Both were interested in learning from the other and had similar goals about both the conservation and development implications of our work (then and now). We were able to avoid the common interdisciplinary communication problems examined in Chapter 3.

ACM emerged out of this experience, combined with findings from Wollenberg's programme on devolution of forest management, which had come to many similar conclusions. As Prabhu and Colfer thought about the next steps, one direct influence was his reading of Kai Lee's Compass and 
Gyroscope (Lee 1993), which laid out in simple English the underlying approach of adaptive management - an approach that differed from ACM in not including the collaborative element and focusing on a wider scale but also shared a number of features (mainly systems and experimental and learning approaches). Prabhu and Colfer had adjacent offices and meandered back and forth, discussing our work. Prabhu called Colfer over one day and showed her what he was reading. The proverbial "light bulb" went off in her head - as Prabhu remembers it, one that had already gone off in Louise Buck's head. Buck and Wollenberg's emphasis at that time was on including communities in conversations and decisions around conservation. Colfer remembers thinking, if we just added "collaborative" to "adaptive management," our work could integrate the people we both hoped could benefit as much as the environment.

The shift from "co-management" to "collaborative management" evolved, intended to address the complaint that some communities felt they should have primary rights to manage their own locale (e.g., Rice 2001, for the Ikalahan in the Philippines) - a sentiment we understood, while realizing that in other cases (e.g., multi-ethnic or in-migrating communities), this might not be possible.

ACM's value in both conflict resolution and the development of shared perspectives became increasingly clear as we moved forwards. Prabhu remembers working in collaboration with Cynthia McDougall's team (Chapter 8), for instance, to bring together polarized stakeholders (the Nepali Government and NGOs, both our partners) whose communications had been disrupted by the Maoist insurgency, the network of community forest user groups (FECOFUN), and others. Prabhu, with McDougall's team, created an informal breakfast group that met once a fortnight to listen to reports from the community forest user groups involved in ACM. This allowed both sides to continue to reconsider their thinking and compromise on decision making outside formal negotiation arenas. They were thereby able to build on social capital that had been built up over many years among the individuals concerned. ${ }^{11}$

Another step that proved necessary was convincing the powers at CIFOR that this was worth doing. ${ }^{12}$ Prabhu recalls the scepticism of both the Director General and the Research Director in the late 1990s regarding both participatory action research (PAR) and ACM. They felt that PAR would not generate the kind of data that would lead to the generalizable conclusions that the Consultative Group on International Agricultural Research (CGIAR) centres were supposed to deliver. Many once-sceptical scientists have altered their views in the intervening years, realizing that principles discovered in such processes may well be generalizable and that individual cases, understood in systemic ways, can provide insights applicable in other places. Another objection Prabhu recalls hearing: "We can't always be holding their [community members'] hands."

Prabhu and Colfer concluded from the C\&I work that while the hierarchically organized principles and criteria might be generalizable, indicators and verifiers were certainly not. But Prabhu notes that at that stage, as we 
were formulating ACM, we were only hypothesizing what principles might be key, nor did we yet have data on what particular contexts might require. We also noted that, although Colfer had experience with PAR, no one else on our team did. Prabhu remembers the workshop that was convened early on, with leadership from Bob Fisher and Mohammad Emadi, as making a lasting impression on him, and it provided valuable understanding to all team members. This effort by Prabhu and Colfer was a precursor to the kind of training now recognized as essential and described well in Chapters 6 and 7.

What we proposed was neither experimental ${ }^{13}$ nor quantitative in its orientation. We had often been told that CIFOR's work was to be "strategic," located midway on a continuum between "applied" and "academic." CIFOR leaders worried that our plans were too "applied", that perhaps an NGO should be doing what we proposed (see Chapter 9). The need for the ethnographic component Colfer saw as central (and as genuine research) was not clear to the forestry world (nor, we have to admit, were we able to fully implement her wish in our work). ${ }^{14}$

Our intent was also to study the process of collaboration and adaptation, as we implemented it - and thereby learn how to do it better and in other places. We wanted to test ACM - as we understood it and its underlying processes in several different contexts, much as we had done successfully with the C\&I project earlier. Prabhu helped to set up the studies in three Asian countries Nepal, Philippines, and Indonesia, the first two selected because of the long history with formalized community forest management approaches and the latter because of our good understanding of forest and local community interactions as a result of our history in Indonesia. He then moved to Zimbabwe to help set up and manage the projects in four countries where the European Union had agreed to support ACM research. We selected two countries in the drier miombo forest region of Zimbabwe and Malawi and two in humid forest locations of Cameroon and Ghana. Prabhu's move was predicated on the need to build new teams for Africa that could conduct participatory action research within ACM.

A little later, thanks to work by Cronkleton in Bolivia and Pokorny and Schmink in Brazil, we were able to extend the initial set of research sites to Latin America during the "first wave" of research. Our own work included a second wave attempting to broaden the scale (CAPRI and Landscape Mosaics); and Larson, Mwangi, and others picked up the work in a third wave that brings us to our present understanding of ACM and how to foster its emergence with local communities, actors, and other stakeholders. In one sense, this book (and our next volume) documents the coming to fruition of the hope that ACM can emerge and be nurtured under very different conditions for the benefit of those involved. As this book and others also demonstrate, ACM has proven useful in contexts far beyond the humid tropical rainforests in which we originally assessed it.

When we began this initial journey, we were urged strongly (in fact, required) to pre-define some contextual studies more fully than we had initially planned, 
identifying features ${ }^{15}$ that we could examine in all our sites - intended to fulfil the generalizability and quantitative concerns of the institution's leadership (the Director General, the Board of Trustees, some of our colleagues). By the time Larson proposed using ACM, the institution's reluctance had melted away; she had met no resistance. ${ }^{16}$

This was by then the early 2010s, when Anne Larson, whose $\mathrm{PhD}$ is in Wildland Resource Science with an emphasis on resource policy and institutions, joined the fray. Together with her CIFOR colleague, the late Esther Mwangi, she implemented a comparative ACM project in Nicaragua and Uganda.

Larson came to ACM from a somewhat different direction and without being part of this history. In the 1990s, she used a political ecology approach for her dissertation research, which explored the relationship between peasants, poverty, and land-use behaviour, examining local people's land-use decisions in their multiple-scale and historical contexts. Specifically, she studied the challenges of "conservation and development" from the perspective of peasants themselves, taking a critical look at various kinds of participatory approaches. Her research since then has focused on power relations in forest decentralization and devolution processes, including forest tenure reforms. So-called participatory approaches that failed to support local decision making were always a concern, and the search for an approach that empowered marginalized groups (women, indigenous peoples) also led her to ACM.

ACM seemed like the perfect approach to use for a new project on tenure that focused on improving women's access to forest land and resources through community-level decision making. ACM was based on embedded local learning, collaboration, and reflection. The idea of Larson's project was to empower women by supporting them, in mixed groups, to define their own needs and priorities regarding forest management and then collaboratively pursue solutions. ACM could, in theory, support women's empowerment in ways highly sensitive to community life and respect for local perspectives (e.g., not imposing Western feminist views). Her only concern was that ACM might be "too local," given that the problems of, and solutions to, deforestation and forest degradation were strongly shaped by forces beyond local communities.

\section{Intellectual forebears}

Here, we switch to the theoretical and disciplinary perspectives that led us to this approach. ACM is a collage of influences from different disciplines. We discuss the different fields that influenced our respective thinking as we developed the concept, and in Larson's case, as she and her teams moved it forwards. We begin with the theoretical perspectives Colfer brought to the programme, as the approach makes significant use of social science as its foundation (something unusual in the early 2000s within CIFOR and other centres in the CGIAR). Prabhu discusses issues that arose as we rolled out the 
programme, and Larson describes her own intellectual orientation as it affected subsequent work in Latin America and Africa.

\section{Key early social scientific theories}

Trained as an anthropologist, Colfer was greatly influenced by that discipline. In developing ACM, Prabhu and Colfer made extensive use of social scientific literature and ideas. In this section, we draw on literature relating to (1) the knowledge and rationality of forest peoples, (2) collective action, (3) stability and change, (4) interlinked scales, (5) inter- and trans-disciplinary collaboration, (6) the involvement of policymakers, (7) power, and (8) systems thinking and iterative process. Although separated here to reflect the streams of literature discussing each topic, many of these intersect (e.g., systems thinking is likely to require input from various disciplines and attention to more than one scale, knowledge may intersect with collective action, etc.). We present these literature/theories to make clear our own epistemological orientation as well.

\section{The knowledge and rationality of forest peoples}

In graduate school (1967-1969), Colfer focused on, and expected to continue to study, cognitive and psychological anthropology. She was intrigued with ethnoscience and later applied it in Indonesia (Colfer, Peluso, and Chin 1997 or Colfer 1991). She appreciated Metzger and Williams' (1966) work on different ways the Tzeltal (of Mexico) categorized firewood and the methods these researchers used to identify/describe what they found. She made subsequent use of taxonomic analysis, componential analysis (e.g., Goodenough 1956, on Trukese kinship), and triadic sorting - all initially from linguistics - as she tried to capture/reflect the mindset and knowledge of the people whose lives she sought to understand. Such studies confirmed the capacities of rural peoples, of forest peoples, to observe, classify, and build on their own experience - capacities that were widely questioned until recent decades. ${ }^{17}$

Her doctoral research made use of The Psychology of Personal Constructs by Kelly (1963) - also influential in her thinking about people's observational and analytical capabilities. This theory of personality and cognition postulates that human beings are like scientists in many ways, routinely making predictions based on their own experience and tending to want at some level to make accurate predictions (even if the predicted future is not a desirable one). Kelly's ideas have meshed well with her decades of observations of people everywhere and have influenced her sense of the logic - based on the assumptions extant in a particular place or person or group - of the people she has worked with.

Later, she studied swiddening, learning from Conklin's (1957) seminal study of swidden agriculture in the Philippines, emphasizing the complexity of people's indigenous knowledge. Other early relatively sympathetic treatments of swidden agriculture - so common (and so maligned) in the tropical forests we studied at CIFOR and in ACM - included Kunstadter, Chapman, and Sanga's 
(1978) collection on Southeast Asian Farmers of the Forest and Dove (1981) on Kantu' swiddeners in West Kalimantan. Such analyses from the literature were augmented by her own long-term experience of swiddening, its variety, logic, and sustainability (in many cases) in East Kalimantan (Colfer and Dudley 1993), West Kalimantan (Dudley and Colfer 1993), and West Sumatra (Colfer 1991).

\section{Collective action}

Long ago, Margaret Mead wrote "Never doubt that a small group of thoughtful, committed citizens can change the world. Indeed, it is the only thing that ever has" - a dictum we took seriously. This view was further advanced by Elinor Ostrom (1990), whose work identified principles of collective action. ${ }^{18}$ These were carried further by her students and the CGIAR programme Collective Action and Property Rights, led by Ruth Meinzen-Dick. A belief in the potential of collective action and shared learning - that would further empower communities and groups within communities - led us to build both centrally into ACM.

Some of these ideas came together for our initial team when we invited Bob Fisher (1995; Fisher and Jackson 1998) and Mohammad Emadi (1995) to give that first workshop, mentioned above, on PAR and collaboration, the approach we intended to use in implementing ACM (see Chapters 9 and 10). Fisher continued his involvement in ACM via participation in the International Steering Committee and later in leading two writing workshops for our teams (both field and headquarters). ${ }^{19}$

\section{Stability and change}

The conclusions Colfer reached, about the logics of forest people's systems, differ from both ideas about unchanging traditionalism, on the one hand, and many economists' view that people always act "rationally" in their economic interest, on the other. Rather, if one looks at the values, beliefs, and expectations in a particular place, one can usually understand the logics being followed and also the variety of decisions people make based on their varying rationales and conditions. We strove, within ACM, to understand both the coherence and stability of cultural systems as well as individual/subgroup differences and change over time.

Although we had no name in 1998 for our recognition that history, the present and the future interconnect and mutually influence each other, Marald et al. (2017) call this awareness "transtemporality." ACM's concerns with historical context, current shared learning and decision making, and future visioning reflect this recognition and its relevance.

\section{Interlinked scales}

In the 1980s, Colfer was drawn into the ecological anthropological (or human ecology) literature. By serendipity, she worked with Andrew P. Vayda on 
the 1979 proposal and the resulting research mentioned earlier that led to his 'progressive contextualization' (Vayda 1983; Vayda et al. 1980). In 1981, she looked at "tree cutting in context" (published later in Colfer 2008a), which involved examining multiple scales and chains of causation outwards from the East Kalimantan village where she lived and back into it. This approach was helpful as we switched at CIFOR to an emphasis on governance, providing a theoretical basis for moving from one scale to the next, showing the causal links among them.

Later, as we became involved in CIFOR's governance programme, Colfer turned to Tsing's (2005) work, Friction, also on Kalimantan. Tsing examined the "friction" that exists when policies from afar are implemented in a particular place ("when the rubber meets the road"). Ferguson (1994) also provided a refreshingly insightful, if discouraging, view of how development works and how scales intersect in southern Africa. Many of his observations coincided, or functioned in parallel fashion, with Colfer's in other contexts. Roe's (1994) writings on the strengths and inaccuracies of global narratives were also influential - we examined global policies and trends as they affected (or failed to affect) local level realities.

\section{Inter- and trans-disciplinary collaboration}

As we dove ever deeper into the extensive development literature, seeking sources of inspiration and important ideas for ACM's development, we focused on the teamwork and interdisciplinary communication that would be necessary. Maruyama (1974) wrote an analysis of the paradigmatic differences among disciplines and cultures that provided a good theoretical basis for our treatment of disciplinary differences as comparable with cultural differences. When Colfer joined the College of Agriculture and Human Resources at the University of Hawaii (UH) in 1980, she knew almost nothing about the disciplines within agriculture. Her strategy to overcome this was to interview individuals in each department, beginning with each department chair, just as she had interviewed villagers, trying to learn how these scientists saw the world. This strategy, combined with participant observation, remained a useful one whenever she encountered practitioners of a new discipline. Interdisciplinary communication and collaboration are central in ACM.

In a Farming Systems Research and Development (FSR\&D) project in the early 1980s at UH and in Sumatra, Colfer and colleagues drew on the work of Shaner, Phillip, and Schmehl (1982) and Norman (1982) - who all called for collaboration with farmers (also incorporating local knowledge, collective action, systems, and iterative place-based approaches, and interdisciplinarity, though focused squarely on agriculture). The UH FSR\&D team found Hildebrand's (1986) practice of "sondeos"20 (a precursor to "rapid rural appraisal" techniques) particularly insightful and practical in strengthening cooperation among disciplines. 
The involvement of policymakers

As time went by, we also drew on the work of Robert Chambers (1997; Chambers, Pacey, and Thrupp 1993). His accounting of the value of bringing teams of policymakers to the field helped us to conceptualize ACM's national steering committees, made up of influential bureaucrats, academics, and NGO practitioners. Prabhu's experience in advertising before coming to CIFOR was another potent inspiration for these committees. We hoped too that the committee members would learn along with us about community lives and feed that information into their policymaking, research, and practice. We had an International Steering Committee with similar goals (one of whom, Bob Fisher, contributed to this volume, Chapter 9). Chambers' acceptance and use of rapid rural appraisal techniques also encouraged us to incorporate these along with other research methods in ACM.

\section{Power}

Colfer's (1983) analysis of the links between power and communication in a logging community in the rural United States, the Qashqa'i in Iran, and international scholars at an American research institute also influenced our thinking. This research clarified to her the importance of power differences between individuals within a community and also between communities and actors at broader scales. Prabhu was taken with Colfer's views on the distortions of voice and power related to "authoritative knowledge" ("knowledge that counts" a la Jordan 1997). We made further use of the thinking reflected in Wollenberg, Anderson, and Edmunds (2001b) and Wollenberg, Anderson, and Lopez (2005), as we strove to facilitate multi-stakeholder processes - among people with very different roles in their societies and varying levels of power. These attempts are brought further forwards in Chapters 6 and 7, this volume. These issues became increasingly important in the later CAPRI and Landscape Mosaics projects. (Chapter 8 suggests a shift from ACM to "adaptive collaborative governance" (ACG), with a more explicit emphasis on power.)

Our concern with power also partially emerged from Freire's (1970) guidance on self- or contextual analysis and empowerment. Escobar (1995) highlighted how defining rural peoples solely or predominantly as "poor people" - ignoring those elements of their lives that were rich - functioned to exacerbate their marginalization. We avoided such characterization; his arguments hit home as our team recognized the many strengths of the "poor" communities we had known. Sen (1985) provided us with a better approach to "poverty" than the usual measures like incomes of $<$ US\$1 or $\$ U S 2 /$ day - emphasizing instead capability deficits (missing freedoms and opportunities).

\section{Systems thinking and iterative process}

Anthropology's insistence on the holistic nature of social and cultural systems had prompted Colfer's readings on limits to growth (e.g., Meadows, Rome, 
and Associates 1974); she was also partially influenced by her husband, Richard Dudley, who routinely exposed her to system dynamics modelling literature. Prabhu remembers being influenced by von Bertalanffy (1968) and systems theory more generally. His system dynamics short course at MIT on organizational learning and another at Wageningen on learning theory coalesced with our own discussions within the C\&I project and in crafting ACM. Two other team members, Cynthia McDougall and Herlina Hartanto, took short courses on adaptive management and brought back their own new understandings to us as well. Meanwhile, Jerry Vanclay organized a "hot topic" discussion at CIFOR on systems approaches, culminating in the development of FLORES (Forest Land Oriented Resource Envisioning System) and other forest-people models (e.g., Haggith et al. 2003a, Legg 2003, Prabhu et al. 2003, Vanclay, Haggith, and Colfer 2003b) as part of ACM.

Closer in time to ACM's inception, we found Waldrop's (1992) review on complexity theory of relevance, along with Axelrod and Cohen (1999) on systems thinking more generally. Exposure to the ideas of system dynamics strengthened our attention to positive and negative feedbacks and to unintended consequences and provided some useful methods.

\section{Ongoing intellectual influences and the initial rollout of ACM}

Meanwhile, we continued drawing on the adaptive management literature (e.g., Hilborn and Walters 1992; Stankey and Clark 1998, Lee's Compass and Gyroscope 1993).

Colfer had not of course forgotten her gender and other equity concerns. She was initially influenced by the very few works available then pertaining to women in forests (e.g., Murphy and Murphy 1965, in Brazil; Siskind 1973, in Peru), as well as her own experience in American (Colfer 1977) and Indonesian (Colfer 2008b) forests. Ardener's (1975) collection on women's invisibility in many anthropological analyses was instructive, and a growing number of studies began to come out of the women in development (later Gender and Development) communities of practice. Alerted as our teams were to gender issues, we quickly saw the various kinds of involvement of women in all of our sites, whether managing, monitoring, harvesting, processing, or trading.

Equity influences grew in Prabhu's thinking around 2000 when Angela Cropper (then a CIFOR Board of Trustees member) invited him to Guyana for an equity conference she had organized as Chair of the Iwokrama Board. This introduced him to the role of "imagination" or "imagining" as a powerful way of surfacing mental models. He was already preoccupied with these, based on inputs from Mandy Haggith, and our systems modelling team, including Herry Purnomo (see e.g., Haggith et al. 2003a, b; Purnomo et al. 2003). But it also planted seeds of doubt about the degree to which forests were actually the purely masculine places foresters were trained to see. Although Prabhu himself did not pursue this, Colfer felt his support in her own efforts. In recent years, 
he's recognized that [what some have viewed as] a toxic masculine view of the world has much to answer for in terms of emphasizing competition over collaboration, individual over collective action, and maintenance of many of the wicked problems we face today (something Colfer recently considered in Colfer 2021).

As we gained experience in conducting ACM, we continued to be influenced by others and by the emerging analyses we ourselves were doing. Colfer found the book Panarchy (Gunderson and Holling 2002) to be exciting and used it to help structure her analysis of ACM's first few years (Colfer 2005a). This book was written on a sabbatical at Cornell where she came in contact with Norm Uphoff's work in Sri Lanka (e.g., 1996). Uphoff's view had been evolving in parallel fashion to ACM and contributed to Buck et al.'s (2001) compilation that described immediate precursors to ACM within the conservation world. We found the research undertaken at Wageningen on social learning to be valuable (e.g., Leeuwis and Pyburn 2002), strengthened by Tendayi Mutimukuru-Maravanyika's and Mcdougall's emphases on this issue in the Zimbabwe and Nepal ACM sites, respectively. See also Wollenberg et al. (2001a) on social learning; a number of our team members published in Guijt's (2007) compilation on monitoring, both key elements in the ACM process.

Lini Wollenberg, David Edmunds, and Louise Buck, working in Kalimantan and Madagascar, developed tools that helped communities envision their futures (Wollenberg, Edmunds, and Buck 2000), as did Evans et al. (2006). These helped us to facilitate such processes, which proved key both to bringing communities together to share common goals and also providing a "star to guide them by" in their decisions about how to move forwards.

As we moved towards working at larger scales with issues of collaborative governance ever more central, Wollenberg et al. (2007) described the "muddling" nature of working on such topics, using Indonesian examples. Members of the Landscape Mosaics project produced an edited book that pulled together the findings from that programme on ACM and governance in five countries (Colfer and Pfund 2011) - a process that also involved a lot of muddling. Chapter 8 of this volume, which builds on ACM, to propose "adaptive collaborative governance," moves these concerns forwards from a more theoretical perspective.

When we began our "conversation" among the co-editors, we found ourselves intrigued that Larson had been influenced by many of the theories and analyses mentioned earlier (her interdisciplinary degree had drawn on anthropology, sociology, geography, and political science, as well as environmental science). Not surprisingly, many of those below that Larson found of use, Prabhu and Colfer did as well, but Larson brought new insights particularly related to her governance and Latin American expertise.

As Larson considered what had led her to use ACM, one pertinent aspect of her life experience stood out: in Latin America, where she lived for over 30 years and where most of her own work has focused, the history of grassroots 
social movements and revolution meant she took the power of local people as a starting point - while also seeing the failure of many Latin American movements to live up to their rhetoric. That is, power relations were altered by revolution but not necessarily in favour of, or out of respect for, local peoples (campesinos, or peasants), and women and indigenous peoples in particular tended to remain treated as second (or third) class citizens.

From her academic background, she had read much of the same literature as Colfer but was also strongly influenced by critiques of traditional development and economics from perspectives such as Peet and Watts (1993) and Bardhan (1984), questioning ideas of apparently irrational behaviour among the peasantry, among other things, and Mallon (1987) from feminist theory. She was particularly drawn to political ecology (Blaikie 2000; Hecht and Cockburn 1989; Peluso 1992; Watts 1999; Schmink and Wood 1992; Leach, Mearns, and Scoones 1999) and social justice literature (Zerner 1999), as well as Sara Berry's No Condition Is Permanent (1993) and John Gaventa's Power and Powerlessness (1982).

She also identified a number of issues that had influenced us as well. We were all concerned about conservation and development, feeling that thencurrent approaches were not working in a way that benefited (or even maintained) local communities or the environment. We all felt that an element of genuine involvement of local people in decision making would have to be central in any successful strategy. People's livelihoods depended on the local context, they had the power to improve or destroy their own areas, and they represented capacities and motivations unlikely to be replicated elsewhere. Larson was also influenced by pertinent analyses conducted in the early 2000s on decentralization and multi-level power struggles (e.g., Ribot 1999, 2001a, b, 2003), see also Larson (2002); on participatory governance, Fox (2000); and on environmentality, Agrawal (2005) - as our respective versions of ACM were being crafted.

Meanwhile in Latin America, significant forest and land tenure reforms were underway. This led to her work with indigenous peoples and local communities - groups that had also been key in the earlier ACM work. Larson also found the work of Wollenberg cited earlier useful.

The focus on indigenous communities led Larson to the globally active discussions about FPIC (Free, Prior, and Informed Consent) and self-determination, which were also being passionately discussed in Latin American debates about citizenship, democracy, multiculturalism, racial dominance, and territory (e.g., Van Cott 1994; Yashar 1998; Postero and Zamosc 2006; Bryan 2012; Hale 2011; Offen 2003). Debates about these issues were less public and passionate in other parts of the world but were recognized by many as equally important in the long run.

Larson's ACM work began with an emphasis on gender, something that both Colfer and Prabhu had recognized as important but had downplayed in public ACM planning (using the less controversial "inclusivity" instead) - partly to preempt yet another potential source of institutional reluctance. ${ }^{21}$ 
Institutional concerns about gender in the early days were mostly lip service. Larson, not confronting the same reluctance the earlier teams had, was able to draw explicitly on feminist and gender literature that were beginning to grow exponentially. She was particularly influenced by Bina Agarwal's take on participation (e.g., Agarwal 2001, 2002).

Larson's emphasis was explicitly about power (see Chapters 4, 5, 7, and 8, this volume) and how people rarely sincerely engaged communities to help them make their own decisions but rather came instead with ideas to impose. ${ }^{22}$ This put the team in a quandary because to some extent her teams came to "impose" the idea of women's participation, although it had emerged out of prior research on issues like exclusion in these same communities. Colfer was also concerned about women's participation elsewhere, as she had seen varying degrees of gendered exclusion all over the world. Larson's view on "participation" was reinforced by working in indigenous areas with legal autonomy, hence communities that should in theory have had significant decision-making power over their own lives, but in fact had little control over their territories, and particularly their forests (for historical, racial, political, and economic reasons, in the case she knew best, Nicaragua). She and her teams strove to turn "participation" on its head in favour of "local decision making." Addressing gender in this context of significant masculine dominance of course was doubly challenging.

Colfer was often asked similarly whether her own gender-related efforts were not a form of cultural imperialism, with adverse effects on local cultural coherence. While she recognized that explicit attention to gender had the potential of adverse (as well as benign) impacts, she felt comfortable pointing out that others were "messing with" local cultures in ways that were far more likely to have adverse effects (capitalist intrusion, governmental reach, religious proselytizing, etc. - see e.g., Colfer, Ihalainen, and Monterroso 2020 or Lin 2008). With ACM, the intent and serious effort have been to facilitate local and more just decision making. We cannot deny, however, having what Li refers to as "the will to improve" (2007) - personal motivations to work towards a more democratic, just, and environmentally sustainable world.

\section{Introduction to the book}

This book begins to answer the question: What have we learned since the early days of ACM that can improve our practice and that of others trying to work collaboratively and adaptively with forest and other natural resource-based communities? We have structured these contributions, beginning with the field and moving upwards and outwards, metaphorically, as the emphasis shifts from research that is directly field-based to broader scale efforts and thence to contributions about training needs and theory.

We begin in Chapter 2, with the most grounded contribution and one that makes clear the steps commonly involved in PAR - a central building block of the ACM approach. Johnson and Pokorny provide an imagined construction 
of a "typical" village participant in a participatory project. Drawing on the authors' experience with 17 community development projects/studies in Bolivia, Brazil, Ecuador, and Peru, these authors highlight many issues that recur in development efforts throughout the tropics: for example, difficult terrain and geographical access; thoughtless expectations and assumptions by outsiders with more resources, formal education, and prestige; and participant fatigue arising from normal, daily farm labour. These authors show the inevitably processual nature - with all its warts - of working collaboratively.

The story begins with an inept fieldworker making the usual mistakes and the community members sharing many common preconceptions about the project's expected extractive approaches and goals. As the story unfolds, we witness the successes that ensue as a new, more field-savvy fieldworker arrives and as villagers begin to understand PAR. These authors demonstrate the creativity and adaptiveness that farmers, both men and women, can bring to problem-solving in contexts they know well - especially obvious when skilled facilitators use approaches that empower.

In Chapter 3, we turn the tables and look at the relations among team members on a collaborative project. Mutimukuru-Maravanyika, Madzudzo, and Songe tackle the issue of interdisciplinary collaboration. Problems with interdisciplinary collaboration are not confined to ACM style approaches, but they must be addressed in any ACM project. These include differing expectations about what constitutes "good work," complex power dynamics combined with geographical distance, multiple institutional cultures and procedures, and local-outsider conflicts, among others. Even simple definitional issues can wreak havoc with communication among those trained in different disciplines (e.g., Colfer, Pfund, and Sunderland 2011, on "muddling through" interdisciplinary efforts). The use of vaguely defined boundary terms is wonderful for bringing people together to work on a common topic, but the next step, the development of implementation plans and actions, can illuminate the different meanings that participants attribute to particular concepts and throw real monkey wrenches into the works ("the devil is in the details"). These authors examine their own experience in recent collaborative work in Zambia and synthesize lessons they found useful.

Chapters 4 and 5 examine the same project in Uganda from two perspectives. ${ }^{23}$ Chapter 4 helps to set the stage, reporting a context study (one of the early steps in a good ACM project) that emphasizes gender and tenure issues, among many others. Bomuhangi et al. document a quantitative approach to a context study - one also designed to communicate village-level realities to Ugandan policymakers. The importance of context has become increasingly apparent to global actors. Unlike the early ACM work in which most context studies were quick and almost entirely qualitative, Bomuhangi et al. have used quantitative approaches to understand the roles, goals, and practices of the partner communities. Specifically, they examine patterned differences in gendered responses and differences between sites approached with ACM and those without - across Uganda. 
Mukasa et al., in Chapter 5, complement the work of Bomuhangi et al., with qualitative and process-oriented analyses that closely replicate our earlier ACM work at the village level - but focused specifically on gender. Their study identifies the disadvantages women experienced in six randomly selected communities in Central Uganda, describing the context, cultural and environmental. The authors then show how women's rights and access to the forest were strengthened and how their participation in forest resource management, decision making, and benefits capture were recognized and enhanced using processes of facilitation and negotiation common to the ACM approach. One important advance over much of the original ACM work is the researchers' emphasis during a second phase on upscaling the approach within the country. Another was their ability to document what followed in the years after the project. The link between their findings and the broader forest restoration literature - an arena only recently recognizing the importance of attending to local communities (e.g., Mansourian and Parrotta 2018, or Fischer et al. 2021) - renders the study even more timely and important.

In Chapter 6, Cronkleton, Evans, and Larson use three cases to discuss their experience of training for ACM - something we all had begun to realize was necessary - in Bolivia, Nicaragua, and Ghana. ACM's work has always involved partners - partners in the research teams, donors, government officials, and the community partners who implemented the goals they set for themselves. The fact that the approach was new, even alien, to most partners when we began doing ACM meant that much time was spent introducing the concepts and gaining acceptance of the qualitative, holistic, iterative, and empowering emphases. We also had to encourage the trust in communities that was required, the willingness to let go of (the illusion of) outsider control and dominance (as in Chapter 2). Eventually, we realized explicit training in these issues would help us move the ACM process along. ${ }^{24}$ This was particularly evident in our attempts to move "upwards," to use the ACM approach at intermediate levels, such as districts and over broader landscapes. Local actors engaged at wider scales often proved both more resistant to adaptive and collaborative approaches and powerful enough to enforce their resistance effectively (e.g., Colfer and Pfund 2011 or Hadi 2006). This chapter provides practical guidance on how to teach partners the key concepts, using three quite different contexts in which such training proved important.

Such partnerships are also the subject of Sarmiento Barletti's contribution (Chapter 7), based on experience conducting research in 14 multi-stakeholder forums in Brazil, Ethiopia, Indonesia, and Peru. The author and his team, in a project led by Larson, studied interactive processes that brought together a variety of stakeholders to discuss, decide, and/or implement actions designed to address a shared problem or achieve a goal for their common benefit. The project was designed from the beginning with the recognition that power inequities were one of the most common elements that could derail a collaborative process, and they set out to understand and address these. The team first clarified the significant power differences among partners in the multi-stakeholder 
forums studied and considered the behavioural ramifications of such interactions. In the process, Sarmiento Barletti worked with participants to develop a process-oriented and locally adapted tool (How are we doing?) that has proven useful in recognizing and addressing these power inequities that are likely to bedevil any multi-stakeholder forum.

Chapter 8 addresses power imbalances directly through an explicitly theoretical discussion of what McDougall and Ojha suggest calling adaptive collaborative governance. ${ }^{25}$ This analysis of power and social learning critiques our and others' participatory work. Similar critiques have been levied before at ACM: for example, Mutimukuru-Maravanyika (2010) on her own work in Zimbabwe, arguing that we paid insufficient attention to power, with adverse effects on the sustainability of our efforts there. McDougall and Ojha, whose early ACM work was in Nepal, take the next step, suggesting some ways to address these power imbalances that confront us in nearly all forests. Specifically, they look at the following questions as they relate to theory: Why do power imbalances persist in community-based natural resource contexts? How and why can new configurations of power emerge? And how can adaptive collaborative governance's potential influence on shifting power imbalances be understood?

Another "bone of contention" about ACM, mentioned earlier, has been the question of its legitimacy as a research topic. Was ACM research or action? This was a recurrent controversy in the early days at CIFOR about our work, which aimed to span the two (see Colfer 2013b). ${ }^{26}$ As noted above, the ACM teams felt that we could (and should) study how to stimulate/encourage collective action and learning better. Fisher and Jackson carry this discussion further (in Chapter 9) examining the roles of action and research in work they have conducted and supervised, emphasizing PAR, a crucial tool in ACM's toolbox. They first discuss their own early experimentation with action research in Nepal - when it was a nascent approach. They then turn to its use for diverse purposes, in Thailand, Cambodia, Iran, New Zealand, and Japan, in theses they supervised (at the University of Western Sydney - Hawkesbury); and in Ghana and China, as part of IUCN's Livelihoods and Landscapes project, to exemplify their points.

In the final chapter (10), we refer to two Greek concepts: the orouboros and the triskelion. The first represents circularity and a static state; the second a continuous cyclical motion that spirals outwards - in the way ACM hopes to function, moving us towards better forest and human conditions. We pull together the strands of thought in this book, first briefly returning to the ACM-PAR distinction, and then summarizing what ACM is - its elements and how they emerge in the foregoing chapters. We then look at the assessment of ACM's successes and failures. The next section discusses some of the dilemmas of shifting from the village level to the district or higher levels and considers approaches that might work better than those tried so far - using two current, larger-scale African cases to illustrate. We also consider the potential applicability of ACM to issues that others are currently struggling with: trying 
to restore forests, mitigate and adapt to climate change, and minimize bio- and cultural diversity loss (and more). The chapter concludes with a warning that a triskelion process is agnostic about its direction: we recognize that it can result in a downward spiral. Hence, the importance of using approaches like ACM to spiral upwards, towards improvement, with local people.

\section{Notes}

1 See our Glossary or Roberts (2000).

2 Australia, Canada, Germany, India, Kenya, Nepal, Peru, Uganda, UK, USA, Zambia, Zimbabwe.

3 In our initial attempts at ACM, Prabhu considered this to be the source of one of our biggest confounding problems - ACM as a body of (emerging) knowledge and practices, as an object for participatory research, and/or as the way researchers referred to themselves (initially "the ACM team" and later just "ACM"). We were always in danger of confusing the approach - as we initially practised it - with our efforts at using participatory methods to understand what was being practised and how that might be improved.

4 There are many other versions whose practitioners we hope can also benefit from this book, such as a cadre at Cornell University (e.g., Louise Buck, Norm Uphoff); the Collaborative Adaptive Management (CAM) group, e.g., Scarlett (2013); or the luminaries represented in this article: Armitage et al. (2009), among others. Here, we build on our own experience.

5 These included one to six sites in each of the following countries: Bolivia, Brazil, Cameroon, Ghana, Indonesia, Kyrgyzstan, Madagascar, Malawi, Nepal, Tanzania, and Zimbabwe (see Diaw, Prabhu, and Aseh 2009, Colfer 2005b, Colfer 2005a; Fisher, Prabhu, and McDougall 2007; Guijt 2007; Mandondo, Prabhu, and Matose 2008; Vanclay, Prabhu, and Sinclair 2006, Vanclay, Prabhu, and Sinclair 2003a; Wollenberg, Anderson, and Edmunds 2001b, for description and early analyses of these projects; also https:// www2.cifor.org/acm/).

6 We worked in the Sumatran villages of Sungai Telang in Bungo district, and in Lubuk Kambing in Tanjabbar from 2005 to 2007. See Komarudin et al. (2008) and Komarudin et al. (2012), for fuller descriptions of this work. Unfortunately, this project was planned (by others) for different villages than the original Jambi ACM research (though in the same province), missing the opportunity to lengthen the period of research/action.

7 Cameroon, Indonesia, Laos, Madagascar, Tanzania (2007-2010). See Colfer and Pfund (2011), for a collection on this work, or Colfer et al. (2011), for an analysis of our challenges and shortcomings.

8 From 14 to 25 September 2020, the editors of this book participated in the annual meeting of the Forests, Trees and Agroforestry Collaborative Research Program (FTA) of the Consultative Group on International Agricultural Research; speaker after speaker declared the relevance of local knowledge, systems perspectives, social learning, and equity - all key elements in ACM, elements that had met mostly with resistance in 1998.

9 The genesis of these names is discussed below.

10 See Colfer (2021) for an analysis of the values that drove forestry researchers, or Colfer et al. (2011) for how ACM had to be repeatedly defended in this scientific context.

11 Bob Fisher (see Chapter 9) and Don Gilmore, both involved in our International Steering Committee, also had longstanding relationships with key Nepali forest actors.

12 See Colfer (2013a) for a thorough account of the hoops we jumped through in order to develop and maintain this work.

13 We had passionate discussions within our CIFOR-based team about the ethics of experimentation on communities, although we did help communities plan their own experiments. 
14 She saw ethnography as a relatively direct way to gain access to, e.g., local value systems (assumed and demonstrated through action, but rarely verbalized), women's worlds, social differentiation, micro-politics (factions, modes of leadership, aspects of accountability), and norms of interaction.

15 These included estimates of levels of conflict, social capital, quality and type of forest, forest management goals, population pressure, and devolution status - discussed at length in Colfer (2005b).

16 Indeed, in 2020, ACM was selected as one of the 50 most important innovations of the CGIAR.

17 One of the central research questions in a research proposal for "Interactions between People and Forests," a project which took place between 1979 and 1980, was investigating whether Kalimantan's forest-dwellers made rational decisions.

18 Of particular interest were these eight principles designed for managing a commons: (1) Define clear group boundaries; (2) Match rules governing use of common goods to local needs and conditions; (3) Ensure that those affected by the rules can participate in modifying the rules; (4) Make sure the rule-making rights of community members are respected by outside authorities; (5) Develop a system, carried out by community members, for monitoring members' behaviour; (6) Use graduated sanctions for rule violators; (7) Provide accessible, low-cost means for dispute resolution; (8) Build responsibility for governing the common resource in nested tiers from the lowest level up to the entire interconnected system (https://www.onthecommons.org/magazine/elinor-ostroms-8principles-managing-commmons).

19 Such workshops resulted in several edited books, including the collections by Colfer (2005a), H. Hartanto, M. C. Lorenzo, C. Valmores, L. Arda-Minas, L. Burton and R. Prabhu. 2003. Learning Together: Responding to Change and Complexity to Improve Community Forests in the Philippines. Bogor, Indonesia: CIFOR. Indriatmoko et al. (2007), Kusumanto et al. (2005), and Yuliani et al. (2007).

20 In a sondeo, an interdisciplinary team goes to the field, splitting into pairs, which are shifted every morning and afternoon, as the varying pairs interview farmers or others of interest. This exposes practitioners to local field realities and the views and knowledge of the different disciplines, bringing new factors to light, and enhancing interdisciplinary understanding and collaboration. It functions to develop the shared experiential foundation Prabhu mentioned earlier.

21 This was very much the strategy that early Women in Development (WID) specialists had taken - emphasizing the economic above other sociocultural elements because that was the only avenue that held the potential to be heard more broadly. Sadly, in recent years, these early pioneers have been maligned for that emphasis, without recognition of the hostile environment in which they had selected research topics.

22 The ACM approach replicates this recent suggestion of Jane Sherman (2021): "For me, it's a question of inverting the relationship, changing the sage on the stage to the guide on the side, putting the advisees/audience/beneficiaries/participants at the centre of the picture and seeing them instead as the main actors."

23 Larson was one of the co-PIs on this project, along with Esther Mwangi. Mwangi, sadly now deceased, led this Uganda team.

24 The early Zimbabwe team recognized the need for attention to such issues in the communities early on, conducting a week of "Training for Transformation" with community members, using Paulo Freire's (1970) ideas about self-analysis and empowerment (discussed in Mutimukuru-Maravanyika et al. 2008). But our recognition of the need to more fully train facilitators only came later (see e.g., Evans, Larson, and Flores 2020).

25 When CIFOR reorganized in 2002-2003, the ACM team was asked if we preferred to join the Governance or Livelihoods Program. As we felt equally comfortable with both designations, we left the decision to CIFOR administrators, who opted for Governance.

26 One reviewer of this chapter seemed to suggest that this boundary should be permeable, noting particular issues like citizen science (which has proven quite useful in many 
contexts) and the opportunity/need to monitor and influence decision making within the broader democratic political realm - we are comfortable with a loose differentiation between research and action/development. Conventional research is not devoid of political implications, despite efforts by researchers to remain "neutral" (or naively consider themselves and their work neutral).

\section{References}

Agarwal, Bina. 2001. "Participatory Exclusions, Community Forestry, and Gender: An Analysis for South Asia and a Conceptual Framework." World Development 29 (10):1623-1648.

Agarwal, Bina. 2002. "The Hidden Side of Group Behaviour: A Gender Analysis of Community Forestry in South Asia." In Group Behaviour and Development: Is the Market Destroying Cooperation?, edited by Judith Heyer, Frances Stewart and Rosemary Thorp, 185-208. Oxford, UK: Oxford University Press.

Agrawal, Arun. 2005. Environmentality: Technologies of Government and the Making of Subjects. Durham, NC: Duke University Press.

Ardener, Shirley, ed. 1975. Perceiving Women. London: Malaby Press.

Armitage, Derek R., Ryan Plummer, Fikret Berkes, Robert I. Arthur, Anthony T. Charles, Iain J. Davidson-Hunt, Alan P. Diduck, Nancy C. Doubleday, Derek S. Johnson, Melissa Marschke, Patrick McConney, Evelyn W. Pinkerton, and Eva K. Wollenberg. 2009. "Adaptive Co-management for Social-ecological Complexity." Frontiers in Ecology and the Environment 7 (2):95-102. doi:10.1890/070089.

Axelrod, R., and M. D. Cohen. 1999. Harnessing Complexity: Organizational Implications of a Scientific Frontier. New York: The Free Press.

Bardhan, P. 1984. Land, Labor and Rural Poverty. Bombay: Oxford University Press.

Berry, Sara. 1993. No Condition Is Permanent: The Social Dynamics of Agrarian Change in SubSaharan Africa. Madison, WI: University of Wisconsin Press.

Blaikie, P. 2000. "Development, Post-, Anti-, and Populist: A Critical Review." Environment and Planning 32:1033-1050.

Bryan, Joe (2012) "Rethinking Territory: Social Justice and Neoliberalism in Latin America's Territorial Turn." Geography Compass 6 (4):215-226.

Buck, Louise, Charles C. Geisler, John Schelhas, and Eva W. Wollenberg, eds. 2001. Biological Diversity: Balancing Interests through Adaptive Collaborative Management. Boca Raton, FL: CRC Press.

Butler, William H., and Courtney A. Schultz, eds. 2019. A New Era for Collaborative Forest Management: Policy and Practice Insights from the Collaborative Forest Landscape Restoration Program. London: Earthscan/Routledge.

Center for International Forestry Research (CIFOR). 1999. CEI Toolbox. 9 vols. Bogor, Indonesia: Center for International Forestry Research.

Chambers, Robert. 1997. Whose Reality Counts? Putting the First Last. London: Intermediate Technology Publications.

Chambers, Robert, Arnold Pacey, and Lori Ann Thrupp, eds. 1993. Farmer First: Farmer Innovation and Agricultural Research. London: Intermediate Technology Press.

Colfer, Carol J. Pierce. 1977. Women's Communication and Family Planning in Rural America: The Case of Bushler Bay. Case Studies in Family Planning 4. Honolulu, HI: East-West Communications Institute (reprinted 1978).

Colfer, Carol J. Pierce. 1983. "On Communication among 'Unequals'.." International Journal of Intercultural Communication 7:263-83. 
Colfer, Carol J. Pierce. 1991. Toward Sustainable Agriculture in the Humid Tropics: Building on the Tropsoils Experience in Indonesia. Tropsoils Technical Bulletin 91/02. Raleigh, NC: North Carolina State University.

Colfer, Carol J. Pierce. 2005a. The Complex Forest: Communities, Uncertainty, and Adaptive Collaborative Management. Washington, DC: Resources for the Future/CIFOR.

Colfer, Carol J. Pierce, ed. 2005b. The Equitable Forest: Diversity, Community and Resource Management. Washington, DC: RFF/CIFOR.

Colfer, Carol J. Pierce. 2008a. "On Kenyah Dayak Tree Cutting in Context." In The Longhouse of the Tarsier: Changing Landscapes, Gender and Well Being in Borneo, 32-49. Phillips, ME: Borneo Research Council \& CIFOR.

Colfer, Carol J. Pierce. 2008b. The Longhouse of the Tarsier: Changing Landscapes, Gender and Well Being in Borneo. Borneo Research Council Monograph Series. Phillips, Maine: Borneo Research Council, in cooperation with CIFOR and UNESCO.

Colfer, Carol J. Pierce. 2013. "The Ups and Downs of Institutional Learning: Reflections on the Emergence and Conduct of Adaptive Collaborative Management at the Center for International Forestry Research." In Adaptive Collaborative Approaches in Natural Resource Governance: Rethinking Participation, Learning and Innovation, edited by Hemant Ojha, Andy Hall and Rasheed V. Sulaiman, 48-102. London: Earthscan/Routledge.

Colfer, Carol J. Pierce. 2021. Masculinities in Forests: Representations of Diversity. London: Earthscan/Routledge.

Colfer, Carol J. Pierce, and Jean-Laurent Pfund, eds. 2011. Collaborative Governance of Tropical Landscapes. London: Earthscan, CIFOR.

Colfer, Carol J. Pierce, and Richard G. Dudley. 1993. Shifting Cultivators of Indonesia: Managers or Marauders of the Forest? Rice Production and Forest Use among the Uma' Jalan of East Kalimantan, Community Forestry Case Study Series 6. Rome: Food and Agriculture Organization of the United Nations.

Colfer, Carol J. Pierce, Nancy Lee Peluso, and See Chung Chin. 1997. Beyond Slash and Burn: Building on Indigenous Management of Borneo's Tropical Rain Forests, Advances in Economic Botany 11. Bronx, NY: New York Botanical Garden.

Colfer, Carol J. Pierce, Etienne Andriamampandry, Stella Asaha, Emmanuel Lyimo, Endri Martini, Jean Laurent Pfund, and John Watts. 2011a. "Participatory Action Research for Catalyzing Adaptive Management: Analysis of a 'Fits and Starts' Process." Journal of Environmental Science and Engineering 5 (1):28-43.

Colfer, Carol J. Pierce, Jean Laurent Pfund, and Terry Sunderland. 2011b. "The Essential Task of 'Muddling Through' to Better Landscape Governance." In Collaborative Governance of Tropical Landscapes, edited by Carol J. Pierce Colfer and Jean Laurent Pfund, 271-278. London: Earthscan.

Colfer, Carol J. Pierce, Markus Ihalainen, and Iliana Monterroso. 2020. "Understanding Gender Dynamics in the Context of Rural Transformation Processes: An East Kalimantan Case Study." CIFOR Occasional Paper 212.

Conklin, Harold C. 1957. Hanunóo Agriculture: A Report on an Integral System of Shifting Cultivation in the Philippines. Rome: Food and Agriculture Organization of the United Nations.

Diaw, M. Chimere, Ravi Prabhu, and Tony Aseh, eds. 2009. In Search for Common Ground: Adaptive Collaborative Management of Forest in Cameroon. Bogor, Indonesia: CIFOR.

Dove, Michael R. 1981. "Subsistence Strategies in Rain Forest Swidden Agriculture: The Kantu' at Tikul Batu." PhD Anthropology, Stanford University.

Dudley, Richard G., and Carol J. Pierce Colfer. 1993. Conservation Sub-Project Quarterly Report and Attachments. Bogor, Indonesia: Asian Wetlands (now Wetlands International). 
Emadi, Mohammad H. 1995. "Pastoralists, Participation and Policy: An Action Oriented, Systemic and Participatory Approach to Improve the Relationships between Pastoralist Nomads, Government and Natural Resources in Iran.” Doctoral dissertation, University of Western Sydney.

Escobar, Arturo. 1995. Encountering Development: The Making and Unmaking of the Third World, Princeton Studies in Culture/Power/History. Princeton, NJ: Princeton University Press.

Evans, Kristen, Sandra J. Velarde, Rocio P. Prieto, Sheila N. Rao, Sandra Sertzen, Karina Dávila, Peter Cronkleton, and Wil De Jong, eds. 2006. Field Guide to the Future: Four Ways for Communities to Think Ahead. Nairobi, Kenya: CIFOR, ASB, ICRAF.

Evans, Kristen, Anne M. Larson, and S. Flores. 2020. "Learning to Learn in Tropical Forests: Training Field Teams in Adaptive Collaborative Management, Monitoring and Gender." International Forestry Research 22 (2):189-198.

Ferguson, James. 1994. The Anti-Politics Machine. Minneapolis, MN: University of Minnesota.

Fischer, Joern, Maraja Riechers, Jacqueline LoosBerta Martin-Lopez, and Vicky M. Temperton. 2021. "Making the UN Decade on Ecosystem Restoration a SocialEcological Endeavour." Trends in Ecology and Evolution 36 (1):20-28.

Fisher, R. J. 1995. Collaborative Management of Forests for Conservation and Development. Gland, Switzerland: IUCN and WWF.

Fisher, R. J., and W. J. Jackson. 1998. "Action Research for Collaborative Management of Protected Areas." In Collaborative Management of Protected Areas in the Asian Region, Royal Chitwan National Park, Sauraha, Nepal.

Fisher, Robert J., Ravi Prabhu, and Cynthia McDougall, eds. 2007. Adaptive Collaborative Management of Community Forests in Asia: Experience from Nepal, Indonesia and the Philippines. ACM Series. Bogor, Indonesia: CIFOR.

Fox, Jefferson. 2000. "Civil Society and Political Accountability: Propositions for Discussion." In Institutions, Accountability and Democratic Governance in Latin America, The Helen Kellogg Institute for International Studies, University of Notre Dame, 8-9 May.

Freire, Paulo. 1970. Pedagogy of the Oppressed. New York: Herder and Herder.

Gaventa, John. 1982. Power and Powerlessness: Quiescence and Rebellion in an Appalachian Valley. Urbana, IL: University of Illinois Press.

Godwin, Gail. 1999. Evensong. New York: Ballantine Books.

Goodenough, Ward H. 1956. "Componential Analysis and the Study of Meaning." Language 32 (1):195-216.

Guijt, Irene. 2007. Negotiated Learning: Collaborative Monitoring for Forest Resource Management. Washington, DC: RFF/CIFOR.

Gunderson, Lance H., and C. S. Holling, eds. 2002. Panarchy: Understanding Transformations in Human and Natural Systems. Washington, DC: Island Press.

Hadi, Mustafal. 2006. "Bungo District, Jambi: Opening Government Doors." In Multistakeholder Forestry: Steps for Change, edited by Elizabeth Linda Yuliani, Djuhendi Tadjudin, Yayan Indriatmoko, Dani W. Munggoro, Farid Gaban, Firkan Maulana and Hasantoha Adnan, 105-109. Bogor, Indonesia: CIFOR.

Haggith, Mandy, Ravi Prabhu, Carol J. Pierce Colfer, Bill Ritchie, Alan Thomson, and Happyson Mudavanhu. 2003a. "Infectious Ideas: Modelling the Diffusion of Ideas Across Social Networks." Small-Scale Forest Economics, Management and Policy 2 (2):225-240.

Haggith, Mandy, Ravi Prabhu, Happyson Mudavanhu, Frank Matose, Tendayi Mutimukuru, Richard Nyirenda, and Wavell Standa-Gunda. 2003b. "The Challenges 
of Effective Model Scoping: A FLORES Case Study from the Mafungautsi Forest Margins, Zimbabwe." Small-Scale Forest Economics, Management and Policy 2 (2):155-170.

Hale, C. R. 2011. "Resistencia para que? Territory, Autonomy and Neoliberal Entanglements in the 'Empty Spaces' of Central America." Economy and Society 40(2):184-210.

H. Hartanto, M. C. Lorenzo, C. Valmores, L. Arda-Minas, L. Burton and R. Prabhu 2003. Learning Together: Responding to Change and Complexity to Improve Community Forests in the Philippines. Bogor, Indonesia: CIFOR.

Hecht, S., and A. Cockburn. 1989. The Fate of the Forest. London: Verso.

Hilborn, Ray, and Carl J. Walters. 1992. "Designing Adaptive Management Policies." In Quantitative Fisheries Stock Assessment: Choice, Dynamics, and Uncertainty, edited by Ray Hilborn and Carl J. Walters. New York: Chapman and Hall.

Hildebrand, Peter E. 1986. "The Sondeo: A Team Rapid Survey Approach.” In Perspectives on Farming Systems Research and Extension, edited by Peter E. Hildebrand, 93-98. Boulder, CO: Lynne Reiner Publishers.

Indriatmoko, Yayan, Linda Yuliani, Yunety Tarigan, Farid Gaban, Firkan Maulana, Dani Wahyu Munggoro, Dicky Lopulalan and Hasantoha Adnan, eds. 2007. Dari Desa ke Desa: Dinamika Gender dan Pengeloalaan Kekayaan Alam. [From Village to Village: Gender Dynamics and Management of Natural Wealth]. Bogor, Indonesia: CIFOR.

Jordan, Brigitte. 1997. "Authoritative Knowledge and its Construction." In Childbirth and Authoritative Knowledge: Cross-Cultural Perspectives, edited by R. Davis-Floyd and C. Sargent, 55-79. Berkeley, CA: University of California Press.

Kelly, George Alexander. 1963. A Theory of Personality: The Psychology of Personal Constructs. New York: W. W. Norton.

Komarudin, Heru, Yuliana L Siagian, Carol J. Pierce Colfer, with Neldysavrino, Yentirizal, Syamsuddin, and Deddy Irawan. 2008. Collective Action to Secure Property Rights for the Poor: A Case Study in Jambi Province, Indonesia. CAPRI Working Paper 90. Washington, DC: Collective Action and Property Rights System-Wide Initiative.

Komarudin, Heru, Yuliana L. Siagian, Carol J Pierce Colfer, with Neldysavrino, Yentirizal, Syamsuddin, and Deddy Irawan. 2012. "The Role of Collective Action in Securing Property Rights for the Poor: A Case Study in Jambi Province, Indonesia." In Collective Action and Property Rights for Poverty Reduction, edited by Esther Mwangi, Helen Markelova and Ruth Meinzen-Dick, 235-269. Philadelphia, PA: University of Pennsylvania Press.

Kunstadter, Peter, E. C. Chapman, and Sabhasri Sanga. 1978. Farmers in the Forest: Economic Development and Marginal Agriculture in Northern Thailand. Honolulu: East-West Center and University Press of Hawaii.

Kusumanto, Trikurnianti, Linda Yuliani, Phil Macoun, Yayan Indriatmoko, and Hasantoha Adnan. 2005. Learning to Adapt: Managing Forests Together in Indonesia. Bogor, Indonesia: CIFOR.

Larson, Anne M. 2002. "Natural Resources and Decentralization in Nicaragua: Are Local Governments Up to the Job?" World Development 30 (1):17-31.

Leach, M., R. Mearns, and I. Scoones. 1999. "Environmental Entitlements: Dynamics and Institutions in Community-Based Natural Resource Management." World Development 27 (2):225-247.

Lee, Kai N. 1993. Compass and Gyroscope: Integrating Science and Politics for the Environment. Washington, DC: Island Press.

Leeuwis, Cees, and Rhiannon Pyburn, eds. 2002. Wheelbarrows Full of Frogs: Social Learning in Rural Resource Management. Assen, The Netherlands: Koninklijke Van Gorcum. 
Legg, Christopher. 2003. "CamFlores: A FLORES-type Model for the Humid Forest Margin in Cameroon." Small-Scale Forest Economics, Management and Policy 2 (2):211-224.

Li, Tania. 2007. The Will to Improve: Governmentality, Development, and the Practice of Politics. Durham: Durham University Press.

Lin, Carol Yong Ooi. 2008. "Autonomy Reconstituted: Social and Gendered Implications of Resettlement on the Orang Asli of Peninsular Malaysia." In Gender and Natural Resource Management: Livelihoods, Mobility and Interventions, edited by Bernardette P. Resurreccion and Rebecca Elmhirst, 109-126. London: Earthscan.

Mallon, F. 1987. "Patriarchy in the Transition to Capitalism in Central Peru." Feminist Studies 13 (summer):379-407.

Mandondo, Alois, Ravi Prabhu and Frank Matose, eds. 2008. Coping Amidst Chaos: Studies on Adaptive Collaborative Management from Zimbabwe. Bogor, Indonesia: CIFOR.

Mansourian, Stephanie, and John Parrotta, eds. 2018. Forest Landscape Restoration: Integrated Approaches to Support Effective Implementation. New York: Routledge/Earthscan.

Marald, Erland, Camilla Sandstrom, Annika Nordin, and others. 2017. Forest Governance and Management Across Time: Developing a New Forest Social Contract. London: Routledge/ Earthscan.

Maruyama, Magoroh. 1974. "Paradigmatology and its Application to Cross-Disciplinary, Cross-Professional and Cross-Cultural Communication." Dialectica 28:135-196. doi: 10.1111/j.1746-8361.1974.tb00635.x

Meadows, Donella H., Club of Rome, and Potomac Associates. 1974. The Limits to Growth: A Report for the Club of Rome's Project on the Predicament of Mankind. 2d ed. New York: Universe Books.

Metzger, Duane G., and Gerald E. Williams. 1966. "Some Procedures and Results in the Study of Native Categories: Tzeltal 'Firewood'.” American Anthropologist 68 (2):389-407.

Murphy, Yolanda, and Robert Francis Murphy. 1965. Women of the Forest. 2nd ed. New York: Columbia University Press.

Mutimukuru-Maravanyika, Tendayi. 2010. "Can We Learn Our Way to Sustainable Management? Adaptive Collaborative Management in Mafungautsi State Forest, Zimbabwe." $\mathrm{PhD}$ doctoral dissertation, Technology and Agrarian Development, Wageningen.

Mutimukuru-Maravanyika, Tendayi, Ravi Prabhu, Frank Matose, Richard Nyirenda, and Witness Kozanayi. 2008. "Facilitating Adaptive Collaborative Management in Forested Landscapes: The Mafungautsi Case Study." In Coping Amidst Chaos: Studies of Adaptive Collaborative Management from Zimbabwe, edited by Alois Mandondo, Ravi Prabhu and Frank Matose, 15-64. Bogor, Indonesia: CIFOR.

Norman, David W. 1982. The Farming Systems Approach to Research. Manhattan, KS: Kansas State University.

Offen, Karl (2003) “The Territorial Turn.” Journal of Latin American Geography 2(1): 43-73.

Ojha, Hemant R., Rebecca Ford, Rodney J. Keenan, Digby Race, Dora Carias Vega, Himlal Baral, and Prativa Sapkota. 2016. "Delocalizing Communities: Changing Forms of Community Engagement in Natural Resources Governance." World Development 87:274-290. doi:10.1016/j.worlddev.2016.06.017.

Ostrom, Elinor. 1990. Governing the Commons: The Evolution of Institutions for Collective Action. Cambridge, UK: Cambridge University Press.

Peet, R., and M. Watts. 1993. "Development Theory and Environment in an Age of Market Triumphalism." Economic Geography 69 (3):227-253.

Peluso, Nancy Lee. 1992. "Coercing Conservation: The Politics of State Resource Control." Global Environmental Change 3 (2):199-217. 
Postero, N.G., and L. Zamosc, eds. 2006. The Struggle for Indigenous Rights in Latin America. Brighton: Sussex Academic Press.

Prabhu, Ravi, Mandy Haggith, Happyson Mudavanhu, Robert Muetzelfeldt, Wavell StandaGunda, and Jerome Vanclay. 2003. "ZimFlores: A Model to Advise Co-Management of the Mafungautsi Forest in Zimbabwe." Small-Scale Forest Economics, Management and Policy 2 (2):185-210.

Purnomo, Herry, Yurdi Yasmi, Ravi Prabhu, Stepi Hakim, Amin Jafar, and Suprihatin. 2003. "Collaborative Modelling to Support Forest Management: Qualitative Systems Analysis at Lumut Mountain, Indonesia." Small-Scale Forest Economics, Management and Policy 2 (2):259-276.

Ribot, Jesse C. 1999. "Decentralization, Participation and Accountability in Sahelian Forestry: Legal Instruments of Political-Administrative Control." Africa 69 (1):23-65.

Ribot, Jesse C. 2001a. "Integral Local Development: 'Accommodating Multiple Interests' Through Entrustment and Accountable Representation." International Journal of Agricultural Resources, Governance and Ecology 1 (3/4):327-350.

Ribot, Jesse C. 2001b. Local Actors, Power and Accountability in African Decentralizations: A Review of Issues. Geneva: UN Research Institute for Social Development.

Ribot, Jesse C. 2003. "Democratic Decentralization of Natural Resources: Institutional Choice and Discretionary Power Transfers in Sub-Saharan Africa." Public Administration and Development 23:53-65.

Rice, Delbert. 2001. Forest Management by a Forest Community: The Experience of the Ikalahan. Bogor, Indonesia: CIFOR.

Roberts, Nancy. 2000. "Wicked Problems and Network Approaches to Resolution." International Public Management Review 1 (1):1-19.

Roe, Emery. 1994. Narrative Policy Analysis: Theory and Practice. Durham, NC: Duke University Press.

Saxena, N. C. 1997. The Saga of Participatory Forest Management. Bogor, Indonesia: CIFOR.

Schmink, Marianne, and Charles Wood. 1992. Contested Frontiers in Amazonia. New York: Columbia University Press.

Sen, Amartya 1985. "Well-Being, Agency and Freedom: The Dewey Lectures 1984." The Journal of Philosophy 82 (4):169-221.

Shaner, W.W., P.F. Phillip, and W.R. Schmehl. 1982. Farming Systems Research and Development: Guidelines for Developing Countries. Boulder, CO: Westview Press.

Sherman, Jane. 2021. The Communication Initiative Networks, 21 January (https://www.com minit.com/global/category/sites/global).

Siskind, Janet. 1973. To Hunt in the Morning. London: Oxford University Press.

Stankey, G. H., and R. N. Clark. 1998. Adaptive Management Areas: Roles and Opportunities for the PNW Research Station. Portland, Oregon: Pacific North West Research Station.

Tsing, Anna Lowenhaupt 2005. Friction: An Ethnography of Global Connection. Princeton, NJ: Princeton University Press.

Uphoff, Norman. 1996. Learning from Gal Oya: Possibilities for Participatory Development and Post-Newtonian Social Science. London: Intermediate Technology Publications.

Van Cott, D.L., ed. 1994. Indigenous Peoples and Democracy in Latin America. New York: St. Martin's Press.

Vanclay, Jerome K., Mandy Haggith, and Carol J. Pierce Colfer. 2003a. "Participation and Model-Building: Lessons Learned from the Bukittinggi Workshop." Small-Scale Forest Economics, Management and Policy 2 (2):135-154. 
Vanclay, Jerome K., Ravi Prabhu, and Fergus Sinclair. 2003b. "Special Issue on Participatory Modelling of Community Forest Landscapes." Small-Scale Forest Economics, Management and Policy 2 (2):117-326.

Vanclay, Jerry, Ravi Prabhu, and Fergus Sinclair. 2006. Realizing Community Futures: A Practical Guide to Harnessing Natural Resources. London: Earthscan.

Vayda, A. P. 1983. "Progressive Contextualization: Methods for Research in Human Ecology." Human Ecology 11:165-81.

Vayda, A. P., C. J. P. Colfer, and M. Brotokusumo. 1980. "Interactions between People and Forests in East Kalimantan." Impact of Science on Society 30:179-90.

von Bertalanffy, Ludwig. 1968. General System Theory: Foundations, Development, Applications. Revised Edition 1976. New York: George Braziller.

Waldrop, M. M. 1992. Complexity: The Emerging Science at the Edge of Order and Chaos. New York: Touchstone Books (Simon and Schuster).

Watts, M. 1999. "Contested Communities, Malignant Markets, and Gilded Governance: Justice, Resource Extraction and Conservation in the Tropics." In People, Plants, and Justice: The Politics of Nature Conservation, edited by Charles Zerner. New York: Columbia University Press.

Wollenberg, Eva, David Edmunds, and Louise Buck. 2000. Anticipating Change: Scenarios as a Tool for Adaptive Forest Management (a Guide). Bogor, Indonesia: CIFOR.

Wollenberg, Eva, David Edmunds, Louise Buck, Jefferson Fox, and S. Broch, eds. 2001a. Social Learning in Community Forests. Bogor, Indonesia: CIFOR.

Wollenberg, Eva, Jon Anderson, and David Edmunds. 2001b. "Pluralism and the Less Powerful: Accommodating Multiple Interests in Local Forest Management.” International Journal of Agricultural Resources, Governance and Ecology 1 (3/4):199-222.

Wollenberg, Eva, Jon Anderson, and Citlalli Lopez. 2005. Though all Things Differ: Pluralism as a Basis for Cooperation in Forests. Bogor, Indonesia: CIFOR.

Wollenberg, Eva, Ramses Iwan, Godwin Limberg, Moira Moeliono, Steve Rhee, and Made Sudana. 2007. "Muddling Towards Cooperation: Spontaneous Orders and Shared Learning in Malinau District, Indonesia." In Adaptive Collaborative Management of Community Forests in Asia: Experiences from Nepal, Indonesia and the Philippines, edited by Robert Fisher, Ravi Prabhu and Cynthia McDougall, 132-159. Bogor: CIFOR.

Yashar, D. 1998. "Contesting Citizenship: Indigenous Movements and Democracy in Latin America." Comparative Politics 31 (1):23-42.

Yuliani, Linda, Djuhendi Tadjudin, Yayan Indriatmoko, Dani Wahyu Munggoro, Farid Gaban, Firkan Maulana, and Hasantoha Adnan, eds. 2007. Multistakeholder Forestry: Steps to Change. Bogor, Indonesia: CIFOR.

Zerner, Charles. 1999. Justice and Conservation. Insights from People, Plants, and Justice: The Politics of Nature Conservation. New York: Rainforest Alliance. 


\section{Introduction to Chapter 2}

In May or June 2020, when we invited one-time ACM practitioners/researchers to contribute to this book, we stressed that we were open to unusual responses. Chapter 2 is the most unusual of the responses that we received. There are several reasons that we like this chapter.

1. The story of the "imagined" farmer is not really imagined. It is a story developed in the course of an assessment of ForLive projects that involved listening to the farmer participants and how they had experienced ACM/ PAR. The authors took these responses and pulled from them patterns that recurred. The broad outlines of these patterns are, from our experience, not atypical in other regions. They provide both information about South American conditions and about principles that can be, with care, generalized.

2. The story also shows the differences in responses when facilitation is done badly (at the beginning of the story) and how things improve with good facilitation (later in the story). These differences bring out issues of rapport, trust, local knowledge, gender differentiation and more - as these issues influence the successful accomplishment of locally determined goals.

3. The authors make clear the steps involved in conducting PAR correctly. This is valuable because, within the development and conservation worlds, there is a great deal of very superficial effort that is labelled "participatory" but does not meet the standards we feel are needed - standards that are made clear in this story. This is also valuable in laying the groundwork for the analyses to follow, providing a common understanding of what is being discussed (ACM/PAR), an understanding that might not otherwise exist (see Chapter 3 or Colfer et al. 2011).

4. I also see it as a reminder (or for neophytes an introduction) to the realities of rural, developing country forest lives - of the unconscious assumptions many practitioners and researchers make based on their own comfortable and convenient conditions. 


\section{Introduction to Chapter 2}

\section{References}

Colfer, Carol J. Pierce, Etienne Andriamampandry, Stella Asaha, Emmanuel Lyimo, Endri Martini, Jean Laurent Pfund, and John Watts. 2011. "Participatory Action Research for Catalyzing Adaptive Management: Analysis of a 'Fits and Starts' Process." Journal of Environmental Science and Engineering 5 (1):28-43. 


\title{
2 Local people's perspectives on action learning
}

\author{
Impressions from the Amazon
}

James Johnson and Benno Pokorny

\section{Contextualization}

With the initial aim to consider more adequately the needs, views, and capacities of local resource users, from 2005 to 2009, a consortium of nine universities and non-governmental organizations (NGOs) from Europe and Latin America implemented the EU-funded research and development project, "Forest management by smallholders in the Amazon - An opportunity to enhance forest ecosystem stability and rural livelihood" (ForLive; Pokorny 2013). The project, in partnership with governmental organizations, NGOs, and other relevant actors, analysed promising tree and forest management initiatives of local resource users in the Bolivian, Brazilian, Ecuadorian, and Peruvian Amazon. The purposes were to elaborate locally viable forest use options contributing to local livelihoods and the ecological stabilization of landscapes and define possibilities to promote them as a basis for sustainable local development of the Amazon and beyond. The project focussed on five study areas representing typical agricultural frontier contexts. It described nearly 150 initiatives indicated as promising by experts from governmental agencies and NGOs, as well as representatives from local resource user groups. The initiatives analysed showed great heterogeneity, with cases located in both recent and older frontiers, involving Indigenous people, traditional communities, and settlers. Some locals had small farms with forest areas of less than 5 ha; most holdings were between 50 and 100 ha, and others had access to collectively owned forests of up to several thousand hectares. More than $80 \%$ of the initiatives analysed received external support from governmental or non-governmental organizations for sustainable management of natural forests, plantations, and agroforestry systems for the production of timber, but also NTFPs such as fruits and fibres.

Seventeen initiatives were selected for in-depth analysis. In these case studies, beyond doing conventional academic research, the project invested in transdisciplinary learning. This particularly included an action research and learning component that stimulated and accompanied families and communities in doing their own research on topics defined by them. This component principally sought to establish routines for local learning structured in a sequence 
of learning loops of planning, action, and reflection (Pokorny, Cayres, and Nunes 2005). Followed by an initial phase of informing and mobilizing community members, interested persons were invited to discuss needs and options for local development. Then, the locals decided on the most relevant options and formed local research groups. To achieve their goals, the groups regularly set up short-term plans that defined activities and responsibilities following the specific possibilities and interests of the group members.

In each case study, the project's field assistants facilitated the local research groups; most importantly, they supported the reflection meetings to discuss the group's performance and to define and adjust new work plans to be implemented in the upcoming learning loop. Field assistants were $\mathrm{PhD}, \mathrm{MSc}, \mathrm{BSc}$ students, and NGO employees, who, besides working or assisting the academic project agenda, dedicated up to $50 \%$ of their working time to serving the local research groups. The field assistants were intensively prepared in training workshops held by senior researchers with considerable experience in action and collaborative research, who also supervised the activities in the field including bi-annual personal meetings. Also, a field manual was prepared to explain the working approach and its conceptual underpinnings.

Most local research groups decided to invest in exploring technical questions such as the control of pests and diseases, management of specific crops or trees, and control of fire; others were concerned with markets, particularly those for timber; in some sites, issues related to community organization also played a role. Despite severe challenges for both sides, the local researchers and the field assistants, many of the groups managed to generate valuable and locally relevant findings, and, most importantly, contributed to collective action and improved self-governance of community organizations.

In its final phase, the project invested in a profound reflection on the experiences of all local researchers and field assistants. Reflection included semistructured face-to-face interviews and focus group discussions about the most positive and negative experiences, achievements, and problems and on factors that motivate or demotivate, as well as the interests in and possibility for post-project continuation. Interviews and group meetings were documented - partly recorded and transcribed - and analysed in three steps. First, a small researcher team systematically reviewed the documentation to crystallize the essential statements on the above-mentioned aspects. The outcomes were then presented, discussed, and if necessary corrected and complemented at national meetings with the field assistants and community representatives. The consolidated findings were then reported back to all actively engaged project participants and finally evaluated and summarized at the project level by the authors.

The reflection process revealed manifold insights about the experiences and perceptions of the local researchers and field assistants, the strengths and weaknesses of the local research group approach, and of including action research and learning as a local development component in conventional academic-style research projects. This text is an attempt to compile the principal outcomes of this reflection process from the perspective of the locals who participated in the 
research groups. To emphasize this local perspective, we refrain from an academic presentation of the results. Instead, we compiled the text fragments and original statements of the local researchers into a single virtual journal written by a fictitious farmer who participated in one of the local research groups. This way of presenting the insights gained allowed us to abstract the many specific observations from the case studies and condense the diverse experiences and perceptions into a single, hopefully easily readable, story. However, although we have done our best to include and reflect the intentions and statements of local researchers whenever possible, it should not be forgotten that we, academics, wrote the text, and thus it naturally reflects our interpretation and evaluation of the discussion process. The text does not describe a specific case study, nor does it describe any single real person, but an idealized composite of what we observed and heard in the talks, interviews, group meetings, and field visits during the four years of the ForLive project and the final sequence of reflection meetings.

We present a virtual journal written by the fictitious farmer, Pedro Martinez, living in the also fictitious, small community, Nuevo Horizonte, located in the Amazon region of northern Bolivia. The journal expresses, in a greatly summarized way, how the farmer and his family may have viewed the project and the work of the local research group. We also created the character of the recently graduated Ing. Miguel as the project's first field assistant responsible for the facilitation of the group. ${ }^{1}$ He reflects, to a certain degree, the typical professional profile of some of our field assistants. The document accompanies the process from the first arrival of the field assistant in the community and how this is viewed by the residents. The series of meetings in Nuevo Horizonte follows the sequence of events proposed under the action research process involving several steps. The problems and perceptions of the community are presented through the eyes of Don Pedro, presenting his understanding of the process in the first place and as it evolved; the identification and selection of priority themes for local research and learning, and the formulation of research questions; the formation of the local research groups and their coordination; the planning and implementation of activities to answer the relevant questions; and the evaluation and reflection on the process and the subsequent cycles of planning, implementation, and reflection.

\section{Introduction by Pedro Martinez}

My name is Pedro Martinez, I am a farmer from the community of Nuevo Horizonte in the municipality of Puerto Rico located in the Pando, the northernmost department of Bolivia. I am aged 36 and was born and raised in the village, leaving occasionally to look for work with logging companies or on the nearby haciendas (cattle ranches). I left school at the age of 13 and went with my brother to look for gold on the River Beni. My father and mother live in Nuevo Horizonte. My father used to live in a barraca (a large rubber estate) tapping rubber trees for latex, but after the collapse of rubber prices, he 


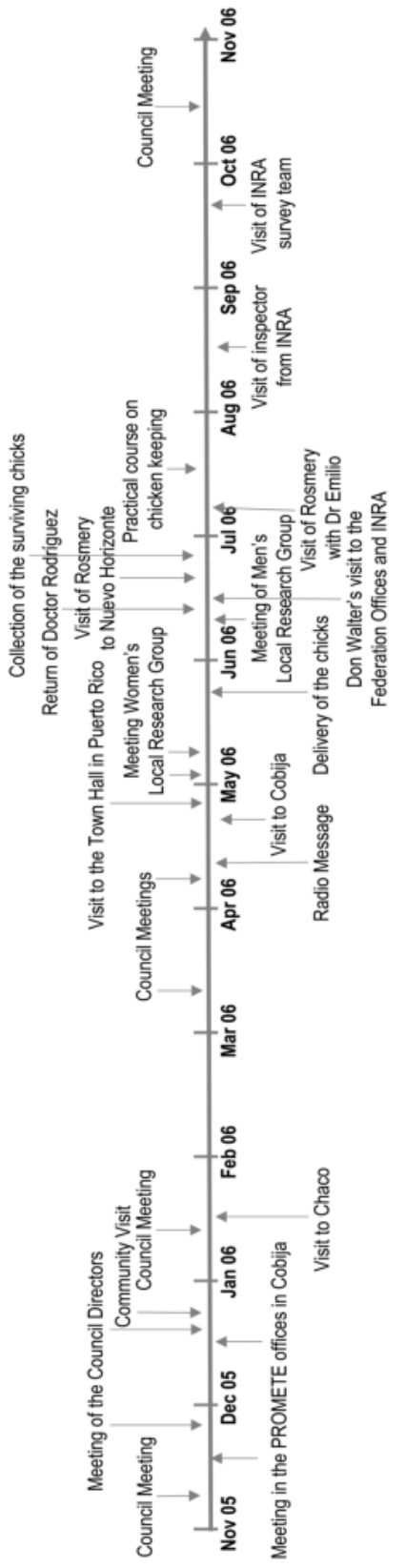


moved with the rest of the family to Nuevo Horizonte just before I was born. I met my wife, Maria, when I was working on a hacienda and came here to live when our first son was born. We have six children, Marco aged 19, Fernanda 18, Angelina 16, Julio 14, José 12, and Pedrito 5. We work on our 50-hectare plot of land, growing rice, maize, cassava, bananas, cocoa, mangoes, guava, and oranges. I own six cows. My wife has two pigs and 34 chickens. Every year, like my neighbours, I select an area of forest to clear for the chaco (crop land) to sow rice and maize, mainly for the family and the chickens, selling a little to get some ready cash. In December, I go to the forest to gather Brazil nuts, and from this, I earn enough money to buy the children's books and clothes for school with a little left over for the house.

Although I left school early, I can read and write reasonably well, and, for the past three years, I have been secretary of our community council and I am responsible for taking minutes of the meetings. Life for us has not changed much despite the promises from organizations that come and go, but something strange began to happen in our community three years ago. An NGO called PROMETE came to tell us about a different way of working that they called action research, something to do with a project called ForLive, or something like that. To be honest we didn't really understand anything at first. But little by little the young agronomist, Ing. Miguel slowly began to gain the trust of the community and explain a different way of working. Anyway, since I am the secretary of the council, I thought it would be of interest to you to share our experiences. This all began in our November meeting of the council in 2005 (Figure 2.1).

\section{The story}

\section{Council meeting on Sunday, 20th November 2005}

Today, we had our monthly meeting of the council to discuss the organization of community affairs and how to carry out the work to weed the football pitch. Just before the meeting started, three men turned up in a brand new Toyota pick-up. I thought to myself that they must be here from the timber company again, but when they got out of the vehicle one of the men looked familiar, and I had seen him in the village before; another was a well-dressed young man, and the third man was a Gringo. Towards the end of the meeting, the welldressed young man raised his hand, stood up, and asked if he could tell us about a new way of working in the community. He introduced himself as Ing. Miguel from the NGO "PROMETE" based in Cobija. The other man, Ing. Juan, was also from PROMETE and told us he had worked here before with the NGO CHOCLO on a project to improve farming practices in the community. The Gringo introduced himself as Simón, but I couldn't understand what else he said. Ing. Miguel told us about a project called ForLive; it was a new way of finding out information that would help our community to develop. He told us that he wanted to work with a family that would be a case study, he said something about our forests and also that we could decide what we wanted to 
find out, but I didn't understand what he was really getting at. Looking at the Gringo, Don Walter (our president) asked Ing. Miguel how much money they would bring to the community and told him that we need a machine to cut the grass for the football pitch and a new bridge on the access road into the community. Ing. Miguel didn't seem to pay much attention. Instead, he asked us all to stand in a circle holding hands and talk about problems in the community. I thought that that was a real fairy business. I saw Ing. Miguel taking some notes. God knows what for. He must have some weird ideas about our customs here. At the end of the meeting, he asked if they could come again to explain the work in more detail at our next meeting. Nobody in the village was paying much attention, but we agreed that we would discuss the matter among ourselves and send a message to the PROMETE offices in Cobija to let him know our decision. We had to hurry off after the meeting as the lorry was waiting for us to go to a football match in Villa Bella, a village five kilometres away, to play a key match in the local Sunday league.

\section{Meeting of the council directors on Thursday, 14th December}

A group of us met at the house of Don Walter in the evening to talk about the request of the people from PROMETE to meet with the community. We have always had institutions visiting and working with us in the past and we have a particularly good relationship with the church that has brought all sorts of benefits. Last year, the church brought us a water pump and tank. Other projects like the NGO CHOCLO have worked with us and given us plants and seeds. So, when we heard that PROMETE wanted to come to work with us as well, it did not take long to decide to accept their request to meet the following Saturday. Don Walter was very keen; he could only see benefits, especially as he knew that whenever a Gringo is involved in a project there is a lot more money involved. He had already started to make a list of the things that he thought would be of benefit to the community. So it was decided that as I had to go to Cobija on Friday to do some paperwork for the council, I would pass by the offices of PROMETE and inform Ing. Miguel that he would be welcome to come to our meeting on Saturday.

\section{Meeting: PROMETE offices in Cobija on Friday, 15th December}

On Friday morning I got up at three o'clock to start the journey. I had to walk for two hours to the main road as my bicycle had a puncture. As I sat by the roadside waiting for the bus to arrive, it started to rain. How I wished I had a Toyota pick-up like the technicians from PROMETE! At 7:30, just as I was beginning to think the bus would never come, it came around the corner bursting with people travelling from Puerto Rico to the market in Cobija. I managed to find a space to stand between two large women and their chickens.

On the journey to Cobija, I thought about the injustices of life. Here I was, travelling to Cobija on a hot and sticky bus, where I would have to stand for 
three hours surrounded by people and animals. The purpose of my visit was to meet with people who at the drop of a hat could get into an air-conditioned pick-up and ride out in comfort to our community. What was it that made it possible for these ingenieros to work in this way and why had I agreed to go to see them? Why could I not achieve as much if not more than them if I had the same conditions? After all, they seemed to know very little about agriculture or the conditions of our community and gave very little advice that was of any practical use. People who came from outside asked more questions and provided very few answers to the problems we faced. I began to wonder to myself if people coming from their comfortable homes in the towns were capable of understanding how we live and work in the forest? Are these people who come from such a very different world to us capable of understanding us and helping us to make a real difference in how we live? If they lived with us in the community for a week, I am sure they would learn more from us than in a year at the university. I also wondered if Ing. Miguel realized that we have so much to do. He seemed to think that we had time on our hands and could just stop work. He doesn't seem to realize how difficult it is to get the community to agree to act on a particular issue. Ing. Miguel seems to think that it can all be done so quickly. It is not like that at all in the community, we need time to discuss.

I arrived in Cobija and asked a friend I met there, Miguel Bustos, my wife's uncle, where I could find the PROMETE offices. He had a vague idea and pointed me in the general direction of a new suburb on the outskirts of town. I had come with just enough money for my bus fare, and for a bite to eat at lunch time so I had to walk to the offices, which I eventually found after wandering the streets for an hour or so. I knocked timidly at the door; the secretary seemed to ignore me although I knew she had seen me. Perhaps it was my dirty sandals or my old shirt that didn't create a good impression. Then, in the corner, I saw Ing. Miguel coming out of the bathroom. I called him over and he greeted me but didn't seem really to remember who I was or where I came from. I reminded him of our meeting last Sunday and told him that the council directors had met the previous evening and had decided that we would be glad to receive him at our meeting on Saturday so that he could tell us more about the benefits that he would bring to Nuevo Horizonte. He told me that he would be there at ten o'clock but had to rush off as it was nearly midday and had to collect his daughter from school. He jumped into his jeep and drove off in a hurry. I turned round to walk back to the centre to visit the Federation and find something to eat for lunch. When I finished my business in the Federation it was too late for lunch, so I walked back to the bus terminal to catch the five o'clock bus to Puerto Rico. By the time the bus reached my stop, it was dark. I arrived home at ten o'clock in the evening, tired and hungry.

\section{Council meeting on Saturday, 16th December}

Although I had not slept much, I woke up early as usual and went round to the house of Don Walter to tell him that Ing. Miguel would attend our meeting 
and that we should go and tell everyone to prepare. Between the two of us, we managed to visit every household in the village. At around nine o'clock it began to drizzle a bit and we gathered in the schoolroom to arrange the chairs for the meeting. By ten o'clock it was raining a bit harder. Because it was Saturday and the weather was not good for weeding the rice, nearly everyone from the community was there. We had finished our own agenda after an hour with Don Walter deciding what we would do to get the water pump repaired and how we would get the municipal government to repair the leaks in the school roof. There was still no sign of Ing. Miguel, so we waited for a while thinking that he would arrive any minute. At midday I was ravenous, and everybody was beginning to get restless and blame me saying that I had made a mistake and that Ing. Miguel would not come. I persuaded everyone to wait for a bit longer. By one o'clock most people had lost faith and had left to have lunch and even my wife began to tell me that we should go as the children were hungry and the youngest was beginning to cry. We waited for another half hour and decided that Ing. Miguel would not be coming, after all, so we went home to have lunch and then to do a bit of weeding although it was hardly worth it by this time.

\section{Community visit on Wednesday, 20th December}

Today was a beautiful sunny day so I got up early to go to the rice field to make the most of the good weather to finish off the weeding. At around 11 o'clock my eldest daughter, Fernanda, came out to the field. I thought it was early for her to bring me lunch, and since I had run out of coca, ${ }^{2}$ I was hungry and glad to see her. As she got closer, I saw that she had brought nothing with her for me to eat and she looked troubled. She told me that Ing. Miguel had arrived at the house, and he had sent for me to go to talk to him. I was really annoyed as I needed to finish weeding the crops and it was such good weather to work, but I thought again of the benefits that he would bring to the community and thought it better to go talk to him. Half an hour later I arrived at the house to find Ing. Miguel sitting at the table eating lunch. My wife is always very hospitable to visitors and especially people from the city. Ing. Miguel explained that he could not come on Saturday because of the rain but asked for another appointment at the next council meeting in January. I told him that I could not decide, but that it was the responsibility of Don Walter, the president of the council to decide. So, once he had finished his lunch, we went round to Don Walter's house. Don Walter was naturally delighted to think that Ing. Miguel would be able to meet with the community after all and told him that he could come to present his project at the next meeting to be held on Sunday 15th January. I then returned to the rice field to continue weeding during what little was left of the day.

\section{Council meeting on Sunday, 15th January 2006}

Although it had started to rain, I was now less worried. My rice and maize were weeded, and the other crops were doing well. I had not left the community 
this year to harvest Brazil nuts like many men because I thought I could get a bit of casual work repairing fences on the nearby hacienda. Because of the Brazil nut harvest, there were not many people at the meeting, and when the men are away the wives don't participate either. Besides Don Walter and myself, there were only eight people present altogether. This time Ing. Miguel arrived in time for the meeting accompanied only by the Gringo - just as well, as he was bound to be the person with the money. In his explanation, Ing. Miguel told us that ForLive researched how the forest in the community is of benefit to us and the way we live. He explained all the different benefits of the forest and how it could make us rich! It really made me wonder why I was so poor after listening to everything he said. He told us that there were different kinds of research: research that people like Don Simón, the Gringo would be doing that he called academic research, research that Ing. Miguel himself would be doing that was of general interest to the project, and research that we from the community would do that would be relevant to our daily needs. He told us that research was to create understanding and discover how to improve the way we live and work. In addition to the research, he also told us that they would be visiting the community to collaborate with us to resolve other problems. He called this the "collaborative agenda."

Ing. Miguel also asked us to choose a family from the community with which he would be able to work and also told us that it was important to sign an agreement with the project so that PROMETE would be able to work formally with the community. He finished his presentation explaining the steps of what he called "action research," telling us that we should meet to decide the themes that we want to research, and that women should form one group and men another group. In the steps, he told us that we had to plan activities, carry them out, and then think about what we had done and then plan again. All very confusing, and I wondered if we had already done the work why we should plan to do it again, but I didn't want to appear stupid, so I didn't ask Ing. Miguel to explain. Anyway, thinking of the benefits that all this would bring, we decided to do as he said and suggested that it would be better to organize this in March when the men come back from the Brazil nut harvest and when the rice and maize harvest were also finished. In the meantime, we would continue to think about what it was we would investigate. As there was nobody else at the meeting who was prepared to accept the responsibility of the case study, Don Walter said that I should be the person that Ing. Miguel could work with from the community. I was not too sure what this would mean but hoped that Ing. Miguel would not take up too much of my time. I also found the idea interesting as I am always keen to learn how to do things differently on my land and thought that Ing. Miguel would be able to help. Ing. Miguel told me that he would come the following week to visit me, but that we needed to organize a meeting with as many people as possible from the community to plan the action research activities. So we fixed the next meeting for Sunday 12th of March. In the meantime, Ing. Miguel said he would come to visit me in my chaco and talk with the family on the following Thursday. 


\section{Visit to chaco on Thursday, 26th January}

When Ing. Miguel arrived, I had already done four hours of work slashing back the weeds in the cows' pasture and stringing the barbed wire fences. He arrived all hot and sweating with my eldest boy, Marco, who had brought his machete to help me. Ing. Miguel asked me if I could take him on a walk around the farm to show him the main areas where I produced the crops. He wanted to see the areas of forest at the back of the farm where I have a few Brazil nut trees and where, on occasion, I fell a tree to make fence posts or to sell timber to buy some of the family essentials. It took us about two hours to walk around the farm and the forest. Ing. Miguel was full of questions that seemed really strange to me. He asked me the names of the trees and what they were used for. He seemed confused by the names of the plants and was a bit frightened of the cows when we went into the pasture. When we got back to the house, he was tired and could hardly talk. He asked my wife and children to help me draw a map of the farm to show where everything was and then to tell him what was produced where and if it was consumed on the farm or sold. He continued to ask questions and take notes at the same time. I wondered what it was he was writing and how he would use all this information. Ing. Miguel also had some suggestions, telling me that it was bad to burn and that there are other ways of farming without burning. I couldn't imagine how on earth he thought this might be possible and imagined that he would not survive for long as a farmer. He left with the map under his arm and promised to come back after Carnival.

\section{Council meeting on Sunday 12th March}

When Ing. Miguel came back for the meeting, this time he brought a young girl with him, she spoke with a strange accent. It turned out that she was called Marta and was from Mexico and she was studying how people use plants from the forest. Eventually, we summoned most of the people who were in the community at that time, and surprisingly, there was quite a lot of interest with 26 people turning up, between men and women. After we had finished our agenda, Ing. Miguel stood up to present the subject of action research and describe how he wanted to work with us, repeating the points that he had made in the previous meeting. This was useful because, to be honest, it was not at all clear what he expected, and nobody remembered or understood the complex diagram that he had presented. He divided the people up into two groups, one for the men and one for the women, and asked each group to draw up a list of the important issues. During the discussion, Ing. Miguel visited the groups to help guide discussion and provide ideas. I didn't really understand this as I thought we were supposed to give him ideas of what we should research and not him give us the ideas, but since he was in charge, I supposed he knew what he was doing.

After an hour or so of discussion, the men's group had a list of seven points, but nobody could agree on which of these was most important. The list was as follows: 
- Improvement of roads

- $\quad$ Rice mill for the community

- Control pests and diseases in cocoa

- Improve cattle production

- Demarcation of plots

- Control of fires

- Management plan for timber

So it was good that Ing. Miguel was there, as he was able to make suggestions about the need to control fire and having a management plan for the forest. I wasn't sure what a management plan was, but it sounded important. Also, I felt that if Ing. Miguel suggested it then it must be a good idea. Unfortunately, there were some members of the men's group who did not agree, so we could not make any firm decisions about what it was we wanted to do. The three biggest farmers who had more cows wanted to study the problem of cattle production, but those without cows were not at all interested. On the other hand, a group of farmers who had large cocoa plantations was keen to find out how to control pests and diseases in this crop, but this was of no interest to the cattle farmers. In the end, we decided to just present a list and not define until later what would be the theme of research.

The women's group had fewer problems in working together and quickly decided how they wanted to work. The key areas that they identified were:

- Control of diseases in chickens

- Improvement to the health post

- Reroofing the school

- Sewing machines for the mothers' group

I was elected by the men's group to present the result of the discussion and tell everyone why we had chosen the themes. It seemed obvious to me, with the roads in such a bad state why we should improve the roads. Also, with the rice mill to dehull and polish rice locally, we would be able to improve the price for the sale of rice and not depend on intermediaries who buy our rice at low prices. We also have terrible losses of our cocoa and don't really know why, although some people in the community have been on training courses. This is really worrying for some of us as the price of cocoa is pretty good, but we lose a lot just before the harvest. The three bigger cattle farmers told us of the problems they have as many calves suffer from diarrhoea and die, and this represents a big loss.

We also have a permanent problem in the community as nobody knows exactly the limits of their plots of land and there are many disputes caused by the sale of timber or harvest of Brazil nuts from neighbours' plots. Only last year my neighbour, Don Felipe, felled two Cedro ${ }^{3}$ trees in my forest, insisting that they were on his land. Also, over the past two years, we have suffered a lot from forest fires that have spread from pastures when burning has got out 
of control. Two members of the community have lost their houses and all of their belongings in fires. Ing. Miguel is convinced that all of our problems will be solved if we have a management plan for our forest, although we are not too sure what this is.

The women's group selected Doña Rosa, the wife of Don Walter, to present the results of the discussion of their group. She told us that the major concerns of the women were with the so-called pest that kills off flocks of chickens every now and again. Doña Rosa also told us that the women were worried about the state of the health post that was falling down and had no possibility of storing vaccines in a refrigerator due to the lack of electricity. The other great problem is with the school roof that leaks like a sieve, affecting the children's studies. The women also suggested that they needed sewing machines to make or mend clothes. I was glad to hear this last suggestion as I could really do with some new shirts.

Ing. Miguel told us that some of the themes we could do under action research and that others would be more suited to work in the collaborative agenda. For example, he said that we could study how to repair the roof of the school or construct a tree nursery (I couldn't remember that this had been mentioned by either group, but he seemed to think it was a good idea) as part of the collaborative agenda. It was then for the first time that he told us that action research was not about giving benefits to us, but that we had to go out and do the work ourselves and find out how to bring resources to the community. This caused much discussion, and some people began to lose interest at this point thinking that they had wasted all this time in the expectation that Ing. Miguel would bring resources to benefit the community. Ing. Miguel explained that there were some resources to use for action research but that it was to cover local costs such as travel and food but not much else. He asked both groups to consider our priorities and that he would come back in two weeks for another meeting. Because we did not have a meeting on our agenda in two weeks, we suggested to Ing. Miguel that it would be better if he could come during the week and stay overnight and have the meeting in the evening when nobody works. He did not seem to like the idea very much, but in the end, he agreed, so we set the meeting for Tuesday 4th April. It was agreed that Don Walter would inform those members of the community who had not attended the meeting of the importance of the next meeting in helping to decide the subjects that would be of most interest to the community. Marta, the girl from Mexico, asked if she could also come to work in the community and if it would be possible for her to stay with a family for a month to do her fieldwork. We felt sure that if Marta came to stay in the community, then Ing. Miguel would also want to visit more often. As they departed, two brothers, Jorge and Miguel Ibañez approached Ing. Miguel and asked him to bring grass seed for their new pastures that they were sowing.

\section{Council meeting on Tuesday, 4th April}

Ing. Miguel and Srta. Marta arrived just after lunch in the community and came to look for me in my rice field. Ing. Miguel continued to ask me questions and 
take loads of notes about what I said. He told me that it was for an information pack and that people from a university in Germany sent him messages the whole time to provide information for them to process. Marta seemed to manage well and talked most of the time with my wife and children when they were in the house. She even helped my wife with the cooking and taught her to make tortillas!

In the evening we met in the school. This time there was a good turnout, and there seemed to be more interest as rumours had run around the community that the NGO was going to build a new school and give plants away. This seemed to have raised a lot of expectations and people were really interested in what they could get out of PROMETE. At the beginning of the meeting, Don Walter explained what had happened to date and asked Ing. Miguel to describe the process again, and what it was that PROMETE was doing in the community and the different forms of work that were proposed. We finally got to talk about the collaborative agenda of the project that PROMETE was doing and the action research that was meant for our topics. Jorge Ibañez, reminded by this, asked Ing. Miguel if he had brought the seeds he had asked for. Ing. Miguel told him that he had forgotten but that he would bring them the next time he came. Jorge was really annoyed and accused him of only helping me and told him that he also wanted Ing. Miguel to visit him and tell him what to do on his farm. I tried to explain that this was not the case, but he would not listen, and in the end, walked out of the meeting in disgust. Ing. Miguel did not know what to say.

Eventually, we started the meeting talking about action research again. The two groups met separately again, and the women's group quickly decided that the subject they wanted to research was the cause of the deaths of their chickens and how to manage it. The men's group continued to have problems in deciding what to do. There was a heated discussion between those who grow cocoa and the three wealthier cattle farmers. In the end, both groups reluctantly decided that they thought that the problem of internal land disputes was of most relevance to the community. So it was agreed that this would be the issue to be researched. Key people from the newly formed groups were selected to be "local researchers," and we then met again to plan what it was that we were going to do.

The women's group decided to form a commission that would travel to Cobija to visit a local vet from the NGO ALITAS that Ing. Miguel told us helped with small animals. The women then sat down to think about how they would travel to Cobija and visit the vet. The commission was made up of three people, Doña Rosa, Sra. Miguela, and Sra. Jacinta. They drew up a plan to travel to Cobija by bus to visit ALITAS to consult the vet. Ing. Miguel said that as promised PROMETE would cover the travel costs. The women's group, with some help from Ing. Miguel, then calculated how much this would cost and presented their budget to everyone.

For the men, this was not quite so easy. They had many problems agreeing about the composition of their commission and who should be designated 
as the local researcher responsible for the coordination of the activities in the group. In the end, I was designated as a representative along with my cousin, Enrique Lopez, and his brother-in-law, Erick Cortez. Ing. Miguel came over to our group to help us design a plan, and also draw up a budget for a visit to the local office of INRA ${ }^{4}$ in Cobija.

Nobody in the community really had a clear idea about the collaborative agenda and how this was different from action research and, to be honest, it seemed that Ing. Miguel was not too sure either as he seemed to doubt at times what he was telling us. In any case, it didn't really matter much to us as long as we felt that we could obtain some benefit from the effort that we were putting in. We continued to talk about our agenda and how we would work together to organize a visit to the Mayor of Puerto Rico, our municipal capital, to get him to repair the roof of the school.

We planned to travel in two weeks in a joint commission made up of the representatives of the women's and men's groups to visit ALITAS and INRA respectively; then both groups would visit the Mayor of Puerto Rico on the way back to Nuevo Horizonte. The journey to Cobija was planned for Thursday 27th April with the visit to Puerto Rico taking place the following day, catching the evening bus back from Cobija to Puerto Rico where we would stay the night with relatives.

The community meeting ended at nearly midnight but oddly nobody complained, and we all felt very positive about the discussions and the way things were being planned; we were feeling as if we were really making decisions and defining what was best for our community. At the end of the day, we were deciding for ourselves. This had not happened before, and in the past, Don Walter or people from the municipality or the church had come and given us what they thought we needed according to their programmes and projects. My wife took Marta back to the house to sleep, and Ing. Miguel strung up his hammock in the school room to sleep there.

The next day we got up early as usual to prepare breakfast. Marta helped Maria to make some coffee and I went to see if Ing. Miguel was up and about. He was still fast asleep when I arrived at the school room. I woke him up and invited him round to the house for breakfast. Ing. Miguel was covered with mosquito bites and his face was quite red. But he had survived his first night out in the community. After breakfast, he and Marta wanted to visit the forest and take some samples of plants and asked me to accompany them to tell them the names and uses of the plants. We finished this task by lunchtime. He told us that he would send a message on the Radio Pan Amazonica to confirm our meetings before departing with Marta for Cobija. It seemed he didn't want to stay for lunch although my wife, Maria, had invited them.

\section{Radio message on Wednesday 19th April 2006}

As usual in the morning, before going out to the field, I was listening to the news and local announcements on the radio when I heard the message for 
Community Nuevo Horizonte telling us that the meetings were confirmed for the 27th of April and that we should travel to Cobija as planned. I hurried round to the houses of Enrique and Juan to tell them and also to tell Doña Rosa so that she should mobilize her commission as well. Ing. Miguel had not left any money to pay for the bus fare so between us we had to go round and ask our neighbours to lend us 12 bolivianos each. We planned to meet on the evening of the 26th of April to plan our questions and what we were going to say in our meetings as Ing. Miguel had asked us to do.

\section{Visit to Cobija on Thursday, $27^{\text {th }}$ April}

As I had done on the previous occasion when I travelled to Cobija, we left Nuevo Horizonte early to walk to the main road to catch the bus; the only person who stayed behind was Enrique who got cold feet about the journey. Although it was a mild morning we were in good spirits and full of hope that we were on the road to doing something that would make a difference in our community. When we arrived in Cobija it was still early, and we were all hungry from the walk but had no money to buy breakfast in the market, so we set off to walk slowly up to the offices of PROMETE. Luckily, we met Ing. Miguel in his pick-up coming down the road. He told us that he was coming to take us to the meetings, but that first he wanted to take us to the offices of PROMETE to reimburse our costs. He gave each of us 56 bolivianos (24 bolivianos for the return bus journey, three bolivianos for breakfast in Cobija, six bolivianos for lunch in Cobija, five bolivianos for supper in Puerto Rico, three bolivianos for breakfast in Puerto Rico, another six bolivianos for lunch, and finally nine bolivianos for the bus back to the turning to Nuevo Horizonte). We realized that we were not going to get rich on this project, but it meant that we could now go and get something to eat at the market before our meetings. Ing. Miguel took us back down to the market and we sat discussing what we were going to say at the meeting. Ing. Miguel took the women round to their meeting with the vet, and we waited for him to return to go to the meeting with INRA.

We arrived at the offices of INRA with Ing. Miguel who had returned having left the ladies in the offices of ALITAS. We were shown in somewhat reluctantly by the policeman at the door and asked to take a seat. There were only two chairs and three of us, including Ing. Miguel, so we stood waiting for the secretary to return to her desk. After about ten minutes she emerged from an office and sat down to answer her mobile phone without even saying good morning. After her call, she shuffled the papers around on her desk and looked up at us. Ing. Miguel spoke for us telling the secretary that he had made an appointment with the regional director of INRA for representatives of the community of Nuevo Horizonte to speak to him about a process of regularization of land titles and demarcation of land plots in the community. The secretary told Ing. Miguel that the director had not arrived but that he would be there in an hour or so. We had no option but to wait. Our high 
spirits fell, and we suddenly felt unimportant and ignored. Although we had heard about INRA, we had no idea about how it could work for us and what this implied. Anyway, after two hours of waiting the director arrived. The secretary asked us to go through to his office. The director spoke to us briefly and then called in a lawyer called Dr Hinojosa who would be able to tell us what we needed to do to sort out our land titles. The director then left for an important meeting. Dr Hinojosa told us that INRA was completing some land titling processes in the region, including neighbouring communities and that if we formalized a request, then Nuevo Horizonte could be included under the simplified titling procedure. He provided us with an example of a formal request and suggested that we should contact a nearby lawyer who advises the Federation of Campesinos (small-scale farmers) on the land titling procedure.

We left the offices of INRA to find the women's commission waiting outside for us. They had finished their meeting earlier and told us that the vet had suggested that the community of Nuevo Horizonte could be included in a project to provide technical assistance to communities in the region to improve small animal production. The vet, $\operatorname{Dr}^{5}$ Rodríguez, had said that he could visit the following Saturday, 6th May, to give a talk to the women's group and to tell them about the project. So, on an optimistic note, we went off to the market for lunch, leaving Ing. Miguel to go to pick up his children from school.

To make full use of our time, we decided to visit the lawyer of the Federation of Campesinos to ask him how we could formalize the request to be included in the process of land titling that INRA was carrying out in the region. Dr Suarez, the lawyer of the Federation, told us that he could do the necessary paperwork but that he would need Don Walter to come to visit him to sign the papers and provide copies of the necessary documents that proved the legal status of the Community Council and Don Walter as its legal representative. So far all seemed to be going well.

We left the Federation feeling that we had done a good day's work and walked over to the bus terminal in good time to catch the early evening bus to Puerto Rico where our relatives were waiting for us to stay. We waited for ages for the bus to arrive but there was no sign of it. In the end, it left two hours late arriving in Puerto Rico at ten o'clock at night. We had to wake up the relatives when we arrived to let us in. So we went to sleep again without having any supper.

\section{Visit to the town hall in Puerto Rico on Friday, 28th April}

When we woke up in the morning, the relatives told us that they had seen the mayor leaving on the road to Cobija in the afternoon. We had breakfast early and hurried round to the town hall to see if we could get an early appointment with him. It turned out that he was still in Cobija. Instead, we had a short meeting with the municipal coordinator, explaining the problem to him. We 
invited the mayor to come to visit Nuevo Horizonte to see the state of the school for himself. We felt that although we had not met him, we had made a first contact and we could go back to the town hall in the future. The meeting ended in time for us to walk round to the bus stop and catch the bus back to the road turning to Nuevo Horizonte. We arrived home in the late afternoon and went round to the house of Don Walter to inform him of the events.

\section{Meeting of the women's local research group on Saturday, 6th May}

The women had met on several occasions to discuss how to prepare for the meeting with Dr Rodríguez, and on one occasion Ing. Miguel had visited the group for a day to talk to them about how to present their problem and the research question that they had selected. The ladies felt well prepared and that they knew how they wanted to tell the visiting vet about their problems. So it was with great expectation that they awaited his visit. In fact, the visit had generated so many expectations that half the village had turned out to meet the vet, including most of the men from the community. At around ten o'clock, Dr Rodríguez arrived in his Suzuki jeep shortly followed by Ing. Miguel in his pick-up. We wondered why they had at least not come together in the same vehicle. The ladies were ready with their presentation and had invited Doña Rosa to do the initial presentation of the group and their project. Upon their arrival, Ing. Miguel and Dr Rodríguez were promptly greeted by Don Walter who led them to the schoolroom where the meeting was to take place. Don Walter gave a long introductory speech in which he said how pleased he was to have a visit from the vet, and he now hoped that the problems of those farmers who kept cattle in the community would, at last, be attended to by Dr Rodríguez. With his opening words, he then asked Dr Rodríguez to address the group. Dr Rodríguez opened a huge roll of papers that explained the origin of the domestic fowl, the feed, habitat, history, anatomy, and everything else you could possibly want to know about the humble chicken, except that is, what the women's group really wanted to know.

At the end of his talk of nearly two hours, Doña Rosa stood up to thank Dr Rodríguez and explained as briefly as she could, now somewhat upstaged by the illustrious visitor, the problems that the community had with the sudden death of their chickens for no apparent reason. Dr Rodríguez explained about Newcastle's disease, parasites, vitamins, and such like, but told the ladies that in short, their chickens were not worth bothering with and that he could bring them ten chickens per family of an improved breed that he was sure would do much better. Moreover, he told the ladies, his project with ALITAS could provide the chickens at a very low cost as these were subsidized by the International NGO Proyecto Pollito. The women's group was delighted to hear this news and accepted the offer, immediately forgetting completely about their original proposal and the project that they had thought about and prepared during the previous days. Dr Rodríguez told the women's group 
that he would talk to Ing. Miguel to make arrangements for the chickens and explained that the group would have to prepare new chicken runs, improve the diet with a ration based on soymeal, and also give them a ready supply of clean water every day. Ing. Miguel told Dr Rodríguez that he thought the costs of the project could be partially met by his project if Proyecto Pollito could cover the rest. So it was agreed that each of the nine members of the women's research group would receive ten-day-old chicks of this wonderful new breed with sufficient food to rear them for the first 30 days.

The meeting closed and Dr Rodríguez and Ing. Miguel agreed to make the necessary arrangements for the delivery of the chickens from their respective institutions in Cobija. Dr Rodríguez told the group that the chicks would be delivered before the end of the month if the necessary preparations had been made according to the list of instructions that he would leave with Ing. Miguel. With this, Don Walter took the doctor round to the house of his great friend, Miguel Pinto, the biggest cattle owner in the community who had quickly prepared a barbecue for lunch and got a crate of cold beer in honour of the vet's visit. Don Miguel then primed the doctor for guidance and after lunch took him round to his corral to get some advice on how to treat his cattle for the tick infestation that was particularly bad that year.

After the departure of the doctor, the women's group met briefly to discuss the plans and preparations that they would make for the arrival of the chicks. The plans that the vet had left were complicated and difficult to understand but they thought that with the help of Ing. Miguel they would be able to get by. They decided that they would need the help of the men to build their new sheds using Motacu $^{6}$ palm thatch. The real problem was the chicken wire that would cost 56 bolivianos per roll, more than the value of two adult chickens! The ladies decided to go back to talk to their husbands and return to meet later in the week to finalize arrangements.

\section{Meeting of the women's research group, Thursday, 11th May}

After an early supper on the evening of the 11 th of May, the nine women who had originally made up the local research group met to discuss the outcome of their discussions with their husbands to analyse who would be able to continue with the project of the improved chickens. All but two members of the group had found a way of mustering up the money for the wire and managed to get their husbands to agree to help build the henhouse and run. Although two women had opted not to continue because of the high cost of the investment, other women now wanted to join the group seeing that benefits might be obtained by joining. The group discussed the admission of further members but decided not to permit this as this may reduce the number of chicks that they would each receive. So it was decided that they would send a message to Ing. Miguel and Dr Rodríguez indicating the outcome of their discussions and asking that ten-day-old chicks should be sent out to seven members of the women's group. 


\section{Delivery of the chicks on Saturday, 27 May}

Over the following two weeks, the seven families worked to cut and prepare the palm leaves, cut timber for posts and beams, and find 56 bolivianos to buy a roll of chicken wire, borrowing money from friends and relatives, selling a couple of chickens or in one case, selling a pig. In our case, Maria had convinced me to sell a sack of our recently harvested rice to cover the cost of the chicken wire. I did this reluctantly because of the high cost but said nothing knowing that she was convinced by everything the vet had told them. I spent three days cutting poles, posts, and cutting and preparing palm leaves. I spent a further two days building the shed and chicken run. I hadn't counted on doing all this work but if it made my wife happy it was a good investment of my time.

It was now the great day and Dr Rodríguez had sent a message over the radio saying that he would be arriving with the chicks before midday on Saturday. The women were so anxious that, from seven o'clock onwards, they met at the entrance to the village to wait for Dr Rodríguez to arrive. Finally, at 10:30 his Suzuki came into view, this time together with Ing. Miguel. The expectation was enormous. Upon arrival, Dr Rodríguez unloaded the chicks, which were packed in seven neat little cardboard boxes each with ten chicks. He also brought seven $10 \mathrm{~kg}$ bags of the special chicken rearing concentrate. No grubs and worms for these special creatures! Dr Rodríguez visited the families one by one to release the chicks into their new quarters, giving each family a word of advice. On arrival at our shed, he was critical of the height of the roof and the orientation saying that it should have been sited to run from east to west and that the eaves were too high for chicks, which might catch a chill with the onset of the cold southerly winds at this time of year. We didn't feel too bad as he had criticized virtually every chicken shed that he had visited, which in one way or another did not fulfil the specifications that he had given. The combination of the complicated text and the inability of most of us to read very well was a recipe for misinterpretation, but we were happy with the outcome at least; certainly, the chicks didn't seem to mind too much and appeared to adapt well to their new surroundings. If it hadn't been for the presence of Marta in the community, we would have been at an utter loss in understanding the instructions. Before leaving, Dr Rodríguez told us that he would return in two weeks to see what progress the chicks were making.

\section{Meeting of men's local research group on Wednesday, 7 June}

Events had caught up with the men's local research group and ever since the visit to Cobija they had not met formally except for the report of the visit that was presented to Don Walter. The success of the women's group spurred the men's group into action and stimulated them into meeting again to assess how they might advance in their mission to sort out the community's land titles 
and put an end, once and for all, to the internal disputes over the boundaries between the plots of land. Don Walter had not had time to go back to visit the Federation lawyer to sign the formal request to submit to INRA and start to do the work on the community titling process. We agreed to each pay two bolivianos to cover the cost of Don Walter's visit in the hope that all the community members would eventually support the work. So it was planned that on the following Wednesday, Don Walter would travel to Cobija to look for Ing. Miguel in the offices of PROMETE, visit the Federation lawyer to fill in and sign the necessary forms, and then go round to the INRA offices to formally submit the application as indicated by the INRA lawyer, Dr Hinojosa. The need to establish some contact with the Mayor of Puerto Rico was mentioned but no action was defined.

\section{Return of Dr Rodríguez on Saturday, 10 June}

By the time Dr Rodríguez was due to return to Nuevo Horizonte the spirits of the women's group had changed somewhat. Early expectations and hope had given way to concern and in one case despair as time went by. We had been lucky and only one chick of our ten had died. Doña Rosa had lost all but three of her chicks but did not know why they had died. She imagined that they needed a mother hen to keep them warm and that the charcoal embers burning in a tin were a poor substitute. Doña Jacinta had lost all of her chicks to a Carachupa (a predatory opossum) while Doña Juana had lost one to a Chuubi (a hawk), and three had been eaten by her neighbour's cat. When faced with this harsh reality, Dr Rodríguez appeared to be indifferent to the tragedy that this represented to most of my wife's colleagues, and instead suggested that he could provide 30 replacement chicks to be shared among the unfortunate ladies and recommended that more care should be taken by ensuring that the chicken wire was properly closed off, and if necessary, more should be bought to prevent animals from entering. In addition, he suggested that all of the chicks should be given antibiotics in their water and that the group could buy a flask of antibiotics costing 100 bolivianos and that this would be sufficient for all seven lots. So much had been invested so far it seemed a waste to give up now, so the group decided to accept the suggestion of Dr Rodríguez, and buy the antibiotics to give to the chicks. Dr Rodríguez said he would send the chicks out with Ing. Miguel on his next visit the following week and would visit the community again at the end of June.

\section{Don Walter's visit to the Federation Offices and INRA in Cobija on Wednesday, 14 June}

On the evening of the 13th of June, there was a knock on the door late, at around nine o'clock. I was tired from my day's work in the chaco planting 
cassava and with the cold south wind, I had decided to go to bed early. It was Don Walter at the door asking me to accompany him on his visit to Cobija the following day. He told me he could cover the cost of my ticket from council funds but that he needed me to go with him as I already knew the man from INRA and the offices of PROMETE. Although I had a lot of weeding to do, Don Walter convinced me to go with him. So, before going back to bed I cleaned my sandals and prepared my best clothes for the trip.

Don Walter and I got into Cobija around 9:30. We were both cold and tired as the wind had got up in the night and was now blowing hard. We went round to the offices of PROMETE to find Ing. Miguel, but to our great surprise, we were told that he no longer worked there and had taken a new job with the Superintendencia Forestal in San Borja. This was devastating news as we were beginning to get used to Ing. Miguel and understand the complicated words that he used, and at the same time, it seemed that he was also beginning to understand a little about the way we work and think in the community. The secretary told us that a new person had been designated to work with us, her name was Ing. Rosmery. The secretary called the director of PROMETE, Ing. Marcial, a very important man we guessed who came out to greet us. We explained the purpose of our visit to Cobija and the importance of our visit to INRA. He seemed to be aware of what we were doing. He told us that he was very interested in our work and had talked a lot to Ing. Miguel about ForLive and the importance of the work to PROMETE. Ing. Marcial told us that Ing. Miguel had left feeling uncomfortable about his role in the work in Nuevo Horizonte but that, upon reflection, he had learned a lot from the community and about his own role in working with groups of small farmers. Ing. Marcial showed us a note that Ing. Miguel had written, explaining the reasons for his departure and his suggestions as to how the work might be taken forwards in the future. Ing. Miguel had also commented in the note that he now recognized the value of farmers' own knowledge and experience and that the most important aspect of his work had been to enable families to come together to discuss common concerns and their solutions. Ing. Marcial seemed to be quite moved by the note and told us that the lessons shared by Ing. Miguel within PROMETE had influenced his decision in the selection of his replacement to work in Nuevo Horizonte. At this point, he told us that Ing. Rosmery would be working with us from now on due to the departure of Ing. Miguel at short notice. He called Ing. Rosmery to come to meet us and asked her to accompany us on our visit to INRA.

I was very sceptical that a young girl like Ing. Rosmery would be able to work with us in the community. How could she possibly know anything about our farming practices, how we live, and the reality of the rural communities in this area of the Bolivian Amazon? How I wished that Ing. Miguel, for all his defects, could return to accompany us and tell us how we should do our work. As we walked down the road, Ing. Rosmery started to ask a lot of questions, just like Ing. Miguel had at the beginning. It appeared that Don Walter was thinking the same as I was and told her that we had 
answered these questions before, and asked her if she had not read the reports that Ing. Miguel had written from all the notes that he took from his visits to Nuevo Horizonte. Ing. Rosmery told us that she had not received any notes or reports from Ing. Miguel and that one of the problems that he had in PROMETE was that he had not written anything down about his work or the process in Nuevo Horizonte. She told us that the project coordination had written a strong letter asking him to send the missing information by the end of June. As we walked on to the Federation I began to wonder if it was really worth all the time and effort that we had invested in the project and if, at the end of the day, it would bring any benefit to the community or if it might not be yet another project that would waste our time and come with false promises?

In the Federation, we were welcomed warmly by the General Secretary, who turned out to be some distant relative of Don Walter's. Somehow, he also knew Ing. Rosmery, which surprised me. After a few minutes, he called Dr Suarez, the Federations lawyer, to come to meet us and inform us what it was that Don Walter had to fill in and sign. Within half an hour we had completed the forms and taken photocopies of the relevant documents including the identity card of Don Walter and the minutes of the meetings at which Don Walter was confirmed as president of the community. In order to facilitate the process, Dr Suarez offered to go round to INRA together with us where he said he had some "contacts" who would help with the paperwork.

On arrival in the INRA offices, we got quite a different reception from the last time. On seeing that the Federation lawyer was with us, as well as Ing. Rosmery, we were invited to wait to see Dr Hinojosa and offered coffee and water! When Dr Hinojosa arrived, he greeted us cordially, paying special attention to Dr Suarez. Don Walter explained the motive of our visit. Dr Hinojosa informed us that as chance would have it at that moment, INRA had a team of topographers working in the field with the communities slightly further to the south of Nuevo Horizonte. He examined our forms and asked Don Walter to put his thumbprint on the bottom of each of the documents. He told us that all was in order and that if all went to plan and the regional director approved the process, then the topographers would be arriving before the end of September, before the end of the dry season. Dr Hinojosa asked us to return towards the end of July and suggested that in the meantime we could assist the work by cleaning the borders between neighbouring plots, especially where land disputes between neighbours existed.

\section{Visit of Ing. Rosmery to Nuevo Horizonte, Thursday, 22 June}

I had been out in the fields since dawn to harvest some cassava and came back early to have breakfast together with the family when to my surprise, I saw 'Ing. Rosmery' walking across the football pitch carrying a pile of books coming towards the house. I thought immediately that the Ingeniera does not know how to drive and has got stuck or had a puncture. As she got closer, I realized 
that the books that she was carrying were not books at all, but three boxes of chicks that the doctor had sent to replace the ones that had died. She came over and put the chicks down on a bench and produced a flask of new antibiotics recommended by the doctor from her pocket. She told us that this was to be paid for from ForLive project resources, which was a huge relief, especially now as the women's group had severe doubts about these new chickens. Some of the women began to question what had happened to the chicks' mother, and surely the mother hen had died and the vet now wanted to send the chicks out to them. They could not imagine that so many chicks could hatch and have no mother. We asked Ing. Rosmery how she had got to the village, and she told us she had caught the early morning bus to Puerto Rico and then walked in from the road. We somehow found this hard to believe. This was not the way for a real professional to behave!

Unfortunately, by the time of Ing. Rosmery's visit, the situation of the chicks had deteriorated even further. Of the 90 chicks that had been sent out, there were now only 20 survivors and six of these belonged to my wife, Maria. Our last hope lay in this flask of antibiotics that the vet had sent out to us, but, to be honest, nobody believed that this would make much difference. To make matters worse, the special chick-rearing feed that he had provided had just finished and no more had been sent. We managed to keep our chicks alive by breaking open termite mounds and feeding the grubs to the chicks, but they hardly seemed to know what to do with them, unlike our chickens that were used to this delicacy.

Ing. Rosmery talked with Maria for a while, and then they decided to go round to the house of Don Walter and Doña Rosa to discuss the situation of the chicks. It turned out that Ing. Rosmery had been brought up in one of the neighbouring communities and had then gone to study, so she understood everything we told her, and we also found that she had a simple way of expressing herself that really made communication much easier. She told us that she had heard that other communities had similar problems to our own and that the best way to start to improve the chicken production had been to vaccinate the chickens and to improve their diet. She said that it would be better to have a meeting with the rest of the group to discuss what had happened and to try to plan a way forward. There and then Doña Rosa and Maria decided to go out and summon the members of the group to a meeting.

Although the school room was unoccupied, the women's group decided to meet under the mango tree by the health post. Maria told me that they thought back about the process of planning and remembered that what they really wanted to do was to improve the way they kept the chickens that they already had and that it was not their idea to bring these wretched chicks to the village, but the idea of the vet who had convinced them that this was the best thing to do. They told Ing. Rosmery how they had borrowed money to buy the wire netting for the hen run and all the effort that had gone into building the sheds. Ing. Rosmery suggested that they might think again about the chicks and perhaps use the sheds for the chickens that they already had, and she could return 
the chicks to the doctor if that was what they wanted to do. Ing. Rosmery also told the women that she knew of a vet who was very good with traditional chicken breeds, and she could speak to him to see if he could visit the community to listen to the women and to see what suggestions he could make to improve the production of the chickens. This, the women said, was what they had intended to do in the first place, but Dr Rodríguez had convinced them to rear these useless chicks and made them forget what it was that they really wanted to do. Ing. Rosmery told the group that she would be accompanying the project until it ended and would attempt to facilitate the group to enable them to do what they wanted and strengthen their organization. The women's group asked Ing. Rosmery to see if she could organize the visit of this other vet and asked her to arrange for Dr Rodríguez to collect the chicks to take them back to Cobija.

By the time the meeting ended it was just about 11 o'clock and getting on for lunch time. Maria invited Ing. Rosmery to stay for lunch. Obviously relieved, she accepted the invitation and produced some rice and a piece of charque $^{8}$ from her backpack as a contribution to the lunch. Then both set about preparing lunch. Ing. Rosmery told Maria that she intended to stay the night in the schoolroom and go back on Saturday to carry out field visits to gather some of the missing data. Maria invited her to stay in the house, and the two of them carried on chatting. We quickly began to feel like Ing. Rosmery was part of our household and community and became accepted and recognized, especially by the members of the women's research group. The men's group, however, found it difficult to listen to her and to think that a young professional, particularly a girl, could really understand how their farms functioned and how she could be useful to them. Time passed quickly, and it was soon Saturday. To be honest, I was quite glad because with Ing. Rosmery's visit I had already missed two of the first round football matches of the World Cup on the radio, and on Sunday afternoon I was determined to cycle to the neighbouring village, Bella Vista, which has a generator and satellite dish to watch the game between Argentina and Mexico. What with the cassava harvest and the World Cup, there wasn't much time left for action research.

\section{Collection of the surviving chicks on Tuesday, 27 June}

We were surprised when just before lunchtime, Dr Rodríguez arrived in his Suzuki jeep to pick up the few surviving chicks to take them back to Cobija, where no doubt they would die. He seemed indignant that we should reject his wonderful offer and said very little. Upon giving him the 25 survivors that Ing. Rosmery had brought last week, Doña Rosa told him that she wished she had never heard of his supposedly wonderful chicks that had cost them so much money and made them buy so many items that they could ill afford, and which did not respond at all to the local conditions. After thinking for a while Dr Rodríguez said that it was their fault that the chicks had died as they did not know how to look after them and if they had done as he had said then 
they would have been fine. It seems that the vet could not understand what we were trying to tell him.

\section{Visit of Ing. Rosmery with Dr Emilio, 5 July; council meeting}

Early in the morning, I heard the sound of an approaching motorbike. I could not think who it might be until who should come round the corner but Ing. Rosmery bringing somebody as the pillion passenger. She pulled up to the house and presented Dr Emilio Choque, the vet she had told us about on her last visit. I really hoped that the visit would not take long as it was the day of the second semi-final of the World Cup, and I didn't want to miss it. I had got my bicycle specially repaired to go to see the game. Fortunately, Dr Choque was also keen to get back to Cobija to watch the match and wanted to have a quick meeting with the women's local research group to discuss possible collaboration. They went round to Doña Rosa's house and quickly organized a meeting of the group. Doña Rosa explained their research project to improve the production of their local chickens, and especially how to reduce loss from diseases that ravage the flocks every now and again. Dr Choque explained how they could use the infrastructure in which they had invested and how by improving the nutrition of the local chickens they could improve their productivity. He also explained how, by vaccinating, it would be possible to reduce losses from disease. He agreed to return to give a course on the subject in the middle of July. With that Ing. Rosmery and Dr Emilio hopped back onto their motorbike and drove off just in time for me to cycle off to see the Portugal versus France match.

\section{Practical course on chicken keeping with Dr Emilio on Wednesday, 19 July}

Just as he had promised, Dr Emilio returned to give a practical course to the women's group on chicken keeping. Instead of everyone sitting in the school room, they went first to see the chickens running around the houses. There were several men participating who were as keen to learn as the women. Dr Emilio pointed out some of the characteristics of more productive animals so that the women could learn to select these. He also very dexterously caught two hens and showed how to detect symptoms of illness and especially diarrhoea and how to distinguish between infectious diarrhoea and what he called physiological diarrhoea provoked at the onset of laying. When we went to see the hen runs, he was quite enthusiastic about the possibility of using these to improve the management of the chickens and especially their health care and nutrition. He then asked to be taken to a typical farm to see the plants being produced to see which of these would be appropriate for use in chicken feed. He showed us the cassava leaves, pigeon pea, maize, cassava peelings, kudzu, and a range of other products that we did not know were useful for chickens. In this way, by walking round the houses and chaco we were all able to learn and see that this was applicable to the conditions in which we live. At the end 
of the course, we returned to the house of Doña Rosa where we carried out a practical exercise of capturing ten chickens and one cockerel to be enclosed and kept under "improved management," in a way that the women could readily manage and copy if they wished to do so.

\section{Visit of an inspector from INRA on Tuesday, 22 August}

Throughout this period, Ing. Rosmery visited Nuevo Horizonte on a regular basis often staying the night and on various occasions staying for several days running, especially over the weekend, which she seemed to enjoy. Whenever she gathered data, she explained what it was for and how it would be used by those people organizing the research. Dr Emilio also came on a regular basis to visit the women's group and their chickens. He taught them how to vaccinate, select, and cull animals as well as the importance of providing good chicken feed.

During this time, the men's group remained relatively inactive as if they were waiting for something to happen before mobilizing themselves to act. Eventually, though, something did happen. Towards the end of August, a site inspector from INRA arrived in the community asking to see Don Walter and to make a few on the spot site inspections to quantify the amount of work involved in surveying the community and drawing up plans. With one matter or another, we had not organized the workgroups to clear the limits between plots. The inspector said that this was urgent if we were to receive the surveyors in the next three weeks as planned. Unfortunately, with the advent of the rains, we had been totally absorbed with the work of preparing the land to sow rice and maize and selling timber. We also had number of emergencies with the need to rush to put out fires that sprung up all around the community. We organized a meeting of the men's group later that same day and managed to stir up enough interest to organize workgroups to clear strips in the undergrowth of the forest between the plots of land. We drew up a work plan to show who was in which group and where they should be working so that all the parcels would be taken into account. The main stimulus to working in this way was the organization demonstrated by the women's group.

\section{Visit of INRA survey team on Tuesday, 26 September}

With the support and encouragement provided by Ing. Rosmery and the accompaniment of the work plan, it proved to be possible to clear all the old plot boundaries and discover some of the old boundary posts. The survey team was happy to be able to work in this way, and some of the young men from the village even learned how to use the GPS. The young overseas researcher, Simón, who had been away working in Brazil, was especially helpful with this task. By the end of the week, the community had agreed on the draft plans and divisions marked on the ground so that the intention now was to draw up a legal document called a land-use plan at the community level. 


\section{Council meeting on Sunday, 14 October}

Ing. Rosmery had asked the community if she could participate in the council meeting of October to be able to reflect on the experience to date of the action research and to draw on some of the lessons learned from the process. The women's group stressed the importance of defining their own agenda and sticking to it, saying that the experience for them had been very valuable. Together they had learned and been able to share their knowledge and experience, thereby enabling them to improve the productivity of their chickens and improve the nutrition for their children. They now felt that they were able to take on more challenging projects and that their organization had been strengthened by the process. Those women who had not participated directly in the process felt that although they had not been directly involved, the knowledge remained in the community. They felt that they would be able to consult with their fellow colleagues on how to go about improving their production and that together they had benefited from the improved organization. They recognized the role of the facilitator and had learned a lot about how they themselves can help and facilitate their own activities if they decide to do so.

The men's group, on the other hand, was more self-critical. They reflected on the fact that they had not been very active in the process and had suffered from a lack of understanding as to the purpose of action research and how it would affect them and their organization. They could see the benefit now that the issue of land titles was being resolved and were keen to continue to explore new areas of action related to production. Both groups found that the process had strengthened their organization and that they were now less dependent on external assistance. Ing. Rosmery thanked them for the generosity of the families and for having been so patient with her during the time she had spent in the community. Although this moment represented the end of the current phase of support to the community, she would remain working in the area and continue to visit the community on a regular basis.

Don Walter closed the meeting by announcing the forthcoming visit of the mayor to inspect the school for the repair to the roof and also repair and equip the classroom and promote a series of classes on adult literacy in the community. This would be the first time the mayor had visited the community in 12 years!

\section{Conclusions}

The short story reflects the big challenges that collaborative research, such as the work with local research groups, mean to both the local researchers and facilitating field assistants. To translate well-grounded theoretical underpinnings and elaborated methodological guidelines on collaborative research into practice is not so easy. Neither technicians and researchers nor local resource users come prepared to collaborate in this way. Still, schools and universities 
educate people to penetrate the socio-environmental realities and to implement expert solutions but not to enter into a dialogue with local resource users grounded in mutual respect. And the local research users are constrained by traditionally paternalistic structures that have created dependency and expectations on outsiders, marginalizing their own cultures and capacities to find solutions.

Of course, it could be argued that many of the mistakes reported in the story could have been avoided. But one should be aware that it is very likely that initiatives for collaborative research will be confronted with the same ingredients that initially severely limit the possibilities. The fact that we have observed many of the above-outlined difficulties in almost all case studies in similar ways confirms this observation, despite different institutional and socio-environmental settings, and most importantly, the involvement of very different people, locals as well as field assistants.

Challenges are manifold. First, they include difficult working conditions often related to long and costly travel and poor lines of communication. Then there is the expectation of communities that desperately wait for concrete, immediate help from outsiders approaching them with generous promises. Under the often very difficult conditions in which these communities live, they need their efforts above all to be dedicated to meeting their subsistence needs and the livelihoods of their families; they can only devote limited energy to time-consuming and longer-term solutions. Nor should we forget the lack of experience and willingness for collective work of many families, as well as (quite-justified) scepticism towards project staff, who often have little time and lead a privileged and secure life elsewhere. Another critical issue is the necessity to work with not always optimally selected and sufficiently trained field assistants. This includes experienced employees from NGOs and governmental agencies who were trained to effectively implement technical and organizational solutions following the mission and expertise of their host organizations. For most of these professionals, particularly foresters, environmentalists, and agronomists, it is difficult to shed the habits acquired over the years of "knowing" the solution to problems and showing others what to do. Often, it is the young but inexperienced professionals that are confronted with strong (often even mistaken) expectations from both sides, the programme coordinators, and the locals. These often enthusiastic, young professionals might be able to interact empathically with the locals but may suffer from difficulties translating this into concrete action on the ground. More concerning and not uncommon, external professionals often arrive with their own agendas such as the implementation of solutions pushed by their organization, or, in the case of young researchers, the need to gather data and write their theses. This brings a hidden agenda into play that introduces biases through subliminal messages and coding, which can manipulate the outcomes of participatory processes. The fact that almost all the local research groups prioritized topics that largely corresponded to the qualification and interest of the accompanying field assistant shows the great influence of the facilitating professional on the "locally defined 
agendas." Too often, we observed that the facilitators focussed on their agendas and difficulties and were largely unable to imagine the effort that cooperative working arrangements entail for the community members.

Also, we should not forget the wise seniors and bosses who manage these international research and development projects but, due to their duties, seldom have the time for extended fieldwork or intensive supervision. And, last but not least, we should be aware of the normally short time horizons of such projects and related funding, which often allow the initiation of local processes but not the necessary long-term support needed to generate ambitious outcomes.

Nevertheless, the story, as well as our experience from all the 17 in-depth case studies in the ForLive project, also indicates the enormous potential of collaborative approaches, despite all the challenges and drawbacks. Most importantly, collaborative working approaches, grounded in local action, force people to interact and talk to each other in the rhythm of rural realities. This creates understanding of the realities and capacities of others and allows for respectful forms of communication. Nearly every single local engaged in the initiatives reported that they had strongly benefited. They learned about the capacities but also of the problems of others, their specific ways to see reality; the collaborative process created space for mutual learning and discussions on perspectives, experiences, and knowledge. It is also clear that this research component built local learning and research capacity, generated interesting information for the smallholders, and stimulated the creativity and adaptiveness of the local resource users to problem-solving in their difficult contexts. In many of the case studies, this has contributed to a process of empowerment, collective action, and social organization. Also, as a result of the experience, the project's field assistants, be they NGO workers or young researchers involved in the project, expressed their willingness to continue working with an attitude of respect for local resource users and with a healthy scepticism towards quick solutions that are imposed from outside without taking into account local interests and capacities. However, it should be noted that these benefits accrued principally to those who participated more actively in the local initiatives. As always, learning remains confined to the hands of those who were actively involved in the generation of the lessons!

The manifold experiences in the ForLive project confirm the immense potential of collaborative working approaches, but they also indicate the need to carefully take into account the capacities and agendas of all actors involved, the researchers, technicians, their supervisors, and local research partners. It is important to be realistic in the setting of objectives, understanding local capacities, conditions, and timeframes. It is also clear that collaboration requires more than the simple application of participatory techniques and methods. It requires a true interest in and understanding of the perceptions and susceptibilities of the community and the inequalities related to logistics, lifestyles, and priorities. Adequate training and intensive supervision are mandatory but may sometimes be insufficient to overcome confirmed prejudices and working routines. 


\section{James Johnson and Benno Pokorny}

Most strikingly, despite all the enthusiasm about working in partnership with local resource users, it is important not to forget that, in the end, the only long-term commitment to the communities lies within the communities themselves. Supporting organizations, development professionals, and researchers come and go. Thus, building and strengthening the capacity of the families and communities to develop their own projects and facilitate their own processes might be the most important tasks for external actors.

\section{Notes}

1 Professional agricultural technicians receive the university title of ingeniero agronomo, which is abbreviated to Ing.

2 Farmers often chew coca leaves as a mild stimulant to offset the sense of tiredness and hunger. Coca is also chewed at meetings, and the exchange of coca is an important means of strengthening relationships of trust.

3 In Bolivia, Cedro includes a number of species that belong to the genus Cedrela spp. The species in the Bolivian Amazon region is Credrela odorata.

4 In Bolivia, the National Institute of Agrarian Reform (Instituto Nacional de Reforma Agraria) is responsible for defining land rights and granting of titles.

5 Vets are given the title of "doctor" in rural areas in Bolivia. Professionals tend to be referred to by the title as a term of respect.

6 Attalea phalerata, a palm tree.

7 The Bolivian Forest Service.

8 Dry salted beef.

\section{References}

Pokorny, B. 2013. Smallholders, Forest Management and Rural Development in the Amazon, 212p. Oxford, UK: Earthscan Forest Library/Routledge.

Pokorny, B., G. Cayres, and W. Nunes. 2005. "Participatory Extension as a Basis for the Work of Rural Extension Services in the Amazon." Agriculture and Human Values 22 (4):435-450. 


\section{Introduction to Chapter 3}

Here, we move from the very grounded, synthetic Latin American farmer participants' experience of action research in Chapter 2 to that of researchers collaborating within an agricultural development project designed to use participatory action research (PAR). Mutimukuru-Maravanyika and her co-authors reflexively examine their own experience of carrying out PAR within a complex institutional framework, spanning divergent countries, disciplines, cultures and research organizations.

Using examples of conflict, miscommunication and divergent goals to illustrate problems that often bedevil attempts to work across disciplines - something needed in any ACM programme - these authors are able to extract recurrent patterns and offer the solutions they were able to devise within the "Aquatic Agricultural Systems (AAS) Program" in the Barotse Floodplain in western Zambia. Practitioners of ACM will recognize many of the issues discussed in this chapter, issues that often plague interdisciplinary approaches, regardless of the natural resource system studied.

This chapter also highlights the importance of recognizing the key roles of researchers themselves (ourselves) as co-producers of knowledge, as collaborators with communities and among themselves. We study and work with communities and other stakeholders but must also attend to the structures, power, learning and collaboration processes within our teams if we hope to work effectively. This example explores a complex project in which the PAR approach was formally institutionalized; it draws from experience in a very complex and structured programme.

One of the lessons we have learned from our authors' experience (see e.g., Chapter 6) is the necessity to devote more attention to making sure ACM teams and communities better understand the basics - the principles of the ACM approach - than we originally realized. 


\title{
3 Researcher collaboration complexities in participatory action research
}

\author{
Zambian experiences
}

\author{
T. Mutimukuru-Maravanyika, E. Madzudzo \\ and M. M. Songe
}

\section{Introduction}

There has been an increasing realization that agricultural and natural resource systems are complex due to interactions between socio-economic and ecological factors (Foran et al. 2014). Natural resource/agriculture managers must deal with a wide range of factors as they conduct their day-to-day activities (see Table 3.1). These multiple and complex factors and their interactions render decision making an equally complex process.

Where there are many interacting factors at play, seemingly simple events at local levels can lead to complex phenomena at the macro level. Trajectories and outcomes of such events cannot be predicted by simplistic knowledge of individual factors at lower levels (Reynolds and Holwell 2010). Consequently, in agricultural research, there has been a shift away from linear models to more holistic and systemic research approaches. The new approaches require researchers from various disciplines and other stakeholders to collaborate and work together. Such a collective initiative integrates data, techniques, tools and theories from various disciplines holistically (Barković 2010).

These holistic approaches, such as PAR, seek to change the focus of research toward the generation of actions for social change (Werkman et al. 2011; Ojha, Hall and Sulaiman 2013). A key feature of these approaches is a collaboration between researchers and natural resource-dependent local communities, aiming to help stakeholders "muddle through" complex socio-ecological systems, making deliberate and explicit attempts to embed learning into management processes and foster cooperation among those involved in managing such systems (Ojha, Hall and Sulaiman 2013). The common aim of these holistic approaches is to address challenges on the basis of insights into everyday practices that are obtained by means of participatory research.

Although these holistic approaches have been implemented over decades, many projects have remained at pilot stages - few cases exist where there has been continuous implementation in the same place with the same actors over time. Limited progress has therefore been made to demonstrate the efficacy of this approach in improving livelihoods, particularly of resource-poor farmers,

DOI: 10.4324/9781003197256-5 
Table 3.1 Examples of factors that make NRM and agricultural systems complex ${ }^{a}$

\begin{tabular}{ll}
\hline Factors at play in NRM & Examples \\
\hline Geographic & Climate \\
& Extreme weather \\
& Winds \\
& Currents \\
& Soils \\
& Governments and their willingness to address local problems \\
Political & Culture \\
Social & Social structures \\
& Religion \\
Ecological & Regeneration rates \\
& Predator-prey interactions \\
Economic & Cash needs \\
& Employment opportunities \\
& Exchange rates \\
Institutional & Markets \\
& Governance in development projects \\
Random/surprises & Tenure \\
& Disease outbreaks \\
& Earthquakes \\
& Volcanoes \\
& Economic crashes \\
\hline
\end{tabular}

Adapted from Reynolds and Holwell (2010).

${ }^{a}$ This list is not exhaustive.

and maintaining the natural resources they depend on (Allen 2001; Ojha, Hall and Sulaiman 2013). Challenges faced in implementing these approaches also include those related to the process of conducting the collaborative research itself (Smith, Syndall and Taylor 2004; Barković 2010). Hence, there is a need for new ways of dealing with these challenges (Ojha, Hall and Sulaiman 2013; Burns and Worsley 2015; Mutimukuru-Maravanyika 2010).

This chapter presents the implementation experiences of a collaborating team of researchers on one of the Consultative Group of International Agricultural Research (CGIAR) research programs, the Aquatic Agricultural Systems (AAS) Program $^{1}$ in the Barotse Floodplain in western Zambia (WorldFish Center 2011; CGIAR 2011). The team aimed to tackle a jointly identified problem using the PAR methodology (WorldFish Center 2011; Apgar and Douthwaite 2013). This chapter addresses the following questions: How does collaborative research play out in practice? What challenges arise among researchers in the process of implementing collaborative research, and how can these be addressed?

The next section presents the study site and a literature review on the challenges of collaborative research followed by a detailed description of PAR 
research methodology as used in the Zambian study. Thereafter, the chapter discusses various challenges that collaborating researchers faced as they implemented PAR and the strategies they employed to deal with these challenges. The chapter ends with a discussion and concluding remarks.

\section{The study area}

Barotse Floodplain, also known as Bulozi Plain or the Zambezi Floodplain, is located in the Western Province of Zambia (Figure 3.1). The floodplain is considered an important resource internationally, nationally and locally - it is located within the Zambezi River Basin that flows through eight countries. Although the floodplain is designated a Ramsar site and is considered to be of high conservation value, it is characterized by widespread poverty among the inhabitants (Madzudzo et al. 2013).

The floodplain has a high potential for agricultural and ecosystem services, with the lower parts of the floodplain being most suitable for crop production, especially rice (Madzudzo et al. 2013). In addition to supporting a variety of livelihood activities such as fishing, papyrus harvesting, forest product harvesting and marketing, and crop and livestock production, the floodplain provides several other functions, including supplying water for domestic use and

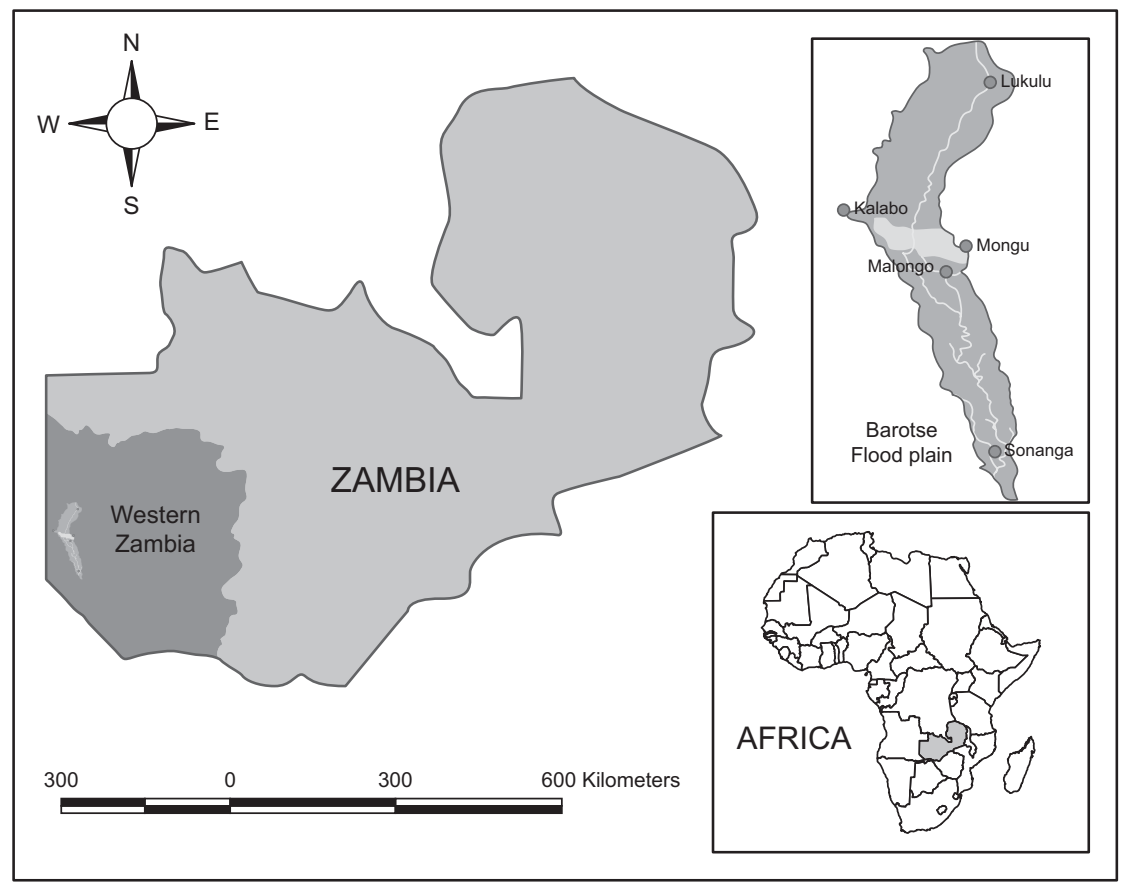

Figure 3.1 Map showing the Barotse Floodplain. 
agricultural production, and regulatory, transport and information functions. Over the years, however, the ability of the ecosystem to sustain livelihoods has been threatened, leaving communities vulnerable and heavily reliant on seasonal fishing (WorldFish Center 2007). The heavy reliance by floodplain households on a variety of natural resources makes governance and access arrangements for natural resources critical for household livelihood resilience (Madzudzo et al. 2013). Almost all households harvest grass, reeds and papyrus for house construction purposes, thatching, mat and basket production, broom making and fishing apparatus (gear) construction. Clay is also an important product that is harvested by households for use in house construction and pottery making (IUCN 2003).

The floodplain is also of cultural significance to the Lozi people who form the majority (95\%) of its inhabitants (Kazungu 2014). The tidal variations of the floodplain lead to the transhumant movement of people from the lower basin to the upper basin, and this movement is termed Kuomboka. This movement is a significant cultural event graced by the Lozi King. The Lozi traditional kingdom has been in existence for more than 400 years, including the Barotse Royal Establishment, led by a king (Litunga).

\section{Collaborative research challenges}

This section reviews the literature to highlight key challenges for collaborative research. Two distinctive categories of collaborative research can be identified in the literature: (a) disciplinary collaboration whereby collaborators identify within a single discipline but bring skills, knowledge and expertise from their own disciplines to a jointly agreed assignment; and (b) cross-disciplinary collaboration, which refers to broader interaction that spans disciplines. Crossdisciplinary research can take various forms including:

(i) multi-disciplinary collaboration, where scientists from different disciplines collaborate to address a jointly identified problem. The interpretation of results, however, is done from the perspective of one discipline that emerges as dominant in the work;

(ii) interdisciplinary research where more coordination among disciplines is required in problem formulation, analysis and interpretation. Here, collaborating researchers accept and understand and sometimes apply other disciplines' methods and approaches. Interdisciplinary research may lead to new questions and methods; and

(iii) trans-disciplinary research where research problems are jointly formulated by all and cannot fit in any single discipline. Here, collaborators accept and adapt new methods, analyses and interpretations that span several disciplines (Eigenbrode et al. 2007).

Collaborating teams of researchers, local communities and stakeholders are an anticipated essential and defining element of PAR - a key element of the 
adaptive collaborative management approach (Piggot-Irvine 2012). The PAR process that was implemented in the Barotse Floodplain is a process of collaborative systematic inquiry undertaken by participants. The research was designed to address community challenges (Greenwood and Levine 1998; Crane and Richardson 2000; Evans et al. 2014; German et al. 2012). Ideally in PAR, the difference between the researcher and the researched is blurred, as both co-generate knowledge as they undergo self-reflective cycles of planning for change, taking action and observing the process and outcomes, reflecting, learning and re-planning (Mackenzie et al. 2012; Kemmis and McTaggart 2007). In practice, as this analysis shows, the PAR process is not as sequential as outlined but fluid with some stages overlapping.

Several earlier studies (Mutimukuru-Maravanyika et al. 2016; Diaw, Aseh and Prabhu 2009; Ojha, Hall and Sulaiman 2013; Mandondo, Prabhu and Matose 2008) show that PAR has the potential to result in breakthroughs in the face of complex problems. Mutimukuru-Maravanyika was part of many of the teams that implemented PAR (or adaptive collaborative management) in several of the earlier African sites, including Mafungautsi State Forest in Zimbabwe, several communities in Central Uganda and the Anlo Beach fishing community in Ghana, in addition to the AAS Program. Madzudzo coordinated a multi-stakeholder conflict management exercise in Zambia's Lake Kariba, where PAR was being implemented in addition to the AAS Program. In this chapter, we focus on one of the challenging issues that we have experienced: how researchers from different disciplines can effectively collaborate when implementing PAR to deal with complex problems that stakeholders face. Based on the typology discussed earlier, the collaboration in the Zambian AAS case can be classified as "disciplinary collaboration" - researchers from different disciplines collectively addressed a jointly identified problem using the PAR methodology. The researchers later returned to their own disciplines for analysis and interpretation of results. At the beginning of the implementation of the project (Mutimukuru-Maravanyika and Songe joined the project a year after implementation began), collaboration among researchers was taken as a "given." As observed in similar projects (Piggot-Irvine 2012; Piggot-Irvine 2015), researchers went straight into the research process, taking a shared understanding for granted. However, it took only a short while before collaboration challenges began to emerge, such that many challenges were apparent by the time Mutimukuru-Maravanyika joined the project.

Multi-disciplinary collaboration by researchers encounters numerous difficulties. These include low prioritization and therefore lack of funding for collaboration initiatives; conflicts among researchers that arise during the collaboration; deciding on the appropriate level of integration of collaborators (Eigenbrode et al. 2007); modes of professional working, linguistic and conceptual challenges (Colfer et al. 2011; Eigenbrode et al. 2007); and collection, analysis and validation of evidence biases. Different researchers are influenced by: disciplinary research cultures (Eigenbrode et al. 2007), different ways of integrating stakeholder input into the research process, and, finally, different 
norms and perceptions of the world. Some researchers have a positivist world view, i.e., the world as something that is objectively "out there" to be investigated without researchers themselves being part of it. Others have an interpretivist view, i.e., the world as subjective - a result of human interpretation and construction (Ojha, Hall and Sulaiman 2013; Werkman et al. 2011).

Table 3.2 reflects how collaboration among researchers evolves from a superficial to an intensive level. According to Piggot-Irvine (2012), research collaborators must strive to operate at level 5, where creativity, innovation and learning operate - this is where genuine collaboration takes place. Levels 2 and 3 are important for collaborators to overcome defensive, self-protective values and strategies. This shift enables the collaboration process to move to inquiry (level 3) and eventually to trust (level 5) - in this case, trust is not a given but an outcome that emerges from complex interactions by collaborators (Piggot-Irvine 2012). There are, however, many variations in the literature on how these stages in the development of effective collaboration play out; in some cases, trust is present at the beginning but may be eroded as time goes on. Effective collaboration (level 5) requires a high degree of skill development for individuals as well as the development of dialogue and

Table 3.2 Levels of collaboration and their characteristics

\begin{tabular}{ll}
\hline Collaboration level & Characteristics \\
\hline 1 Introduction & a) Exploring commonality \\
& b) Excluding discussion of differences \\
& c) Superficial collaboration on specific tasks \\
2 Recognition of & d) No examination of defensive strategies \\
potential of self and & a) Raising awareness of differences between self and others \\
others & b) Increasing willingness to entertain multilateral \\
& c) If doubt arises, response action is mainly defensive and \\
3 Gaining an inquiry & a) Increasing empathy for others' perceptions \\
perspective & b) Genuine acceptance of validity of others' ways of \\
& c) Seeing the world through others' eyes \\
4 Transition to & a) Suspending one's known perceptions and opening up to \\
collaboration & b) True inquiry \\
5 Trust and & c) Genuine collaborative action \\
co-generation & a) New levels of awareness of our own and others' \\
& b) Inquiry leads to action \\
\hline
\end{tabular}

Adapted from Piggot-Irvine (2012). 
inquiry-based values and strategies that are associated with openness (PiggotIrvine 2015).

This section has highlighted key challenges for collaborative research. However, few examples exist that show what actually transpires among researchers and how such challenges are dealt with in practice. Our story and experiences aim to contribute to this body of knowledge as collaborative research increasingly takes center stage.

\section{Methodology}

As former members of the AAS collaborative research team, we are using the benefit of hindsight to analyze our experiences, using reflexivity to critically analyze the process we implemented from 2012 to 2016. Reflexivity involves a researcher turning the investigative lens away from others toward him or herself by explicitly examining how his or her research agenda, assumptions, beliefs and emotions influenced the outcome of the research process. Reflexivity is a critical element in qualitative research where the researcher is not a neutral bystander but an active participant in knowledge co-production (Gluck and Daphne 1991; Hammersley and Artinson 1995) and dissemination. Reflexivity requires researchers to question and examine their preconceived ideas and perceptions. This poses challenges as sometimes researchers feel threatened by exposing their positions and experiences (Borochowitz 2005) in confessionlike-reflexive accounts. This challenge is not unique as other scholars point out that it becomes easier to be more reflexive with time, distance and detachment from the research process itself (Mauthner and Doucet 2003). In our case, we are privileged to be writing this account four years after the project came to an end - at least regarding the outside intervention.

It is also important to understand the background regarding connections among the PAR practitioners. This is valuable in helping us demonstrate the difference between the ideal and real inter-organizational and intrateam dynamics. The team comprised two tiers: researchers and field officers. The former comprised about 20 researchers from four international agricultural research institutions - Bioversity, WorldFish, the International Water Management Institute (IWMI) and the International Livestock Research Institute (ILRI) - with different experiences in natural resource management. Researchers from WorldFish and ILRI were based in Lusaka, Zambia, while those from Bioversity and IWMI, were based outside Zambia, regularly visiting to conduct and follow up on research in the Barotse Floodplain. Some of the researchers responsible for leading different components of the program such as PAR, value chain research and gender transformative research were based in Lusaka, others were based outside of Zambia. The latter tier, field officers (dubbed the hub team), was responsible for implementing field activities with support from the researchers who were based in the Barotse Floodplain, $600 \mathrm{~km}$ from Lusaka. A hub manager coordinated the work of field officers and oversaw the implementation of all field activities. A regional 
coordinator had oversight of the researchers in Lusaka. The researchers were required to liaise and communicate with the hub manager before going to the field. All Barotse researchers were being supervised by global AAS researchers based in the different headquarters where the different participating institutions were based - for example, for WorldFish, the global researchers were based in Penang, Malaysia. The linkages between the researchers in Lusaka and their global offices as well as the field are shown in Figure 3.2. The figure shows what was supposed to happen ideally, but in reality, the linkages were more

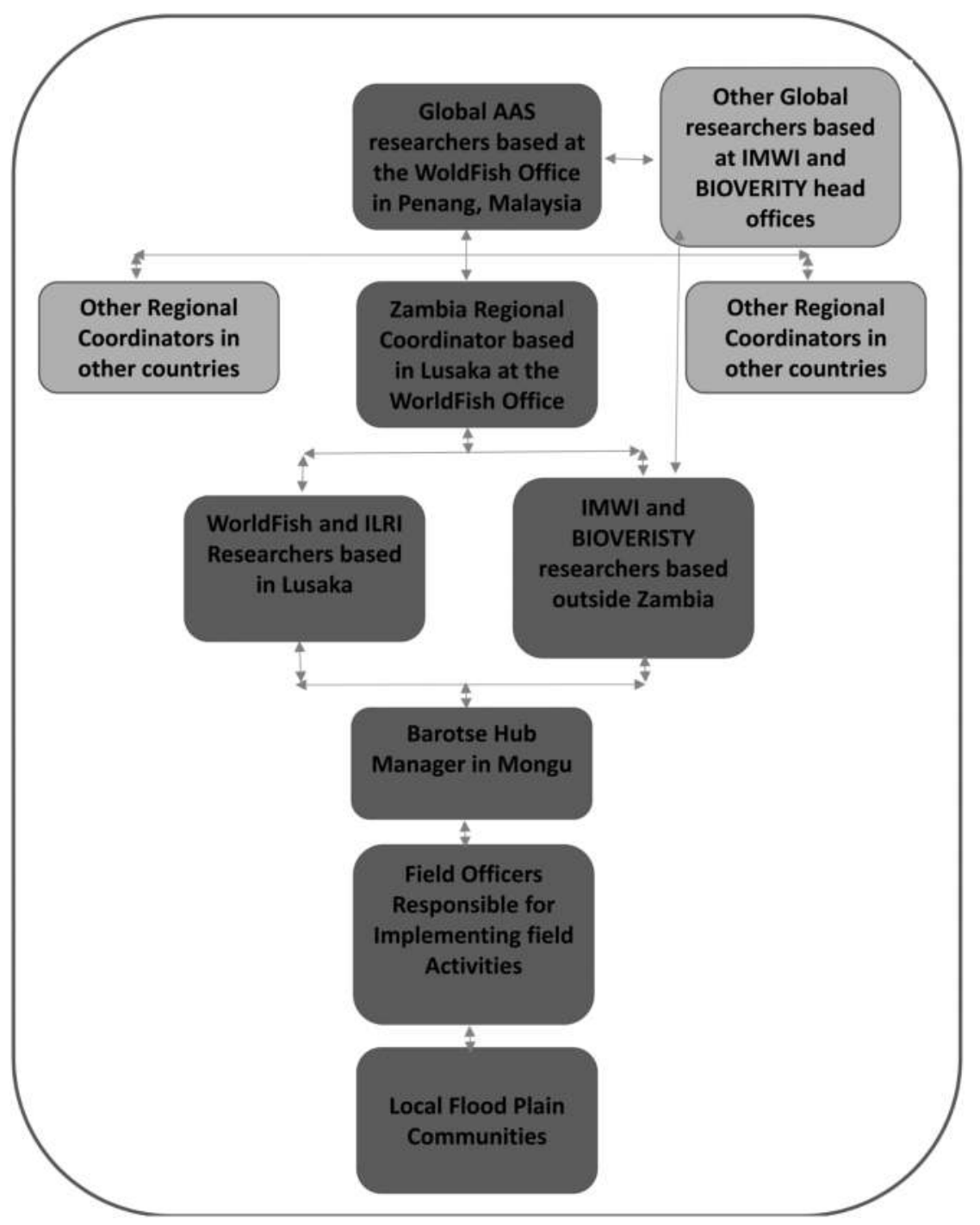

Figure 3.2 Expected linkages between the global, Lusaka and Barotse Hub researchers. 
complex, with researchers in Lusaka communicating directly with their head office supervisors and also directly with the field officers without engaging the hub manager, resulting in many tensions as managers felt their authority was not being respected. Issues of authority, power and influence were inherent to the project and sometimes had nothing to do with the program's intended outcomes.

In this research, process documentation was done by various stakeholders including researchers, local community facilitators and local partners who were engaged in the research activities. Here, we analyze both the data collected through process documentation (including community reflections) and also our own personal documentation, experiences and observations. Most of the data we collected was qualitative in nature and we used content analysis, a qualitative method for analyzing data and interpreting its meaning. We now turn to a discussion of our PAR experience in greater detail with analysis.

\section{An overview of the Barotse Floodplain PAR process}

In this section, we retell the story of how PAR was implemented in Barotse, paying attention to elements of the story that are directly related to the focus of the study. PAR processes were implemented using the learning by doing approach and stakeholders learned and improved over time as the story will show.

\section{Understanding the context}

Following global AAS procedures, several context studies were intended to be conducted at the start of the program. These included diagnostic studies governance, agro-biodiversity, flood risk and ecosystem assessments - and gender studies (though some were conducted much later in the program). These studies aimed to generate understanding about resource governance, local community nutrition status and community gender dynamics. At these early stages, the implementation of these studies was less coordinated, and the studies were conducted separately by various researchers with limited interactions with each other. Because of this limited coordination, researchers sometimes collected similar information from the same communities, leading to community research fatigue. After about a year of studies, community members began to ask questions like, "when will research stop and development work begin?" Community members, perhaps because of their previous experiences with other "donors" who delivered assistance, were becoming impatient and wanted to get tangible benefits from the project. This quickly became a thorny issue that was later discussed at several platforms. For instance, during a theory of change workshop organized in June 2014 at Senanga Safaris in Barotse, the same question arose and there were varied responses from researchers present. Some expressed the opinion that the tangible benefits were at that time limited because of the few development partners engaged by the project, while others 
felt that tangible benefits would eventually be realized when implementation began after understanding the context. These varied understandings of how development was to come about brought frustrations to both the researchers and program stakeholders, including community members.

When conducting these studies, researchers were unclear about how their studies were related. They were conducted individually in silos - mostly pursuing individual goals and objectives. Some researchers were unhappy when asked to collect data for others as discussion with one researcher revealed.

After I sent my draft questionnaire to AAS team members for their inputs, I realized some people wanted me to collect additional data on their behalf... and they got angry when I refused to add their own questions. Doing these initial surveys cost a lot of money mainly because I was not based in Zambia and I decided to work with highly skilled and expensive researchers from the University of Zambia. Adding the extra data from other team members would make my survey too long, too expensive and it would probably cause research fatigue among farmers.

Two years into implementation of the program (from 2011 to 2013), many researchers still had not understood why they were supposed to collaborate with others - and the situation was the same for those who joined the program later. The following story from a researcher working for one of the CGIAR centers illustrates this point (Box 3.1).

\section{BOX 3.1 A STORY THAT SHOWS A LACK OF UNDERSTANDING BY RESEARCHERS OF REASONS TO COLLABORATE}

Since I was coming from a completely different world of animal health and my institution was neither coordinating nor directly implementing the AAS program, it became very difficult for me to understand why I was supposed to "waste my time" participating in joint planning activities with AAS researchers who were mostly from a social sciences background. I initially felt that the PAR expert was being pushy and domineering as she asked me for my activity reports, which I would have shared with my boss at our head office in Nairobi. For me, I thought that I had to interact with these people just because I was being hosted by WorldFish as our institution had no physical presence in Zambia. At first, I saw no value in investing so much time in other researchers' activities given the fact that I had my own individual obligations to fulfill toward my employer and these were clearly spelled out. 
However, my point of view changed drastically for the better after I was invited to, and attended a PAR workshop where, simply by interacting with fellow researchers as well as stakeholders in a relaxed setting, I came to appreciate the wonderful synergies that existed between the initiative I was leading and the others such as productivity, value chains, knowledge sharing and learning, to mention just a few. I later was able to realize that my research was also going to take place in the exact same place, the Barotse Floodplain and it would be easier to make prudent use of all available resources. Collaborating with other researchers would therefore afford everyone the leverage to collect data "on one trip" in the same vehicle and interacting with the communities all at the same time.

The studies were also conducted without a prior understanding of how the collected data would be shared among researchers after collection, considering that these researchers were coming from different institutions. For instance, when asked to share his data, one researcher from a CGIAR lead partner wanted to confirm the data-sharing policy with his institution first. This resulted in huge delays before data sharing could be done and by the time it was shared, many of the researchers had already gone ahead and duplicated the data gathering process, thereby further tiring the community and wasting program resources.

\section{Developing shared visions and planning the collaborative research process}

Following the same global AAS processes, in August 2012, representatives of all stakeholders convened a workshop to create a vision for their joint work in the hub. ${ }^{2}$ Using the diagnostic studies and through their own visioning process, they defined potential areas for research intervention and devised a development challenge dubbed the hub development challenge ${ }^{3}$ (CGIAR Research Program Aquatic Agricultural System 2012) to be tackled through PAR initiatives:

To make effective use of the seasonal flooding and natural resources in the Barotse Floodplain system through more productive and diversified aquatic agricultural management practices and technologies that improve the lives and livelihoods of the poor.

Engagement in selected communities through PAR commenced during the planning phase starting with visioning and action planning. Several meetings were organized to help community members in the villages build a "community dream" (Wollenberg et al. 2000; Evans et al. 2006). In addition to articulating their dreams, community members then developed action plans to 
Table 3.3 Summary of dreams from the communities

Emerging themes identified as a priority by communities ${ }^{4}$

1. Improved farming practices and diversification

2. Canal management

3. Livestock management and diversification

4. Sustainable management of fisheries

5. Improved water and sanitation

6. Natural resource management

7. Food processing and post-harvest handling

8. Access to markets

9. Improved gender relations

a These were later synthesized by the facilitators and other key stakeholders. In their visions, communities identified various desires, including schools, tarred roads, hotels, airports, better houses, food security and so on. Many of their desires fell outside the agricultural scope that was the focus of the project. Non-agricultural activities were therefore dropped, and only agricultural related ones were picked up and synthesized. The team paid attention to gender, age and so on when communities were developing their visions.

address the salient challenges they faced. The action plans were developed to harness the opportunities and local strengths so as to realize their dream for the next five years. Table 3.3 provides a synthesis of community dreams that action plans focused on in order of their importance. In developing their dreams as well as coming up with the action plans, facilitators made sure that all views of different gender groups as well as age groups were captured.

After development of the community-level plans, the research program of work was developed by all stakeholders in a strategic design workshop. The community representatives, researchers and other stakeholders were brought together to identify a number of research interventions that would enable collective tackling of the hub development challenge. Although these research interventions were at a higher (hub) level, community differentiated responses were implemented in response to specific issues raised in each community. The research initiatives that stakeholders agreed on included: value chains, flood risk management, gender transformation and productivity and each one was led by a researcher. The focus of these initiatives evolved and transformed over time through reflection and learning processes at both community and hub levels. It is important to note that there was some worry among the researchers as some community aspirations were not agriculture related - these were kept on the list for a while to avoid demoralizing the communities but were later offloaded to relevant institutions that were best placed to address them.

\section{Implementing research initiatives in Barotse}

After the program planning phase outlined earlier, researchers leading different initiatives were asked to develop individual action plans for their initiatives and 
these formed the individual performance management goals. The researchers' supervisor would then approve the initiatives before implementation and the individual performance goals were the basis of researchers' evaluation at the end of the year. Although the research was being done jointly through the PAR methodology, each researcher was to be evaluated on the basis of his or her own performance goals. The results of this evaluation determined the fate of the researcher at the end of the year - whether or not the researcher continued to be employed by her/his organization. Obtaining an unsatisfactory grade for two consecutive years would lead to the termination of employment. This individual performance evaluation system complicated the implementation of the collaborative research work, as individuals were under pressure to implement activities according to their individual performance goals; this resulted in many researchers working in silos. Some, because of the pressure to perform, used different approaches to convince stakeholders to participate in their work, thereby contradicting the participatory nature of the program. For instance, some paid large sums of money to AAS Program partners as part of their travel and subsistence $(\mathrm{T} \& \mathrm{~S})$ allowance to lure them to participate. Although all AAS staff were paid T\&S allowances when implementing activities in the field, the T\&S amount for program implementing partners was not fixed and varied depending on the researchers and the funding they had for their research initiatives. This created unhealthy competition among researchers as some partners refused to work with those who paid less T\&S, even though they were part of the same program.

Working with and through partners was one of the critical issues that was strongly emphasized to researchers at the beginning of the AAS Program; researchers were made to understand that this was a pre-condition for sustaining research outcomes. How this was to translate into practice, however, remained unclear at the beginning of the program and researchers made all sorts of arrangements with partners as they were rushing to implement their activities. Some researchers established contact with the program partners directly while others did this through the field or hub office in Mongu. Sidelining the hub office, it later turned out, did not go well with the hub manager as she felt that her authority was being undermined.

As mentioned previously, the program was supposed to be implemented using the PAR approach and it was assumed that the researchers who were hired knew what the approach was about and how to implement it in practice. It however became apparent two years later that this assumption was wrong, as one scientist pointed out:

When I joined the program there was no discussion about what the Research in Development Approach (RinD, whose key element was PAR) was. It was assumed that everyone was well equipped to implement the approach. My colleagues and I, for instance, were aware of the research for development approach that the Livestock and Fish CRP was using as we had links with it. We therefore decided to use this approach to 
design our work as to us this was participatory action research. We however were later informed by the AAS Program Coordinator that the RinD approach involved engaging with various stakeholders at every stage. We therefore set up a stakeholder group, but we were initially not sure of what was supposed to be done with the group. The group later evolved into a sounding board and later still, an innovation platform.

\section{Learning lessons and adapting}

Reflection and learning workshops were part of the explicit PAR design to support teams and took place regularly. We tackled many contentious issues in such workshops. The first was a three-day event in November 2013 at Senanga Safaris (Mutimukuru-Maravanyika et al. 2013), attended by 19 men and eight women, including staff from the CGIAR collaborating centers. The workshop objectives were to: reflect on the progress made through the implementation of the various components of the program; consolidate learning from implementation; further develop the hub theory of change; and use lessons learned to contribute to 2014 planning. At this meeting, all stakeholders, including the researchers, had an opportunity to share their work, challenges and outputs and learn from each other. Participants of the workshop agreed that there was a need to:

- improve linkages between the different components of the program;

- build capacity for all stakeholders on what PAR was;

- $\quad$ put in place effective communication platforms;

- $\quad$ rethink data sharing and management systems;

- improve collaboration and joint planning so as to reduce community research fatigue; and

- revisit the way researchers engaged local communities and program implementing partners.

Implementing PAR activities, including reflection and learning platforms, however, was not easy and many conflicts arose among the AAS researchers during such workshops. An example of such a conflict is presented in Box 3.2.

\section{BOX 3.2 RESEARCHER CONFLICT DUE TO DIFFERENT BACKGROUNDS}

When the first reflection and learning workshop was organized in November 2013 (Mutimukuru-Maravanyika et al. 2013), two researchers with different backgrounds (one was African and had experience facilitating workshops in Africa, while the other was European and had 
experience facilitating workshops in Latin America) were tasked to lead the activity. When discussing the finer details of the workshop program, a conflict erupted. The African researcher suggested including an item on workshop rules and the European researcher was uncomfortable with this, saying that including this item would seem as if workshop participants were being treated as little children.

The African researcher, who eventually facilitated the workshop, decided to include the workshop rules on the agenda. It later turned out that the workshop rules were extremely useful. The workshop participants had a tendency to move in and out of the workshop as and when they wished, had their telephones continuously ringing loudly, thereby disrupting the proceedings, and many were not punctual. The developed workshop rules helped to stop all these disruptive behaviors as workshop participants came up with stiff punishments for those who did not observe the workshop rules. Two of the culprits who were punished for breaking the workshop rules were members of the Barotse Royal Establishment, locally known as Indunas. Indunas were known to always come late for meetings, and no one could question them as they were highly respected in Barotse. The African researcher, probably because she was a foreigner in Zambia, was not hesitant to enforce the rules when the Indunas were late for the workshop - they never came late again after that. At the end of the workshop, the two researchers agreed that the rules helped to bring order in the workshop, and later they became a part of all subsequent workshops.

Conflicts, as the Barotse case shows, were part and parcel of the entire PAR implementation, making the process complex and difficult. For various reasons, including differences in backgrounds, power, gender, beliefs and values, researchers formed "clubs or cartels" whose members would support each other and fight against members of different clubs when the opportunity availed itself. Rivalry among researchers became the order of the day, especially during the early stages of the research process, with researchers sometimes arguing and embarrassing each other in the presence of other stakeholders (e.g., AAS partners). In one such example, two researchers had a heated exchange of words during a PAR learning and reflection workshop where all stakeholders, including partner organizations and local community representatives, were present. The two researchers exchanged unkind words while everyone was listening. Possible reasons such an incident occurred include hidden personal conflicts that were not surfaced and a general lack of communication.

Following the lessons learned from the reflection and learning workshops, we instituted several strategies to address the challenges we faced. Some of the strategies are discussed separately below. 
Joint planning and implementation of research initiatives

We organized face-to-face meetings to enable researchers and all stakeholders to share planned activities, learn and give each other feedback, develop an integrated plan of work and agree on implementation that would avoid duplication and reduce community research fatigue. Several of these planning workshops were organized and began with researchers sharing and agreeing on team objectives and outcomes that were to be realized each year. After developing the team objectives and plans for the hub, individual researchers then developed their individual work plans for the year. This ensured that individual work contributed to the overall hub objectives. Such workshops became important in facilitating a convergence of stakeholders' and researchers' views.

We began jointly planning the different research initiatives to address the challenges of researchers working in silos. Joint planning workshops aimed to nurture researcher synergies and ensure that PAR activities were jointly executed - they led to the development of a hub plan of work that clearly indicated activities to be implemented each month and by whom. From these workshops, researchers then started implementing their activities jointly and in a coordinated manner. With joint planning of activities, communication and relations among the researchers improved - moving from adversaries to genuine collaborators with an increased understanding of the program and how the different pieces of work were all linked up.

\section{Team building}

We hired external facilitators to lead several team-building activities for all researchers (Mutimukuru-Maravanyika and Mwiya 2014). Such activities included retreats that were organized for stakeholders, including the researchers, to encourage joint learning from each other's work. In the team-building activities, researchers had opportunities to give and receive feedback as well as develop team visions and action plans. Researchers extracted their individual action plans from the team action plan, and this helped to deal with the challenge of divergent individual performance goals and team goals. Such team-building activities were part and parcel of the PAR process and they contributed immensely to making collaboration by researchers possible and effective.

\section{Generating a shared understanding of $P A R$}

In line with global AAS capacity development processes, we conducted PAR self-assessments for all stakeholders, including the researchers, in Barotse in 2014 (Mutimukuru-Maravanyika and Apgar 2014; Mutimukuru-Maravanyika et al. 2014). The assessment process, which focused on understanding the core PAR competencies, involved a number of parallel steps designed to enable the engagement of the different sub-teams and to build on and fit into ongoing 
activities in the hub. The process included rapid assessments by AAS researchers, partners and community facilitation teams and culminated in a self-assessment workshop in June 2014. During the workshop, team members assessed their own capacities and prioritized key areas for capacity development interventions. Capacity development activities were later implemented, and these included a mixture of training workshops, on-the-job support and peer learning opportunities.

\section{Transforming partnership engagement approaches}

To tackle the issue of ad hoc approaches for engaging the program partners, stakeholders discussed and agreed on operating standards, for instance, setting a fixed $T \& S$ rate to be offered by the program. In addition, rather than engaging different partners individually, the program decided to develop memoranda of understanding (MOUs) for all partners, taking into account activities for all research initiatives. This standardization of practice helped in reducing confusion and smoothed implementation of activities by partners.

\section{Putting in place a communication system}

Due to the need for improved communication, researchers (together with other stakeholders) agreed on a number of strategies. These included: developing and sharing a comprehensive list of all stakeholders with their contact numbers; developing monthly bulletins to be shared with all stakeholders highlighting the work conducted, key successes and challenges; ${ }^{4}$ and organizing various face-to-face meetings, including seminars where researchers got opportunities to present their work and receive feedback from the rest of the team.

As time went by, the team of researchers transformed from adversaries to improved collaborators. The transformation was phenomenal and required one to change one's mindset and accommodate others. Many researchers formed strong coalitions that have continued to exist up to now, several years after the program ended. Although researcher collaboration had improved remarkably, with the potential of positive influence on the PAR outcomes going forward, the AAS Program was evaluated four years into implementation and donors were not happy with the outcomes that had been realized by that time. The donors immediately withdrew their support and the program ended.

\section{Discussion}

In this chapter, we explored the question of how to manage research challenges associated with interdisciplinary teams. We illustrated these interorganizational dynamics by critically reflecting on our own experience of working together in the Barotse Floodplain of Zambia. Specifically, we sought to address the following questions: How does collaborative research play out in practice? What challenges arise among researchers in the process 
of implementing collaborative research and how can these be addressed? We synthesize our findings here.

Collaborative research becomes a meeting point of different actors from different backgrounds and professional cultures. The Barotse collaborative research experience outlined here clearly shows that effective collaboration among researchers implementing PAR is not spontaneous but is an emergent property of deliberate and conscious efforts by the participants. PAR implementers should not assume that the researchers constituting the implementation team are a homogenous group - rather, they are different and bring along "baggage" that has a bearing on how PAR plays out in practice. In addition, the situation is worsened by individual survivalist strategies that can undercut the team approach required in implementing PAR.

\section{Balancing individual performance agreements and collaborating with others}

As we saw previously, performance management systems are critical in either enhancing or discouraging collaboration among researchers. Performance management systems that promote collaboration, with the benefit of hindsight, are those that link individual performance with team performance goals - as happened later in the AAS Program. Managers of collaborating researchers must not reinvent the wheel but use well-developed management approaches such as management by objectives (MBO) (Drucker and Maciariello 2008). When using $\mathrm{MBO}$, managers realize that each member of an organization contributes something different. But all members must contribute toward a common goal with their efforts pulling in the same direction and fitting together to produce a whole. $\mathrm{MBO}$ ensures that every job in the endeavor is directed toward the objectives of the whole organization. MBO however, does not happen automatically but should be purposefully organized and be made the living law in managing researcher collaborative efforts.

Effective leadership and strategies that promote collaboration among researchers and partners in PAR processes are therefore critical (Barković 2010; Schultz and McIntyre 2019). Leadership is important in creating supportive performance management systems, creating opportunities for joint planning and implementation and ensuring that communication systems are in place. Effective leadership promotes transparency and democracy, creates conducive environments for researchers to communicate, develop trust and collaborate effectively. Short of this, we have shown that performance management systems can promote perverse habits that threaten the positive intentions of development programs.

\section{Lack of coordination and understanding of how one's work contributes to broader program objectives}

"Learning as you go" can be misconstrued as radar-less muddling through. When researchers were collecting data in silos and were opposed to 
collaboration in data collection, multiple researchers ended up collecting the same data, wasting resources and contributing to community research fatigue. Here, the MBO approach could have helped researchers to jointly plan and implement their work as well as see how their work contributed to the broader program goals. With coordination, all studies could have been conducted swiftly, and PAR activities could have been implemented in a timely fashion to avoid the research fatigue that was experienced in the Barotse. If the PAR activities had been implemented earlier, more outcomes would likely have been realized and this could have prevented the premature program closure by donors.

\section{Lack of data-sharing mechanisms}

The issue of data sharing, as seen from Barotse, is critical in collaborative research - lack of clarity on data-sharing mechanisms resulted in different researchers closely following their institutional policies, which did not mesh well with the collaborative nature of this research. Given that all research was being funded by the same program, issues of data ownership and how it would be shared among researchers should have been discussed at the outset. Leaving the issue to be resolved in a learning by doing fashion, as happened in Barotse, was a big mistake, which could have been avoided, thereby saving precious financial resources.

\section{Researcher conflicts}

Conflicts, such as those experienced in Barotse, are inherent to researcher collaboration efforts. Those intending to engage in collaborative research must, from the onset, think about ways of reducing and managing these conflicts. Putting in place effective communication systems is critical for reducing and managing such conflicts. For instance, the combative exchanges between researchers while in the company of stakeholders could have been avoided, since the two researchers were based at the same office. Had communication lines been clear, they could have discussed and resolved their issues privately at the office. Such unhealthy relationships among the researchers themselves stalled progress and worked against the collaborative nature of the program.

\section{Misunderstandings about PAR leading to conflicting approaches}

Rather than assuming that researchers know what PAR is in collaborative research, all researchers need to undergo capacity development on PAR processes. When this happens, the situation of discovering that researchers have different perceptions of PAR years after implementation will be avoided. Colfer et al. (2011) in CIFOR's Landscape Mosaics project made similar observations. The project leader and the ACM coordinator spoke different languages about ACM, and it took a long time for the two to discover this miscommunication. 
With the benefit of hindsight, PAR capacity development for all collaborators must be given high priority in PAR collaborative work (Colfer et al. 2011); see also Chapter 6, this volume). It is important however, not to take such a capacity development program as a one-off activity, but recurrent processes are needed where researchers continue to learn and improve. Such capacity development activities must also be part of all onboarding programs for new staff who join PAR programs.

In addition, many researchers have no previous experience conducting collaborative research. Such researchers need to gain the related skills and should be supported in their learning process. This learning process happens at an individual level as one gets an opportunity to reflect on one's own values, perceptions and beliefs after interacting with others (see also Eigenbrode et al. 2007). This transformation takes place speedily when there is transparency and when opportunities exist to surface and deal with existing conflicts. The more the researchers dialogue and discuss and resolve existing conflicts, the more they will learn from each other and understand why different views and perceptions exist. Although the process takes a considerable amount of time as other scholars have pointed out (Hattori and Lapidus 2004; Piggot-Irvine 2012), without this investment, implementing PAR will be hampered by collaborative challenges among the researchers themselves.

\section{Concluding remarks}

Fostering effective collaboration among researchers should be given a high priority in any effort to implement PAR. An effectively collaborating research team has a high chance of success as confusion, duplication and contradictions are reduced. The Barotse case has shown that collaboration by researchers in PAR processes is not automatic and should not be taken for granted. This is because researcher interactions are filled with challenges that can threaten outcomes of joint work. Doing PAR research in collaborative teams requires a conscious effort by researchers to move from superficial to genuine collaboration. This movement is possible when: effective leadership and supportive performance evaluation systems are in place; conflict resolution mechanisms and effective communication systems function well; researchers gain essential collaboration skills; capacity development activities are organized to ensure a shared understanding of the research process and methodologies to employ; and finally, data-sharing mechanisms are agreed upon at the onset of collaborative research programs.

This chapter examined the process of fostering genuine collaboration among research teams. It has shown that collaboration requires investments in time and financial resources as well as critical personnel to steer the process from the beginning. There is, however, a challenge as such resources are usually not budgeted for at project planning stage; collaboration by PAR researchers is often assumed to already exist. Without nurturing its emergence among collaborative research team members, PAR efforts may fail to realize their potential. 


\section{Acknowledgments}

We would like to thank the CGIAR Fund Council (and its numerous donors) for funding the AAS Research Program - of which this research was part. We are also grateful to Dr. L. Chapungu from Great Zimbabwe University in Zimbabwe for generating the map of the Barotse Floodplain and to the two anonymous reviewers who provided invaluable critique.

\section{Notes}

1 The AAS research program was coordinated by WorldFish and implemented by two other CGIAR centers, Bioversity and the International Water Management Institute. It focused on harnessing the potential of aquatic agricultural systems including inland floodplains, major river deltas and coastal environments to lift people out of poverty. The program was implemented in five countries - dubbed AAS hubs, including the one in Zambia in the Barotse Floodplain System as an exemplar of African inland floodplains. The program was implemented for about three years but was abruptly closed down for various reasons, including a change in donor priorities.

2 Each of the selected countries where AAS was implemented was dubbed a "hub."

3 The challenge was phrased positively showing what stakeholders desired to see when all problems of the hub were addressed. At the time of developing the challenge, there was ineffective use of seasonal flooding with poor agricultural productivity and poor natural resource management (including fisheries).

4 These were similar to ACM Zim News, a learning and sharing platform for forest extension officers involved in the program, published by the Mafungautsi ACM project (Mutimukuru and Kozanayi 2005; Maravanyika and Kozanayi 2006a, b). In the early 2000s, the Bogor-based ACM team also published ACM News, a publication with similar goals, including articles from all the 11 original ACM sites.

\section{References}

Allen, W. J. 2001. "Working Together for Environmental Management: The Role of Information Sharing and Collaborative Learning." $\mathrm{PhD}$ (Development Studies). New Zealand: Massey University.

Apgar, M., and B. Douthwaite. 2013. Participatory Action Research in the CGIAR Research Program on Aquatic Agricultural Systems. Program Brief: AAS-2013-27. Penang, Malaysia: WorldFish Center.

Barković, D. 2010. "Challenges of Interdisciplinary Research.” Interdisciplinary Management Research 6: 951-60.

Borochowitz, Dalit Y. 2005. "Teaching a Qualitative Research Seminar on Sensitive Issues." Qualitative Social Work: Research and Practice 4 (3):347-62.

Burns, Danny, and Stuart Worsley. 2015. Navigating Complexity in International Development: Facilitating Sustainable Change at Scale. Edited by D. Burns. Rugby, UK: Practical Action Publishing.

Consultative Group on International Agricultural Research (CGIAR). 2011. CGIAR Research Program Aquatic Agricultural Systems Program Proposal. Penang, Malaysia: WorldFish Center.

CGIAR Research Program Aquatic Agricultural System. 2012. Scoping Report. Barotse Floodplain, Zambia. Penang, Malaysia: WorldFish Center.

Colfer, Carol J. P., E Andriamampandry, S. Asaha, E. Lyimo, E. Martini, J. L. Pfund, and J. Watts. 2011. "Participatory Action Research for Catalysing Adaptive Management: 
Analysis of a 'Fits and Starts' Process." Journal of Environmental Science and Engineering 5 (1):28-43.

Crane, P., and L. Richardson. 2000. The Reconnect Action Research Kit. Canberra, Australia: Australian Government, Department of Family and Community Services.

Diaw, M. C., T. Aseh, and R. Prabhu. 2009. In Search of Common Ground: Adaptive Collaborative Management in Cameroon. Bogor, Indonesia: CIFOR.

Drucker, Peter F., and Joseph Maciariello. 2008. Management. Revised. Harper Collins E-book. https://www.academia.edu/35149943/Peter_F_Drucker_Management_Rev_Ed.

Eigenbrode, Sanford D., Michael O Rourke, J D Wulfhorst, David M Althoff, Caren S Goldberg, Kaylani Merrill, Wayde Morse, et al. 2007. "Employing Philosophical Dialogue in Collaborative Science.” BioScience 57 (1):55-64.

Evans, K., S. J. Velare, R. P. Prieto, S. N. Rao, S. S Sertzen, Karina Dávila, P. Cronkleton, and W. De Jong. 2006. Field Guide to the Future: Four Ways for Communities to Think Ahead. Nairobi, Kenya: CIFOR, ASB, World Agroforestry Centre.

Evans, K., A. Larson, E. Mwangi, P. Cronkleton, T. Maravanyika, X. Hernandez, P. Muller, et al. 2014. Field Guide to Adaptive Collaborative Management and Improving Women's Participation. Bogor, Indonesia: CIFOR.

Foran, T., J.R.A. Butler, L. J. Williams, J. Wanjura, A. Hall, L. Carter, and P.S. Carberry. 2014. "Taking Complexity in Food Systems Seriously: An Interdisciplinary Analysis." World Development 61:85-101.

German, L.A., A.M. Tiani, A. Daoudi, T. Mutimukuru-Maravanyika, E. Chuma, C. Jum, N. Nemarundwe, E. Ontita, and G. Yitamben. 2012. The Application of Participatory Action Research to Climate Change Adaptation in Africa: A Reference Guide. Bogor: IDRC and CIFOR.

Gluck, Sherna B., and Patai Daphne. 1991. Women's Words: The Feminist Practice of Oral History. New York: Routledge.

Greenwood, Davydd, and Mark Levine. 1998. Introduction to Action Research: Social Research for Social Change. London: Sage.

Hammersley, Martyn, and Paul Artinson. 1995. Ethnography: Principles in Practice. New York: Routledge.

Hattori, R. A., and T. Lapidus. 2004. "Collaboration, Trust and Innovative Change." Journal of Change Management 4 (2): 97-104.

IUCN. 2003. "Barotse Floodplain Zambia: Local Economic Dependence on Wetland Resources; Integrating Wetland Economic Values into River Basin Management." Case Studies in Wetland Valuation 2: May 2003 (produced under the "Integrating Wetland Economic Values into River Basin Management project" as part of the Water and Nature Initiative of IUCN: The World Conservation Union).

Kazungu, M. 2014. Socio-Economic Determinants for Cooperation in the Barotse Floodplain Small-Scale Fishery Management System, Zambia. Bonn, Germany: Faculty of Agriculture, University of Bonn.

Kemmis, Stephen, and Robin McTaggart. 2007. "Participatory Action Research: Communicative Action and the Public Sphere." In Strategies of Qualitative Inquiry, edited by N. Denzin and Y. Lincoln, 271-330. Thousand Oaks, CA: Sage.

Mackenzie, John, Poh-Ling Tan, Suzanne Hoverman, and Claudia Baldwin. 2012. "The Value and Limitations of Participatory Action Research Methodology." Journal of Hydrology 474: 11-21.

Madzudzo, E., A. Mulanda, J. Nagoli, J. Lunda, and B. D. Ratner. 2013. A Governance Analysis of the Barotse Floodplain System, Zambia: Identifying Obstacles and Opportunities. Penang, Malaysia: WorldFish. 
Mandondo, A, R. Prabhu, and F. Matose. 2008. Coping amidst Chaos: Studies on Adaptive Collaborative Management from Zimbabwe. Bogor, Indonesia: CIFOR.

Maravanyika, T., and W. Kozanayi. 2006a. "Collaborative Work in Rural Landscapes. Learning from the Zimbabwean Experiences." ACMZim News, December.

Maravanyika, T., and W. Kozanayi. 2006b. "Reflecting on the ACM Experiment: A Synthesis of the Experiences from the Learning Centres in Zimbabwe." ACMZim News, February.

Mauthner, Natasha S., and Andrea Doucet. 2003. "Reflexive Accounts and Accounts of Reflexivity in Qualitative Data Analysis." Sociology 37:413-31.

Mutimukuru, T., and W. Kozanayi. 2005. "From Glory to Shambles: The Rise and Fall of the Romwe Initiative," In ACMZim News: Keeping the Momentum: Sustaining Projects/ Processes When Outside Support Has Been Withdrawn, edited by Tendayi Mutimukuru and Witness Kozanayi. Harare, Zimbabwe: CIFOR.

Mutimukuru-Maravanyika, T. 2010. "Can We Learn Our Way to Sustainable Management? Adaptive Collaborative Management in Mafungautsi State Forest, Zimbabwe." Wageningen University and Research Centre. http://edepot.wur.nl /136242.

Mutimukuru-Maravanyika, T., and M. Apgar. 2014. Barotse Flood Plain RinD Capacity Assessment: Outcomes and Recommendations. Lusaka, Zambia: WorldFish.

Mutimukuru-Maravanyika, T., and S. Mwiya. 2014. SSA Team Planning Workshop for Mid- Year Review, 19-21 August 2014, Grand Palace Hotel in Lusaka, Zambia. Lusaka, Zambia: WorldFish Center.

Mutimukuru-Maravanyika, T., M. Apgar, E. Madzudzo, E. Mapedza, M. Kwashimbisa, C. Murungweni, S. Mwiya, and S. Cole. 2013. Proceedings of the Zambia AAS Annual Reflection Workshop at Senanga Safari Lodge, 4-7 November 2013, Lusaka, Zambia.

Mutimukuru-Maravanyika, T., C. Muyaule, A. Ward, N. Phiri, R. Paz-Ybarnegaray, and N. Chisonga. 2014. Proceedings of the Outcome Harvesting: TOC and RinD Capacity Assessment Workshop, Mongu, Zambia: WorldFish Center.

Mutimukuru-Maravanyika, T., D. Mills, C. Asare, and G. A. Ameyaw. 2016. "Enhancing Women's Participation in Decision-Making in Artisanal Fisheries in the Anlo Beach Fishing Community, Ghana." Water Resources and Rural Development 10:58-75.

Ojha, H., A. Hall, and R. Sulaiman. 2013. "Adaptive Collaborative Approaches in Natural Resource Governance: An Introduction.” In Adaptive Collaborative Approaches in Natural Resource Governance: Rethinking Participation, Learning and Innovation, edited by Hemant R. Ojha, Andy Hall and V. Rasheed Sulaiman, 1-19. London and New York: Earthscan.

Piggot-Irvine, E. 2012. "Creating Authentic Collaboration: A Central Feature of Effectiveness." In Action Research for Sustainable Development in a Turbulent World, edited by Ortrun Zuber-Skerritt, 89-107. Bingley, UK: Emerald Group Publishing Ltd.

Piggot-Irvine, E. 2015. "Collaboration, Innovation and Evaluation in Action Research. Life with Ortrum for a Better World." In Lifelong Action Learning and Research. A Tribute to the Life and Pioneering Work of Ortrun Zuber-Skerritt, edited by Judith Kearney and Maureen Todhunter, 47-64. Rotterdam/Boston/ Taipei: Sense Publishers.

Reynolds, Martin, and Sue Holwell. 2010. "Systems Approaches to Managing Change: A Practical Guide." In System Dynamics, edited by M. Reynolds and Sue Holwell, 25-85. London: Springer.

Schultz, C. A, and K. B. McIntyre. 2019. "Policy Design to Support Collaborative Landscape Restoration." In A New Era for Forest Landscape Management: Policy and Practice 
Insights from the Collaborative Forest Landscape Restoration Program, edited by W. B. Butler and C. A. Schultz, 195-211. London: Earthscan/ Routledge.

Smith, R, L. Syndall, and R Taylor. 2004. "Overcoming the PBRF Agenda: Fostering a Collaborative Partnership with Academic-Practitioners." Paper Presented at the New Zealand Association for Research in Education (NZARE) Conference, Wellington, New Zealand.

The WorldFish Center. 2007. Proceedings of the International Workshop on the Fisheries of the Zambezi Basin, 31 May-2 June 2004, Livingstone, Zambia. The WorldFish Center Conference Proceedings 75, 83 pp. Penang, Malaysia: The WorldFish Center.

Werkman, Renate, Jolanda Van Den Berg, Annemarie Van Paassen, and Bette Harms. 2011. "What Is Collaborative Landscape Research About?" In Knowledge in Action: The Search for Collaborative Research for Sustainable Landscape Development, edited by Annemarie van Paassen, Jolanda van den Berg, Eveliene Steingrover, Renate Werkman, and Pedroli Bas, 41-56. Wageningen, the Netherlands: Wageningen Academic Press.

Wollenberg, Eva, With D. Edmunds and L. Buck. 2000. Anticipating Change: Scenarios as a Tool for Adaptive Forest Management (a Guide). Bogor, Indonesia: CIFOR.

WorldFish Center. 2011. Aquatic Agricultural Systems. Project Flyer. Penang, Malaysia. 


\section{Introduction to Chapter 4}

Bomuhangi et al. have accomplished something many ACM practitioners and researchers have wanted, but been unable, to do: They have compared forest use and management in eight purposively sampled places around Uganda, looking at three important issues. The first is clarity about the various uses to which these communities put forests. The second is the differentiation by gender in terms of use, management, and benefits. In this regard, the authors show the greater involvement of women in ACM sites, vis a vis where ACM was not conducted. The third is a systematic comparison of a variety of results in ACM vs. non-ACM sites. These include issues like level and quality of participation, perceived abundance of forest resources, harvest of forest products, and use thereof. The authors conclude by recommending the broader use of ACM-like approaches throughout Uganda's forested areas, in collaboration with government, NGOs, and private landowners.

A few of the interesting findings that emerge here include: 1) the greater sense these Ugandan women have of their own involvement in public vs. private forest management; 2) the powerful impact of husbands' support on women's involvement in forest management; and 3) the comparative irrelevance of women's educational level in forest management.

One purpose behind the conduct of this research was to provide an assessment that would be convincing to and useful for policymakers at the national level. The analysis is succinct, well rounded, and convincing; and they are able to present much of their findings in tabular form -- appealing to many policymakers with little time to read. This chapter also sets the stage for the following chapter (5), which presents the ways ACM was conducted in the communities compared here. 


\title{
4 Gender and adaptive collaborative management in forested Ugandan landscapes
}

\author{
Allan Bomuhangi, Abwoli Yabezi Banana, \\ Jimmy Bushoborozi, Concepta Mukasa, \\ Alice Tibazalika and Esther Mwangi
}

\section{Introduction}

While the concept of participation has been a part of development thinking and the political process for the last two decades, today it has become mandatory for planning any natural resource management and development project. Participation is viewed by development scholars and practitioners as a crucial element in enabling poor and marginalized groups to exert greater influence over institutions and decisions that critically affect their lives.

In forestry, participation has been promoted through approaches such as collaborative forest management and/or adaptive collaborative management where decision making by forest adjacent communities in making rules related to enforcement and benefit sharing has been formally acknowledged by the state (Mukasa et al. 2016). Developing countries adopt varied participatory approaches (Banana et al. 2013). Despite design differences, they all aim to ensure better forest governance and management as well as improved livelihoods. However, the question of who participates and why remains critical for those interested in sustainable forest management. The Government of Uganda has undergone reforms since the late 1990s, most of which have recognized gendered issues and the importance of people's participation in the management of development programmes. In 2016, the Ministry of Water and Environment developed the "Environment and Natural Resources Subsector Gender Mainstreaming Strategy, 2016-2021" to reduce unsustainable environmental resource management as well as reduce poverty resulting from inequalities in environmental resource use, access and management (GoU 2016).

In the forestry subsector, Uganda has developed different forest management regimes, with each regime having different effects on user communities and on gender (Banana et al. 2012, 2013; Mukasa et al. 2016). Although Uganda's forest policy highlights the need to ensure the integration of gender concerns and issues into the development of the forest sector, the National Forestry and Tree Planting (NFTP) Act does not provide measures to enforce the gender intentions of the policy; consequently, neither the National Forestry Authority (NFA) nor the Forest Sector Support Department (FSSD) 
has any guidelines on how to mainstream gender in their respective programmes and activities (GoU 2001). The forestry subsector's specific strategies highlighted in the Environment and Natural Resources Subsector Gender Mainstreaming Strategy for the NFA and the FSSD have not been fully adopted (GoU 2016). Consequently, men still dominate the arena of planning and decision making regarding the use, access and management of forest resources, and women's views are often under-represented, implying that women's practical and strategic needs may not be addressed. Women's involvement in forest management and development - such as we see here - has been identified as crucial in achieving Sustainable Development Goal 5 (Lee et al. 2016). Better progress can be made towards this goal if participatory forest management initiatives such as ACM are institutionalized and implemented throughout the country.

In the mid-2010s, we applied CIFOR's adaptive collaborative management approach $(\mathrm{ACM})^{1}$ across several districts in Uganda to strengthen women's rights to forest and tree resources and to increase their participation and leadership in forest decision making (Mukasa et al. 2016; see also Chapter 5, this volume, where Mukasa et al. highlight the governance arrangements, practices and processes that are central to enhancing gender inclusion and the transformation of underlying values and norms in community forestry). Here, we discuss the results of a nationwide study looking at the gender gap in participation and representation in community forestry; we specifically examine the determinants and quality of men's and women's participation in forest management, gendered use of forest resources and factors that influence dependence on forestry resources. Although our initial emphasis was on women's involvement in forest management, we later realized we could analyse our data to assess the effectiveness of ACM in this regard by comparing ACM versus non-ACM sites. Here, we consider the policy implications of whether participatory forest management approaches such as ACM can help reduce the gender gap in forest management and decision making.

\section{Methodology}

\section{Study area and sampling}

We conducted a nationwide intra-household survey in 2016 to ensure that findings would be broadly relevant for different forest management regimes in Uganda and provide a robust basis for national/regional-level policymaking. Study sites were purposively selected to maximize sub-national variation in socio-cultural and ecological conditions. The survey covered eight districts of Uganda located in various regions of the country (Figure 4.1) and across four agro-ecological zones: Albertine Rift and Afromontane agro-ecological zones in western Uganda; the Lake Victoria basin in central Uganda; the Aswa river plain in northern Uganda; and the short grasslands agro-ecological zone in eastern Uganda. 


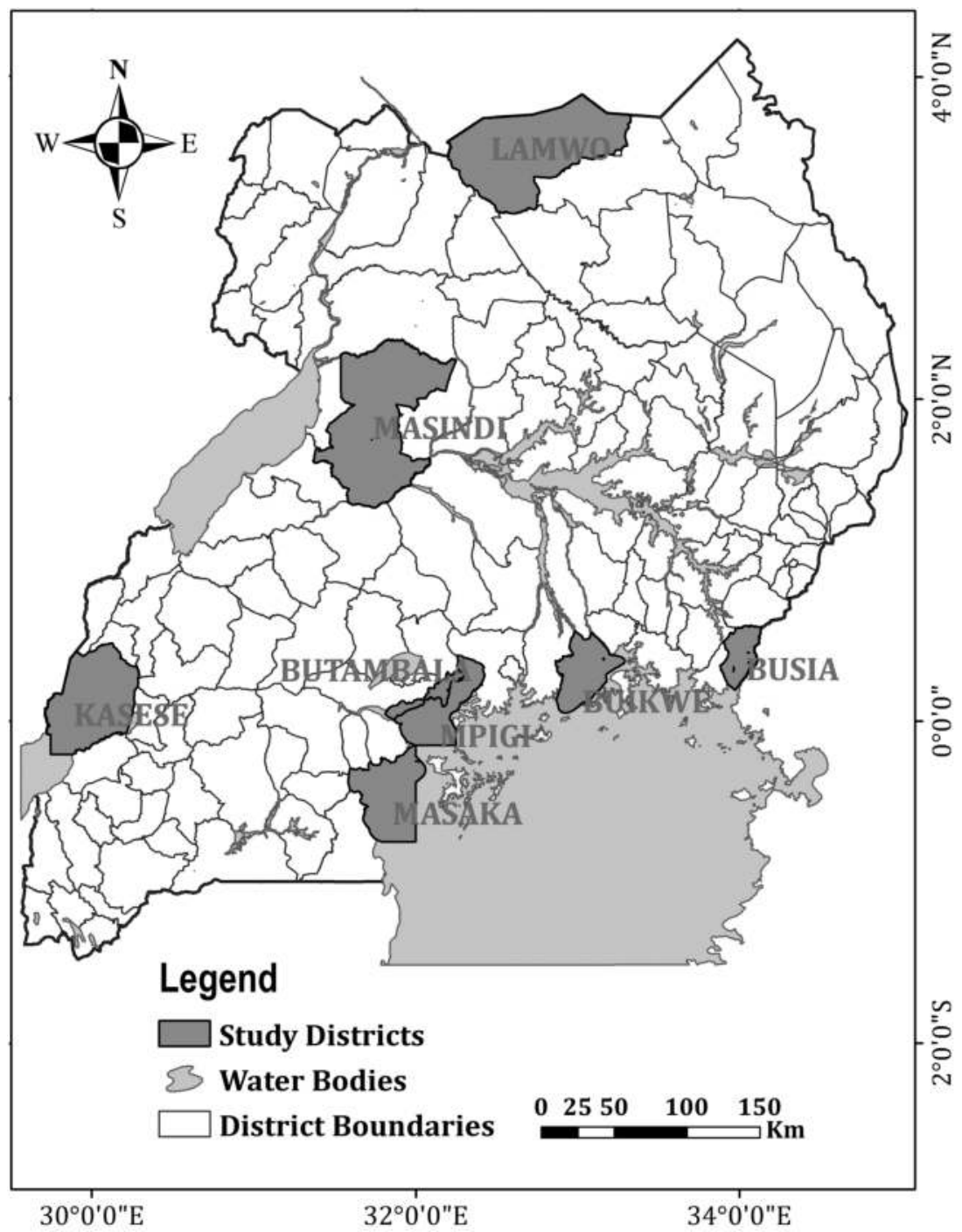

Figure 4.1 Study sites.

The Lake Victoria basin in central Uganda with six sites (including four ACM sites with an ethnically homogenous population and two ACM sites with ethnically heterogeneous populations) is dominated by tropical high forests and forest plantations under multiple tenure regimes and several forest governance arrangements (see Table 4.1). The region is also densely populated with primarily the Baganda and Basoga ethnic groups. The Afromontane region in western Uganda, with four sites (including two ACM sites), is 


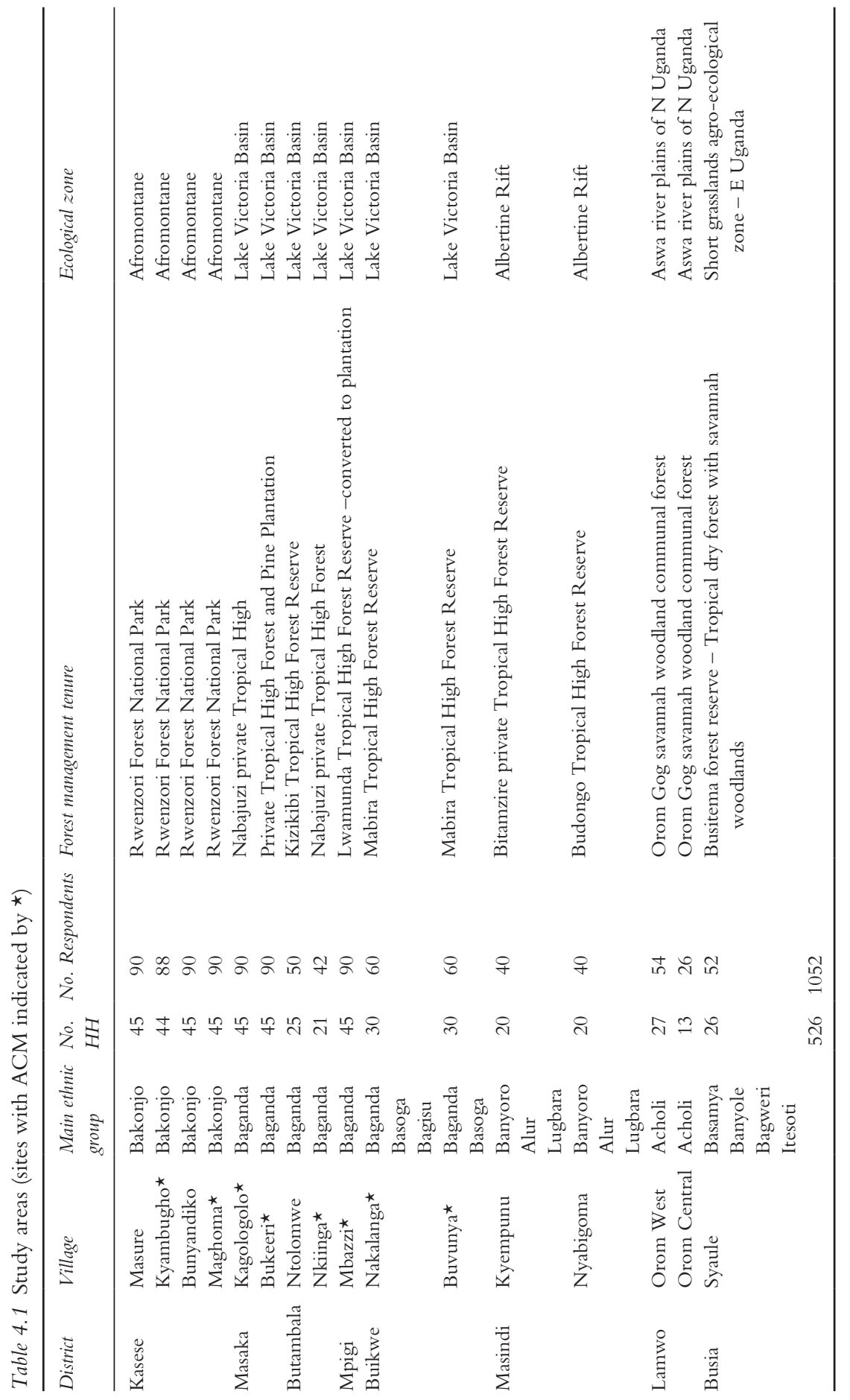


dominated by the Rwenzori Forest National Park and the Bakonzo ethnic group. The two sites in the Albertine Rift in western Uganda are dominated by tropical high forests under state or private governance arrangements. The region is sparsely populated with several ethnic groups. The Aswa river plain of northern Uganda, with two sites, is dominated by savannah woodlands under customary governance arrangements. The region is sparsely populated with the Acholi ethnic group. The one site in the short grasslands agro-ecological zone of eastern Uganda is dominated by grasslands and few forests; it is densely populated with the Basamya, Banyole, Itesoti and Bagweri ethnic groups. ACM was conducted with Bakonjo, Baganda and Basoga peoples, with one site, in Mabira Forest, including some Bagisu. To understand the impact of forest tenure on women's participation in forests, we purposively selected multiple tenure regimes, including private and communal forests, as well as forests officially managed by different government agencies implementing co-management arrangements with adjacent or resident communities (Table 4.1).

Our study focused on 16 communities (eight with ACM) in these eight districts. Although the pairing of ACM and non-ACM sites was not possible, given travel and funding constraints, there are ACM sites located in five of these eight districts, providing reasonable geographic and ethnic distribution. Many demographic similarities (shown in Table 4.2) further support the legitimacy of comparing ACM and non-ACM responses.

We compiled a list of households residing in each selected study community, drawing upon information from village registers and lists provided by village leaders. Households were randomly selected from the village register. A total of 526 households were selected, and 1,052 respondents were interviewed (526 men and 526 women). Husband and wife were interviewed separately to generate broader-scale information on the following issues: factors that affect men's and women's participation in forest management; the quality of their participation; gendered forest use; perceptions on the abundance of forest

Table 4.2 Demographic characteristics of the respondents

\begin{tabular}{|c|c|c|c|c|c|c|c|c|}
\hline \multirow[t]{3}{*}{ Name of variable } & \multicolumn{4}{|c|}{ ACM sites } & \multicolumn{4}{|c|}{ Non- $A C M$ sites } \\
\hline & \multicolumn{2}{|l|}{ Men } & \multicolumn{2}{|c|}{ Women } & \multicolumn{2}{|l|}{ Men } & \multicolumn{2}{|c|}{ Women } \\
\hline & Mean & $\begin{array}{l}\text { Standard } \\
\text { deviation }\end{array}$ & Mean & $\begin{array}{l}\text { Standard } \\
\text { deviation }\end{array}$ & Mean & $\begin{array}{l}\text { Standard } \\
\text { deviation }\end{array}$ & Mean & $\begin{array}{l}\text { Standard } \\
\text { deviation }\end{array}$ \\
\hline \multicolumn{9}{|l|}{ Age } \\
\hline $18-35$ & 17.5 & 13.8 & 23.5 & 18.5 & 18.4 & 15.3 & 25.5 & 20.4 \\
\hline $36-59$ & 17.5 & 10.7 & 8.1 & 7.3 & 18.8 & 11.2 & 10.4 & 9.7 \\
\hline 60 and above & 7.0 & 4 & 3.1 & 2.9 & 6.0 & 4 & 3.5 & 3 \\
\hline Education level (years) & 6.7 & 3.8 & 3.9 & 3.8 & 6.5 & 3.2 & 3.6 & 3.9 \\
\hline Household size (persons) & 8 & 4 & 8 & 4 & 8 & 4 & 8 & 4 \\
\hline Land size (acres) & 1.4 & 1.9 & 1.1 & 1.7 & 1.5 & 1.8 & 1.0 & 1.5 \\
\hline Distance to forest $(\mathrm{km})$ & 1.6 & 0.6 & 1.4 & 0.2 & 1.5 & 0.5 & 1.5 & 0.4 \\
\hline
\end{tabular}


resources; and factors that influence dependence on forest resources and gendered use of income from forest resources across ACM and non-ACM sites. For women-headed households, we interviewed men living in such households aged 18 years and above.

\section{Data analysis}

Descriptive statistics were used to portray the respondents' socio-economic characteristics, while cross-tabulations were used to generate Pearson chisquare $\left(\chi^{2}\right)$ values. The latter were used to test any association between the men's and women's quality of participation in forest management and dependence on forest products, as well as the use of forest income in ACM versus non-ACM sites. We used an alpha level of 0.05 for all statistical tests.

Factor analysis was used to identify latent dimensions underlying indicators that measured men's and women's participation in forest management. Ten participatory indicators (level of husband's support + education / years in school + participation in ACM + distance to forest + dependence on forest resource + position/status of women in community + ethnicity + household income + knowledge of laws and policy + marital status) were considered based on theory and related empirical work (Ostrom 1990; Araral 2009; Dolisca et al. 2006; Lise 2000; Maskey et al. 2006) to influence participation in forest management. Principal component analysis (PCA) was used to extract factors using varimax rotation to ensure that the extracted factors were independent and unrelated to each other and to maximize the loading on each variable and minimize the loading on other factors (Bryman and Cramer 2005). The number of significant factors was determined by calculating the eigenvalue (variance accounted for by each factor). Factors with eigenvalues exceeding 1.5 were considered significant following Kaiser's criterion (Kaiser 1974).

\section{Results and discussion}

Here, we begin with a discussion of the household characteristics of our respondents, which shows the similarities between the ACM and non-ACM communities. We then examine the issues we considered important, both in terms of "normal" practice (non-ACM) and as influenced by ACM activities.

\section{Household characteristics}

Household characteristics are important in explaining the behaviour of respondents in most studies. In this study, they help in explaining the factors that influence the participation of men and women in forest management activities in Uganda. The age of the respondents ranged from 18 to 60 and above in both ACM and non-ACM sites (Table 4.2). The respondents across both study sites were relatively middle aged with an average of 42.1 years for men and 34.7 years for women. The years of education ranged from 0 to 12, with an average 
of 6.65 years (men) and 3.75 years (women), indicating probable low levels of literacy among the study population. Girls in Uganda often drop out of school at an earlier age compared with boys. Households in the study sites had an average of eight persons. This is higher than the national average family size (five people per family; UBOS 2013). The size of landholding averaged 1.45 acres ( 0.59 hectares) according to men and 1.05 acres ( 0.42 hectares) according to women. Results across the sites also show the mean average of perceived distance to the forest as $1.6 \mathrm{~km}$ for men and $1.5 \mathrm{~km}$ for women. Interestingly, women reported relatively smaller sizes for the family's landholdings and shorter distances to the forest in comparison with their male counterparts.

\section{Men's and women's perceptions of their own participation in forest management in ACM versus non-ACM sites}

The study investigated the participation of women in public (community forest) versus private spaces (household farmland). In line with cultural norms, we expected that women would more likely be involved in decision making at the household level than in public. However, the results show that women rated their participation in forest management at the community level $(96 \%$ in ACM sites and $76.2 \%$ in non-ACM sites) to be higher as compared with participation at the household level $(72.4 \%$ in ACM sites and 52.2\% in nonACM sites; Table 4.3). Across both ACM and non-ACM sites, women perceived themselves to be more involved in establishing tree nurseries and tree planting at the community level than at the household level. In comparison, their male counterparts perceived themselves to be more involved overall at the household level as compared with the community level in both ACM (97.4\% to $86 \%$ ) and non-ACM sites (82\% to $78.2 \%)$. The results also reveal that men's and women's perceived participation in forest management activities was higher in ACM sites as compared with non-ACM sites, implying that participation in ACM enhanced their levels of inclusion in forest management activities. Qualitative results suggest that women perceived their communitylevel participation more highly because at that level, as participants in women's groups, they had more control of the proceeds from forest products sales. At home, their husbands controlled such proceeds.

This finding further builds on the argument that women's participation in forestry activities increased with the formation of groups and participation in ACM. A chi-square test of independence was performed to examine the relation between gender and participation of men and women in private versus public spaces. The relationship between these variables was significant. Women were more likely to engage in forest management activities in public forested spaces (community forests) as compared with their involvement in private forested spaces (household level): $\chi^{2}(4, \mathrm{~N}=526)=8.9, p=0.0032$. In contrast, men were more likely to engage in forest management activities at the household level as compared with their involvement at the community level: $\chi^{2}(4, \mathrm{~N}=526)=1.7, p=0.0043$. 
94 Allan Bomuhangi et al.

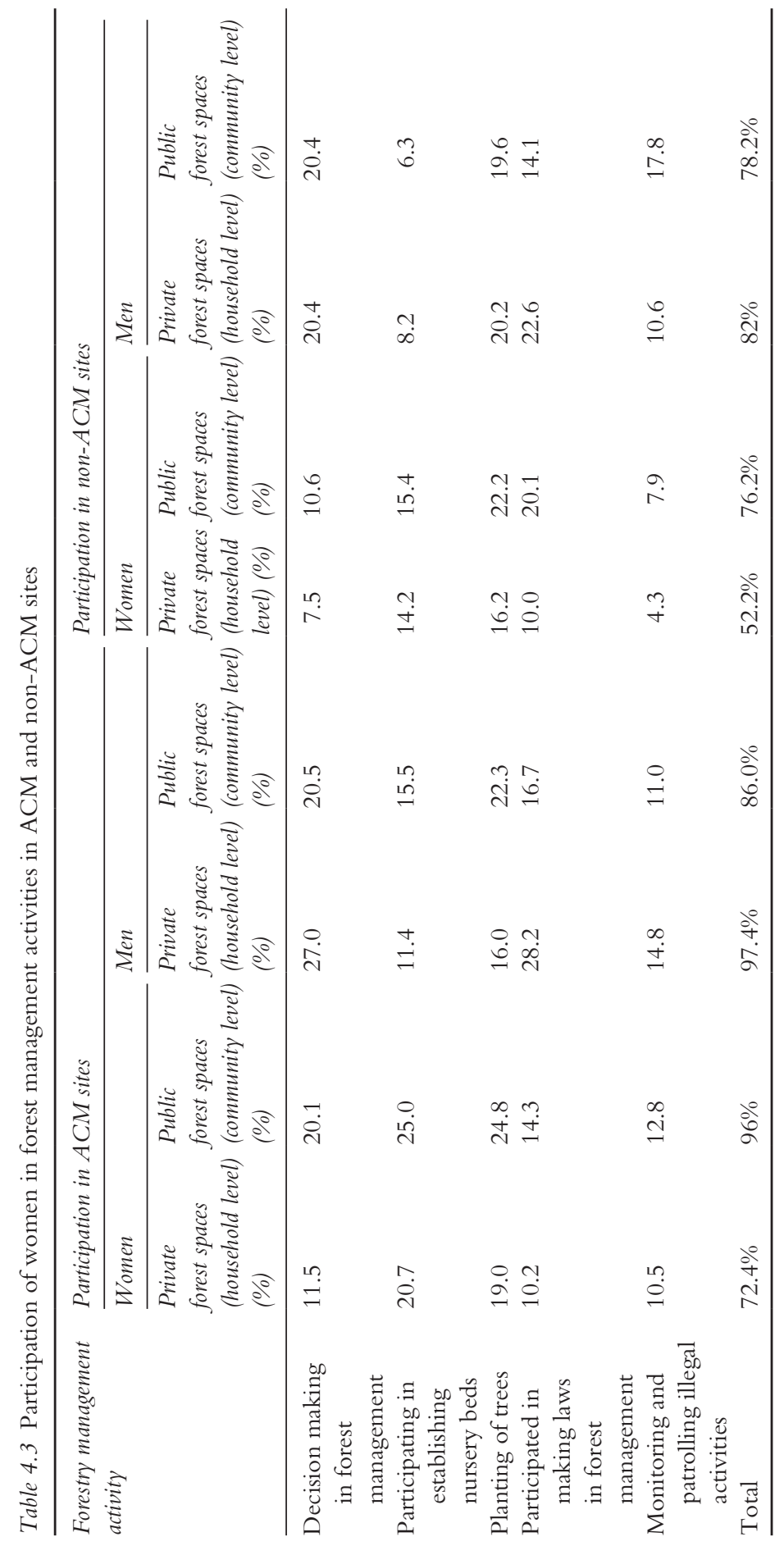




\section{Men's and women's perceptions of the quality of their own participation in forest management in ACM versus non-ACM sites}

Having established men's and women's perceptions of their own participation in forest management in ACM and non-ACM sites, we were also interested in how men and women rated the quality of their participation (Table 4.4). The a priori expectation was that if women evaluated their quality of participation as poor, this could indicate a host of reasons: for example, lack of involvement, discrimination (unintentional or active) and a perception that the forests are a man's concern. Contrary to expectation, descriptive statistics reveal that a substantial number of men (37\% in ACM sites and 46\% in non-ACM) considered their own quality of participation as poor. This number was slightly higher in comparison with the women who rated the quality of their participation as poor (25\% in ACM sites vs. $43 \%$ in non-ACM sites). This may well be related to cultural expectations that men should be involved in forest management, whereas there may be no such expectation for women. Interestingly, a slightly greater number of women (13\% in ACM vs. 3\% in non-ACM sites) reported that the quality of their own engagement was very good while only $6 \%$ of men in ACM sites versus 4\% in non-ACM sites reported the quality of their own participation as very good.

In our study, both men and women perceived their quality of participation in forest management in ACM sites as above average (63.8\%) as compared with their participation in non-ACM sites (33.1\%). Women's participation in ACM sites was rated better (25\% poor) as compared with $43.3 \%$ poor in non-ACM sites, implying that involvement in ACM played a significant function in improving women's participation in forest management in Uganda.

Table 4.4 Men's and women's perceptions of the quality of their own participation in forest management activities

\begin{tabular}{|c|c|c|c|c|c|c|c|c|c|c|}
\hline \multirow[t]{2}{*}{ Gender } & \multicolumn{5}{|c|}{ Quality of own participation in $A C M$ sites } & \multicolumn{5}{|c|}{ Quality of own participation in non- $A C M$ sites } \\
\hline & Poor & Moderate & Good & Very good & Undecided & Poor & Moderate & Good & Very good & Undecided \\
\hline Men & 36.6 & 32.3 & 20.2 & 6.1 & 11.1 & 46.0 & 33.6 & 12.0 & 4.4 & 7.8 \\
\hline Women & 25.0 & 42.4 & 22.3 & 13.2 & 10.7 & 43.3 & 36.4 & 13.7 & 3.0 & 13.6 \\
\hline Total & 61.5 & 74.7 & 44.5 & 19.3 & 21.8 & 89.3 & 70.0 & 25.7 & 7.4 & 51.6 \\
\hline
\end{tabular}

\section{Factors for participation in forest management in ACM versus non-ACM sites}

Factor analysis summarized the original ten participatory indicators ${ }^{2}$ in three factors, which accounted for $68.5 \%$ in ACM sites and $51.8 \%$ in non-ACM sites of the total variance of factors influencing women's participation in forest management (Table 4.5). 
96 Allan Bomuhangi et al.

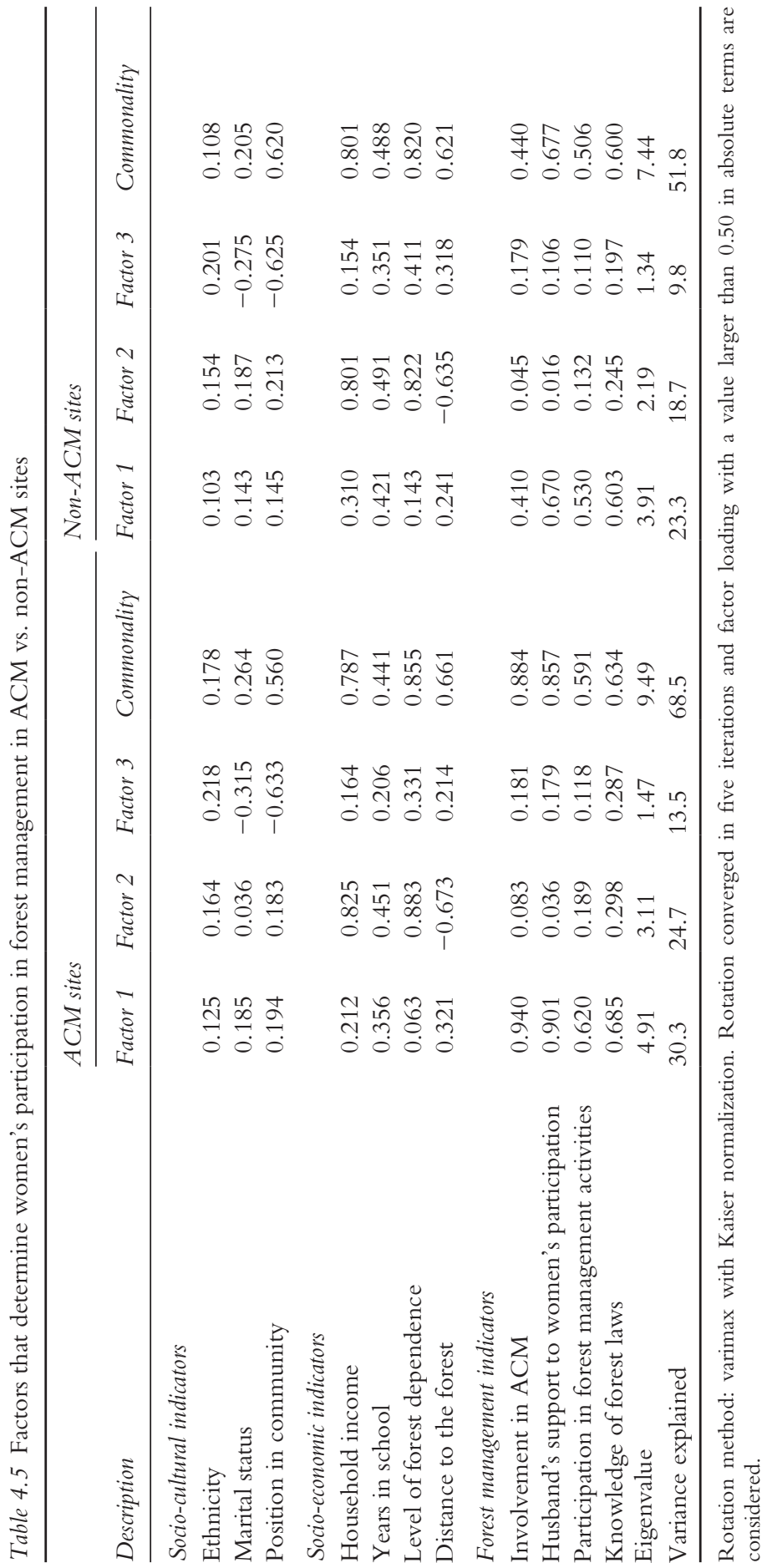


The dominant variables for the first factor (Table 4.5), which explained $30.3 \%$ and $23.4 \%$ of the variation in ACM and non-ACM sites, respectively, are mostly indicators related to inclusion in forest management. The level of participation in ACM and the husband's support to women's participation had the highest loading of 0.94 and 0.90 in ACM sites, while in non-ACM sites, husband's support and knowledge of forest laws had the highest loading of 0.67 and 0.60 , respectively. Qualitative results indicated that husband's support to women's participation increased if the husband also participated in ACM.

The dominating variables for the second factor, which explained $24.7 \%$ and $18.75 \%$ of the variation in ACM and non-ACM sites, were related to the socio-economic characteristics of the respondents. The level of dependence on forest resources had the highest loading of 0.88 and 0.82 in ACM and nonACM sites, respectively. The majority of the women were benefiting economically from the forest since it provided them with forest products for both subsistence and income. Household income had the second-highest loading with 0.83 and 0.80 in ACM and non-ACM sites, respectively. Furthermore, distance to the forest had a negative loading in both sites, suggesting that when the forest was distant, due to the various roles that women play and dangers they may experience, long-distance acts as a disincentive to participation in forest management.

The third factor explained $13.5 \%$ and $9.8 \%$ of the variation in ACM and non-ACM sites, respectively. The position of women in the community (leadership) had the highest loading of -0.63 and -0.62 , implying that low status decreased the women's ability to express themselves and voice their opinions in forest management, leading to less participation.

Contrary to Lise (2000) and Owubah et al. (2001), who argue that education influences participation in forest management and conservation, in our study, the number of years spent in school did not influence women's participation in forest management. This may be due to the fact that most of the women had reported low levels of education (mean average of 3.75 years in school).

Factor analysis revealed that men's participation in forest management was influenced by three factors that accounted for $64.8 \%$ in ACM sites and $55.8 \%$ in non-ACM sites of the total variance of factors influencing men's participation in forest management (Table 4.6). Like the female counterparts, forest management factors had the highest loading for factor 1 , followed by socioeconomic characteristics and finally socio-cultural characteristics. The status of men in the community, unlike that of women, did not have a significant role in influencing men's participation in forest management.

The marital status of men and women across both ACM and non-ACM sites had no significant positive impact on participation in forest management; however, it had a negative loading, implying that married men and women were less willing to participate in forest management than those who were single. This could mean that younger women or men are more willing to participate in and contribute to forest management. This could be related to 


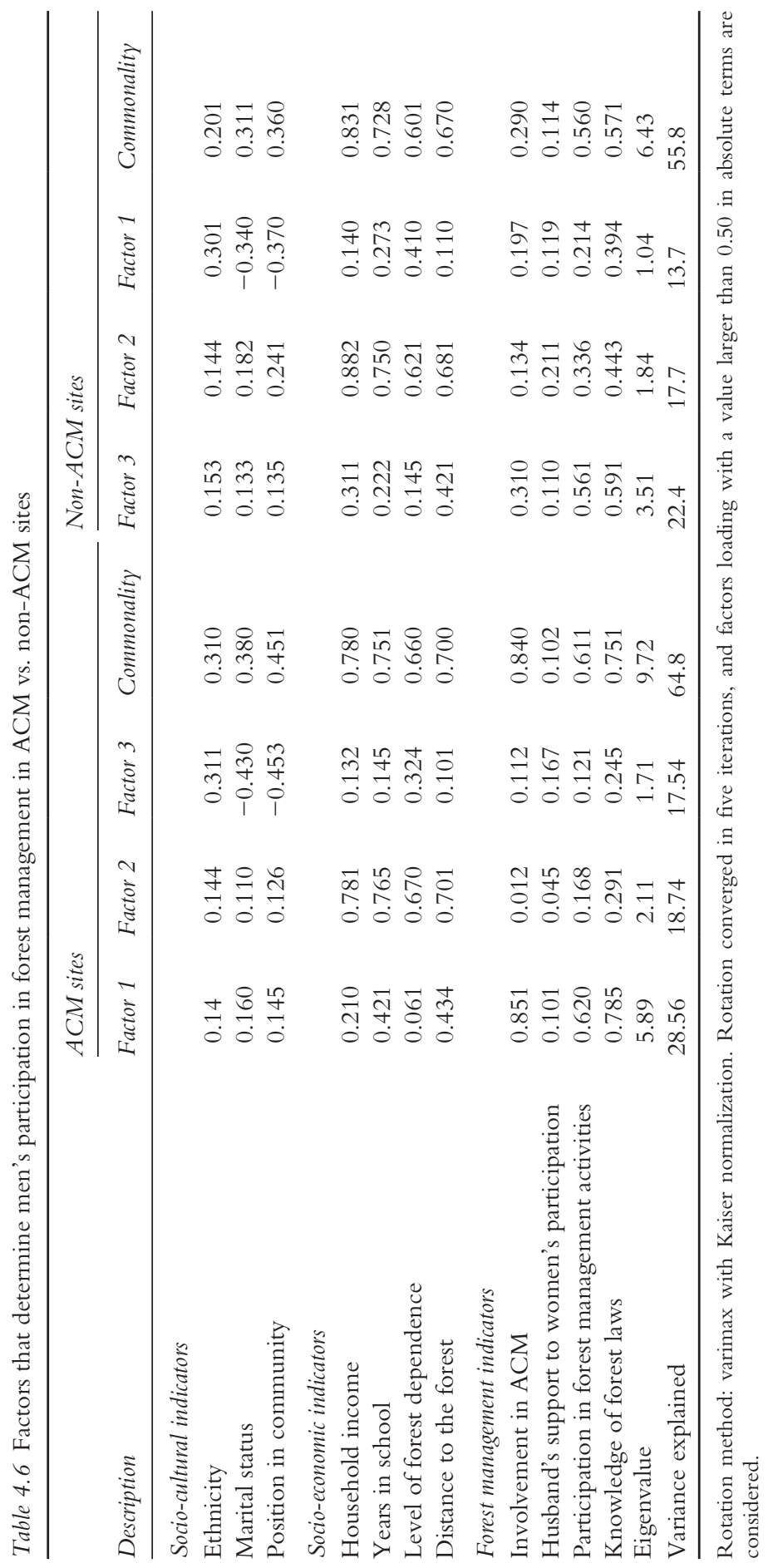


the additional workload of married members, which can reduce their time available to participate in forest management compared with single members. In addition, ethnicity, like marriage, had no significant positive impact in forest management, implying that the ethnic background of respondents did not matter in forest management participation.

\section{Dependence on forest products}

In order to obtain insights on community dependence on forest products, we investigated the forest products harvested by men and women from ACM sites and non-ACM sites (Table 4.7). While the same range of forest resources is harvested by men and women across both ACM and non-ACM study sites for most products, there was increased charcoal harvesting in non-ACM sites as compared with ACM sites. In addition, there was more harvesting of honey by women in ACM sites compared with non-ACM sites. The difference may be at least partially attributed to the stricter forest law enforcement under ACM sites. But the fact that during ACM implementation sustainable harvesting of forest products such as honey production was emphasized while destructive harvesting practices such as charcoal production were discouraged (see Chapter 5) was another important factor. Results also show evidence of marked gender specialization in the collection of forest products. Men mostly harvested the following products: poles, charcoal, honey and sand. On the other hand, women's harvesting emphasized firewood, water, herbs and craft material (Table 4.7). A chi-square test of independence was performed to examine the relation between gender and products harvested from ACM and non-ACM sites. The relationship between these variables was significant in both ACM sites $-\chi^{2}(10, \mathrm{~N}=400)=2.4, p=0.0014$, and non-ACM sites $-\chi^{2}(10, \mathrm{~N}=652)$ $=1.06, p=0.0027$. Men and women were likely to harvest different products

Table 4.7 Forest products harvested by women and men in ACM and non-ACM sites

\begin{tabular}{lcccc}
\hline \multirow{2}{*}{ Products } & \multicolumn{2}{l}{ ACM sites } & \multicolumn{2}{c}{ Non-ACM sites } \\
\cline { 2 - 3 } \cline { 5 - 5 } Women $\%$ & Men $\%$ & Women $\%$ & Men $\%$ \\
\hline Poles & 10.7 & 1.6 & 29.1 & 4.2 \\
Firewood & 5.7 & 43.8 & 5.7 & 35.4 \\
Carbon/charcoal & 6.8 & 0.5 & 22.9 & 35.4 \\
Wild animals & 6.0 & 0.0 & 4.6 & 0.0 \\
Craft materials & 1.6 & 22.3 & 2.3 & 5.4 \\
Herbs & 3.8 & 28.0 & 8.0 & 21.4 \\
Honey & 21.6 & 0.0 & 10.9 & 0.0 \\
Water & 12.3 & 8.9 & 3.4 & 34.5 \\
Sand & 12.3 & 2.2 & 5.7 & 1.2 \\
Fodder/grass & 9.6 & 8.3 & 4.6 & 0.6 \\
Fibre & 4.5 & 2.1 & 10.5 & 2.9 \\
\hline
\end{tabular}


from the forest. However, when the two site types were compared, results revealed that both ACM and non-ACM sites provided men and women with relatively similar amounts of products $\left(\chi^{2}(10, \mathrm{~N}=1052)=1.7, p=0.0033\right)$.

The results from this study support work by Sunderland et al. (2014) who report that there is significant gender differentiation in the collection of forest products - men and women play distinctive roles in the forest sector.

Having investigated the products harvested, it was important to further examine if the respondents considered the forest products to still be abundant within the forest in comparison with ten years ago. Results revealed that men and women had different opinions on the abundance of forest products (Table 4.8). Across both ACM and non-ACM sites, there is general agreement that forest resources have greatly decreased and are thus less abundant. However, when a comparison is made between the study site types, both men and women report that forest products are slightly more abundant in ACM sites than non-ACM sites. This could be attributed to a lower extraction of forest products from ACM sites compared with non-ACM sites by both men and women because of improved enforcement of forest rules, but also because of increased investment in alternative sources of livelihood-capacity as a result of ACM training.

The results also reveal that slightly more women than men were of the opinion that forest products were slightly more abundant; men considered the availability of forest products to be on the decline. This may suggest that forest products harvested by women, such as firewood, crafts material, water and herbs, remain abundant even when the forests are degraded. On the other hand, products harvested by men, such as poles, honey and timber, have become very scarce as forests have diminished. The relative perceived abundance of forest products in ACM sites may also be attributed to better conservation efforts due to ACM training and implementation.

Table 4.8 Perceptions on availability/abundance of forest resources

\begin{tabular}{|c|c|c|c|c|c|c|c|c|}
\hline \multirow[t]{3}{*}{ Products } & \multicolumn{4}{|c|}{ ACM sites } & \multicolumn{4}{|c|}{ Non- $A C M$ sites } \\
\hline & \multicolumn{2}{|c|}{ Women \% } & \multicolumn{2}{|c|}{ Men $\%$} & \multicolumn{2}{|c|}{ Women \% } & \multicolumn{2}{|c|}{ Men \% } \\
\hline & Yes & No & Yes & No & Yes & No & Yes & No \\
\hline Poles & 17.5 & 82.5 & 15.1 & 84.9 & 4.0 & 96 & 2.4 & 97.6 \\
\hline Firewood & 22.1 & 77.9 & 19.1 & 80.9 & 17.7 & 82.3 & 16.8 & 83.2 \\
\hline Carbon/charcoal & 2.2 & 97.8 & 1.9 & 98.1 & 2.3 & 97.7 & 16.8 & 83.2 \\
\hline Wild animals & 1.6 & 98.4 & 1.6 & 98.4 & 0.0 & 100 & 0.0 & 100 \\
\hline Craft materials & 7.9 & 92.1 & 37.1 & 62.9 & 1.1 & 98.9 & 0.6 & 99.4 \\
\hline Herbs & 12.6 & 87.4 & 12.1 & 87.9 & 10.3 & 89.7 & 11.3 & 88.7 \\
\hline Honey & 5.2 & 94.8 & 4.6 & 95.4 & 6.3 & 93.7 & 0.6 & 99.4 \\
\hline Water & 61.7 & $38 . .3$ & 13.7 & 17.6 & 13.7 & 86.3 & 13.7 & 86.3 \\
\hline Sand & 2.9 & 97.1 & 1.3 & 98.7 & 1.4 & 98.6 & 0.6 & 99.4 \\
\hline Fodder/grass & 4.1 & 95.9 & 3.8 & 96.2 & 0.0 & 100 & 0.6 & 99.4 \\
\hline Fibre & 6.3 & 93.7 & 3.0 & 97 & 2.7 & 93.3 & 2.4 & 97.6 \\
\hline
\end{tabular}




\section{Gender dimension of forest product and income use}

In order to understand how the forest contributes to the livelihoods of men and women, we first investigated how the communities use forest products. The results show that both men and women in ACM and non-ACM sites use forest products mainly to meet their domestic needs (Table 4.9). However, in ACM sites, a larger percentage of men $(33 \%)$ and women $(28 \%)$ reported using more forest products for income generation (commercial vs subsistence) as compared with non-ACM sites ( $22 \%$ men and $14 \%$ women). This could be attributed to the fact that during implementation of ACM, the community members were encouraged to participate in sustainable forest income-generating enterprises such as beekeeping for honey production and tree planting - contributing to global restoration efforts as well, on a small scale - for both domestic and commercial purposes (see Chapter 5).

Table 4.9 Gender dimensions of forest product and income use

\begin{tabular}{|c|c|c|c|c|}
\hline \multirow[t]{2}{*}{ Use type } & \multicolumn{2}{|c|}{ ACM sites } & \multicolumn{2}{|c|}{ Non- $A C M$ sites } \\
\hline & Men $(\%)$ & Women (\%) & Men $(\%)$ & Women (\%) \\
\hline \multicolumn{5}{|l|}{ Forest product use } \\
\hline Subsistence use & 67 & 82 & 78 & 86 \\
\hline Commercial use & 33 & 28 & 22 & 14 \\
\hline \multicolumn{5}{|l|}{ Expenditure item } \\
\hline Food & 15.3 & 17.9 & 15.5 & 14.3 \\
\hline Medical and school fees & 22.1 & 23.7 & 18.3 & 20.7 \\
\hline Investments and savings & 5.7 & 10.2 & 3.3 & 2.8 \\
\hline Mutual aid groups expenditure & 9.2 & 16.0 & 6.5 & 5.0 \\
\hline Personal expenditure & 23.5 & 12.2 & 18.5 & 8.2 \\
\hline
\end{tabular}

For those who earned income from the use of forest products, we wanted to understand use patterns of this income as this could have implications for people's participation in forest management. Results reveal that utilization of forest income is gendered in ACM and non-ACM sites. In both ACM and non-ACM sites, women spent income along the same budget lines, though we observed that women had increased capacity to spend in ACM sites as compared with non-ACM sites. This is attributed to the fact that women were not only harvesting for subsistence but were engaging and investing more in income-generating activities than in non-ACM sites. ACM was crucial in building capacity for women to engage in income-generating activities. Women also had better savings in mutual aid groups in ACM sites than their counterparts in non-ACM sites. Again, these are capacities obtained during ACM where members identified income-generating projects they felt would help meet their needs for basic goods and services and thus lower their level of dependence on the forests. Exchange visits among the ACM groups exposed participants to investment opportunities while the ACM village banking programmes allowed them to pool resources (see Chapter 5). 
Although qualitatively, it seemed that men spent most of their forest income on personal expenditures (as has been observed elsewhere) and women, on medicines, school fees and food, this was not borne out by our statistical tests. A chi-square test of independence was performed to examine the relation between gender and use of forest income within ACM and non-ACM sites. The relation between these variables was not significant: $\chi^{2}(4, N=400)=4.3$, $p=0.22$ in ACM; and $\chi^{2}(4, \mathrm{~N}=652)=6.9, p=0.37$ in non-ACM sites. In fact, both women and men contributed to the wellbeing of the family, along the same budget items. The results of this study suggest that forests, in addition to being important sources of subsistence foods and materials, make a significant contribution to rural household income and consequently to poverty reduction. However, the per cent contribution of income from the sale of forest produce to general household income was beyond the scope of this study.

\section{Conclusions}

Our findings indicate that factors related to forest management itself are the most important determinants of men's and women's participation in forest management in Uganda. More women in ACM sites reported enhanced participation and quality of participation in forestry management activities as compared with women in non-ACM sites. We consider participatory forest management approaches such as ACM as crucial for enhancing women's participation, particularly those whose livelihoods are directly and highly impacted by the forest. Additionally, women's participation in forest management is enhanced by participatory forest management approaches that open up public forested spaces as opposed to private forested spaces, implying that the probability of women participating at the community level (in community forests) is higher than that at the household level.

We also found that men's and women's participation in forest management can be influenced by their socio-cultural and socio-economic characteristics such as status in their community, income and level of dependence on forest resources. Women's personal and household attributes combined with sociocultural norms and values may constrain or enhance their participation in forest management in Uganda despite their participation in ACM.

Lastly, the study reveals that there is a marked gender specialization in the collection of forest products from both ACM and non-ACM sites. While there is no significant difference between the products harvested from ACM and non-ACM sites, in each of these sites, men and women harvested different forest products; men and women also both harvested forest produce for subsistence and sale. However, more women in ACM sites harvested forest produce for income generation compared with women in non-ACM sites.

\section{Policy recommendations}

These results lead us to several policy recommendations: first, in order to increase men's and women's participation in forest management, we recommend that 
participatory forest management initiatives such as ACM be institutionalized and implemented throughout the country. Forest adjacent communities should enter into collaborative forest management arrangements with the forest owners/managers (national forest authority, local government or the private forest owners) or be facilitated to form tree-planting groups or associations by NGOs and local government forestry officials. The latter kinds of activities could also contribute to more benign attempts to restore forests, in line with global efforts to do so more collaboratively (e.g., Butler and Schultz 2019; Mansourian 2020). The process should be simplified, adaptive and fast-tracked in order to increase the number of communities with collaborative forest management agreements.

Second, our study shows that the level of dependence on forest resources provides an incentive for both men and women to participate in forest management. However, present forest law allows limited use rights to forest adjacent communities. They can only legally harvest dry dead branches of trees for firewood in "reasonable quantities." Thus, communities adjacent to rich forest resources are often poor. We recommend that the withdrawal and exploitation rights of these communities be improved but regulated so that they can exploit forest resources to improve their livelihoods on a sustainable basis through collaborative forest management approaches.

\section{Acknowledgements}

We would like to thank all the communities in our study sites who cooperated with us by providing information for the study. We are very grateful to Anne Larson and the late Esther Mwangi, both of CIFOR and the research team in Nicaragua, for their valuable input in the preparation of the proposal and study instruments. We wish to express our heartfelt gratitude to the Austrian Development Agency (ADA) for providing the funds for this study.

\section{Notes}

1 CIFOR's approach is described in a number of publications, archived at https://www2 .cifor.org/acm/.

2 Level of husband's support, education/years in school, participation in ACM, distance to forest, dependence on forest resources, position/status of women in community, ethnicity, household income, knowledge of laws and policy and marital status.

\section{References}

Araral, E. J. 2009. "What Explains Collective Action in the Commons? Theory and Evidence from the Philippines." World Development 37: 687-697.

Banana, Abwoli Y., Paul O. Ongugo, W. Gombya-Ssembajjwe, Tadesse W. Gole, Fayera Senbeta, Justine Namaalwa, Emannuel Luoga, Joseph Bahati, L. A. Mbwaambo, and Franz W. Gatzweiler. 2013. "Forest Governance Reforms in East Africa: A Comparative Analysis of Institutions, Livelihoods and Forest Sustainability Outcomes.” In Institutional and Livelihood Changes in East African Forest Landscapes: Decentralization and Institutional Change for Sustainable Forest Management in Uganda, Kenya, Tanzania and Ethiopia, edited by F. Gatzweiler, 17-48. Frankfurt am Main: Peter Lang. 
Banana, Abwoli Y., Mohamed Bukenya, Eusobio Arinaitwe, Betty Birabwa, and Sylvester Ssekindi. 2012. Gender, Tenure and Community Forests in Uganda. Bogor, Indonesia: CIFOR.

Bryman, A., and D. Cramer. 2005. Quantitative Data Analysis with SPSS12 and 13: A Guide for Social Scientists. East Sussex: Routledge.

Butler, William H., and Courtney A. Schultz, eds. 2019. A New Era for Collaborative Forest Management: Policy and Practice Insights from the Collaborative Forest Landscape Restoration Program. London: Earthscan/Routledge.

Dolisca, F., D. R. Carter, J. M. McDaniel, D. A. Shannon, and C. M. Jolly. 2006. "Factors Influencing Farmers' Participation in Forestry Management Programs: A Case Study from Haiti." Forest Ecology and Management 236: 324-331.

Government of Uganda. 2001. The Uganda Forest Policy 2001. Kampala, Uganda: Ministry of Water, Lands and Environment.

Government of Uganda. 2016. Environment and Natural Resources Sub-Sector Gender Mainstreaming Strategy 2016-2021. Kampala, Uganda: Ministry of Water and Environment.

Kaiser, H. 1974. "An Index of Factorial Simplicity.” Psychometrika 39: 31-36.

Lee, Bandy X., Finn Kjaerulf, Shannon Turner, Larry Cohen, Peter D. Donnelly, Robert Muggah, Rachel Davis, et al. 2016. "Transforming Our World: Implementing the 2030 Agenda Through Sustainable Development Goal Indicators." Journal of Public Health Policy 37 (1) Supplement 1: 13-31.

Lise, Wietze. 2000. “Factors Influencing People's Participation in Forest Management in India." Ecological Economics 34 (3): 379-392.

Mansourian, Stephanie. 2020. Enabling Factors to Scale Up Forest Landscape Restoration: The Roles of Governance and Economics: Full Report with Case Studies. Berlin, Germany: WWF and IUFRO.

Maskey, V., T. G. Gebremedhin, and T. J. Dalton. 2006. "Social and Cultural Determinants of Collective Management of Community Forest in Nepal." Journal of Forest Economics 11: 261-274.

Mukasa, C., Alice Tibazalika, E. Mwangi, A. Y. Banana, and K. Evans. 2016. Adaptive Collaborative Management: A Simplified Guide for Practitioners. Bogor, Indonesia: CIFOR.

Ostrom, E. 1990. Governing the Commons: The Evolution of Institutions for Collective Action. New York: Cambridge University Press.

Owubah, Charles E., Dennis C. Le Master, J. Michael Bowker, and John G. Lee. 2001. "Forest Tenure Systems and Sustainable Forest Management: The Case of Ghana." Forest Ecology and Management 149 (1-3): 253-264.

Sunderland, Terry, Ramadhani Achdiawan, Arild Angelsen, Ronnie Babigumira, Amy Ickowitz, Fiona Paumgarten, Victoria Reyes-García, and Gerald Shively. 2014. "Challenging Perceptions About Men, Women, and Forest Product Use: A Global Comparative Study.” World Development 64: S56-S66.

Uganda Bureau of Statistics. 2013. Statistical Abstract. Kampala: Uganda Bureau of Statistics. 


\section{Introduction to Chapter 5}

Mukasa et al. continue in Chapter 5 with the ACM programme that was conducted in Uganda, but these authors focus instead on the process of ACM, the specific attempts the community members undertook with the team's facilitation and the impacts at that time. The authors have also been able to revisit these sites more recently and provide up-to-date assessments of the longevity of many, though not all, of their efforts. A number of the communities' concerns have significance for the global restoration efforts now underway - efforts that frequently inadequately attend to the needs, interests and capabilities of local people. The experience of this ACM team should be directly applicable to many such programmes.

Mukasa's team also demonstrates the value of attending to both genders in attempts to empower women. They were able - through equitable and careful facilitation, regular and consistent involvement and a focus on local priorities to interest local men as well in improving livelihoods and voice for the whole community while also addressing gendered power imbalances there. Their successes speak to the value of concerted, local level, responsive development efforts that emphasize learning among all participants. The complementarity between the research reported in Chapter 4 and this chapter shows an effective way to address multiple levels (from local to national). Chapters 4 and 5 conclude that ACM demonstrates efficacy, though somewhat erratically. It is worth noting the agreement in results, despite the divergent research methods used in analysis. 


\title{
5 Strengthening women's tenure rights and participation in community forestry in central Uganda ${ }^{1}$
}

\author{
Concepta Mukasa, Alice Tibazalika, \\ Abwoli Yabezi Banana, Esther Mwangi and \\ Tendayi Mutimukuru-Maravanyika
}

\section{Introduction}

Global approaches to forest management have, in the past 25 years, shifted from state-centric management to co-management, to sometimes devolving authority to whole communities (Belcher and Schreckenberg 2007). Despite this, evidence shows that in these devolution processes, women continue to be marginalized from decision making and in the distribution of tree or forest resource benefits (Mai, Mwangi and Wan 2011), while Arora-Jonsson et al. (2020) suggest that gender equality is a precondition for sustainable forestry management. In many countries, women's roles and representation in decision making in the forestry sector are very limited (FAO 2005). There are important differences between men's and women's perspectives on - and use of - forest resources for the wellbeing of their families and communities (IUCN 2011). In all regions of the world, women and men have different access to, control over and use of trees and land (IUCN 2011; FAO 2003). Unlike men who are largely involved in the extraction of timber products, women use products such as firewood and non-timber forest products, which may demand more frequent interaction with forests (Pandolfelli, Meinzen-Dick and Dohrn 2007; Mwangi, Meinzen-Dick and Sun 2011). Moreover, the ownership of forests and the sale of forest products are largely under the control of men, and women's needs and concerns over forests are often neglected (Women's Environment and Development Organization 2012).

A growing body of evidence demonstrates that women's involvement in forest management produces substantial gains for forest conservation and livelihoods (Agarwal 2010). The World Bank forestry strategy clearly states that sustainable use of forests requires the participation of all groups in rural communities, including women. It also states that women's needs differ from those of men, and many policies and programmes continue to overlook women's specific needs, knowledge, roles and relations regarding forest and tree resources (World Bank 2002).

DOI: $10.4324 / 9781003197256-9$ 
Studies to understand the extent to which gender was addressed in Uganda's natural resources sector found important progress in formal gender mainstreaming but weak implementation at all levels of governance, from national to subnational levels (Mukasa et al. 2012; Banana et al. 2012). These studies revealed that although the Uganda Forestry Policy, Forestry Act and Forestry Plan address gender and women's specific needs, they are not backed up by relevant regulation and mechanisms for monitoring implementation and ensuring compliance (Mukasa et al. 2012). In addition, existing customary rules in Uganda undermine women's participation in resource governance and limit their rights, benefits and participation in forests and tree resources decision making. Further, benefits from forests and tree resources continue to be allocated disproportionately, with men benefitting from the trade in high-value products while women's gains are from their subsistence use of resources or trade in lowvalue products. Because of cultural norms, women continue to access forest and tree resources through their relationships to their male counterparts as wives, daughters or sisters; any form of control or ownership is reserved to men. This puts women in vulnerable positions when divorced or widowed.

Here, we present the findings of a six-year process of negotiation and facilitation among mixed groups of men and women. The purpose of the process was to (a) explore how women's rights and access to forest and tree resources (on-farm tree resources, private forests, local and central government forest reserves) could be strengthened and (b) investigate the impact of the adaptive collaborative management (ACM) approach on gender equity in rights, decision making and benefits sharing in forest management activities. We highlight the governance arrangements, practices and processes that are central to enhancing gender inclusion and to the transformation of underlying values and norms in community forestry.

The next section provides the background to the ACM approach that was applied in this study. The third section presents the context and describes socio-economic conditions, and local land and tree/forestry tenure systems. Next, we describe the methods and materials used for the study. The fifth section presents and discusses our findings, and the sixth presents challenges and lessons learned from the study, followed by our conclusions.

\section{Gender and collaborative resource governance: An overview}

According to several scholars (McDougall et al. 2010; MutimukuruMaravanyika et al. 2017), the participation of women and other marginalized groups in resource (e.g., forest) management can be enhanced by using an ACM approach. ACM is a management approach that has gained popularity due to its equitable and sustainable outcomes in forest management situations (Colfer 2005a, b; Diaw, Aseh and Prabhu 2009; Mandondo, Prabhu and Matose 2008). The ACM approach is designed to enhance participation by all stakeholders (especially marginalized groups) in deliberate community efforts including decision making and benefit sharing. 
By facilitating negotiations between stakeholders, practitioners may support the development of collaborative and adaptive strategies to manage forests (FAO 2006). For example in the ACM process, factors that hinder women's participation are identified and addressed, using participatory action research (PAR), a 'learning by doing' process through which a group, together with other stakeholders, identifies a problem, takes action to resolve it, monitors and evaluates the outcomes, reflects and learns from the activity (Figure 5.1) (Colfer 2005b; German et al. 2012; Mandondo, Prabhu and Matose 2008; Mutimukuru-Maravanyika et al. 2008).

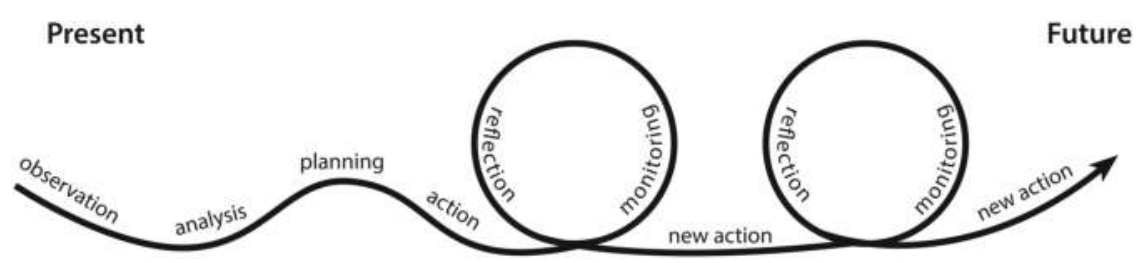

Figure 5.1 Participatory action research process.

The ACM approach seeks to empower women and other marginalized groups who live in and around forests by giving them a greater say in how forests are managed (CIFOR 2004). The approach has proven successful in encouraging both men and women to participate in managing their natural resources. For example, in Mafungautsi Forest Reserve, in Zimbabwe, women were not initially involved in formal forest management, as this was deemed a man's sphere. After representatives (both men and women) from the communities were invited to participate in capacity development activities (including a "training for transformation" workshop), women's attendance and participation in formal meetings rose dramatically and they became actively involved in various forest user groups (e.g., broom grass resource user groups; Mandondo, Prabhu and Matose 2008). Further, these women adopted sustainable harvesting techniques and began to generate more income through value addition (Mutimukuru-Maravanyika 2010; Mutimukuru-Maravanyika et al. 2008). Similar results have been found in Nepal, where lower caste women gained sufficient confidence after participation in ACM processes (Dangol 2005), and in Ghana, where women in the artisanal fisheries sector gained confidence and actively participated in resource management platforms after their capacities were developed through ACM processes (Mutimukuru-Maravanyika et al. 2017).

The implementation of ACM may however confront significant challenges. For example, ACM can create dependency, especially among disadvantaged groups who may require continued facilitation (Gondo 2011). And if care is not taken, the elites in the group may tend to influence decision making to support their own interests. On the other hand, the elites may stop participating in resource management platforms when they realize that the poor and marginalized are gaining more confidence and power (Mutimukuru-Maravanyika 
2010). Similarly, external actors, such as government and NGOs, can advance their own interests at the expense of intended beneficiaries (Gondo 2011). Successful ACM implementation thus requires commitment from all stakeholders in terms of time, financial resources and genuine support of community objectives (Gondo 2011; Plummer and Armitage 2007).

\section{The study area}

Our study was conducted in Mpigi, Butambala, Masaka and Rakai Districts, which are all in the Lake Victoria agro-ecological zone of Uganda (Figure 5.2).

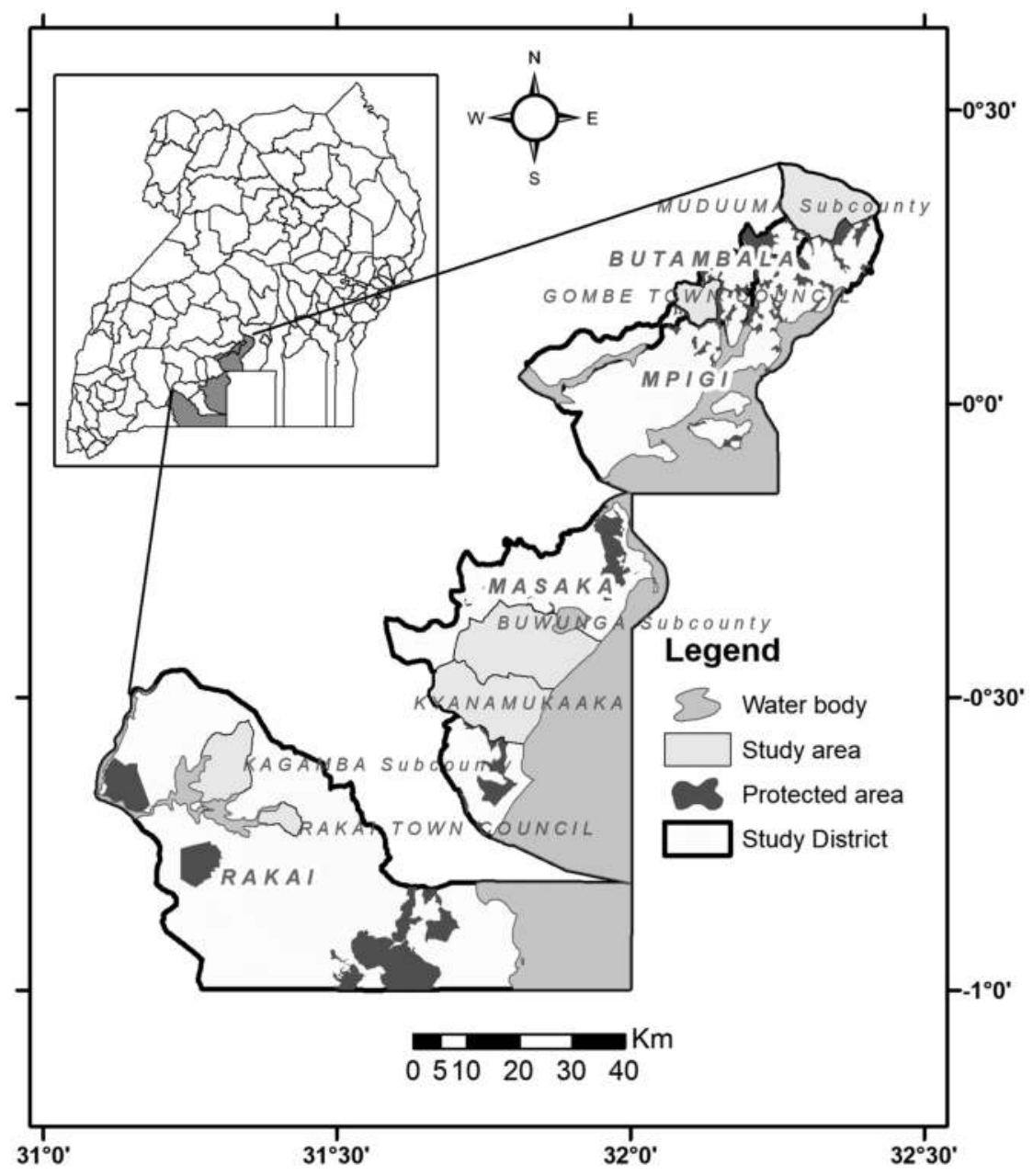

Figure 5.2 Lake Victoria Crescent covering the initial study districts of Mpigi, Masaka and Rakai. 
Although generally equatorial, the climate is modified by the altitude with an average of between $1500 \mathrm{~mm}$ and $1800 \mathrm{~mm}$ of rainfall, per year and temperatures ranging from $21^{\circ} \mathrm{C}$ to $29^{\circ} \mathrm{C}$ (Banana et al. 2010). The average elevation of the study area is $1200 \mathrm{~m}$ above sea level. The vegetation of the region used to be tropical moist forests - however, most of this has been cleared for farming. The four districts have a total population of 1,164,701, with an average of 291,175 inhabitants each. Population densities range from 144.5 to 192.2 people per $\mathrm{km}^{2}$ (Uganda Bureau of Statistics 2017). The study sites are dominated by the Baganda - the largest ethnic group in Uganda. This group is characterized by patriarchal values, with men as heads of household and main decision makers in the household and community. These norms and values have impacts on how tree and forest resources are utilized in the communities. ${ }^{2}$ According to local cultural norms, a woman cannot own land, and therefore trees, through inheritance, but can access and manage land and trees through her male relatives (e.g., father, brother or husband). ${ }^{3}$ However, these norms are gradually changing due to supportive policies and continuous sensitization mostly by NGOs and other institutions focusing on gender issues, allowing some women (whether married, widowed or single) to inherit and own land and trees. Lately, women are increasingly attaining education and gaining economic empowerment, thus increasing their ability to purchase and own land. It should be noted that women own from $7 \%$ to $20 \%$ of land in Uganda (Lewis 2012; Mukasa et al. 2012).

Most people in the study sites grow a mix of crops, which include bananas, coffee, maize, beans, vegetables, trees and fodder grasses in agroforestry systems. Due to land pressure, encroachment on forest land for agricultural production is common and frequent, mostly by local community members living in areas adjacent to the forest reserves (Namaalwa, Gombya-Ssembajjwe and Hofstad 2001; Banana et al. 2012).

Several property-rights regimes exist in the study area including: central forest reserves (CFR) managed by the National Forest Authority (NFA), local forest reserves managed by district local governments, and private and communal forests on privately owned land. Past and current studies have found degradation of forestry resources to occur in all property-rights regimes (Banana and Gombya Ssembajjwe 2000). Tree tenure regimes also follow the forest property regimes whereby the government owns the trees in CFRs while trees on local forest reserves and private forests are owned by the local government and landlords, respectively.

\section{Methodology}

We used a mixed methods approach comprising both qualitative and quantitative methods. Following the participatory action research approach, qualitative methods included resource mapping, problem identification and problem tree analysis, pairwise ranking to prioritize problems, visioning that resulted in action planning (actions were then implemented to see what worked best), 
focus group discussions, transect walks, key informant interviews and participant observation. In order to obtain the most recent information about the groups, phone calls to contact persons were used. Quantitative methods included surveys conducted using questionnaires (see Chapter 4).

The study area consisted of six selected project sites located in the four districts (Table 5.1) that were selected to vary by property regimes, distance to markets/main capital city (Kampala) and interaction with external actors. Further details of the site selection criteria can be found in (Banana et al. 2012).

Table 5.1 Selected study sites (see also Table 4.1)

\begin{tabular}{|c|c|c|c|}
\hline District & Sub-county & Site & Neighbouring forest reserve \\
\hline Butambala & Gombe T/C & Nkinga village & Nawandigi Central Forest Reserve (CFR) \\
\hline Mpigi & Muduuma & Mbazzi village & Lwamunda CFR \\
\hline Masaka & Buwunga & Bukeeri village & $\begin{array}{l}\text { Nabukonge CFR and Catholic Mission } \\
\text { Forest }\end{array}$ \\
\hline Masaka & Kyanamukaka & Kagologolo village & Mujuzi CFR \\
\hline Rakai & Rakai T/C & Kajoki village & No forest \\
\hline Rakai & Kagamba & Kizira village & No forest \\
\hline
\end{tabular}

The adaptive collaborative management approach was used by a team of researchers, dubbed the ACM team, ${ }^{4}$ to implement community-selected, forest-related activities in the study sites and to facilitate gender inclusion within the context of these activities.

ACM is an approach whereby people who have interests in a natural resource agree to act together to plan, observe and learn from the implementation of their plans while recognizing that plans often fail to achieve their stated objectives. It is characterized by conscious efforts among such groups to communicate, collaborate, negotiate, resolve conflicts and seek out opportunities to learn collectively about the impacts of their actions.

(CIFOR 2008)

A key element of the ACM approach is participatory action research - a process of systematic inquiry that is collective, collaborative, self-reflexive and undertaken by participants seeking to answer questions about real-life concerns to improve their wellbeing. "Learning by doing" is the mode of operation in the PAR process whereby a group identifies a problem, takes action to resolve it, monitors the outcomes, reflects and learns from the activity - the community in this case is also actively involved in the research process. The iterative nature of this approach is illustrated in Figure 5.1. The process is driven by a 
need to move from an undesired current situation to a desired future state that the actors agree upon, and the end goal of PAR is to empower the community to create change and deal with their own challenges rather than waiting passively for outside help (Apgar and Douthwaite 2013; Evans et al. 2014).

The ACM process was implemented in two phases and activities implemented in each phase are described separately below.

\section{First phase (May 2011 to June 2013)}

The process began with an analysis of Uganda's natural resources policies to understand how gender issues were being addressed there as well as what had worked and what had not worked (Banana et al. 2012). We also analysed the extent to which gender issues were considered in government and nongovernment forestry projects and programmes (Mukasa et al. 2012). A baseline survey with a larger group of communities was carried out. We then selected a subset of communities for the ACM work. The follow-up survey was then conducted in both ACM and non-ACM sites after the implementation of ACM to look for changes in the participation of women in forestry management over time. The results of this survey were reported in detail in Chapter 4.

The baseline surveys were followed by the training of trainers in the ACM approach. Several stakeholders participated in this training including government officials, researchers, NGO staff and staff from the private sector. During the training, the art of facilitation and PAR, among other issues, were demystified. The ACM team later established contact with district and community officials in order to identify, build and strengthen partnerships. This was followed by community entry and mobilization and implementation of ACM activities facilitated by two female external facilitators ${ }^{5}$ (from the Association of Uganda Professional Women in Agriculture and Environment).

At the beginning of the PAR cycle, with facilitation of the district-level stakeholders (who participated in the ACM capacity development workshop; see Chapter 6 for similar examples), the community members (both men and women) were involved in a visioning exercise. Using knowledge of their current situation, including identifying opportunities and problems in their communities, they generated their desired visions and later developed action plans for implementation. Visioning exercises resulted in five-year community action plans that were specific for each user group. All activities were conducted through segregated gender groups of elderly men and women, adult men and women, young men (aged 15-19) and women. The younger married women refused to be grouped under female youth as they felt their needs were similar to those of the older women. Presentations and discussions were done in plenary sessions to reach a common agreement. Across the four districts, a total of 222 (113 men and 109 women) community members voluntarily participated in the visioning exercises (Table 5.2). During the exercise, male youth were separated from adult men because of their different interests. Attendance per community (both youth and adults combined) is illustrated in Table 5.2. 
Table 5.2 Attendance per community

\begin{tabular}{lllrcc}
\hline \multirow{2}{*}{ No } & \multirow{2}{*}{ District } & Village/community & \multicolumn{2}{c}{ Number of participants } \\
\cline { 4 - 6 } & & Men & Women & Total \\
\hline 1 & Mpigi & Mbazzi & 19 & 16 & 35 \\
2 & Butambala & Nkinga & 8 & 21 & 29 \\
2 & Masaka & Bukeeri & 20 & 15 & 35 \\
& & Kagologolo & 31 & 27 & 58 \\
3 & \multirow{2}{*}{ Rakai } & Kizira & 22 & 21 & 43 \\
& \multirow{2}{*}{ Total } & Kajoki & 13 & 9 & 22 \\
& & 113 & 109 & 222 \\
\hline
\end{tabular}

After the visioning exercises, community members developed indicators to track the changes in women's participation. The indicators developed through participatory monitoring tracked progress in implementation and in gender equality, including the number of women: (a) in leadership positions; (b) attending community meetings; c) contributing actively during discussions; (d) owning trees on "their" farms and/or in CFRs; and (e) controlling income/ benefits. The formulation of these indicators built on the prior knowledge of women's participation in key fora (i.e., community meetings) and influence in decision-making processes.

Most ACM implementation groups were formed voluntarily by both men and women in study sites after community sensitization and facilitation by the ACM team members. The groups selected activities both on-farm and in nearby forests that were mostly under the management of the governmental National Forestry Authority. On-farm activities were intended to reduce pressure on forests while generating income for both men and women. These on-farm activities included the establishment of individual and group tree nurseries, tree planting in agroforestry systems and woodlots, improved coffee, banana and vegetable production for income and improved food security, water harvesting and intensive fish farming in water tanks. These findings are particularly relevant for global forest restoration efforts (Erbaugh et al. 2020). Forest-based activities included group tree nursery establishment, tree planting using a taungya ${ }^{6}$ system, beekeeping and fish farming. During the process of implementation of planned activities, the participants identified capacity development needs in various aspects including alternative livelihood opportunities to reduce forest dependence, improved forest management practices, leadership and representation and gender concepts and applications. Consequently, the facilitation team organized trainings as well as exchange visits to other groups with good gender and forestry management practices.

In addition, linkages with relevant stakeholders (e.g., NGOs, government departments) who were able to support capacity development were established. These organizations provided various kinds of support to the groups, including 


\section{Concepta Mukasa et al.}

training in gender concepts and relations, tree nursery management, beekeeping, forest management and fish farming as well as material support such as seedlings and energy-saving stoves. Moreover, group organization allowed them to enter into legal agreements with the National Forestry Authority and to plant trees in areas allocated to them with a level of confidence that the NFA would not evict them, hence, incentivizing tree planting by both men and women. For women in particular, this pathway for acquiring assets was much more secure than through their husbands' land. Importantly, withingroup rules of engagement, through the designing of constitutions, and their compliance with rules, helped to deal with the free-rider problem and other customary laws that were a hindrance to women's ownership of tree resources.

Monitoring and evaluation of planned activities followed implementation and was done through monthly community meetings. Group members reflected on activities they undertook, the lessons they learned and the re-planning process. Documentation of the process was a major component in order to present a complete record of the group's analysis, reflection and learning. All ACM team members were involved in process documentation (including local level co-facilitators). Visits to individual members' households were also made to monitor the progress of activities at the household level.

\section{Second phase (February 2014 until September 2016) ${ }^{7}$}

The second phase involved continued implementation of the first-phase activities and the addition of others aimed at disseminating experiences, obtaining feedback and expanding the ACM processes to other districts. These new activities included:

a) Reporting progress of implementation to district political, technical and community officials

b) Improvement of monitoring and evaluation indicators

c) Conducting dissemination workshops to district and national level stakeholders to solicit feedback and validation of phase one results

d) Conducting participatory planning workshops at the community level to reflect on their visions and re-strategize

e) Leadership training

f) Identification and training of co-facilitators

g) Community exchange and study visits

h) Training of communities, NGOs and government officials in ACM approaches in three new Districts

i) Engaging legislators and other policy-makers in an effort to institutionalize ACM in government programmes.

At this stage, we focused on mixed groups of men and women in order to take advantage of synergies from both genders (Mwangi, Meinzen-Dick and Sun 2011). In addition, because gender is relational, increasing gender equity 
requires an understanding of both men's and women's perceptions, values and activities in a culturally sensitive and open way (Evans et al. 2014). We used community-identified priorities and needs as logical entry points into the community. We anticipated that change towards gender equity in rights, decision making and benefit sharing would occur through careful facilitation and moderation by the ACM team while supporting the implementation of diverse activities and action plans identified jointly by men and women in the communities. These were focused on alleviating key forest-related concerns. The details of the overall ACM process pathway evolved organically as participants worked to implement their action plans. Figure 5.3 provides a framework illustrating the implementation of ACM and the pathway towards change.

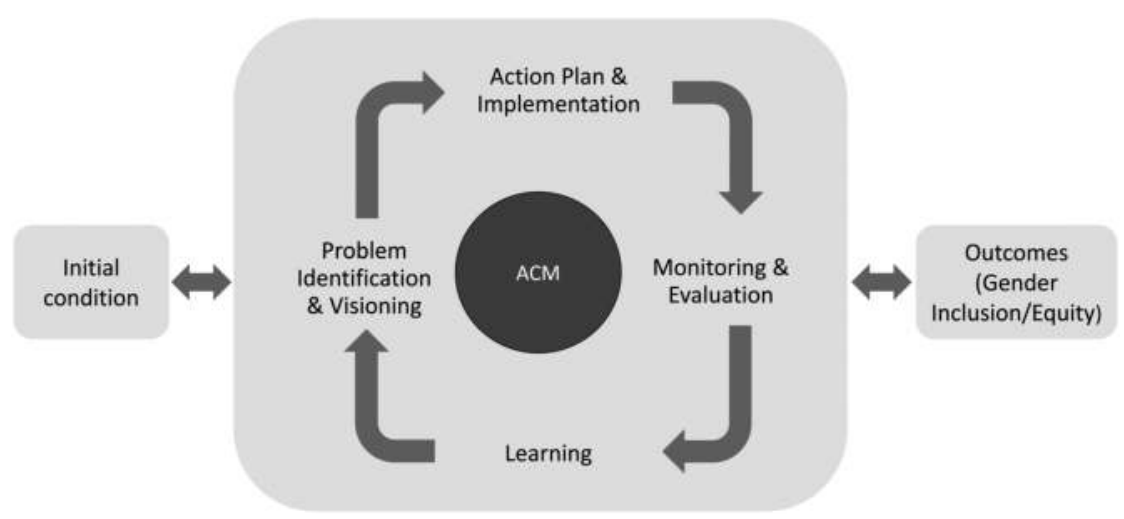

Figure 5.3 Framework of implementation of ACM activities.

\section{Results and discussion}

Our findings are presented in two parts: a) gender-focused dimensions, in particular women's and men's participation in decision making, group leadership, rights to trees and forests ${ }^{8}$ and $b$ ) the performance of the forest user groups after implementation of ACM activities. ACM implementation used communitylevel needs and priorities as an entry point for identifying and addressing gender-differentiated needs. The set of indicators used was developed jointly and validated by community members and other relevant stakeholders.

\section{Advancing gender inclusion in forest management using the ACM approach}

Enhanced women's participation in tree planting

Cultural norms ${ }^{9}$ inhibiting women from planting trees were a major concern raised by women during the visioning exercises. In the case of land, the local norms are quite strong. Although the constitution does not allow discrimination 
in ownership of land, in reality, women own a negligible percentage of land. For instance, planting by women of certain trees on land owned by men in the central region of Uganda was taboo. This is because the planting of trees such as Ficus natalensis indicated land ownership and leadership. Some trees such as fruit trees could be tolerated, but Ficus natalensis and other timber tree species that were being promoted by the ACM project ${ }^{10}$ were not tolerated at all. Ficus and other timber trees could only be planted by the landowner. Therefore, even though the project goal was to increase women's participation in forest management, this was proving difficult to achieve even though government policies were supportive and fair. In order to deal with this challenge, the following activities were undertaken:

1. The ACM team facilitated and encouraged the formation of mixed groups of both men and women even though the project was targeting women. This was done to: remove all suspicions from men about the project inciting women to become insubordinate; ensure that both men and women accessed land for tree planting; and encourage men who were participating in the project (and whose attitudes had been transformed) to convince other men to support the women in their families to access land. It also enhanced women's confidence to speak out in the presence of men.

2. We provided gender training for both men and women group members. This helped to bring to the fore cultural taboos that were a hindrance to development such as preventing women from owning land, planting trees or even climbing them to harvest some products. Members were able to discuss these issues and suggest solutions to address the taboos related to forest management and tree planting. This further encouraged the men and women to practice equity at home and in group and community work.

3. The ACM teams continually sensitized participants about the importance of involving women in forest and tree management. Local examples of women who were involved in tree planting and management were given and their farms visited.

4. Land for men and women planting trees in the NFA CFR was allocated equally. This was made possible by the facilitation of the ACM team that signed an MOU with NFA to enable the participation of community members in collaborative forest management (CFM). Thereafter NFA allocated land to the community members, and community members themselves allocated land to members for tree planting in addition to allowing regeneration of the natural forest. In Mbazzi, each member (women and men) received 0.25 hectares (ha) where they each planted 200 eucalyptus trees, as individuals. The rest was left for indigenous tree species that they planted or left to regenerate. Women were encouraged by ACM facilitators to demonstrate to men their ability to manage tree planting as well as using the benefits for home development. 
With the above facilitation from the ACM team, some men allowed women to plant trees on their farmland (Table 5.3). Women were allocated pieces of land by their husbands and were allowed to decide what tree species to plant. Across all sites, nearly 30\% of women's user group members planted Ficus species, a "forbidden" tree species, as noted earlier, that symbolized land ownership. Two of these women reported earning income from the sale of bark cloth made from Ficus. Women also planted income-generating trees like Eucalyptus, Pine and Maesopsis spp. Table 5.3 shows the number of trees and species types planted by both men and women through the duration of this project. Overall, 98\% of all group members in the study areas owned trees either on their farms, in the allocated forest reserves or in both areas (110 men and 173 women). The $2 \%$ comprises new members who had not yet gotten an opportunity to plant trees. This ownership of trees by women represents a deviation from widespread cultural norms.

Table 5.3 Number of trees planted by men and women user group members, four years after the facilitation of ACM processes in 2015

\begin{tabular}{|c|c|c|c|c|}
\hline Species & Women & Men & Where women planted & Where men planted \\
\hline Eucalyptus & 6493 & 38,616 & $\begin{array}{l}\text { Mostly in allocated areas in } \\
\text { CFR }\end{array}$ & $\begin{array}{l}\text { Mostly in woodlots on } \\
\text { private land }\end{array}$ \\
\hline Grevillea & 740 & 460 & On boundaries on farmland & As shade trees in coffee \\
\hline Ficus & 190 & 400 & $\begin{array}{l}\text { In agroforestry mixtures on } \\
\text { farmland }\end{array}$ & $\begin{array}{l}\text { In agroforestry mixtures on } \\
\text { farmland }\end{array}$ \\
\hline Maesopsis & 247 & 450 & On privately owned land & $\begin{array}{c}\text { As boundary markers and as } \\
\text { shade trees in coffee }\end{array}$ \\
\hline Fruit trees & 350 & 460 & $\begin{array}{l}\text { Mostly in the compound and } \\
\text { tended seedlings in home } \\
\text { gardens }\end{array}$ & $\begin{array}{l}\text { Compound and elsewhere } \\
\text { on the farm }\end{array}$ \\
\hline Pine & 209 & 534 & $\begin{array}{l}\text { One or two as compound } \\
\text { trees }\end{array}$ & As woodlots on private land \\
\hline Others & 312 & 450 & $\begin{array}{l}\text { As allowed by the owner of } \\
\text { the land }\end{array}$ & As deemed necessary \\
\hline Total & 8,541 & 41,370 & & \\
\hline
\end{tabular}

When young, trees on farmland were mostly managed by women, with men taking over when the trees were mature, while those in woodlots and coffee plantations were mostly managed by men. Trees planted in the CFR were managed by their owners (both men and women). When it came to the marketing of the products, the selling of products from trees on farmland and woodlots was mostly by men while those from the CFR were sold by both men and women owners. We learned that women had decision-making powers on trees grown in the CFR that they owned, and they received all the resulting income.

The difference in the numbers of trees planted by women and men in Table 5.3 was driven by land ownership and access to financial capital. The 
area available for tree planting for women was largely static as they did not have the ability to purchase or sell the land. Women and men members of the group received equal allocations of land in the CFR, which was a quarter of a hectare each. This was used to plant Eucalyptus in order to get quick wood products. The rest of the land was planted with indigenous tree species. The higher numbers of trees planted by men were due to the male youth having gained a keen interest in tree planting - many youths acquired more land through either purchase or from their parents.

A survey conducted in 2013 revealed that out of a sample of 144 group members, about $80 \%$ had planted their priority tree species - of these, $55 \%$ were women. The most popular species was Eucalyptus (for fast generation of poles and firewood) followed by Grevillea (for timber, firewood and its capacity to integrate well with crops). The survey indicated that a total of 18,753 trees had been planted, with a survival rate of $80.6 \%$.

Most of the women participating in the programme claimed to have gained control over benefits from the trees and to have made decisions about the use of incomes from tree sales. With regard to timber, only 49 women (out of 173 respondents to this question) had planted Eucalyptus, some in the CFR and others on their farmlands. As earlier explained, some could not convince their spouses to allocate them land for Eucalyptus planting; others knew that they would not benefit from their efforts even if they planted so they resorted to other tree species. In 2015, four years after implementation of ACM activities, only five women had started harvesting and two claimed to have independently made the decision to harvest and control their income. Three of the five women who had harvested their trees used the poles for constructing poultry housing. Overall, only $10 \%$ of the women reported earning income from selling forest/tree products (e.g., poles, handicrafts and fruits) and controlling the income. By 2020, members of the Mbazzi ACM group reported that about $70 \%$ of the women in the group had sold their trees after reaching maturity. The majority of them had replanted their woodlots. The control of incomes and benefits from trees planted and managed by women and other alternative income-generating activities represent yet another deviation from household practices that had mostly conferred decision making and control rights to men.

With the implementation of ACM activities, some women became more empowered to the extent that they handled large sums of money. This was demonstrated by the following statement by a woman from the Mbazzi group:

I am not educated. Previously, I was shy and could not say anything openly in a meeting but now I also talk in meetings and some of my ideas are taken seriously. In addition, I had never handled even Ugandan Shillings 100,000 [USD1 $=3,500$ Ug. Shs.] as my own, but now I get even a million shillings. I have an asset of 200 Eucalyptus trees which I never thought I would own. Now if I have a critical financial need, I can sell some as poles. But I would like to wait for them to grow bigger. After seeing the benefits from the ACM group, my husband who is not an ACM group 
member is now the one who reminds me of the meeting days and time so that I do not miss the meeting.

(Female, 38 years, Mbazzi).

\section{Enhanced women's participation in leadership and decision making}

Exclusion from tree and forestry-related decision-making processes, despite their use and management of forests and trees, and their absence in leadership positions were major concerns raised by women during visioning exercises in the study sites. At the beginning of the project, a few women had been involved in leadership in the local government due to the affirmative action by the government, requiring that $30 \%$ of leaders should be women. The women mostly filled posts as secretaries for forest user groups but were not empowered for decision making. The ACM team adopted the following strategies to encourage women to take on leadership posts in the groups.

- From the start, it was clearly stated that the involvement of men in the project was mainly to support the process of empowering women to participate in decision making. Men who were not in support dropped out.

- There was a deliberate effort to encourage women to actively participate in discussions during monthly meetings and trainings. The ACM team members would deliberately call out individuals to give their input even if they were quiet during meetings.

- On realizing women's capacity gap in leadership, the ACM team organized leadership training courses for the leaders during the implementation. Thus, every woman who accepted a leadership post was given leadership training, twice during the life of the project.

- The women were deliberately encouraged to stand and compete for all leadership posts both in the group and in the local government.

- They were also taken for exposure visits to see and learn from other successful groups with women in leadership positions.

- Special rewards (such as recognition, taking visitors to their homes, taking them to workshops) encouraged them to keep participating in leadership positions.

Various capacity development trainings were offered to group members (including the women leaders) and these included training on PAR. Tailormade trainings to meet felt needs were also offered and these included: how to collaborate, manage and work together as a group; community forest management rules and regulations; tree nursery management; grafting; apiary management; fish farming; look and learn tours; and leadership. All these trainings helped to boost the confidence of all forest user group members, especially the women, and equip them with the skills they needed to deal with the challenges they faced. Leadership training provided women leaders with knowledge, communication skills and confidence. Similarly, men 
who participated in the leadership training were equipped with the same skills and in addition they were able to recognize the need to make room for women to get involved in leadership. This further enhanced women leaders' confidence and capability to lead and guide the groups effectively. Training in gender concepts and applications for both men and women also provided opportunities for open discussion of underlying gender norms and values and the usefulness (or not) in the context of forest management and broader development.

Prior to implementing ACM, the two existing user groups each had one woman among nine men on the executive committees. One year after the introduction of ACM and the formation of four more forest user groups, more women were elected to leadership positions on these committees. By 2012, a total of 24 women were now part of the executive committees in the six forest user groups. By 2016, the number of women executive committee members had risen to 36. In 2016, three out of six groups were chaired by women, five women were vice-chairpersons, six were treasurers, one was a secretary and ten were committee members. The remaining 11 were executives in the village bank committees. Executive committees had the responsibility of mobilizing group members to implement joint activities, with each member responsible for a particular activity, such as documentation, treasury, tree nursery, beekeeping, information and gender and HIV activities. The chairperson heads the executive committee and represents members at different forums. She/he was supposed to reach out and communicate with outsiders on matters concerning the group. All the groups have women treasurers because women were usually more trusted locally with money than men. There was only one woman in the position of secretary because generally women had lower educational levels. Table 5.4 summarizes the distribution of leadership positions between women and men in the groups.

Electing women to leadership positions was an important step towards involving them in user group decision making, setting agendas and ensuring

Table 5.4 Leadership in ACM groups in 2016

\begin{tabular}{lccll}
\hline Group & $\begin{array}{c}\text { Total no. of executive } \\
\text { committee members }\end{array}$ & Men & Women & Chairperson \\
\hline Mbazzi user group & 9 & 4 & 5 & Woman \\
Mbazzi village bank & 8 & 3 & 5 & Woman \\
Nkinga user group & 8 & 6 & 2 & Man \\
Nkinga village bank & 7 & 2 & 5 & Man \\
Kajoki user group & 7 & 3 & 4 & Woman \\
Kizira user group & 7 & 4 & 3 & Man \\
Kagologolo user group & 7 & 4 & 3 & Man \\
Kagologolo village bank & 7 & 2 & 5 & Man \\
Bukeeri user group & 7 & 3 & 4 & Woman \\
Total & $\mathbf{6 7}$ & $\mathbf{3 1}$ & $\mathbf{3 6}$ & \\
\hline
\end{tabular}


that women's interests were reflected in forest use and management decisions. The larger the number of women on the executive committee, the greater the likelihood of women participating effectively in governing forests (Agarwal 2010).

Follow-up on the groups revealed that many women who were empowered during the ACM activities had continued to hold leadership positions within the projects and some even went beyond project activities to represent their communities in decision making for several years after the project ended, showing the sustainability of the outcomes realized by the project (Table 5.5).

Table 5.5 Women's leadership roles in ACM groups in 2020

\begin{tabular}{|c|c|c|}
\hline District & Group & Leadership situation \\
\hline Masaka & Bukeeri village & $\begin{array}{l}\text { Empowered women still in group leadership trying } \\
\text { to steer the limping group and find alternative } \\
\text { support (not yet realized). }\end{array}$ \\
\hline Butambala & $\begin{array}{l}\text { Nkinga village } \\
\text { Twekembe } \\
\text { Environmental } \\
\text { Group (NTEGO) }\end{array}$ & $\begin{array}{l}\text { Women still hold leadership positions. Also because } \\
\text { of their empowerment, many women in forest } \\
\text { user groups continue to be nominated to represent } \\
\text { their constituencies on various fora. }\end{array}$ \\
\hline $\begin{array}{l}\text { Rakai } \\
\text { District }\end{array}$ & $\begin{array}{l}\text { Kizira Village Bataka } \\
\text { Twekembe farmers } \\
\text { group }\end{array}$ & $\begin{array}{l}\text { Group leader is a male youth and women still hold } \\
\text { leadership posts as treasurer, secretary for defence } \\
\text { and secretary for information. }\end{array}$ \\
\hline $\begin{array}{l}\text { Rakai } \\
\text { District }\end{array}$ & $\begin{array}{l}\text { Kajoki village } \\
\text { Kajoki farmers group }\end{array}$ & The chairperson is a woman. \\
\hline $\begin{array}{l}\text { Mpigi } \\
\text { District }\end{array}$ & $\begin{array}{l}\text { Mbazzi village Mbazzi } \\
\text { Farmers Association }\end{array}$ & $\begin{array}{l}\text { The group separated into two groups after some } \\
\text { leadership misunderstandings - the old leadership } \\
\text { refused to hand over instruments of power and } \\
\text { this caused the separation of members into two } \\
\text { groups. One of the groups has } 26 \text { members and } \\
\text { is led by a man, another has } 14 \text { members led by a } \\
\text { woman. }\end{array}$ \\
\hline
\end{tabular}

Improved confidence of women members in leadership and decision making

Poor attendance at meetings and general lack of confidence to speak up and express their interests and preferences during meetings were other concerns raised by women in the visioning exercises. Leadership training and facilitation by the ACM team helped increase women members' confidence. In the initial stages of ACM interventions, the elected women leaders lacked confidence and delegated most of their work to the men on the executive committees. After the leadership training and with continuous encouragement from the ACM facilitators, unnecessary delegation stopped and the women leaders also began to approach necessary offices in person or through telephone calls. 
To assess change in women's confidence in contributing to discussions during group meetings, the number of contributions by women during meetings were recorded for 23 community activities for the six user groups. The average contribution to discussions per activity was 23 times for men and 20 times for women (this information covers the second phase of implementation as women rarely contributed during the first phase). Before ACM, women rarely spoke during the meetings. After the implementation of ACM activities, women have sometimes contributed more than men on a subject matter of interest to them, such as discussions about herbal medicine and handicraft raw materials.

In addition, there was a noticeable increase in attendance at meetings by women. Average attendance per monthly meeting, during the second phase, was nine for men and 14 for women out of 47 recorded meetings. A total of 105 monthly meetings (58 meetings during the first phase and 47 meetings during the second phase) at community level were conducted through the course of the project. Each monthly meeting involved an average of 13 women and 11 men in each user group. For all groups, attendance was always best on village savings meeting days for both men and women since there was an incentive to attend and a penalty for not attending.

Overall, women showed more commitment towards group activities and were also becoming more open and confident. A case in point demonstrating the gained confidence is where 18 women vied for village-level political leadership positions during the national elections of 2016; compared with only two who had attempted to do so in the past. One woman attributed her decision to stand for political leadership to the fact that she had gained enough experience of leadership in the ACM group; she was in charge of nursery operations where she was required to mobilize and manage both men and women for work. Another woman group member has been chosen as a chief in the Buganda Kingdom, a cultural institution, after demonstrating her leadership skills.

\section{Performance of forest user groups using ACM}

Implementation of ACM resulted in several positive developments that have been sustained by four of the six groups involved in the study. These results are discussed separately below.

\section{Improved formalization of forest user groups}

Prior to the start of the ACM facilitation, four out of six forest user groups were operating informally without registration. By the end of the first phase of ACM facilitation, all six communities had formally registered. Registration for all the groups was renewed in 2016. Most forest user groups in the region operated informally mainly because of the tedious registration process. Through ACM, groups acquired the confidence, skills and contacts with stakeholders who helped them to negotiate and register their groups as required by Community Based Organizations' (CBO) regulations. 
Using ACM facilitators, all six groups developed constitutions, which stipulated the group objectives, election of leaders, duration and terms of leaders, membership requirements, benefits and privileges of membership, penalties for infractions, conditions for exit and terms and conditions for disbanding the group. Further, with the help of the ACM facilitators, the groups crafted regulations to govern their activities.

Legal recognition of the user groups created new opportunities not available to informal groups. For example, the groups were able to obtain funding from the central and local governments in support of income-generating activities and training in improved farming practices. One group received widespread recognition as a national model of good practice in reforestation using indigenous tree species.

\section{Improved participation in CFM activities}

Community participation in CFM substantially increased over the course of the ACM intervention. Prior to ACM, people were not regularly participating in CFM activities. They were concerned about limited involvement in decision making in forest-related issues, for example, the leasing of CFR land to outsiders (non-community members) under the NFA's reforestation programme. Through ACM facilitation and support, two groups formalized CFM partnerships with the NFA. They were subsequently allocated 75 ha of degraded forest reserve land for replanting on a 35-year lease basis (MBAFA from Mbazzi was allocated 50 ha and NTEGO from Nkinga village, 25 ha). The MBAFA members decided to allocate 0.25 ha to each member for individual tree planting. The rest of the land was left for indigenous tree species, which were either planted or left to regenerate from stumps. This part was owned and managed as a group. Under this programme, both men and women in the two groups own the trees they plant within the time frame of the lease.

\section{Improved relationship between local communities and other stakeholders}

The relationship between NFA officials and community members living around the CFRs in the study sites has improved substantially compared with what it was before ACM. NFA, as the official manager of the CFRs, has all the power to allow or refuse use of the forest. Regular interactions between NFA and the communities is important in order to access allowable CFR products. NFA interactions were more frequent with the four groups neighbouring the CFR. The reserves neighbouring the remaining two groups were completely degraded, which minimized the perceived need for interactions between these communities and the NFA. Prior to ACM, there was a lot of mistrust: communities were illegally harvesting forest products while the NFA was viciously enforcing the forest laws and regulations. Community members used to complain about "strange people" (outsiders) who came with permits and harvested from the forest, which made locals think that the forest 
only benefited outsiders. Another complaint was failure by NFA officials to discuss matters of forest management amicably with the communities. The ACM process involved NFA officials in community-level planning, implementation and monitoring and created a platform that brought officials in closer contact with communities on a regular basis, allowing a discussion of community grievances, NFA limitations and the building of joint/common objectives.

Besides strengthening linkages and relationships between community groups and the NFA, the ACM team reached out to other actors, including NGOs, the private sector and religious organizations. Some of these actors, through their involvement in the ACM process, have provided support to the groups to enhance forest and tree management. For example, several organizations supported communities through training in leadership, provision of tree seedlings, tree grafting, purchase of solar systems, improved firewood cook stoves, installation of village internet, permaculture, improved agricultural practices in support of land intensification and value addition to their produce. Support by NGOs and the government to these groups continued even after the project ended (see Table 5.6).

\section{Improving conflict resolution}

Conflict management was one of the topics handled during leadership training, and as a result, group leaders used the acquired skills to develop various methods of resolving internal conflicts to prevent escalation to a level that would disrupt group activities. Examples of common within-group conflicts included failure by leaders to call for regular meetings or misuse of the group's income from the sale of tree seedlings. Such conflicts have been resolved through discussions, and in some cases, the leaders resigned but still remained members of the forest user groups. Other causes of conflict have included: poor loan repayment; misuse of nursery equipment; destruction of tree seedlings; lack of trust and transparency; poor leadership; poor benefit sharing; lack of respect; and gossiping. Groups have been able to resolve such issues without disrupting their activities or disintegrating. Similarly, misunderstandings between the NFA and some group members over land allocation in the CFR were resolved amicably.

\section{Investment in income-generating activities}

At the start of the project, communities expressed concern over forest degradation. One of the reasons given for the continuous degradation of forests was the lack of alternative income-generating activities. Through the project's ACM intervention, participants identified income-generating projects that they felt would help meet their needs for basic goods and services and thus lower their level of dependence on the forests. These included village banking, the promotion of improved cook stoves, water harvesting facilities and 


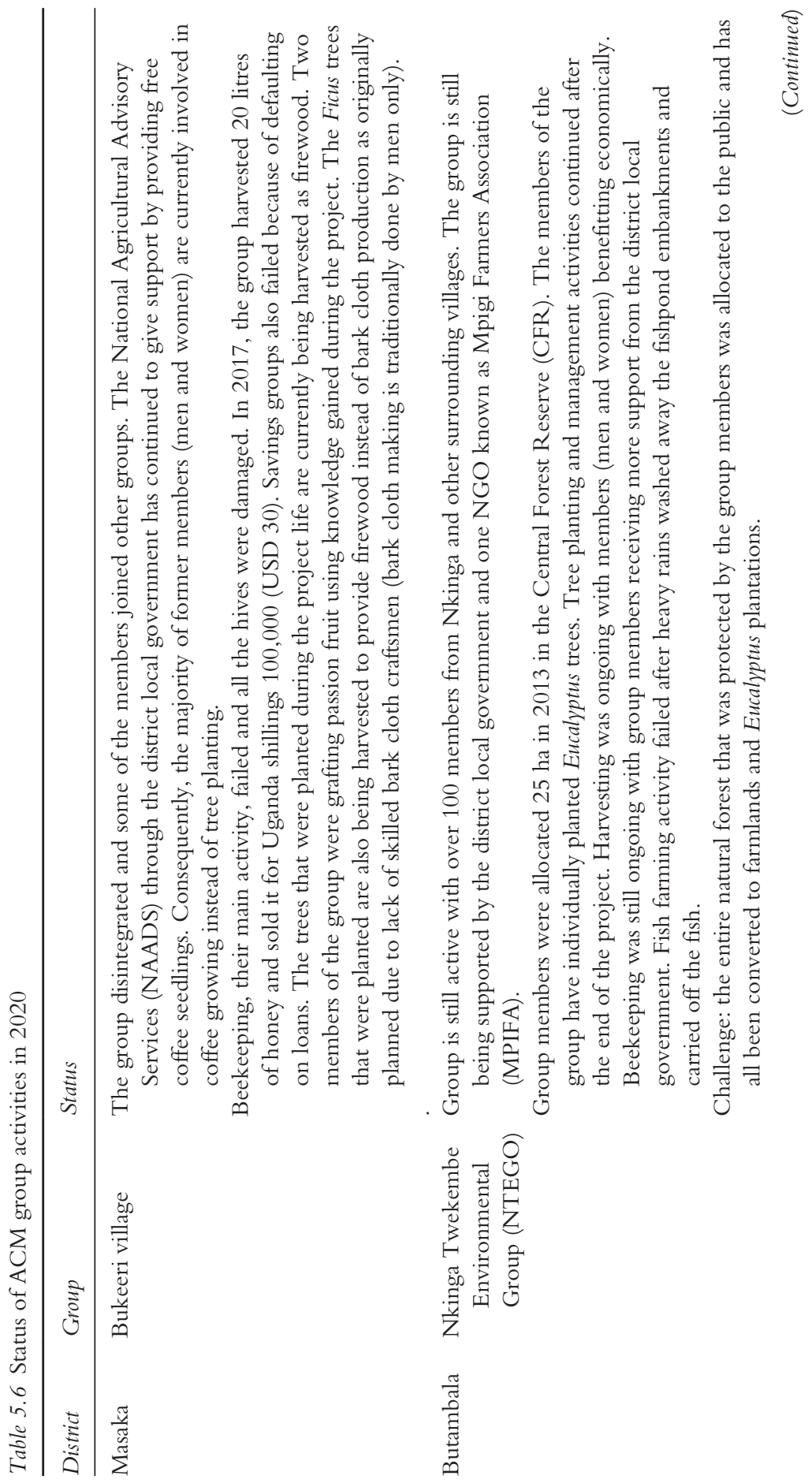




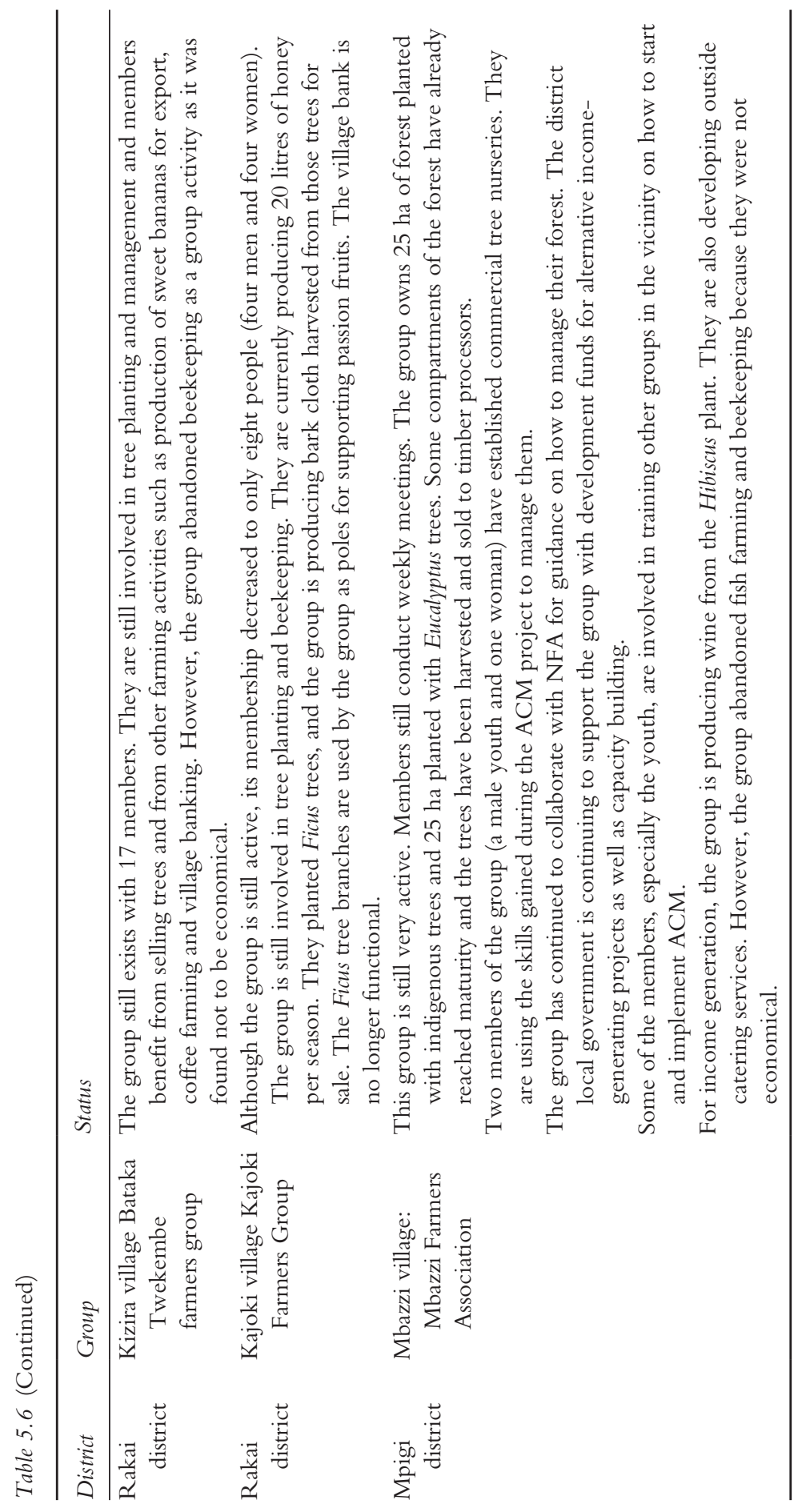


raising tree seedlings. Exchange visits among the ACM groups exposed them to opportunities availed through village banking programmes, which allowed them to pool resources. All six groups started village banking projects in which women demonstrated their leadership capabilities as well. Through village banks, women were able to obtain loans guaranteed by their fellow members that they used to run other income-generating activities, which served to reduce pressures on the forests and for livelihood improvement. The majority of women had previously never saved money and were not able to get loans, but after the implementation of ACM activities, they were able to accumulate some savings. Two village banks with 76 members had accumulated capital of up to USD 21,000 after three years of implementation of ACM activities. The village banks attracted additional members into the ACM groups and the anticipation of monetary benefits helped spur a greater commitment of members to group activities. Other non-ACM village banking groups also developed as a result of this initiative.

One woman from Mbazzi summed up the impact of the ACM activities in the community by saying

When I came to Mbazzi village, firewood selling, locally known as kabajjo, was the main business venture. Men and women would cut trees from the forest and turn them into firewood which was sold to people from the nearby city. This was done until the forest was completely degraded and the area turned into maize gardens. However, with the coming of ACM, all this has been reversed. The forest has been restored and there are alternative income-generating projects that are not forest based.

An early 2020 follow-up of ACM activities revealed that, although some activities had stopped, many were still ongoing, years after the project ended, showing their sustainability (Table 5.6). In some cases, for example, Mbazzi, the group was still very active and had moved further in adding value to their products, resulting in the realization of more income. On the other hand, the Bukeeri group is less active and members have joined other groups. However, the positive impacts of some of the activities that were carried out in the early days of the project are being realized. For example, the Ficus natalensis trees that were planted are now being harvested for their various products such as bark cloth, fodder and firewood from the branches. No information was available from the Kagologolo group as leadership had been disbanded.

\section{Concluding remarks}

After six years of ACM implementation in six field sites, involving 110 men and 173 women, the results show remarkable improvements with regard to women's empowerment and decision-making as demonstrated by the increased 
number of women in leadership positions and hence participating in decision making, attending community meetings, owning woodlots, venturing into public and political spaces and planting trees.

These gender-transformative outcomes can be attributed to several factors. The most fundamental is the creation of safe, non-intimidating spaces for women to speak up and share their opinions in the presence of men in mixed-gender forest user groups. Working with women alongside their husbands and other men helped both groups to benefit, providing a safeguard against possible backlash against women, as has occurred elsewhere. The process importantly brought men more squarely into the centre of gender equality initiatives, securing their buy-in and laying the foundation for a sustainable transformation of gender relations. Additional factors include the following: exposure through exchange programmes; leadership training (for both men and women); and continued support for forest user groups from collaborating partners. The ACM approach in this study provided a promising pathway for achieving meaningful gender inclusion in forestry access, management, decision-making and benefit sharing. This in turn resulted in broader positive livelihoods and sustainable forest management outcomes.

In terms of lessons that can be learned from this study, ACM seems to provide a promising pathway for achieving meaningful gender inclusion in forestry (a male-dominated arena) and tenure (gender-biased customary norms) but also for achieving joint livelihoods and resource sustainability outcomes. Importantly, men appear to be critical in strengthening women's rights and overall empowerment and mixed groups of men and women can be useful pathways for this, particularly after a phase of women-only groups. This study has also demonstrated that even though rights may be granted by statute, they are not automatically exercised due to cultural norms, lack of information and inadequate budgets to implement them. Additionally, in the absence of effective implementation of gender-equitable statutes, negotiation and facilitation by trusted intermediaries can begin to strengthen women's rights and participation. Indeed, exercising rights and deriving value/benefit are two sides of the same coin; and although tenure rights matter in and of themselves, to most forest adjacent communities, they are a pathway to securing their livelihoods. Benefits derived from exercising rights are also critical incentives for sustainable forest use and management. Also, collective action/organization and linkages to external actors are key to communities being able to exercise rights, secure them and derive value from their rights. Customary laws that are usually regarded as "sticky" were possible to change, thereby offering the potential for enhancing gender equity over a short period of time. Moreover, ACM demonstrated that joint outcomes of resource and livelihoods sustainability (and gender inclusion) are possible and not always necessarily at cross-purposes, and supporting on-farm, income-generating projects can have benefits for forests. Finally, cross-community visits and exchanges are a valuable source of learning and diffusion of good practices that deserve sustained investment and/or integration into sector projects and programmes. 
As a way forward, the scaling up and out of the ACM approach to policymakers and development practitioners in other parts of the country was critical. This project began this process through training practitioners and policy-makers in an additional three districts, however, this was insufficient, and much more needed to be done in terms of dissemination and supporting practice. Fortunately, government officials in the forestry sector noted the usefulness of the approach and with further support pledged to build elements of ACM into their projects and programmes as part of a broad process of institutionalizing the approach.

\section{Acknowledgements}

We thank the Austrian Development Agency (ADA) for funding our activities. We also acknowledge the stakeholders with whom the project collaborated, especially the National Forestry Authority, District Forest Services (DFS), VI Agroforestry, Tree Talk, Narozari Catholic Mission, Rubaga Rotary Club, Mpigi District Farmers Association (MPIFA), Mr Sekyeewa - a tree farmer - and Kigazi Tukwatirewamu Collaborative Forestry Management group, among others. Finally, we wish to express our heartfelt gratitude to all the user group members (men and women) in the six sites who worked tirelessly to implement ACM.

\section{Notes}

1 The chapter is dedicated to the memory of the late Dr Esther Mwangi, whose dedication and commitment to improving the wellbeing of women in forestry was unsurpassed.

2 In the central region, much of the land is mailo (freehold by individuals) and Kibanja (tenant), both owned by individuals. The individual has all rights, and the state or clan elders will come in to arbitrate in cases of violation of those rights.

3 In this part of Uganda, tenure rights do overlap. The landlord has the land title from the government, but on this land, there may be other occupants, sometimes referred to as tenants. They have rights as long as they pay rent. But if one stays on this land for more than 12 years, the right to the land is assured by the state as well. To remove him or her from the land, the owner has to compensate him or her for the developments on the land. The tenant can transfer his or her rights to other people through sale or inheritance following customary norms. There are other rules normally set by the state in case of customary disagreements.

4 The ACM team was comprised of several members from various institutions including the university, non-governmental organizations and the local community. The members had various skills and expertise and played specific roles in the implementation of ACM activities. Expertise of team members included agroforestry, forestry and forestry governance, environment conservation, participatory methods, gender mainstreaming, agricultural extension, natural resources management and leadership development. Local community members who were part of the team comprised a gender-balanced team of two, one man and one woman selected by the local communities using the following criteria: i) local residence; ii) literate and fluent in the local language; iii) Some knowledge of English; and iv) willing to receive training in communication and documentation. 
5 External facilitators were critical during the beginning of the PAR process as local community members were doing this for the first time. Because these two facilitators were women, they could spend a lot of time working with women and sometimes visiting them individually to check on their progress.

6 Taungya is a method of planting forest trees in combination with food crops - usually introduced to restore tree cover. Farmers are allowed to cultivate crops for the first few years as the seedlings get established on degraded forest land.

7 There was a hiatus in implementation of the project when a new contract was being negotiated and approved with the donor-ADA.

8 These were the main indicators selected for monitoring the progress of ACM implementation.

9 These included their exclusion from tree and forestry-related decisions despite their use and management of forests and trees, their absence in leadership positions, their poor attendance at meetings and their general lack of confidence to speak up and express their interests and preferences during meetings. In addition, gender biases and cultural norms prevented them from planting trees, a traditional way of marking land ownership.Various studies have also shown that lack of policy instruments to support gender implementation at all governance levels, low literacy levels, insecure tenure to land and tree resources and inequitable benefit sharing are some of the factors impeding women from participating in forest management (Banana et al. 2012; Mukasa et al. 2012).

10 This species had been selected based on community preferences. These derived from ease and speed of planting, speedy growth of useful products, easy pollarding, and beneficial integration with other crops.

\section{References}

Agarwal, Bina. 2010. Gender and Green Governance: The Political Economy of Women's Presence Within and Beyond Community Forestry. Oxford: Oxford University Press. doi:10.1093/ acprof:oso/9780199569687.001.0001.

Apgar, M., and B. Douthwaite. 2013. Participatory Action Research in the CGIAR Research Program on Aquatic Agricultural Systems. Program Brief: AAS-2013-27. Penang, Malaysia. http://fac.dev. ids.ac.uk/farmerfirst/files/Farmer_First_Revisited_Post_Workshop_Summary_Final.pdf.

Arora-Jonsson, S., S. Agarwal, C.J.P. Colfer, S. Keen, P. Kurian, and A.M. Larson. 2020. "SDG5: Gender Equality: A Precondition for Sustainable Forestry." In Sustainable Development Goals: Their Impacts on Forests and People, edited by P. Katila, C.J.P. Colfer, W. de Jong, G. Galloway, P. Pacheco and G. Winkel, pp. 146-177. Cambridge: Cambridge University Press.

Banana, A.Y., and W. Gombya Ssembajjwe. 2000. "Successful Forest Management: The Importance of Security of Tenure and Rule Enforcement in Ugandan Forests." In People and Forests: Communities, Institutions, and Governance, edited by C. Gibson, M. Mackean, and E. Ostrom, 87-98. Cambridge: MIT Press.

Banana, A.Y., M. Buyinza, E. Luoga, and P. Ongugo. 2010. "Emerging Local Economic and Social Dynamics Shaping East African Forest Landscapes." In Forests and Society: Responding to Global Drivers of Change, edited by M. Guido, P. Katila, R.I. Alfaro, M. Kanninen, M. Labovikov, and J. Varjo. IUFRO World Series 25. Vienna, Austria: Global Network for Forest Science Cooperation.

Banana, A.Y., M. Bukenya, E. Arinaitwe, B. Birabwa, and S. Sekindi. 2012. "Gender, Tenure and Community Forests in Uganda." CIFOR Working Paper 87. Bogor, Indonesia.

Belcher, Brian, and Kathrin Schreckenberg. 2007. "Commercialisation of Non-Timber Forest Products: A Reality Check." Development Policy Review 25 (3): 355-377. doi:10.1111/j.1467-7679.2007.00374.x. 
CIFOR. 2004. "Forests for People and the Environment." In CIFOR Annual Report. Bogor, Indonesia: CIFOR. http://www.cifor.org/publications/pdf-files/A reports/AR 2004.pdf. P31.

CIFOR. 2008. Adaptive Collaborative Management Can Help Us Cope with Climate Change. CIFOR Infobrief 13. Bogor, Indonesia. http://www.cifor.org/publications/pdf_files/I nfobrief/013-infobrief.pdf.

Colfer, C.J.P. 2005a. The Complex Forest: Communities, Uncertainty, and Adaptive Collaborative Management. Washington, DC: Resources for the Future. doi:10.4324/9781936331727.

Colfer. C.J.P. 2005b. The Equitable Forest: Diversity, Community, and Resource Management. Washington, DC: Resources for the Future. doi:10.4324/9781936331673.

Dangol, Sushma. 2005. "Participation and Decision Making in Nepal." In The Equitable Forest: Diversity, Community and Natural Resources, edited by C. J. P Colfer, 54-71. Washington, DC: Resources for the Future.

Diaw, M. C., T. Aseh, and R. Prabhu. 2009. In Search of Common Ground: Adaptive Collaborative Management in Cameroon. Bogor, Indonesia: CIFOR. doi:10.17528/cifor/002633.

Erbaugh, J.T., N. Pradhan, J. Adams, et al. 2020. "Global Forest Restoration and the Importance of Prioritizing Local Communities." Nature Ecology and Evolution 4: 14721476. https://doi.org/10.1038/s41559-020-01282-2

Evans, K., A. Larson, E. Mwangi, P. Cronkleton, T. Maravanyika, X. Hernandez, P. Muller, et al. 2014. Field Guide to Adaptive Collaborative Management and Improving Women's Participation. Bogor, Indonesia: CIFOR.

FAO. 2003. Gender: Key to Sustainability and Food Security Gender and Development. Plan of Action: Gender and Development. FAO Corporate Document Repository. ftp://ftp.fao.o $\mathrm{rg} /$ docrep/fao/005/y3969e/y3969e00.pdf.

FAO. 2005. "Gender and Forestry, Overview." In Forestry and Livelihoods: Changes and Trends. siteresources.worldbank.org/.../Resources/Module15.pdf.

FAO. 2006. "Non-Wood Forest Product Community-Based Enterprise Development: A Way for Livelihood Improvement in Lao People's Democratic Republic." Forestry. Working Paper Series No. 16. Rome, Italy. http://www.fao.org/forestry/static/data/ enterprises/Laos-casestudy.pdf.

German, L.A., A.M. Tiani, A. Daoudi, T. Mutimukuru-Maravanyika, E. Chuma, C. Jum, N. Nemarundwe, E. Ontita, and G. Yitamben. 2012. The Application of Participatory Action Research to Climate Change Adaptation in Africa: A Reference Guide. Bogor: IDRC and CIFOR. http://r4d.dfid.gov.uk/Output/189934/Default.aspx.

Gondo, Tendayi. 2011. "Adaptive Co-Management of Natural Resources: A Solution or Problem.” Journal of Human Ecology 33 (2): 119-131. www.earthsystemgovernance.org/ ac2009/papers/AC2009-0367.pdf.

IUCN. 2011. Gender Key to Sustainable Forests. IUCN Media Relations. www.iucn.org/me dia/media_statements/?8714/Gender-key-to-sustainable-forests.

Lewis, P. 2012. The Fight for Women's Land Rights. Think Africa Press. GPF. www.global policy.org/global-taxes/52091-uganda-the-fight-for-womenns-land-rights-html.

Mai, Y. H., E. Mwangi, and M. Wan. 2011. "Gender Analysis in Forestry Research: Looking Back and Thinking Ahead." International Forestry Review 13 (2): 245-258. doi:10.17528/cifor/003789.

Mandondo, A, R. Prabhu, and F. Matose. 2008. Coping amidst Chaos: Studies on Adaptive Collaborative Management from Zimbabwe. Bogor, Indonesia: CIFOR. doi:10.17528/ cifor/002558.

Mcdougall, Cynthia, Hemant Ojha, Mani Ram Banjade, Bishnu Hari Pandit, Tara Bhattarai, Manik Maharjan, and Sushila Rana. 2010. Forests of Learning: Experiences from Research 
on an Adaptive Collaborative Approach to Community Forestry in Nepal. Bogor, Indonesia: CIFOR.

Mukasa, Concepta, Alice Tibazalika, Alice Mango, and Harriet Nabirye Muloki. 2012. "Gender and Forestry in Uganda: Policy, Legal and Institutional Frameworks." CIFOR Working Paper 89. Bogor, Indonesia. http://www.cabdirect.org/abstracts/20143006941 .html;jsessionid=401063D0AB8BE9F8C3019A17A602583E.

Mutimukuru-Maravanyika, T. 2010. "Can We Learn Our Way to Sustainable Management? Adaptive Collaborative Management in Mafungautsi State Forest, Zimbabwe." Wageningen University and Research Centre. http://edepot.wur.nl $/ 136242$.

Mutimukuru-Maravanyika, T., Ravi Prabhu, Frank Matose, Richard Nyirenda, and Witness Kozanayi. 2008. "Facilitating Adaptive Collaborative Management in Forested Landscapes: The Mafungautsi Case Study." In Coping Amidst Chaos: Studies of Adaptive Collaborative Management from Zimbabwe, edited by A Mandondo, R. Prabhu, and F. Matose, 15-64. Bogor, Indonesia: CIFOR.

Mutimukuru-Maravanyika, T., D. Mills, C. Asare, and G. A. Ameyaw. 2017. "Enhancing Women's Participation in Decision-Making in Artisanal Fisheries in the Anlo Beach Fishing Community, Ghana." Water Resources and Rural Development 10: 58-75. doi:10.1016/j.wrr.2016.04.001.

Mwangi, Esther, Ruth Meinzen-Dick, and Yan Sun. 2011. "Gender and Sustainable Forest Management in East Africa and Latin America." Ecology and Society 16 (1): 17. doi:10.5751/ES-03873-160117.

Namaalwa, J, W. Gombya-Ssembajjwe, and O Hofstad. 2001. "The Profitability of Deforestation in Uganda." International Forestry Review 3 (4): 299-306.

Pandolfelli, L., R. Meinzen-Dick, and S. Dohrn. 2007. "Gender and Collective Action: A Conceptual Framework for Analysis." CAPRI Working Paper 64. Washington, DC: Collective Action and Property Rights. doi:10.2499/capriwp64.

Plummer, Ryan, and Derek R. Armitage. 2007. "Charting the New Territory of Adaptive Co-Management: A Delphi Study." Ecology and Society 12 (2): 10. doi:10.5751/ ES-02091-120210.

Uganda Bureau of Statistics. 2017. "National Population and Housing Census 2014, Final Results Report." www.ubos.org/2016/03/24/census-2014-final -results/.

Women's Environment and Development Organization. 2012. "Forests and Gender." www.wedo.org.

World Bank. 2002. Sustaining Forests: A Development Strategy. Washington, DC. http://sit eresources.worldbank.org/INTFORESTS/Resources/Sustaining Forests.pdf. 


\section{Introduction to Chapter 6}

This chapter focuses on the importance of providing training - training of local participants but also the external facilitators who will work with the community - in how to conduct ACM. The authors also argue that capacity building should be seen as part of the ACM process, and training should reflect the ACM approach itself. The chapter acknowledges the degree to which ACM approaches fundamentally differ from much of the training many fieldworkers have received for more conventional field research or extension, and it differs from villagers' more typical experience with outside "developers" or conservationists. It also builds on insights (and gaps) highlighted in Chapters 2 and 3 , as well as the observations and extensive experience of Cronkleton, Evans and Larson.

These authors present three cases from Bolivia, Nicaragua and Ghana in chronological sequence, thereby showing methodological developments in ACM approaches as well as variation necessitated by geographical and contextual difference: They emphasize the importance of reflexivity in learning to help facilitators and community participants to be more conscious of how they learn experientially and the advantages of learning together.

The chapter concludes with specific suggestions for enhancing ACM processes, including encouraging would-be practitioners to "jump into the ACM process and embrace an ethos of experimentation, trial-and-error and learningby-doing." Real understanding tends to come as practitioners implement the iterations of "the worm" (Figure 5.1) and the learning that results. 


\title{
6 Capacity building for ACM \\ Lessons learned from training in distinct contexts
}

\author{
Peter Cronkleton, Kristen Evans, \\ and Anne Larson
}

\section{Introduction}

A significant challenge to using the adaptive collaborative management (ACM) approach is building the capacity of participants so that they have the skills, awareness, and confidence to understand and implement ACM methods to address local priorities. Not only is this true for community participants, but it is also true for the facilitators, researchers, and donors who are involved in the process. This chapter examines our insights from three cases from Bolivia, Nicaragua, and Ghana in which we introduced ACM methods in distinct contexts to assist local stakeholders in addressing forest management challenges. In each case, an initial capacity-building phase was necessary to facilitate ACM processes.

Just as social learning lies at the core of ACM (Colfer 2005a; Lee 1993; Maarleveld and Dabgbégnon 1999), training should be approached through an ACM lens to generate social learning processes, placing experimentation and reflexivity at the core of such capacity-building programmes. Social learning is central to adaptive collaboration (Berkes 2009). It is a process of "iterative reflection" where experiences, ideas, and environments are shared with others (Keen, Brown, and Dyball 2005). Iterative reflection is often conceptualized as cycles (Kolb 2014), or loops (Colfer 2005a; Kolb, Osland, and Rubin 1995), where conscious phases of group reflection are interspersed within information collection and analysis (Colfer 2005a). Applying ACM in training creates a self-reinforcing cycle that allows participants to reflect on their learning so that they can better facilitate learning with others. It also allows trainers to gauge the effectiveness of capacity building in imparting information and new understanding.

While conscious reflection on learning is foundational to ACM, communicating this basic message to both communities and facilitators, and demonstrating ways to do it, requires creativity. We found that building capacity in ACM often requires flipping conventional ideas about what it means to learn and relearning what it means to teach. One of our favourite examples from our trainings illustrates this point: as children, did we learn to ride a bicycle by going to a classroom, listening to a teacher present concepts on a flipchart 
and then passing an exam? Of course not! We watched other children, then gave it a try ourselves (probably with other children's help), and undoubtedly fell down a few times until we got it right. In this situation, the primary actor is not a teacher, but the learner, who drives the learning process through her own interest and determination with the help of the group. This simple story of learning by doing shows how we naturally embrace experimentation and trial-and-error; in turn, we can channel our innate curiosity through the ACM process to learn together systematically. These experimentation processes are just as important to support during the ACM training process. In other words, just like riding a bicycle, the best way to learn to do ACM is to jump in and try. And that can be scary, especially for adults who are trained to avoid failure.

Our capacity-building efforts focused on making trainees conscious of how they learned so that they could facilitate learning with others. This involved creating learning loops that are structured to occur in short cycles, as in the course of a day or week, or over longer cycles, such as during a harvest. In our examples, we illustrate how both short and long cycles operate, and how nested learning loops can create more fundamental shifts in knowledge and understanding. Ensuring that these concepts were clear to trainees and village participants was key to engagement in these activities. Collaboration can be complicated and time-consuming, and facilitators and donors alike often underestimate the learning required on all sides to adopt collaborative approaches.

ACM is perhaps best conceptualized as an ethos - a way of understanding the world and how we can engage with change. In ACM, the ethos should apply throughout the lifecycle of a project from the initial design, through training of technicians, and engagement with local stakeholders, continuing as the project evolves and practitioners and participants alike learn together. We discuss how our approach to training emerged as experience transformed our thinking of how best to convey an understanding of social learning and experimentation as crucial components of ACM at every step of the process.

\section{Methods}

The three cases were synthesized from the authors' observations as participants in different ACM processes over a 20 -year period. We present the cases in chronological order. The evidence draws from documentation, observations, and reflections created at the time. Documents included publications, training plans, workshop proceedings, project reports, evaluations, and surveys. Observations were recorded by the researchers during the ACM activities. Reflections include those among the researchers as well as regular reflections in the field with ACM teams during and after training events and ACM activities. We use these experiences to distil lessons learned for training both ACM facilitators and community members participating in ACM activities. We present the cases in chronological order to provide a historical perspective and to demonstrate how our understanding evolved as we learned over almost 20 
years. As we learned how to teach others to do ACM, our own perspectives evolved - a process of researcher learning.

The cases are geographically dispersed, involving different constellations of actors and focused on different management issues; however, common themes emerge from these experiences. In the first case, ACM helped Indigenous people in lowland Bolivia to develop novel community institutions for sharing benefits from a forest management initiative. In the second case, ACM facilitated the involvement of Indigenous women in territorial and forest governance in Nicaragua. ${ }^{1}$ In the final case, ACM created conditions for farmers, particularly women, to engage in dialogue about resource degradation in northern Ghana. In all cases, ACM provided a flexible set of tools for addressing diverse management problems; nonetheless, we faced the recurring challenge to provide local actors - both facilitators and participants - with the capacity, insight, and confidence to apply ACM to local priorities. We hope that our experiences provide insights into addressing that challenge, both during the initial ACM implementation phase as well as over the long-term uptake of ACM concepts and practices.

\section{Case study 1: Indigenous community forestry organizations testing benefit distribution mechanisms in Guarayos, Bolivia}

\section{Issue}

The first case focuses on the use of ACM methods to help a Guarayo Indigenous community in Bolivia develop a benefit distribution system as a component of their sustainable forest management plan. In the mid-1990s, Bolivia instituted reforms that devolved communal property and forest rights to Indigenous people. When the ACM work started in 2002, the Guarayo village of Cururú had gained the approval of a forest management plan with assistance from the USAID-funded Bolivian Sustainable Forest Management Project (BOLFOR), and the village was in the process of negotiating their first timber sale. The community expected that commercial timber management would generate needed income, but there was much uncertainty about how it would work. Residents had invested almost two years working on the plan, and there was increasing tension as they waited for the promised economic return from the project. It was crucial to develop a system for distributing benefits from timber sales before payments arrived to ensure that residents understood how it would work and agreed that the rules were fair (see Cronkleton, Keating, and Evans 2007 , for a fuller discussion). Once cash payments were at play, it would be difficult to set the rules. By treating this challenge as a training opportunity, the ACM approach was ideal for building capacity to govern benefit distribution and create consensus around a system that villagers could trust.

\section{Context}

Cururú is located in the Guarayos TCO (the Spanish acronym for Tierra Comunitario de Origen or Indigenous Community Land) located in Bolivia's 
Santa Cruz Department, in a lowland area characterized by broadleaf semihumid Amazonian transitional forest. Guarayos was one of the first TCOs, created in 1996, so villages in the TCO had only recently gained rights over forests on their land (Cronkleton et al. 2009). Cururú residents were interested in using the surrounding forests to generate income opportunities, but to undertake logging activities, policies required the preparation and approval of a sustainable forest management plan and compliance with management regulations, which mostly focused on silvicultural practices, such as minimum cutting diameters and rotational harvest cycles. In 2000, the 26 families of Cururú started developing a management plan for 29,000 hectares of forest with the assistance of BOLFOR. The BOLFOR project helped the village form a community forestry organization (CFO). While the law required the formation of a CFO, the only instructions defining these institutions stated that they should follow "usos y custumbres" (i.e., customary practice). However, CFOs were novel institutions, as Indigenous communities lacked prior experience managing commercial timber operations.

BOLFOR provided technical guidance for Cururú's inventory of the forest management area, as well as a commercial census for the first harvest unit. BOLFOR also provided financial support that paid half the daily wage for each community member participating in the forest brigades gathering information for the inventory and census. The plan was that the Cururú CFO would pay the remainder of the daily wages with proceeds from timber sales. In 2001, the Center for International Forestry Research (CIFOR) was invited to assist BOLFOR with its community forestry programme. CIFOR introduced an ACM approach as part of a strategy to strengthen management institutions at the community scale.

By that time, Cururú's CFO was aspiring to manage a complex, commercial forestry operation. The annual harvest unit covered approximately 1500 ha, each with 4000 to $6000 \mathrm{~m}^{3}$ of commercial timber. The harvests could potentially generate vast sums of money in the context of Guarayos. For example, in 2003, the negotiated sales grossed 60,000 USD. In 2002, BOLFOR helped Cururú negotiate a good price for their timber, however, the terms of sale were for logs delivered to forest log landings (puesto en rodeo) ready to be transported to the sawmill. The community would receive a higher price but also agreed to take on more responsibility. The CFO would have to pay service providers such as skilled sawyers and skidder operators to fell and yard the logs. If they did not set aside money for those operations, the harvest and sales would grind to a halt. The organization also would need to set aside funding to invest in start-up and operating costs for the following year to prepare a logging plan and receive authorization for a second sale. In addition, the CFO's revenue had to cover other expenses - such as maintenance of the forest access road as well as payments for professional services, including a licensed forest engineer to sign timber transportation permits and an accountant to manage payments to service providers and receive payments from timber buyers. Only after setting aside funds for these costs would benefits be allocated to reimburse 
community members, who worked both as administrators and labourers in the CFO.

The CFO's challenge was how to distribute benefits in a way that paid those who worked on the project, benefited the community at large, and sustained project activities into the future. Because it was a communal forest, the law required that benefits from timber sales would go to the community, but the law did not explain the mechanics of how this should take place. To function well, benefit distribution had to happen transparently and generate both trust and accountability among the community members who were managing and receiving the funds. The potential for conflict, misunderstanding, and corruption was rife.

The distribution of timber sale benefits offered a surprisingly complex challenge. As a communal forest, one might think that benefits derived from the forest should be spread equally to all residents; but would that be equitable? Not everyone had invested labour to develop the management plan. Of those who had, some worked many weeks, while others worked only a few days. Some women had spent weeks in the forest working as cooks for the brigades. Others expected to receive benefits through their husbands' payments. However, for that to work, women needed information on how much their husbands were owed, as well as how and when payments would take place (see Cronkleton 2005).

Furthermore, payments from buyers would come in instalments, so benefit distribution would have to take place over time. This meant that individual payments from loggers would not cover all wages the CFO owed its members until weeks or months after the harvest. Payments would have to be made incrementally as the sawmills processed and sold lumber, since, in general, cash flow was a critical bottleneck across the entire timber value chain. Finally, to overcome these challenges, it was important that community members understood that cash flow would have to be managed to reimburse their labour investments, pay service providers, and set aside capital for the next year.

\section{How we applied ACM}

We looked to ACM as a way to generate a culture of transparent information sharing and learning in an environment where examples of good governance were rare, and where logging historically had been conducted through bribery, conflict, and clientelism. Fortunately, Cururú had a detailed record of labour investment by CFO members: BOLFOR's financial assistance to support the forest inventory and commercial census had been conditional on the submission of timesheets and signed invoices from members to release funds to cover $50 \%$ of wages. These records provided information on who had worked and when, and, importantly, tracked the CFO's debt owed to members who had invested in the forest management plan.

Therefore, prior to payments arriving, we (the ACM team) worked with the CFO members to create a system to visually illustrate the relative debt 
owed to members for the days of labour invested in the project, track payments of wages to members for days worked, and mark the deposit of timber payments from loggers. Importantly, the system also explained the allocation of payments between operating costs and payment of wage debt. This involved creating meaningful visuals as well as carefully prepared paperwork so that members - often with low levels of literacy and numeracy - could verify and hold accountable the process as well as those responsible for the accounts.

The system was designed to adhere to several basic criteria. First, it needed to be transparent so that people understood the process, could see how they would get repaid, and could compare their share to others in the community. Second, the payments must be equitable: when payments were distributed, everyone should get a portion of debt reimbursed, but those who had invested more should receive a larger share. Third, the information had to be accessible, meaning that the accounting had to be simple and visible but maintain accuracy. Finally, to be sustainable, everyone needed to understand that the CFO could not just make payments to members but had to ensure that funds were set aside for forest operations and future activities.

To manage payments, we developed a simple system to visualize the CFO's financial transactions and show members' individual wages as well as the CFO's accounts and payments. The CFO's administrators had piles of receipts and timecards from their reporting to BOLFOR, so, working with the CFO leaders, we tabulated the records and created a large poster depicting all members and the days worked as a bar chart. The chart would be used to illustrate how timber payments were distributed. Funds allocated for reimbursing members would be distributed as a proportion of the total debt (e.g., if a payment was $10 \%$ of the total wage debt, each member was reimbursed $10 \%$ of funds owed, ensuring equitable distribution). Segments of the chart would be coloured in with each payment distributed to members during CFO meetings.

In addition to the large chart held by the CFO leaders, each member would receive a paper receipt accounting for the transaction (i.e., what they were owed in total, what they had received in payment, and how much remained). Community members could individually or in small groups review the materials and the accounts. Those who could not read could get help from family members in a more private small group setting. However, even when simplified, there would be a steep learning curve, and errors or misunderstandings were possible. Relying on trial-and-error could risk conflict once money was at stake. Therefore, to test the system and build capacity, we introduced several different simulation activities.

In the first simulation, we used an "aquarium" (fishbowl) method with a small group of volunteers play-acting while the others sat around the outside observing and then discussing. The volunteers were divided into several groups for their pretend roles: CFO administrators, members who were owed wages, and service providers such as chainsaw and skidder operators. We started with a first timber sale, and the leader had to allocate the money. If the leader paid all wages in full, the service providers could not be paid to harvest more wood, 
so there would be no second sale and no second payment. Alternatively, dividing the funds between wages and service providers meant that, while members would not be paid their wages in full immediately, service providers could harvest timber and there would be a second payment, and then another so everyone would eventually be fully reimbursed. The objective was for people to understand - before money was in hand - that payments would have to be distributed to both members and service providers to sustain the activities, and that members would not receive their full payments, at least not immediately. After this exercise, we also adapted the system to create colour-coded individual statements and a notebook with receipts to match it up to each person's account and wages to make the system easier to follow.

The process worked. When the first payment was deposited, the CFO leaders convened a community meeting to distribute payments as they had practised. Afterwards, members stayed and talked in small groups, comparing and discussing how it had worked. Because of the practice, they understood that it would take multiple payments to be fully reimbursed. Sure enough, after three or four payments over the following months, members were fully paid. The $\mathrm{CFO}$ was able to use a portion of the funds to finance a commercial census for a second timber harvest, continuing the practice of paying only half wages prior to the timber sale. The process also catalysed more interest among members in monitoring the CFO's activities. For example, members requested that the CFO leaders report regularly on log volumes delivered to the landing. The CFO kept detailed records of log volumes delivered to landings as this was the basis for paying service providers and sales to the timber company buying the wood. This monitoring tracked progress with the logging operation and indicated the future payments that were in the pipeline. Since the big picture was not as opaque, people had a clearer understanding of how the money moved, and they wanted more information about it. This is crucial to transparency: presenting financial information creates accountability only if people can understand and question it.

The next year, after a successful harvest, members wanted to double their daily wage, so we tried a different scenario-type game to simulate how that would work. To do this, we worked with the CFO members to develop three different scenarios of how to distribute the funds. We worked through the scenarios several times before there was any real money in play so that people could practice and know how the different steps fitted together. It made it possible for them to discuss different wages for different roles in the CFO and determine how much money should be left for the community projects and the CFO. It was time-consuming but preparing useful and visual materials mattered. This is an example of short-cycle learning, and it was an exercise in accountability, transparency, and social learning because the CFO literally "opened up the books" to all of its members. Short-cycled processes created meaningful opportunities for learning and identified issues early to head off conflict before it occurred. This included creating scenarios before cash distributions were made, then returning to discuss with people if they had concerns 
or suggestions. Through this process, members also learned what a transparent and accountable system looked like so that they could hold their own administrators to it.

\section{Building capacity for ACM}

It can take several learning cycles for ACM concepts, and the value of the process, to sink in. For the BOLFOR technicians, we were uncertain if we ever convinced them that ACM had value. The concepts were so different from how they were trained as foresters; they did not see their jobs as facilitating group learning or how ACM related to getting trees out of the forest. We had a lot to learn as facilitators, and this included recognizing that we did not have all the answers. In our own learning processes, we realized that we needed to better understand the problems as well as where the opportunities existed. This required listening, observing, and learning from the range of actors involved, including community members, BOLFOR foresters, and others involved in the CFO's interactions, such as timber buyers and sawmill operators. If we had not learned how the logging operations were functioning, how timber payments would take place, or the differences between members in terms of investment in the forest management plans, we would not have known where to start.

\section{Case study 2: Indigenous women in territorial and forest governance in Nicaragua}

\section{Issue}

The second case, from Nicaragua, illustrates the use of ACM to strengthen the role of women in forest governance in Indigenous communities within a multi-ethnic autonomous region on the Caribbean coast of eastern Nicaragua. In theory, decentralization in Nicaragua has transferred power to subnational levels, and particularly to the autonomous region and its Indigenous territories $^{2}$ (A. M. Larson and Lewis-Mendoza 2012). Furthermore, several laws have mandated quotas for women's participation in governance bodies. However, the challenges faced by the subnational government and local authorities in Indigenous territories are steep; governance reform must address the realities of a region that lacks financial resources, lacks democratic traditions and institutions, favours local elites, and privileges men over women. In spite of a policy context in Nicaragua that may seem favourable to the political participation of women (see http://www3.weforum.org/docs/WEF_GGGR_2020 .pdf), women living in rural communities tend to play a nominal or passive role in formal and informal decision-making processes, particularly on natural resources at the community level (Mairena et al. 2012; Evans et al. 2016). Studies of Indigenous community cultures have found strong disincentives for women to participate, with sanctions by community members, other women, 
and spouses (Flores et al. 2016). How to encourage good forest governance and equitable women's participation in this disadvantageous context formed the central motivation for our research.

\section{Context}

From 2011 to 2015, CIFOR and the Institute of Research and Development of the Central American University of Nicaragua (Nitlapan) implemented a participatory research project promoting more proactive roles for women in community forestry-related decisions in Indigenous communities (Mwangi and Larson 2009, see also Chapters 4 and 5). The study site included five communities with majority Indigenous presence in Nicaragua's Northern Caribbean Autonomous Region (RACCN for its initials in Spanish). Equitable forest governance is a salient issue in this complex region (Finley-Brook 2007; Larson, Cronkleton, and Pulhin 2015). The RACCN is ethnically diverse, with Miskitu Indigenous people making up the largest ethnic group (57\%), Mayangna Indigenous people representing 4\% of the population, and mestizos comprising 36\% (according to the last census, INIDE 2005). ${ }^{3}$ Although national legislation established quotas to encourage gender equity in national and municipal elections, this does not legally apply to Indigenous territories and communities. In fact, customary practice and institutional inertia mean that women are typically marginalized in decision-making processes at the communal and territorial scale.

\section{How we applied ACM}

We used ACM because it explicitly recognizes the importance of collaboration at various levels and seeks to create opportunities for the participation of marginalized stakeholders, especially women, in forest-related decision making (Colfer 2005a; Kusumanto 2007; Evans et al. 2014). After initial scoping research and training the field team, the ACM activities started with a series of community-based visioning workshops where participants articulated current problems, envisioned possible future scenarios, set priorities for the future, and discussed how to enhance community governance and women's participation in decision making (Evans et al. 2006). Three of the nine communities identified the need to improve governance as their priority problem and requested support in strengthening community-level governance. This included improving the participation of women in community decision-making forums, in particular, the community assembly. The other communities decided to focus on projects related to tree planting, building a community garden, and a carpentry shop. The idea was that all these projects would use the ACM approach, meaning that the field teams would facilitate iterative cycles of learning during the activities, applying approaches such as monitoring and group reflection.

Together with community members, we created simple monitoring activities to track the participation of women in this range of ACM projects. Initially, 
the field team themselves struggled with implementing the monitoring: the process was new, and, without guidance, it was difficult for them to know where to start. We found it important to support the field team with regular visits where we all worked together with community members to define a set of simple monitoring activities that allowed for follow-up discussion and group reflection. These included counting the number of times that women spoke in meetings, or how often their ideas were adopted.

As the fieldwork proceeded, a moderate increase in the attendance of women at meetings was observed. However, men continued to dominate meetings and workshops, both in discussions and decision making. When the ACM activities were moved out of a schoolroom or community house, which were typical meeting spaces, women's participation improved, with more active discussion and expression of their opinions. Women were most active in the monitoring activities that took the groups out of a meeting room and into the field, where they engaged in discussions and reflections at levels equivalent to men as we stood in the forest or in a garden. This was contrary to what community leaders had said - that women would not show up for work in the forest or participate. In fact, monitoring tended to create a more welcoming space where women were more likely to participate as equals with men.

In response to the interest in addressing governance, and the growing participation of women in the monitoring activities, we then proposed creating a monitoring tool that would focus on monitoring goals specifically related to governance. With the support of facilitators, community members and leaders came together in workshops to define the aspects, of governance, or indicators, to be monitored. To do this, first the groups constructed a vision of good governance. They identified four key components: (a) strengthened community organization; (b) good participation by women; (c) good leaders; and (d) good forest management. The next step in the workshop was to analyse each component and specifically define that component in terms of questions that could be answered with either a yes or no.

We learned the importance of keeping the process simple and uncomplicated to keep everyone focused on the goals. Generating monitoring questions instead of indicators can lead to monitoring that is more locally relevant and usable (Demeo et al. 2015; Kusumanto 2007; Lawrence et al. 2006), and it avoids the complicated practice of trying to define indicators in a participatory context (Dey and Schweitzer 2014). Monitoring can start with a simple (although not easy) goal, like "A strengthened and institutionalized community government." To avoid confusing terms like "monitoring," it helped to instead adopt the Miskitu term that translates as "looking from above" (see Chapter 7, this volume).

Similarly, we never used the term "indicators." In our contexts, finding the questions that people want to answer instead of seeking indicators helped avoid overly technical and abstract goals. Other researchers have similar findings with regard to indicators and also recommend focusing on questions instead (Paudel and Ojha 2007; Demeo et al. 2015). In fact, the ACM project arose 
out of a project to define criteria and indicators for sustainable forest management, which subsequently found the emphasis on indicators sometimes to be unnecessarily complex (Pokorny et al. 2004; Purnomo, Mendoza, and Prabhu 2005). ${ }^{4}$

For instance, to monitor women's participation in forest-related decisions, the participants defined several questions that would tell them if they were achieving "equitable benefits for both men and women from forest resources," one of which was: "In the last three months, did the community leaders respect the area used by women to collect fruits?" We found creating questions such as these came relatively easily, whereas deciding upon indicators would likely have been more challenging and confusing.

Over the next year and a half, the ACM team helped to organize three monitoring sessions in each community, and, in most cases, the local monitoring committee leaders did the facilitation. During the meetings, community members voted "yes," "no," "sometimes," or "don't know" on each monitoring question by putting his or her vote into a ballot box. Then the votes were tallied in front of the group. This process, while emphasizing the importance of each individual's vote, became tedious because of the long list of questions. Participants grew tired, participation started to lag, and the group discussion suffered. Therefore, three adaptations were made. First, components were combined, and the number of questions was cut down from 73 to 18. The second adaptation was collecting the monitoring information from each committee member at his or her home in the form of a poll and then presenting results in a meeting with monitoring participants. This adaptation allowed more time in the monitoring meetings to reflect upon and analyse the results. Finally, not all components were evaluated at the same time, so people could focus on one aspect at a time, for instance, women's participation.

In each community, the monitoring activities were performed at least three times. Then, after the results were collected, communities discussed them in a session geared towards group reflection. These opened up meaningful dialogues about women's exclusion from decision making, particularly in forest management issues. For instance, the monitoring discussions brought to the forefront several instances where women's access to forest resources was negatively impacted by men.

\section{Building capacity for ACM}

While initially we had conceptualized the project as launching mini ACM "projects" in each community, where ACM approaches were facilitated by the ACM team, we came to realize that the entire project itself was adopting the ACM mindset. The learning occurred among all participants, including the ACM team, and we adapted the project activities as we learned.

This learning was catalysed by a regular practice of reflecting as a team immediately after an activity. Our reflections started with the simple question: "What did we learn?" 
In addition, in the process of encouraging the uptake of ACM within the communities, ${ }^{5}$ the research team too adopted adaptive collaborative behaviours, learning and adapting their own methods, approaches, and attitudes. In other words, they "learned how to learn." The team, composed of Indigenous members with roots in the communities as well as international researchers, had their own learning processes: about gender and Indigenous identity, and how to feel comfortable adapting methods as needed. Because the team members had left the community and earned university degrees, they felt they had to come back with their degrees as "experts," and the communities expected them to show their expertise. In other words, both sides expected experts with solutions, not facilitators. One facilitation technique that helped them overcome this barrier - both conceptually and in practice - was to make it a habit to always ask questions, when possible, instead of giving answers.

The team's perspectives on gender also evolved; by changing their assumptions about how women and men relate and interact in different spaces, their new frameworks made it possible to understand women's and men's behaviours and obstacles to participation. For instance, when encountering little participation of women in meetings or in leadership positions, the men in the team at first repeated what the leaders of the community (who were men) said: that the women are given opportunities to participate in meetings, but that women simply do not want to. In other words, it was women's fault for not participating. These perspectives were reinforced by what they saw in meetings and workshops: men participating and women sitting silently, with few exceptions. We realized that the team needed to learn more about gender. Field team members attended gender trainings, and the male team members attended a masculinity workshop. These trainings provided them with concepts and language to discuss and question gender. When the team members began to engage in other methods - participant observation, participatory monitoring, interviews, and activities outside of the meeting spaces - they observed significant obstacles to women's participation, including social exclusion and physical violence. They noted how the three most active female leaders were each sanctioned by the community at certain points. The team learned that barriers to participation are complex and that a more in-depth understanding of dynamics at the household level would be necessary to fully understand the constraints on women's participation. They also noted that outside of meetings - particularly in the field - gender roles were less rigid, and women assumed leadership roles. For example, they observed one woman who, after a morning activity in the community forest, spontaneously led a group reflection on the activity. In contrast, in the afternoon community meeting, she sat silently.

Learning how to do ACM together - deliberately reflecting on our attitudes and the roles and interactions of women and men - generated new knowledge about gender. As one technician noted

ACM promotes gender participation in a more diplomatic way through activities. For example, in the ACM workshops on monitoring, there was 
an activity on gender, but no one knew that that same activity encouraged the participants to have equal opportunity and rights. In this sense I believe that approach to gender in ACM works in the communities.

Furthermore, the team learned and adapted the methodology as our knowledge about gender evolved: we applied ACM learning cycles to our own ACM activities. One team member reflected, "At the beginning we were resistant. Now we know that not all experiences have to come out as successes. We recapture those experiences and learn from them."

\section{Case study 3: Encouraging farmers, particularly women, to engage in dialogue about resource degradation in northern Ghana}

\section{Issue}

This final case focuses on northern Ghana, in a landscape consisting of six villages in the Kassena-Nankana West District in the Upper East, a semi-arid region of dry forest and savanna parklands. This work was part of the West African Forest-Farm Interface (WAFFI) project that worked to understand smallholder management of complex multi-use landscapes and to build capacity so that resident villagers could engage with policymakers and represent local interests in public meetings. The goal of the WAFFI project was to create platforms where local people - traditionally with little voice in policymaking - could effectively express their concerns and share information about their realities with decision makers.

\section{Context}

We knew that resource management in this landscape was governed by a complex mix of customary rules and formal regulations. Understanding this complexity would be improved by gaining local perspectives of people living at these sites (Boakye and Baffoe 2006). To meet the project goals, it was crucial to build the capacity of villagers to assess local needs and problems, identify shared interests, and engage with authorities to discuss common issues.

We also knew that this pluralistic system assigned differentiated rights to access and use of land and trees, which created complex mosaic patterns of resource management and socio-economic outcomes. As in many parts of West Africa, collecting shea nut (Vitellaria paradoxa) is an important component of women's livelihoods (Carney and Elias 2006). Traditionally, women do not own land but access areas to cultivate through husbands or other male relatives. Although men are involved too, women have customarily had a dominant role in shea nut collection and processing (Elias 2016). Shea provides a crucial source of nutrition and income for women to meet the needs of the household (Kent 2018). However, commercial demand for shea nut has increased 
because of its growing use by the international cosmetic and confectionary industries (Laube, Awo, and Derbile 2017). As a result, in some locations, men are asserting more decision-making control over the women in their households in exchange for allowing them to collect more shea, in an example of intra-household bargaining (Kent 2018).

We wanted residents to identify local patterns of resource management and wellbeing within their families and communities to define strategies to address their problems. Considering the particular challenges facing women and their crucial roles in household wellbeing, we decided to make sure that women participated and that their voices were prioritized. This meant creating an environment of trust where women felt welcomed, where their opinions were valued, and where topics that were interesting and meaningful to these time-strapped women were discussed. ACM and participatory action research (PAR) have been particularly effective at involving economically or socially marginalized groups, such as rural people and women, in problem-solving processes (Colfer 2005b; Guijt 2007; Evans et al. 2014).

\section{How we applied ACM}

To create a process that helped us to understand the local context and facilitated participation by people from these villages in analysis and knowledge creation, we started with training workshops for technicians from partner organizations and local village facilitators in the use of ACM approaches. We adopted a multi-stage approach that built on our previous ACM experience. These stages consisted of an initial appraisal of the local context using an innovative approach called auto-appraisal, followed by exchange workshops that brought participants from all the villages together, followed by periods of participatory action research. However, these stages were interspersed with training activities during implementation.

We began with training for "auto-appraisal," a structured assessment of local conditions, needs, and opportunities (Taylor et al. 2008), carried out by teams of community members trained as facilitators rather than external technicians. Auto-appraisal includes a series of structured information-gathering activities that include sketch mapping of village boundaries and features, historic timelines for the community, and group interviews to collect information on community capitals - social, human, economic, physical, and natural - using DFID's sustainable livelihoods approach (DFID 1999). At the end of the autoappraisal stage, the village facilitators came together for an exchange workshop and invited village leaders to share results and discuss common issues and differences between the communities. These discussions laid a foundation for the next stage, which applied PAR. PAR uses hands-on experimentation to catalyse group learning processes that are foundational to ACM (Borda 2001; Colfer et al. 2011, see Chapter 9, this volume). In other words, applying PAR is one way to operationalize ACM. 
When it came time to start the PAR activities, we realized that additional training was needed for the field technicians implementing the work. They had learned the PAR terms and concepts, but as they returned to work, their tendency was to return to conventional extension approaches. We needed to rethink training and decided to adapt elements of the ACM approach to address a training challenge. We drew on earlier experiences using techniques like "learning by doing" to create situations where the technicians could discover the effectiveness of ACM to orient capacity building. We did this through a training exercise in mapping, where community facilitators and WAFFI team members learned the basics of using a GPS, plotting coordinates, and mapping features in their villages and landscapes. This training activity gave the technicians a more tangible understanding of the ACM approach and learning cycles. We learned that as ACM trainers, we too had to observe and adapt as we went.

After the training, the team was able to lead PAR groups through an iterative process that brought women together to examine distinct village-scale problems (fuelwood supply, land access, shea access). Then, over time, and after exchange meetings, the field team helped the PAR participants converge on shared issues, such as competition for shea nut, and further refined the understanding of the problems surrounding women's access. For example, women were still harvesting from on-farm trees, but men were increasingly claiming the income.

The PAR groups, assisted by the WAFFI team, then focused on problems related to shea access and collection. They did this by tracking the shea harvest through participatory monitoring. Villagers in PAR groups used worksheets to record the quantities and the locations of daily nut collection. They then used the information to discuss underlying problems. Men were claiming more control over shea trees on farmland, which were not only closer to home but were also the most productive trees, less damaged by fire and firewood collectors. These discussions revealed that on-farm purchases of shea - as opposed to selling in the market - removed the stigma of male involvement in selling the shea nut. Furthermore, women were growing more dependent on the shea trees in the forest, which were common-pool resources and not as productive. The information that was collected informed discussions with community leaders and policymakers. We do not know the degree to which women achieved greater impact on decision making, but it was evident that on an individual level, the ACM process empowered women to express their opinions and placed topics important to them on the agenda. Leaders noted a difference in women's capacity to engage in multi-stakeholder meetings; they were surprised at how confidently women presented their findings in front of customary chiefs and government authorities.

\section{Building capacity for ACM}

In all cases, ACM was not familiar to local collaborating partners, who were more familiar with conventional approaches to agricultural and forestry extension 
that emphasized technical expertise over group learning. This required more time for training and follow-up than we had anticipated. We learned that it was important to accompany the work of technicians at first, including regular visits to the field and workshops, to help technicians and partners use the approaches and adapt activities to local reality. While the methods were not complex, they did require people to change how they worked and to be selfaware of their roles. For facilitators, the ACM work with communities took them into a level of empathy with community life, touching on the challenges the people face every day. As one technician stated "Doing this work, we are learning a lot from the communities. Before we did not think that the communities could teach us much."

For our part, we learned that group learning was necessary not just at the community level, but among the entire team implementing ACM. This required adapting training in the field together, facilitating together, and learning together. As a team and as individuals, we developed trust and rapport and built on our shared experiences: travelling, eating, sharing jokes, laughing, succeeding and failing together. This part of the process - nurturing the human connections - is as much a part of ACM as training.

\section{Lessons learned from the cases}

Our principal insight gained from ACM training - whether the trainees are field teams, village facilitators, or local participants - is that successful training should be organized to replicate ACM processes. Out of that broad message, we can identify four interrelated insights that illustrate what this meant in practice. The first is that "learning by doing" helps individuals become more conscious of how they learn so they can facilitate learning with others. The second is the importance of focusing on the interests/needs of participants, which maintains their enthusiasm but can also catalyse creativity. The third is to emphasize short-cycle learning at the early stages, which allows participants to conceptualize connections and logic in the approach. Finally, we learned the importance of designing and implementing capacity-building activities to accentuate collaboration between participants (including trainers) to catalyse social learning and adjust the programme content to address learning needs and opportunities. Below, we expand on these insights.

\section{"Learning by doing" to build capacities}

Helping people to become more conscious of how they learn entails creating opportunities for them to reflect on the process they are experiencing. We learned early on that building understanding and skills occurred best when participants were actively working together to solve a problem or complete a task. Facilitating an activity like ACM entailed approaches that are different from the conventional training typically experienced in formal education where an expert or teacher lectures the trainees. Instead, the facilitator needs to guide 
others as they explore an issue, learn about it, and practice. As we mentioned earlier, to introduce this concept, we would often start training workshops asking people whether they knew how to ride a bike. As participants responded, we would shift the question to ask them to tell how they learned to ride a bike. Then, how they knew they had learned to ride a bike. This discussion would allow us to introduce "learning by doing," a key focus of our training approach.

It was also important to scale the learning to the capacities of the participants. Trainers need to gauge the skill or knowledge level of participants and tailor content and materials at an appropriate scale. It takes an iterative process and periodic adaptation of the training approach throughout. A central tenet of this type of learning is making people conscious of how they learn by embracing experimentation and not being afraid to make mistakes. This extended to the design of training efforts. Embedding a tangible technical skill into the ACM process - in the case of Ghana, GPS use and mapping - generated so much interest that people embraced and adopted ACM learning cycles without realizing it. This not only built capacity, but also helped people develop sufficient understanding of the tool so that they could imagine applying the tools to solve other problems.

\section{Focus on the needs and interests of participants}

When doing ACM, and particularly PAR, it is important to focus on a problem or issue that is a concern or priority to participants. This ensured continued motivation and engagement with the exercise. In Bolivia, people were understandably most interested in determining how much money they would be putting in their pockets and how much the community could put towards badly needed projects like wells for potable water. While there were some presentations about the overall enterprise and accounting, the core area of the scenarios was on wages because that was what people cared about most. These experiences were crucial for building transparency and lowering tension.

In the same way, it is important to make sure that training aligns with local concerns and needs. Not only should training address an objective seen as important, but the training should also offer clear steps or techniques that participants recognize as useful. For instance, in Ghana, we used training techniques that addressed practical, relevant topics, with real-world experiential exercises so that training activities were purpose-driven and interesting to participants. We focused on skills that helped participants solve problems, such as learning how to use a GPS, map coordinates, and interpret maps for discussion. As a result, turnout for mapping training and related activities was enthusiastic, and participation grew as the activities progressed.

\section{Focus on simple, short cycles of learning initially}

Learning occurs at different scales, combines multiple processes running in parallel, and in cycles that vary in duration. In agriculture and forestry, some 
processes that producers track may stretch across a season, years, or decades. When leading ACM training, for example, using PAR techniques, facilitators need to find examples that will allow participants to track the process to allow reflection and discussion of results. Introducing an activity that would take months to come full circle, that is spread out geographically, or is extremely complex is unlikely to succeed. Participants will lose interest or not understand why they are doing the activity. In order to encourage people to consciously think of learning as a loop, it is important to engage in short cycles - monitoring/observation, discussion, new action, monitoring/observation - initially so that people understand how the different activities fit together. The short cycles allow participants to conceptualize the entire process and to see the connections between the steps and link back to the evaluation of the original question. In fact, if a full learning cycle can be completed within a single day, the learning is immediate and further motivates participation. For example, we learned to plan workshops so that each day was organized to provide opportunities to reflect on the learning loop; even individual sessions were arranged this way. We made this explicit at the start and returned to this message frequently. Short cycles help people visualize and understand the iterative learning process created through ACM. As participants gain skill, it is possible to take on greater complexity and duration.

Learning cycles also happened at longer scales, such as across timber harvest cycles, as we showed in Bolivia. We learned that an ACM learning process can be effective when it includes nested loops of both short-cycle and long-cycle learning, as we saw in the case in Nicaragua, where the many short cycles created by the monitoring activities over multi-year time periods led to larger shifts in behaviours. As one technician observed:

With this process, the women woke up; they gave opinions more, expressing their concerns, needs and lack of compliance by authorities who made decisions about natural resources, and in a certain way they demanded that they be taken into account in the consultations about their resources or that they know better how [resources] were being managed by the authorities, with greater transparency of funds and taxes.

\section{Emphasize collaboration to promote social learning}

Collaboration is crucial for training exercises to help ensure facilitators understand how they should engage with people at the community level. Group work among trainees and trainers is a key element of capacity building for ACM. It is important to make clear that the dynamics in training reflect how ACM is done in the field. We learned that technicians could go through training workshops following all the instructions and learning all the terminology, but without realizing this really entailed changing how they engaged with communities. We learned that the best way to assess whether trainees understood was to create realistic situations where they used the method to observe 
how they worked and then followed up periodically to see how they were doing. For trainees, grasping the need to adjust their approach required working hand-in-hand with trainers to fully understand how the approach would work in the field. Due to social pressure, inertia, or fear, it is easy for trainees to fall back into business as usual or conventional approaches that are usually top-down and non-collaborative.

For instance, in Nicaragua, the team was sceptical about ACM at the beginning: the goals seemed abstract (i.e., learning, adaptation), the methodology seemed open and unstructured, and the potential for impacts was unclear. Initially, the trainees interacted little with community members outside of the meetings and resisted engaging in participant observation. Over time, however, several admitted that their perspectives shifted in fundamental ways. For instance, at first, they perceived gender as a foreign concept imposed from outside on their culture. They were uncomfortable discussing or challenging the gender roles in communities because, in some local views, preserving Indigenous culture and preserving gender roles are linked. That perception evolved and became more nuanced and complex. As one technician mentioned, "Through the ACM process I learned that gender is a concept about relationships and values and complementarity." These shifts changed the way these young professionals perceived and worked with their communities.

We also learned that trainees need to observe how an ACM approach supports learning so that they can facilitate the process. For example, in Ghana, the field team was at first uncertain how to analyse the data collected by the PAR groups until they realized, when working with the CIFOR team, that the analysis could be simple and should be done in the communities with the participants. It did not take much data to generate good reflection and discussion. It was also good not to wait until all the data had been collected, but to begin facilitating reflection on the process as data collection took place. Furthermore, it was more important to collect data in a way that was sufficient to "adequately and practically answer the question" (Demeo et al. 2015, 6), rather than insist on the most scientifically rigorous data.

\section{Conclusion}

This chapter described insights we gained facilitating ACM activities and training local technicians to do the same. As we worked with ACM, we realized that an initial capacity-building phase was usually necessary to introduce the methods and underlying concepts. The challenge was then how to train people in an approach that was different from most of the formal training they had been exposed to previously. We learned that training people to use an ACM approach is best done by deliberately creating an ACM experience in the capacity-building process. This could mean structuring a training workshop to include short cycles of learning. It also means that the real learning of "how to do" ACM often does not occur until ACM related activities begin; this means encouraging everyone - participants, facilitators, technicians, and 
researchers - to jump into the ACM process and embrace an ethos of experimentation, trial-and-error, and learning by doing. Furthermore, ACM blurs the line between training and implementing - as ACM is about creating a series of experiences and opportunities to strengthen capacity on the part of the participants and facilitators. The goal was to create self-reinforcing cycles in which participants reflected on their learning so that they could consciously facilitate learning with others. This allowed us to gauge the effectiveness of the capacity-building exercises and whether key messages were being captured by trainees.

The three cases presented, from Bolivia, Nicaragua, and Ghana, drew from distinct contexts to help us distil our insights about training people to use ACM. We realized that "learning by doing" needed to be part of training so that trainees would become more conscious of how their views changed through capacity building. It became clear that focusing on locally relevant topics was key for driving enthusiasm and creativity. Structuring activities to provide "short-cycled" exercises gave participants active experiences that helped them understand the intuitive links between distinct steps in the process. Finally, structuring training activities so that trainees and trainers worked together accentuated the role of collaboration in this approach and indicated ideal relationships between facilitators and participants in ACM activities.

In ACM, everyone is learning. As one of the field team members in Nicaragua commented after a team reflection that generated insights into their personal growth: "We are now applying ACM to our own lives." We argue that training local partners and field teams in ACM is not simply about teaching a new methodology, it is about adopting an ethos of experimentation, learning, and collaboration. This ethos can be transformative for all involved, including researchers and facilitators. ACM can be time-consuming and challenging to get off the ground; the approaches require creativity and an openness both to new ideas and to making mistakes. However, the outcomes and benefits - engagement, transparency, learning - for all involved are fundamental and lasting.

\section{Acknowledgements}

We express our heartfelt thanks to all the community members in Bolivia, Nicaragua, and Ghana who worked with us over the years and shared their perspectives, knowledge, and ideas. We also thank the following field teams and organizations who helped carry out this research. In Bolivia, we thank Marco Antonio Albornoz and Robert Keating for assisting fieldwork in Cururu, and USAID for funding our work within the BOLFOR initiative. In Nicaragua, we thank Selmira Flores, Xochilt Hernández, Ceferino Wilson, Pilar Müller, Roberto Marchena, and Alejandro Pikitle who participated in the fieldwork with support from Nitlapan as well as the Austrian Development Agency (ADA) for funding. In Ghana, we thank our colleagues Mathurin Zida, Emilie Smith-Dumont, Houria Djoudi, and Thomas Addoah from CIFOR 
and ICRAF working in WAFFI, as well as Jonathan Naaba, Stella Basefeli, and Kenneth Afagachie from Tree Aid and Julius Awaregya and Vitus Achagituni from the Organization for Indigenous Initiatives and Sustainability (ORGIIS), who participated in fieldwork, and also the International Fund for Agriculture and Development (IFAD), which funded the WAFFI project. In addition, the authors received support from the CGIAR Research Program on Forests, Trees and Agroforestry (FTA) during the preparation of this chapter. Finally, we would also like to thank the anonymous reviewers who provided their invaluable feedback on earlier versions of the manuscript.

\section{Notes}

1 Part of the CIFOR project "Gender, Tenure and Community Forests in Uganda and Nicaragua." Findings here focus on Nicaragua; see Chapters 4 and 5 for discussion of the experiences in Uganda.

2 The relationship between the different entities - autonomous regional government, municipalities, Indigenous communities and territories - is very complex and beyond the scope of this chapter.

3 Recent trends in migration suggest mestizos were a much larger portion by 2021 .

4 Other researchers however found them appealing, e.g., Dangol (2005); Gunter (2001); Colfer et al. (2001). See also Chapter 7 and 8.

5 See discussion by Fisher and Jackson (Chapter 9).

\section{References}

Berkes, Fikret. 2009. "Evolution of Co-Management: Role of Knowledge Generation, Bridging Organizations and Social Learning." Journal of Environmental Management 90 (5): 1692-1702. https://doi.org/10.1016/j.jenvman.2008.12.001.

Boakye, K. Akyeampong, and K. Affum Baffoe. 2006. "Case Study from Ghana." In FAO Regional Workshop, 151. Nakuru, Kenya: Food and Agriculture Organization of the United Nations. http://www.fao.org/3/a-i0161b.pdf\#page=166.

Borda, Orlando Fals. 2001. "Participatory (Action) Research in Social Theory: Origins and Challenges." Handbook of Action Research: Participative Inquiry and Practice, edited by Peter Reason and Hilary Bradbury, 27-37. New York: Sage Publications.

Carney, Judith, and Marlene Elias. 2006. "Revealing Gendered Landscapes: Indigenous Female Knowledge and Agroforestry of African Shea." Canadian Journal of African Studies/La Revue Canadienne Des Études Africaines 40 (2): 235-67.

Colfer, C.J.P. 2005a. The Complex Forest: Communities, Uncertainty, and Adaptive Collaborative Management. Washington, DC: RFF/CIFOR.

Colfer, C.J.P. 2005b. The Equitable Forest: Diversity, Community and Resource Management. Washington, DC: RFF/CIFOR.

Colfer, Carol J. Pierce, Reed L. Wadley, Emily Harwell, and Ravi Prabhu. 2001. "Assessing Intergenerational Access to Resources: Using Criteria and Indicators in West Kalimantan, Indonesia.” In People Managing Forests: The Links Between Human Well-Being and Sustainability, edited by C.J.P. Colfer and Yvonne Byron, 190-213. Washington, DC: Resources for the Future/CIFOR. 
Colfer, C.J.P., E. Andriamampandry, S. Asaha, E. Lyimo, E. Martini, J.L. Pfund and J. Watts. 2011. "Participatory Action Research for Catalyzing Adaptive Management: Analysis of a 'Fits and Starts' Process." Journal of Environmental Science and Engineering 5: 28-43.

Cronkleton, Peter. 2005. "Gender, Participation and the Strengthening of Indigenous Forest Management in Bolivia." In The Equitable Forest: Diversity, Community and Natural Resources, edited by Carol J. Pierce Colfer, 256-273. Washington, DC: RFF/CIFOR.

Cronkleton, Peter, Robert E. Keating, and Kristen Evans. 2007. "Helping Village Stakeholders Monitor Forest Benefits in Bolivia." In Negotiated Learning: Collaborative Monitoring in Forest Resource Management, edited by Irene Guijt, 58-65. Washington, DC: Resources for the Future.

Cronkleton, Peter, P. Pacheco, R. Ibarguen, and M. A. Albornoz. 2009. Reformas En La Tenencia de La Tierra y Los Bosques: La Gestión Comunal En Las Tierras Bajas de Bolivia. La Paz: CIFOR/CEDLA.

Dangol, Sushma. 2005. "Participation and Decisionmaking in Nepal." In The Equitable Forest: Diversity, Community and Resource Management, edited by Carol J. Pierce Colfer, 54-71. Washington, DC: Resources for the Future/CIFOR.

Demeo, Thomas, Amy Markus, Bernard Bormann, and Jodi Leingang. 2015. "Tracking Progress: The Monitoring Process Used in Collaborative Forest Landscape Restoration Projects in the Pacific Northwest Region." Working Paper 54. Ecosystem Workforce Program. Eugene, OR: University of Oregon.

Department for International Development (DFID). 1999. Sustainable Livelihoods Guidance Sheets. London: Department for International Development.

Dey, Daniel C., and Callie Jo Schweitzer. 2014. "Restoration for the Future: Endpoints, Targets, and Indicators of Progress and Success." Journal of Sustainable Forestry 33 (sup1): S43-65. https://doi.org/10.1080/10549811.2014.883999.

Elias, Marlène. 2016. "Gendered Knowledge Sharing and Management of Shea (Vitellaria Paradoxa) in Central-West Burkina Faso." In Gender and Forests: Climate Change, Tenure, Value Chains and Emerging Issues, edited by C. J. P. Colfer, Bimbika Sijapati Basnett, and Marlene Elias, 263-282. New York: Earthscan/Routledge.

Evans, K., S. J. Velarde, R. P. Prieto, S. N. Rao, S. Sertzen, K. Davila, P. Cronkleton, and W. de Jong. 2006. Field Guide to the Future: Four Ways for Communities to Think Ahead. Nairobi: CIFOR, ASB system-wide program of the Consultative Group on International Agricultural Research, ICRAF, Secretariat of the Millennium Ecosystem Assessment. http://www.asb.cgiar.org/PDFwebdocs/Evans-et-al-2006-Field-guide-to -the-future.pdf

Evans, K., A.M. Larson, E. Mwangi, P. Cronkleton, T. Maravanyika, X. Hernandez, P. Müller, et al. 2014. Field Guide to Adaptive Collaborative Management and Improving Women's Participation. Bogor, Indonesia: CIFOR. http://www.cifor.org/nc/online-libr ary/browse/view-publication/publication/5085.html

Evans, K., Selmira Flores, Anne M. Larson, Roberto Marchena, Pilar Müller, and Alejandro Pikitle. 2016. "Challenges for Women's Participation in Communal Forests: Experience from Nicaragua's Indigenous Territories." Women's Studies International Forum 65: 37-46.

Finley-Brook, Mary. 2007. "Indigenous Land Tenure Insecurity Fosters Illegal Logging in Nicaragua." International Forestry Review 9 (4): 850-64.

Flores, S., K. Evans, A. M. Larson, A. Pikitle, and R. Marchena. 2016. La Participación de Mujeres Indígenas Rurales Para Fortalecer La Gobernanza Comunitaria. Bogor, Indonesia: CIFOR. http://www.cifor.org/library/6142/la-participacion-de-mujeres-indigenas -rurales-para-fortalecer-la-gobernanza-comunitaria-2/. 
Guijt, Irene. 2007. Negotiated Learning: Collaborative Monitoring in Forest Resource Management. Washington, DC: Resources for the Future.

Gunter, Mario. 2001. "Intergenerational Equity and Sharing of Benefits in a Developing Island State." In People Managing Forests: The Links between Human Well Being and Sustainability, edited by C. Colfer and Y. Byron, 171-189. Washington, DC: Resources for the Future.

Instituto Nacional de Información de Desarrollo (INIDE). 2005. "CENSO 2005." Managua, Nicaragua: Instituto Nacional de Información de Desarrollo. http://www .inide.gob.ni/censos2005/VolPoblacion/Volumen\%20Poblacion\%201-4/Vol.IV\%20Po blacion-Municipios.pdf

Keen, Meg, Valerie A. Brown, and Rob Dyball. 2005. Social Learning in Environmental Management: Towards a Sustainable Future. New York: Routledge.

Kent, Rebecca. 2018. “'Helping' or 'Appropriating'? Gender Relations in Shea Nut Production in Northern Ghana.” Society \& Natural Resources 31 (3): 367-81.

Kolb, David A. 2014. Experiential Learning: Experience as the Source of Learning and Development. New York: Pearson Education.

Kolb, David A., Joyce Osland, and Irwin M. Rubin. 1995. The Organizational Behavior Reader. Upper Saddle River, NJ: Prentice-Hall.

Kusumanto, T. 2007. "Learning to Monitor Political Processes for Fairness in Jambi, Indonesia." In Negotiated Learning: Collaborative Monitoring in Forest Resource Management, edited by I. Guijt, 124-34. Washington, DC: Resources for the Future.

Larson, A. M., and Jadder Lewis-Mendoza. 2012. "Decentralisation and Devolution in Nicaragua's North Atlantic Autonomous Region: Natural Resources and Indigenous Peoples' Rights." International Journal of the Commons 6 (2): 179-99.

Larson, Anne M., Peter J. Cronkleton, and Juan M. Pulhin. 2015. "Formalizing Indigenous Commons: The Role of 'Authority'in the Formation of Territories in Nicaragua, Bolivia, and the Philippines." World Development 70: 228-38.

Laube, Wolfram, Martha Adimabuno Awo, and Emmanuel Kanchebe Derbile. 2017. "Smallholder Integration into the Global Shea Nut Commodity Chain in Northern Ghana." Working Paper 153. ZEF Working Paper Series. https://www.econstor.eu/h andle/10419/162194

Lawrence, Anna, Krishna Paudel, Richard Barnes, and Yam Malla. 2006. "Adaptive Value of Participatory Biodiversity Monitoring in Community Forestry." Environmental Conservation 33 (4): 325. https://doi.org/10.1017/S0376892906003432

Lee, K. 1993. Compass and Gyroscope. Washington, DC: Island Press.

Maarleveld, Marleen, and Constant Dabgbégnon. 1999. "Managing Natural Resources: A Social Learning Perspective." Agriculture and Human Values 16 (3): 267-80. https://doi .org/10.1023/A:1007559903438

Mairena, Eileen, Gema Lorio, Xochilt Hernández, Ceferino Wilson, Pilar Müller, and A.M. Larson. 2012. "Gender and Forests in Nicaragua's Indigenous Territories: From National Policy to Local Practice." CIFOR Working Paper 95. Bogor, Indonesia. http: //www.cifor.org/library/3891/gender-and-forests-in-nicaragua\%c2\%92s-indigenous-t erritories-from-national-policy-to-local-practice/

Mwangi, E., and A.M. Larson. 2009. Project Proposal: Gender, Tenure and Community Forests in Uganda and Nicaragua. Bogor, Indonesia: CIFOR.

Paudel, K. P., and H. Ojha. 2007. "Imposing Indicators or Co-Creating Meanings in Nepal." In Negotiated Learning: Collaborative Monitoring in Forest Resource Management, edited by I. Guijt, 49-57. Washington, DC: Resources for the Future. 
Pokorny, Benno, Ravi Prabhu, Cynthia McDougall, and Roberto Bauch. 2004. "Local Stakeholders' Participation in Developing Criteria and Indicators for Sustainable Forest Management." Journal of Forestry 102 (1): 35-40. https://doi.org/10.1093/jof /102.1.35

Purnomo, Herry, Guillermo A. Mendoza, and Ravi Prabhu. 2005. "Analysis of Local Perspectives on Sustainable Forest Management: An Indonesian Case Study." Journal of Environmental Management 74 (2): 111-26.

Taylor, P. L., P. Cronkleton, D. Barry, S. Stone-Jovicich, and M. Schmink. 2008. 'If You Saw It with My Eyes': Collaborative Research and Assistance with Central American Forest Steward Communities. Bogor, Indonesia: CIFOR. http://www.cifor.org/publications/p df_files/Books/BLeighTaylor0801.pdf 


\section{Introduction to Chapter 7}

Sarmiento Barletti's introduction of a tool for use in multi-stakeholder forums (MSFs) follows on naturally from Chapter 6, which looked at the evolution of MSFs within ACM efforts (in Bolivia, Nicaragua and Ghana). Sarmiento Barletti, whose ACM research began later than most contributors, initially reports the findings of a realist synthesis review of the MSF literature, thereby establishing some key parameters that affect the success or failure of an MSF.

Based on this review plus the team's own examples from their research in Brazil, Ethiopia, Indonesia and Peru, he concludes that rather than "designing engagement" in a way that overcomes a given context, we need to begin "designing for engagement" in a way that acknowledges and builds on the local context and treats local peoples as partners rather than mere "beneficiaries."

Sarmiento Barletti then turns to his team's experience developing and later testing a tool designed to address the power inequities that are recognized - but are then often ignored - in so many extant MSFs: How are we doing? Using three cases, two in Peru, one in Indonesia, the research team and MSF participants collaborated to explore how they could address the inequities and exclusions they identified within their MSF and local setting.

This chapter also raises the relevance of ACM and good MSF approaches to better management of extractive industries, a rarity in discussions of such collaborative actions and research. It also proposes MSFs as a field in which to continue developing and adapting ACM. 


\title{
7 Learning from adaptive collaborative management
}

\author{
A participatory tool to support adaptive and \\ reflective learning in multi-stakeholder forums
}

\author{
Juan Pablo Sarmiento Barletti
}

\section{Introduction}

There is interest in multi-stakeholder forums (MSFs) in global development and environmental circles in the context of the climate crisis. This popularity largely rests on the optimism associated with the role that MSFs may play as part of a wider set of actions towards addressing the environmental and social impacts of the crisis (Atmadja et al. forthcoming). Proponents emphasize the potential of these forums as a method for more equitable and inclusive collaboration and coordination processes than is common with mainstream applications of the participatory paradigm (see Sarmiento Barletti et al. [2020a] for a review). These forums are "purposely organised interactive processes that bring together a range of stakeholders to participate in dialogue, decision-making and/or implementation regarding actions seeking to address a problem they hold in common or to achieve a goal for their common benefit" (Sarmiento Barletti and Larson 2019b). Also known as multi-stakeholder platforms and initiatives, MSFs address different kinds of topics, including but not limited to community forest management (e.g., Nayak and Berkes 2008); participatory budgeting (e.g., Wampler 2010); and resource management (e.g., Søreide and Truex 2011).

MSFs hold an important role in current discourses regarding environmental sustainability. NGOs, donor organizations, and government actors are leading the interest in implementing and funding forums as a transformational solution to address the challenges posed by unsustainable land and resource use in tropical landscapes (Bastakoti and Davidsen 2015; Gonsalves et al. 2005; Larson et al. 2018). Although MSFs may be fashionable, they are certainly not "new." Especially at the local level, these forums are the current iteration of the participatory paradigm that was introduced to shake up rural development practice four decades ago. At the time, the paradigm was introduced as an attempt to create equitable development initiatives that were more closely tuned with the priorities and needs of the local "beneficiaries" (Chambers 1983; Chambers et al., 1989). Current debates over the transformational potential of MSFs follow similar arguments to the scholarly discussions regarding the participatory paradigm. The main questions explore whether MSFs can address the power 
inequalities inherent to the interactions between their participants and whether these forums can be resilient to the wide variety of contextual factors at play in the different landscapes where they are implemented (see the contributions to Cooke and Kothari [2001] or Sarmiento Barletti et al. [2020a] for a review of the contextual characteristics that affect MSF outcomes).

This chapter contributes to the debates on the transformational potential of MSFs by engaging with the interest in how to improve equity in MSFs. To do so, this chapter engages with the findings of a multi-country comparative research project carried out by a multinational team of researchers at the Center for International Forestry Research (CIFOR). The project sought to understand how to best enable more equitable processes and outcomes in MSFs (see Sarmiento Barletti and Larson [2019b and a] for the project's methods and analytical framework). Research was carried out with 13 MSFs in Brazil, Ethiopia, Indonesia, and Peru that had been organized at the jurisdictional level to work towards more sustainable land and/or resource use. The research project's findings, described in more detail in the following sections, revealed that there is much potential in MSFs but also serious challenges. In most case studies, the optimism held by MSF organizers for more equitable processes and outcomes was not supported by purposefully designed strategies that aimed at addressing inequalities between their participants (Sarmiento Barletti et al. 2021a). Fieldwork findings were supplemented with the lessons derived from a realist synthesis review of the academic literature on forums seeking more sustainable land and resource use that was carried out as part of the same research project (Sarmiento Barletti et al. 2020a). ${ }^{1}$ The review revealed the need to shift the emphasis on designing initiatives so that they are not affected by context to designing how to engage stakeholders in a context-responsive manner (Larson and Sarmiento Barletti 2020; Sarmiento Barletti and Larson 2020).

These two sets of findings - from fieldwork and the literature review led the research team to conclude that the potential success of participatory approaches rests on whether or not they are designed to address the power inequalities between stakeholders. In turn, this design necessitates a deep understanding of the contextual factors associated with economic, political, and social dimensions that structure those inequalities (Cornwall 2008; Mosse 2014). Recognizing this challenge, and in collaboration with forum participants in Indonesia and Peru, CIFOR researchers identified the need for a tool to support equity in MSFs by allowing participants to monitor their processes and outcomes, understand their main challenges, and discuss how to address them. This collaboration resulted in How are we doing? (Sarmiento Barletti et al. 2020b), a participatory monitoring tool that enables forum participants to build the principles of adaptive collaborative management (ACM) into their MSFs in order to achieve more equitable processes and outcomes. Taking lessons from ACM, the tool was developed as a participatory reflective and adaptive learning tool rather than a conventional monitoring tool. How are we doing? builds upon ACM's conscious effort for collaboration, negotiation, colearning, and adapting a group's work based on the results of those processes. 
As discussed below, the tool builds on ACM's emphasis on the importance of social learning, deploying it as part of an iterative learning cycle to plan, take action, monitor, reflect, and plan again for the MSF's future work based on that reflection.

This chapter starts with a short review of how MSFs have been dealt with in the scholarly literature as a concept, followed by a summary of the key findings of CIFOR's research on MSFs. This will be followed by a section on the development of the adaptive and reflexive learning tool, and its application of ACM concepts to support more equitable processes in MSFs.

\section{Multi-stakeholder forums: Transformational change or more of the same?}

In a recent review, Atmadja et al. (forthcoming) synthesized five elements that scholarly and practice-oriented publications note as key to catalyse "transformational change" in the context of the climate crisis. Two of those elements - "collective learning and reflection" and "consultation and participation" are evident in the interest, optimism, and funding that is currently placed in MSFs. This interest is relevant in international agreements; for example, partnerships are central to Sustainable Development Goal 17 (Franco and Abe 2020), which seeks to "strengthen the means of implementation and revitalize the global partnership for sustainable development."2 This renewed interest in the participatory paradigm is also supported by environmental discourses that recognize the role of Indigenous and other forest-dependent communities as environmental stewards, which has increasingly led to the inclusion of their representatives in forest management at different levels (Nikolakis and Hotte 2019; Pinkerton 2019). The participation of these communities in MSFs dealing with more sustainable land and resource use and governance is part of the appeal of these participatory processes (Lyons et al. 2019). This interest is also linked to Sustainable Development Goals 5 and 10, which call for better integration of women and other marginalized groups, respectively.

MSFs have gained much attention from policymakers and development and conservation practitioners around the world due to their potential to improve collaboration between different actors, sectors, and governance levels in order to address complex challenges that cannot be resolved by one actor alone. This attention reflects the growing awareness that environmental problems cannot be addressed without the effective engagement of the actors that determine resource and land-use practices on the ground, or the fact that such problems cannot be resolved within a conservation community when the drivers are located in other sectors. In theory, MSFs may produce more effective and sustainable outcomes by getting those sectors and actors that have commonly held contradictory development priorities to coordinate and align goals through discussion, negotiation, and planning (see Larson et al. [2018] for a review).

Furthermore, advocates for MSFs highlight their potential for participatory processes that are more collaborative, transparent, inclusive, and horizontal 
than mainstream applications of the participatory paradigm. MSF proponents argue that bringing stakeholders together to discuss a common challenge or opportunity addresses power inequalities among participants, leads to solutions that reflect the priorities of historically underrepresented actors (as opposed to top-down decision making or bilateral negotiations), allows more powerful participants to understand the perspectives of vulnerable groups, and includes actors that can affect the implementation and effectiveness of consensus outcomes (see, among many others, Buchy and Hoverman 2000; Dougill et al. 2006; Faysee 2006; Hemmati 2002; Reed 2008; Tippett et al. 2007). This optimism builds on the notion that creating avenues to include citizens more directly in governance, and to improve their communication with government actors, has the potential to improve democratic practice and enable more equitable and effective governance than unilateral, expert-driven, and/or topdown decision making (Avritzer 2002; Cohen and Sabel 1997).

However, despite expanded avenues for participation, the involvement of marginalized groups in broader scale forums has been an exception rather than the rule. This exclusion is despite the recognition of participation as a right for Indigenous Peoples in international agreements such as the International Labour Organisation Covenant 169 and the United Nations Declaration for the Rights of Indigenous Peoples. Indigenous Peoples and local communities have not been able (or allowed) to participate in decision making regarding land and resource use issues and/or the design of initiatives that may affect their rights, territories, lives, and livelihoods (Espinoza Llanos and Feather 2011). When these groups have been included in participatory processes, there have been questions about the sort of impact that they may have over mainstream development agendas or the interests of powerful groups driving deforestation and forest degradation (Castro and Nielsen 2001; Lane 2003).

In fact, some analysts have noted that participation in these spaces may further marginalize underrepresented actors (see the contributors to Cooke and Kothari 2001). This is a reminder of how power inequalities are challenging for MSFs organized to address unsustainable land and resource use, commonly in landscapes with contexts marked by deep histories of inequalities, conflict, and land dispossession. Trade-offs are inherent in these contexts and the stakeholders involved are significantly diverse in characteristics, ranging from their land and resource priorities to their access to said land and resources (Barnes and Child 2014; Robbins 2012). Furthermore, although research has shown optimism among Indigenous representatives for participation in MSFs, they also understood participation as a potentially flawed avenue for representation. This is due to experiences of not being able or allowed to participate effectively, which is part of the reason why participation is only a part of wider representation strategies that include political, legal, and social action (Rodriguez and Sarmiento Barletti 2021).

Proponents argue that MSFs improve on mainstream governance by leading to outcomes that better reflect the priorities and perspectives of historically underrepresented actors, from women to Indigenous Peoples and local 
communities (Bastos-Lima et al. 2017; Estrada-Carmona et al. 2014; Sayer et al. 2013). MSF proponents claim that stakeholders are more likely to take ownership over initiatives they have participated in designing, implementing, and monitoring and that participation in these spaces has allowed local peoples greater say over the initiatives that affect them and their territories. These forums are described as able to address the main point of criticism levelled at the participatory paradigm - its inability to address the power inequalities and access between different participants (see Chapter 8), especially in cases related to historically conflictive issues such as access to land or control of natural resources (Cooke and Kothari 2001; Warner 2006). These inequalities in access should be taken seriously by anyone interested in participatory processes, as recent experimental research on collaboration and reciprocity has noted that inequalities undermine cooperation (Hauser et al. 2019). As revealed by the results of the research project discussed below, MSFs must be organized and implemented with strategies to address inequalities in order to fulfil their promise of more equitable outcomes and processes.

\section{A comparative research project on jurisdictional multi-stakeholder forums}

Responding to the interest in MSFs, a team of researchers at CIFOR embarked on a multi-country comparative project aiming at assessing the MSF potential for more equitable processes and outcomes. The research team was multi-disciplinary and truly diverse, with researchers from Brazil, Ethiopia, Indonesia, Peru, Spain, and the United States. The team embarked on a research project, carried out between 2018 and 2020, through which they worked with 13 MSFs in Brazil, Ethiopia, Indonesia, and Peru (see Table 7.1 for a summary of case studies). All cases were selected after scoping research according to whether they fulfilled four criteria: they were organized to address unsustainable land and/or resource use; they were organized at the subnational level; they included a forum for in-person interactions; and their participants included at least one government and one local actor. Subnational MSFs were selected because they were closer to the geographical spaces of resource and land-use planning and management, and due to the current interest in jurisdictional approaches to tackle climate change and deforestation (e.g., Fishman et al. 2017).

Research participants included representatives of organizations from government agencies, Indigenous or local organizations, NGOs, research institutions, donor organizations, and the private sector. In each case study, the research team interviewed MSF organizers and participants, actors who were not part of the forum for different reasons but were stakeholders to the issues discussed in it and key context informants. A separate semi-structured questionnaire was designed for each group (Sarmiento Barletti and Larson 2019b). Given the multi-country nature of the project, research materials were translated into Amharic, Indonesian, Portuguese, and Spanish in order to interview 


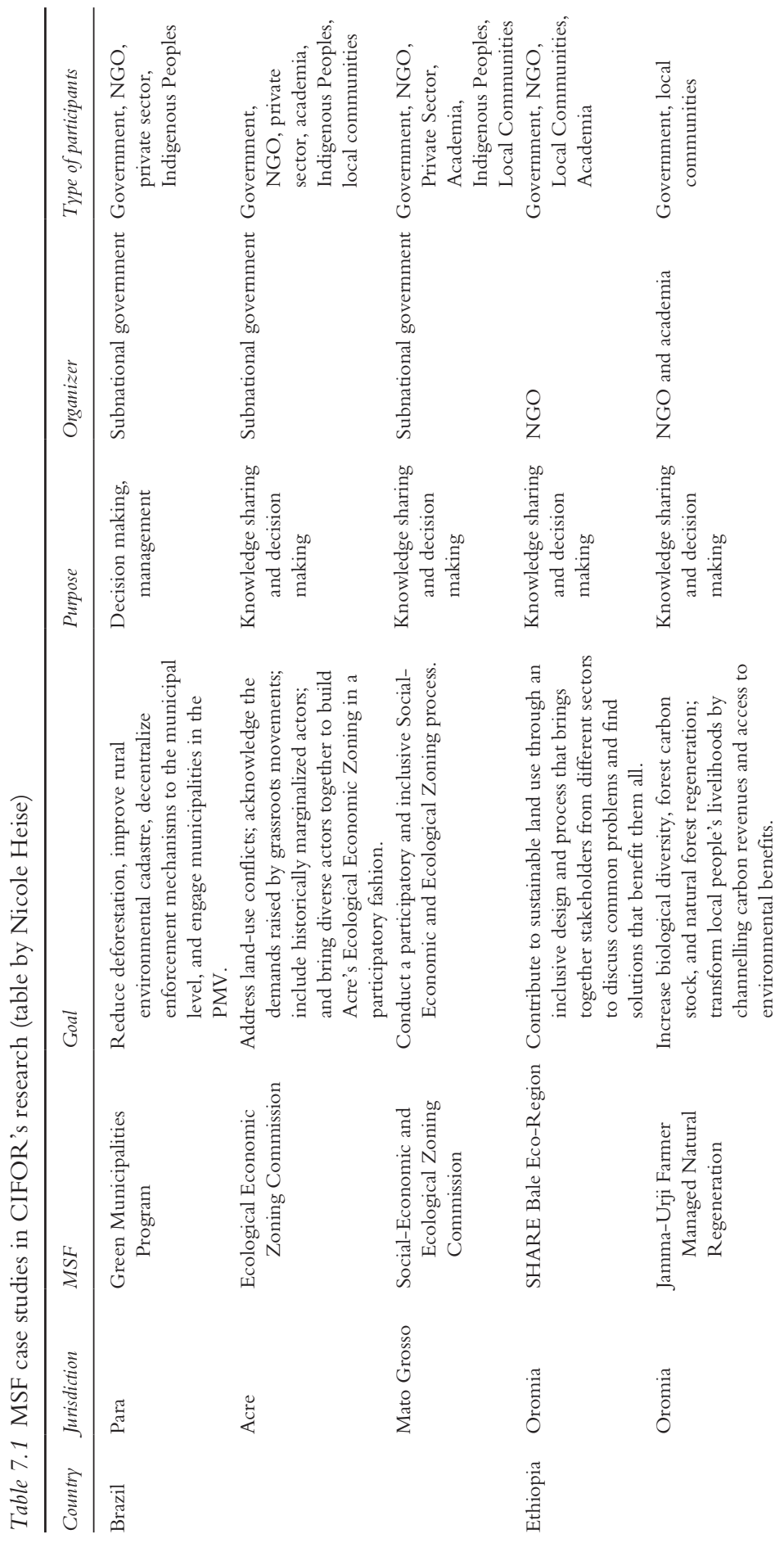



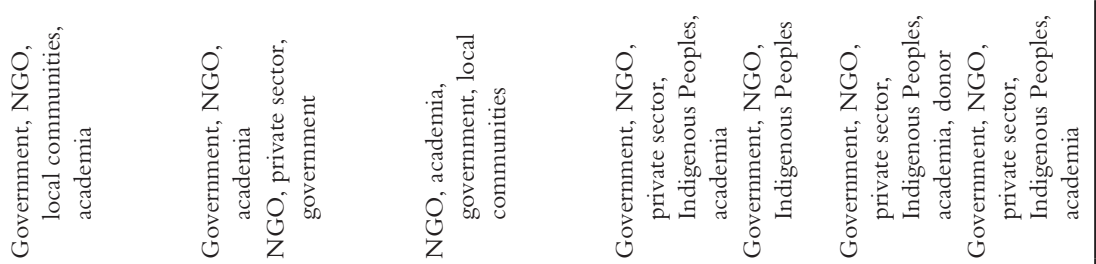

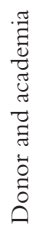
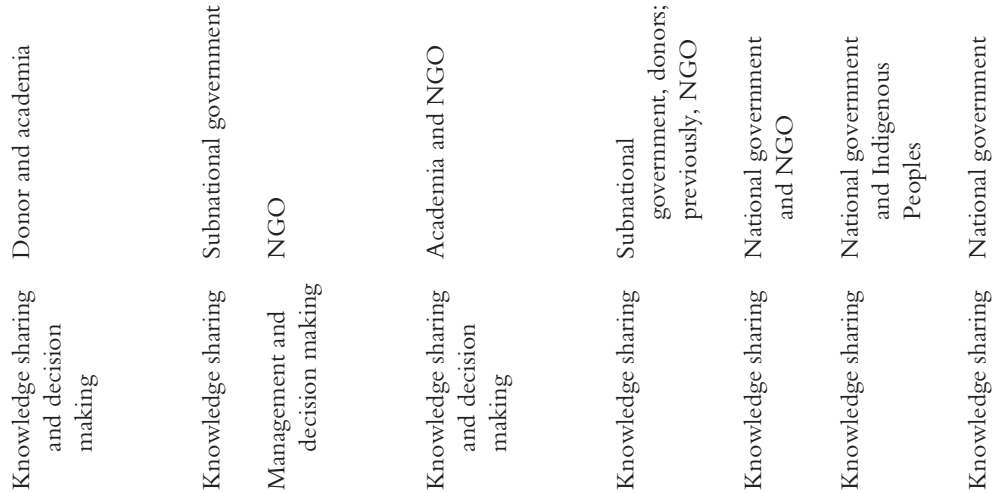

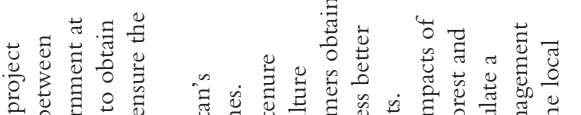

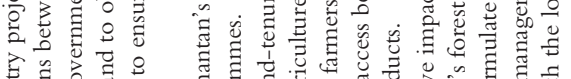

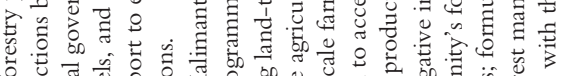

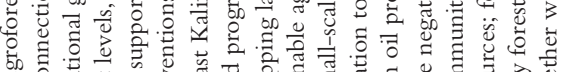

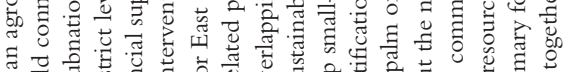

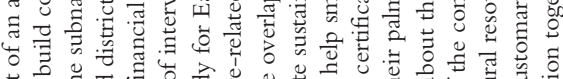

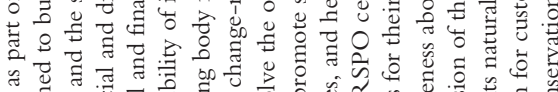
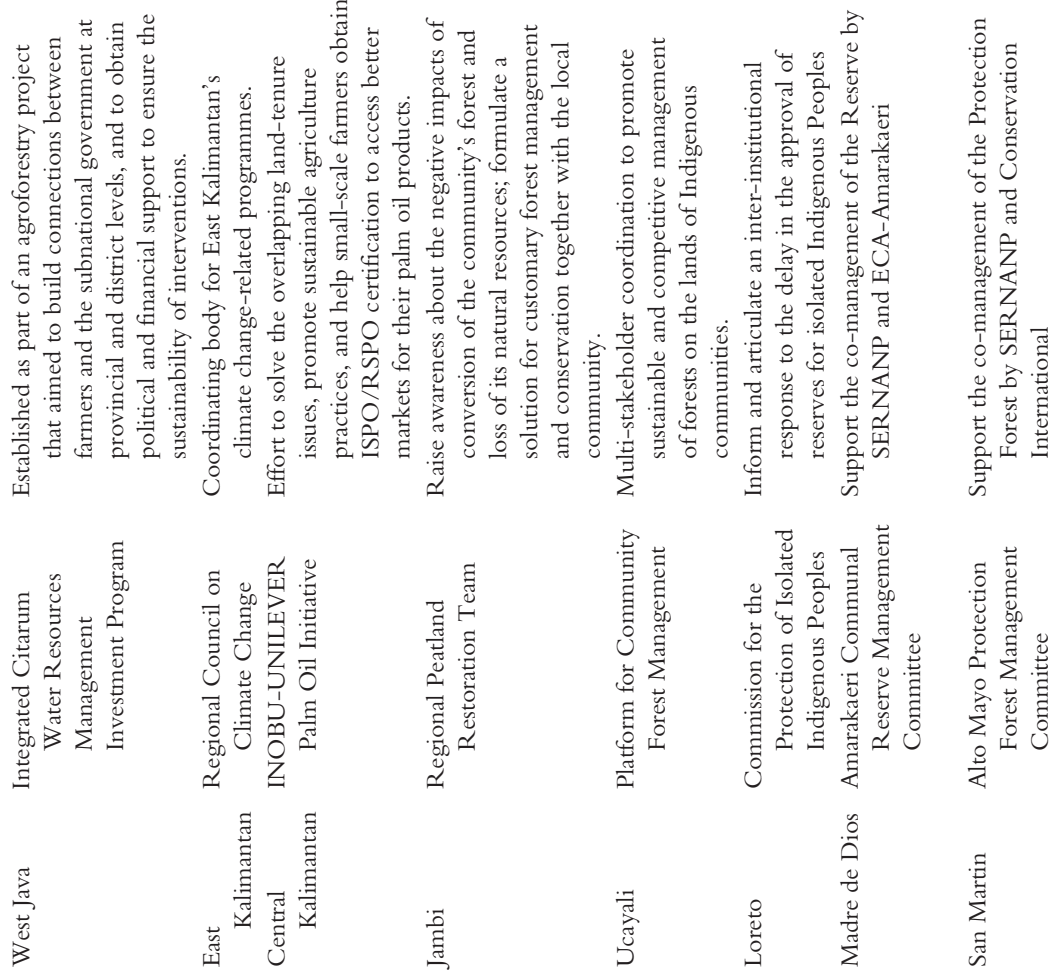

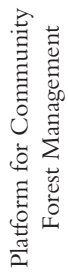

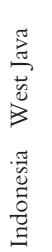

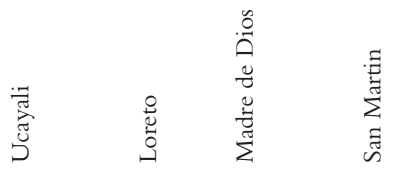

ِ 
more than 500 research participants in their national languages. The range of actors that were interviewed by the research team stemmed from the consideration of important differences between participants in an MSF based on their differentiated access to power, which then led to different experiences of participation in their MSFs. This included who organized and convened the forum, who funded it, what kind of participation in decision making was available to different participants, and who was not taking part in the process (and why), among other characteristics. Recognizing these differences and the interests in the scholarly debates on participatory processes, research was framed to understand power inequalities among MSF participants. The project's analytical framework recognized the multidimensional nature of power as central to any examination of whether and how MSFs may enable transformational change. The framework not only differentiated between sources of power, but also between the different mechanisms through which power was exercised in the MSFs and in the wider context where they were organized. This approach was set with the conviction that research could not engage with interviewees as if they were all able to have the same impact on the outcome of an MSF. The challenge, then, was understood as not merely "more coordination," but "better" coordination. The research team sought to examine what this meant in the different countries and jurisdictions where research was carried out.

Most of the participants in the 13 case studies, regardless of their backgrounds, agreed that MSFs had the potential to empower marginalized actors (Larson et al. n.d.). Interestingly, although this might suggest an optimistic view of the potential of their forums to empower Indigenous Peoples and local communities, most of the 13 case studies were not explicitly designed for empowerment (Sarmiento Barletti et al. 2021a). The optimistic view on the potential of MSFs to empower marginalized actors is also framed by another of the project's findings. Most MSF organizers from across actor types recognized that there were power inequalities between their participants yet believed their forums fostered equity by inviting more actors to the table (Sarmiento Barletti et al. 2021a). In practice, they placed little effort on designing and implementing strategies that would address those power inequalities. Some of these inequalities were longstanding given the history of the areas where the MSFs were organized.

Interviews revealed that many Indigenous and local community representatives stopped participating because they did not feel heard, did not see the MSF as leading to a fair outcome, or could not afford to participate (Sarmiento Barletti et al. 2021a). Representatives of Indigenous Peoples and local community organizations in some of the project's case studies noted that they were in an unequal position in forums and described experiences of unequal access to technical knowledge (which their forums prioritized) or funds to cover the costs of travelling to meetings (commonly held in jurisdictional capitals) or to make up for their lost income during their participation. Some of those representatives said that they had been unable to participate in an MSF at some point because they had no free time to do so, while NGO and government actors 
participated in those same MSFs as part of their paid jobs (Gonzales Tovar et al. 2021b; Rodriguez and Sarmiento Barletti 2021). Research with two MSFs in the same Ethiopian jurisdiction revealed that the more successful one included funds to cover the travel expenses of local actors. The other one did not have funds to do so, and local community representatives found it challenging to participate as they could not afford to set aside their livelihood practices to attend meetings (Yami et al. 2021).

Most of the MSF participants interviewed in four case studies in the Peruvian Amazon said that their forums had the potential for more horizontal decision-making processes than the status quo. More generally, Indigenous and local community participants across case studies noted that MSFs encouraged open debate with more powerful actors (Gonzales Tovar et al. 2021a), and also between the men and women of their communities (Yami et al. 2021). Respondents agreed that to fulfil this potential their forums needed to implement strategies that had been explicitly designed to build more equitable interactions between their participants and empower underrepresented participants such as Indigenous Peoples and local communities (Sarmiento Barletti et al. $2020 b)$. In fact, for some of the Indigenous and local community representatives interviewed as part of the project, MSFs were promising but limited. They only considered their participation in forums as one part of their wider representation strategies (Rodriguez and Sarmiento Barletti 2021). These strategies also included bilateral meetings with government actors, protests, and suing the government in international courts.

Thus, despite much optimism for participation and democratic practice, the research team's work is further evidence that bringing people together is not enough in every context, as laudable as the interest in MSFs may be. Scholarly work on participatory approaches over the past few decades has noted that power inequalities limit the possibility of horizontal collaboration, potentially leading to agreements that only benefit powerful actors and are legitimized by the participation of less powerful actors (see Colfer [1983] and the contributions to Cooke and Kothari [2001] on the challenges of communication between "unequals" in development). Most of the MSF organizers interviewed as part of the research project did not think that their forums would address the local interests and development priorities that were driving unsustainable land and resource use (see also Sarmiento Barletti and Larson 2020a; Sarmiento Barletti et al. 2021). In fact, researchers in Madre de Dios and San Martin regions of the Peruvian Amazon noted that forums only reached their objectives when their processes and outcomes did not challenge the land and/or resource use priorities held by local government and private sector actors (Sarmiento Barletti and Larson 2020b).

Similarly, the Roundtable for Isolated Indigenous Peoples in Loreto (also in the Peruvian Amazon) has been unable to achieve the recognition of Indigenous reserves for Indigenous People in isolation due to the infrastructure and extractive development priorities held by Loreto's government (Rodriguez and Sarmiento Barletti 2021). Rather, the forum has been used by 
government officers to challenge the creation of the reserves in areas that were earmarked for extractive concessions and roads. As those reserves are part of the rights recognized for Indigenous Peoples in Peru, this case study also shows the potential limitations of MSFs' spaces to raise awareness of the rights of vulnerable peoples and coordinate the implementation of actions to support such rights. This is only effective when participants hold a shared respect for those recognized rights rather than allowing them to be up for discussion.

The Amarakaeri Communal Reserve and its multi-stakeholder management committee is another example of the potential limitations of MSFs. Amarakaeri's MSF is part of a progressive effort by the Peruvian government to include Indigenous Peoples in the management of protected areas in their ancestral territories (Palacios Llaque and Sarmiento Barletti 2021). However, the area's history is framed by competing land and resource use interests, best illustrated in the jurisdictional government's support for the extraction of gold from the area at the time of research. This meant that although the reserve's management committee was inclusive as it contained representatives from all the Indigenous communities in its buffer zone, addressing the conflicts created by gold extraction was completely out of their power. Thus, the MSF may inform a more equitable management of the reserve, but it may have little impact in terms of the effectiveness of conservation, given Madre de Dios' development priorities.

MSFs are evidence that portraying inequalities as obstacles that can be overcome by empowering disempowered people through participation is insufficient to enact change (Cornwall 2008). MSFs need strategies to address inequalities in their planning, design, implementation, and monitoring, or else they may reproduce such inequalities under the appearance of effective participation and inclusive decision making. Taking time to recognize the interconnections between individuals, groups, and institutions is important for designing initiatives that address inequities and the challenges that emerge as the initiatives progress (Friedman et al. 2020; Gallina 2010; Stanturf et al. 2017). The following section moves to another set of the projects' research findings to explain what this design might look like.

\section{Designing for engagement: An adaptive, context-responsive approach to MSFs}

Starting from the notion that bringing people together around a table is insufficient to change things, and with an awareness that participation may not always be the best alternative in every context, CIFOR researchers originally sought to synthesize the available evidence into lessons regarding how to organize MSFs that would be resilient despite the different contextual factors that they may face in the landscapes where they were organized. It was clear for the research team that the processes and outcomes of MSFs - like other initiatives - are impacted by their contexts. The team approached forums analytically as framed by the existing networks and relationships in the landscapes where 
they were introduced. This research approach recognized the lessons of an older issue faced by mainstream development and conservation planners and implementers that understood and dealt with context as a challenge to overcome in order to achieve real "progress" (Escobar 1995; UNDP 2017). These approaches to context as an obstacle to otherwise carefully (and technically) planned "progress" tend to place the blame for unsuccessful initiatives on locals (in their guise as "beneficiaries") rather than on those that designed the initiative (Ferguson 1995; Gardner and Lewis 2015).

The findings from the Realist Synthesis Review were clear in terms of the wide variety of contextual factors - stemming from different levels - that may have an impact on an MSF's process and outcomes. The evidence on successful multi-stakeholder forums in the Realist Synthesis Review called for a shift in attention from how to design initiatives to overcome context to how to design engagement in order to build the initiative within and with its distinct social and political context. In a series of publications, CIFOR researchers have proposed designing for engagement as a shift in MSFs - and participatory initiatives more widely - through four interwoven factors (Larson and Sarmiento Barletti 2020; Sarmiento Barletti and Larson 2020a; Sarmiento Barletti et al. 2020a, Forthcoming). The four factors were synthesized from the evidence regarding MSFs that had different experiences of success in promoting the participation of historically underrepresented actors, including Indigenous Peoples, local communities, and women.

The first factor is commitment to the initiative, its process, and its participants. This factor stems from findings that successful MSFs had enough time, economic, and human resources to work towards its outcomes. These were accompanied by an effort to ensure that participation goals were met, and that, when they existed, policies were followed and laws were respected. For example, committed government actors are needed to establish (and respect) legal frameworks that recognize the participation of underrepresented peoples in decision-making processes (see Palacios Llaque and Sarmiento Barletti [2021] and Rodriguez and Sarmiento Barletti [2021] for two examples in the Peruvian Amazon). Commitment is also illustrated in the design and implementation of practices - such as participation quotas, capacity development for more effective participation, and creating separate collaboration spaces - to assure the effective participation of historically underrepresented actors (see Gonzales Tovar et al. [2021a, b] and Yami et al. [2021] on examples in Brazil and Ethiopia, respectively).

The second factor is engagement with implementers, key brokers, and government officials at different levels. This engagement is important as these are the actors who have a major say in what happens on the ground and thus can facilitate or challenge the sort of change sought by an MSF. This is especially so in cases where the MSF may have goals (e.g., sustainable resource use) that run against those of powerful actors (e.g., large-scale resource extraction). Engaging these different actors at different levels will allow for the identification of any potential bottlenecks or capacity gaps that may challenge the forum later down 
the line. It also means assuring everyone is on the same page, with concepts and goals (see Chapter 3). The research team revealed evidence that MSFs are more successful when they are part of a multilevel effort to address the driving forces of unsustainable land and resource use, rather than just addressing unsustainable practices on the ground (Sarmiento Barletti et al. 2020a; see also Fisher et al. [2017] on similar findings in land-use planning in Indonesia).

The third factor is openness to learning from all stakeholders, especially from those with traditionally weaker positions and knowledge systems that do not fit with mainstream definitions of "technical" knowledge (see Evans et al. [2020] on a similar approach to the co-production of knowledge). There is evidence of how critical it is to take the time to research and map local stakeholders and institutions, assess the legitimacy of representative organizations, understand power relationships between stakeholders, and be open to their different ways of knowing (Rodriguez and Sarmiento Barletti 2021; Sarmiento Barletti et al. 2021a; Yami et al. 2021). This approach to learning is key as for most MSF organizers interviewed for CIFOR's research, their own forum was the plan to manage power inequalities (Sarmiento Barletti et al. 2021a). Few organizers had carried out research to understand the local context before implementing the project (Tamara et al. 2021; Yami et al. 2021). In other cases, local communities were unable to participate effectively and their representatives lost any motivation to participate as they did not feel heard (Palacios Llaque and Sarmiento Barletti 2021).

The fourth and final factor is adaptability to the results of the learning process. MSFs need to be designed so that they are able to adapt to implement the lessons learned. This may include changing its process or the kind of outcomes that it pursues in response to those lessons, and if necessary, to be open to prioritize the needs of its participants with weaker positions or support them in challenging the institutions that reinforce inequality (Yami et al. 2021). In the research project's case studies, these approaches allowed for the creation of trust between participants and, in some cases, created a sense of local ownership about the initiative over time (Tamara et al. 2021; see also Butler and Schultz 2019] on similar findings from collaborative efforts in the United States). Adaptability also recognizes the changing nature of the challenges MSFs address, the shifting relationships between its participants and even their shifting conservation and development priorities through time (Klenk et al. 2013). Thus, MSFs require enough time to negotiate challenges as they arise, to learn from practice, and to develop the capacities of local actors so that the responsibilities regarding the MSF can be passed on to them (Stringer et al. 2006). This sort of adaptability may lead to forums that are more resilient in times of crises (e.g., funding cuts) or changes in policy or political leadership that are outside of their control (see McDougall et al. 2013).

All four factors are related to ACM. ACM is a framework that brings together the stakeholders of forested areas in order to collaborate in planning the implementation of activities, collectively monitor those activities, and learn from the impact of their actions to adapt future work to the lessons that arose 
from the monitoring process (CIFOR 2008; Colfer 2005). Although different as ACM is a long-term facilitated process that is not necessarily multi-stakeholder, it still shares some of the most optimistic traits associated with MSFs. They are both spurred by democratic ideals, justice and equity concerns, and place importance on the process as a source of empowerment for underrepresented peoples. ACM, put into practice in an MSF, would consciously reinforce its process in terms of communication, collaboration, negotiation, and collective learning on the results of their actions - all related to the four factors described earlier. An ACM-oriented forum would place great importance on social learning, bringing stakeholders together to share their different perspectives, knowledge, and capacities (McDougall et al. 2008). The point is for participants to critically reflect on their shared challenges and collaboratively design possible solutions. Importantly, ACM - as some of the more successful case studies reviewed for the previously mentioned Realist Synthesis Review show (Sarmiento Barletti et al. 2020a) - invites participants to be aware of the interconnectivity of their initiative with other scales to make things work.

Designing for engagement builds on some important aspects of ACM. Following the research phase and the conversations held with MSF organizers and participants during research dissemination workshops, the research team started to think about the best way to implement the attention to learning and adaptability to enable more equitable forums, while building engagement and commitment. The following section discusses the development and method behind the reflexive and adaptive learning tool as a way to build the principles of both designing for engagement and ACM into the work of MSFs.

\section{How are we doing? A tool to reflect on the process, progress, and priorities of multi-stakeholder forums}

Findings from both field and desk research were clear in terms of the importance of purposefully designing MSFs if they are to have more equitable processes and outcomes than those that have resulted from mainstream participation processes. However, research findings were not proof of the failure of MSFs. Rather, respondents saw them as flawed yet with a potentially positive role to play in improving decision making and coordination in their landscapes given the lack of multi-stakeholder participatory and coordination platforms. After discussing findings with research participants across field sites, the team noticed that only two forums - both protected area co-management committees in Peru - had been periodically applying a tool to monitor their work. However, participants in both groups noted - which the research team corroborated by examining the available handbooks and guides - that the tool was applied as a top-down exercise to evaluate their existence as an MSF (as both are a legal requirement) rather than how well they worked internally.

An important finding from research with the management committees for the Amarakaeri Communal Reserve and for the Alto Mayo Protected Forest was that different stakeholders had different ideas of what the objectives of 
their MSF were, who should be participating in it and who should not. This is unsurprising given the different agendas and priorities that participants brought with them to the forum. However, research showed that these different perspectives - and others, including how to fund their activities and how to communicate their work to other stakeholders who did not participate in the MSF - had not been discussed as a group. For example, the lack of effective communication of both forums' work was considered by local peoples as a lack of transparency on the side of its organizers.

Furthermore, both MSFs faced problems in terms of funding their activities, including their actual meetings as many participants did not have funds to travel to the urban areas where meetings were held or to stay there overnight.

Finally, both MSFs faced equity challenges as their participants did not reflect the diversity of actors in the landscapes where they were organized and were challenged by their lack of inclusion of non-Indigenous local populations. For example, although the Amarakaeri Communal Reserve has been successful in including Indigenous actors as co-management partners, the reserve's multi-stakeholder management committee has been unable to establish a dialogue between Indigenous and non-Indigenous local stakeholders, as migrant gold miners have been excluded from participating in it. This has prevented non-Indigenous actors from participating in the reserve's management and having conversations that could help resolve conflicts over land and resource use by finding a middle ground between conservation and extractive activities (Palacios Llaque and Sarmiento Barletti 2021).

In a similar vein, the management committee for the Alto Mayo Protected Forest excluded local communities that refused to leave their farms within the Protected Forest, as they had been working that land before the area was ringfenced as a protected area. MSF organizers discussed those communities' issues as something to be resolved by the police rather than to be resolved through the MSF (Sarmiento Barletti and Larson 2020).

Given these challenges to MSFs and their participants' desire to explore ways to address them, CIFOR researchers began a collaboration with participants in those two MSFs, and also included a third forum in Indonesia - East Kalimantan's Provincial Council on Climate Change (Dewan Daerah Perubahan Iklim, DDPI) - that showed interest in co-developing a tool to monitor their process and outcomes. From the start, the team decided that the tool would be participatory in two ways - it would be developed with forum participants, representing a wide range of actors, and it would be designed to be implemented by MSF participants themselves rather than external evaluators, as some participants were used to. In facilitating the collaborative development of a participatory monitoring tool, the research team sought to engage with the current interest in this approach to monitoring.

Participatory monitoring tends to be understood as a mechanism to inform how "local knowledge" can support "technical knowledge," or how the former can make the latter more "transparent" (Sarmiento Barletti et al. 2019b). Researchers note the need to include local populations in monitoring the 
initiatives that are implemented in their territories and that affect their livelihoods and wellbeing (Evans and Guariguata 2016). As the specialized literature shows, participatory monitoring can lead to more effective processes in forest-based landscapes, encouraging social learning, and empowering local stakeholders (see Guijt [2007] on ACM monitoring; see also Danielsen et al. 2010; Fernandez-Gimenez et al. 2008; Funder et al. 2013; Pinto et al. 2014). When designed and implemented in an equitable manner, this sort of monitoring can lead to information that allows for social learning and adaptive management (Evans et al. 2014; Reed et al. 2016). Participatory monitoring tools tend to be developed for implementation by or with local peoples to (usually) collect and analyse data. However, it is uncommon that the actual indicators and implementation methods are developed with those same local peoples. The development of local indicators as part of ACM research, though initially routine, is now an exception (e.g., McDougall et al. 2008; Mutimukuru-Maravanyika and Matose 2013; Nyirenda and Kozayani 2007; or Chapter 6), as is more recent work examining the role of gender in the governance of Indigenous and local communities (CIFOR and ONAMIAP 2020; Evans et al. 2019).

The collaboration with the organizers and participants of those MSFs led to the development of four research-based indicators, derived from the team's own analysis (see Table 7.2), and ten "local" indicators derived from a series of workshops carried out with all three MSFs between 2019 and 2020 (see Table 7.3). In Peru, a separate workshop was held with groups of Indigenous women living close to and inside the buffer zone of the Alto Mayo Protected Forest, and another workshop with the participatory governance team in Peru's Protected Areas Service (SERNANP) to develop indicators that were specific to management committees for protected areas. The development of those indicators led to a separate tool that is specific to those committees (see CIFOR and SERNANP [2020] for the tool and its development).

Table 7.2 Research-based indicators

We are all aware of what our MSF's objective(s) is/are.

Our MSF includes everyone who should be present.

We are learning what we need to know in order to participate effectively.

We have a positive impact beyond our MSF.

The team proposed the four research-based indicators to MSF collaborators as they covered key elements about MSFs that had arisen from the research. The rest were developed through exercises where groups of participants reflected on the characteristics they would want their forum to have "in an ideal world" where they had enough funding and commitment from key stakeholders to be able to work towards their goals. Those group discussions were then synthesized into indicators, designed as statements for participants to agree or disagree with based on their own perceptions of the MSF's process and outcome(s). 
Table 7.3 "Local" indicators

We are all treated as equals in our MSF.

We have sought sources of funding for our MSF to achieve its objective(s).

We have implemented strategies for the women of Indigenous and local communities and their organizations to participate effectively and equally in our MSF.

We have identified the role of local populations (e.g., Indigenous, customary, and peasant communities) and their grassroots organizations in achieving our MSF's objective(s).

We have effectively communicated our work to the communities, organizations, and institutions that do not participate in our MSF.

We are all clear on our own and everyone else's role in our MSF.

We have engaged with other institutions/organizations/entities and/or other participatory spaces that impact our MSF's objective(s).

We have engaged with the interests of actors whose objectives differ from those of our MSF.

We have identified what capacities we need to develop to be able to participate effectively in our MSF and have made an effort to develop them.

We have supported research studies (e.g., carried out by different organizations or by our members) to reinforce our MSF's objective(s).

After deciding on a first draft of statements, the research team suggested the development of a set of reflection questions for each statement. This would allow for deeper conversations about each statement, reflection on their answers, and on why some people agreed and others disagreed with each statement. The purpose of this reflection would be to learn from the past, consider progress and obstacles, and collectively plan how to achieve the forum's goals in the future. Following reflection, participants note down the three main lessons arrived at from the discussion questions. This discussion then leads to the recognition of the three main challenges to improving the indicator by the next monitoring period and how they would address those challenges (see Figure 7.1 for an example of a completed reflection sheet). These discussions would then feed into the MSF's annual work plan.

Participants in the tool development process agreed that the tool would use ten statements for its implementation - the four research-based indicators and six other indicators selected from the bank of ten statements. This method was selected as it would allow MSF participants to change the elective statements in different implementations of the tool if their priorities or the context where they worked should change throughout time. The research team went through a few drafts of the full-text tool with all the participating groups until they were all happy to run the version of a tool with their own MSFs. The tool was also peer-reviewed by a group of researchers, practitioners, government actors, and Indigenous and local community organizations.

How are we doing? facilitates participatory monitoring that does more than inform how "local knowledge" can support "technical knowledge," or how the former can make the latter more "transparent." These ideas, common in 


\section{Box 5. Example: completed Reflection sheet}

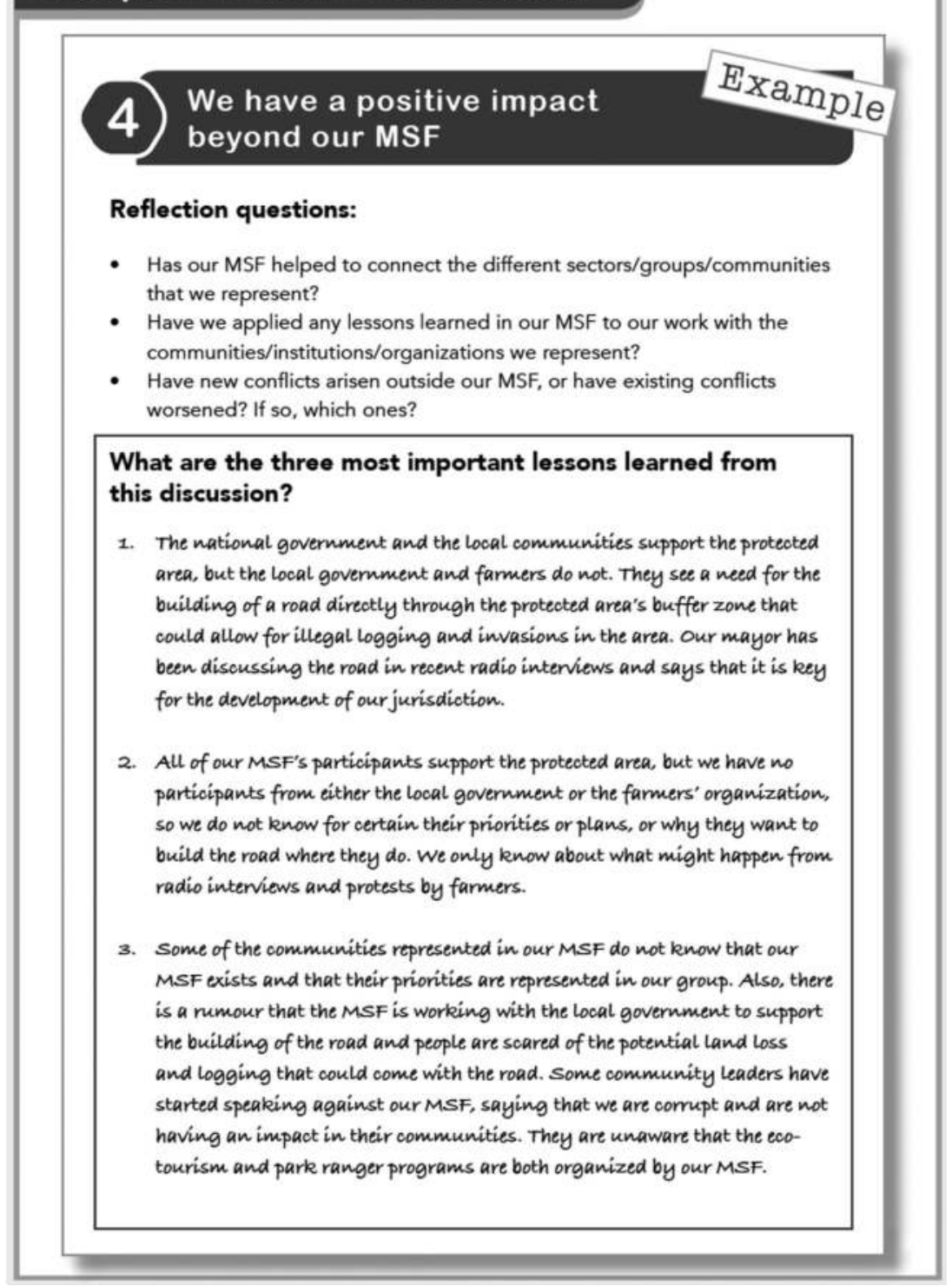

Figure 7.1 Sample completed reflection sheet. 


\section{Box 5. Example: completed} Reflection sheet cont...

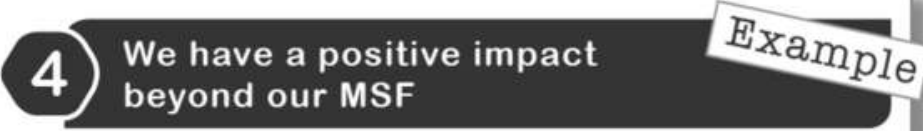

What are the three main challenges to improve or maintain this statement's score for the following period? How will we address them?

We had an average score of 2.5 for this statement. Our three main challenges are:

1. There is a conflict between our role in support of our protected area and the local goverument's plans to build a road for farmers to take their products to sell in our regional capital.

2. There are land conflicts between local communities and farmers in the buffer zone of our protected area.

3. Some of the communities that we represent do not know that our MSF exists or that it represents them

To address these challenges, we will:

1. Start a radio campaign about the threat of the road to the protected area and the services it brings to local populations.

2. Bring in representatives of local farmers to learn about our MSF and for us to learn about their needs and find middle ground.

3. Encourage participants to report to their communities after each of our meetings and actively advertise our activities on our Facebook page and look into designing and printing flyers explaining our work.

Figure 7.1 Continued. 
participatory monitoring tools, tend to be linked to a wider point about monitoring processes - that they have to be "unbiased." De Sy et al.'s (2016) case for independent monitoring approaches calls for "unbiased data, tools and methods (...) that stakeholders involved in land-use sector mitigation activities can rely on for their own goals."

The research team approached this idea with caution. The emphasis on technical approaches and their replicability as a perceived strength may oversimplify what happens on the ground, especially in terms of equity that is not a simple experience to measure, yet is central to the current appeal of MSFs. How are we doing? is based on local peoples' perceptions as the statements were designed based on their ideas of what is important to monitor and reflect upon, and the monitoring process itself is based on bringing their personal perspectives together. Thus, it is biased as, in this case, these perspectives sit on different interests and priorities regarding land and resource use and wider experiences of unequal interactions between stakeholders, and between stakeholders and actors with decision-making power.

\section{Closing remarks}

Research results are clear in that MSFs need strategies to address inequality in their planning, design, implementation, and monitoring, or else they may reproduce and further entrench inequalities under the appearance of effective participation and inclusive decision making. MSFs are evidence that portraying inequalities as obstacles that can be overcome by empowering disempowered people through "participation" (understood as a seat at the table) is insufficient to enact change. This chapter has provided evidence to show how taking time to recognize the interconnections between individuals, groups, and institutions is important for designing initiatives that address inequities and the challenges that emerge as the initiatives progress.

How are we doing? is a reflexive and adaptive learning tool based on principles that resonate with the approach proposed by both ACM and the proposal of designing for engagement. ACM proponents have noted that "addressing climate change will require moving forward with more process-oriented approaches that look to the future, acknowledge local capabilities and opportunities, and build analytical and adaptive capacities at several levels" (CIFOR 2008). As How are we doing? is a participatory tool seeking to support such processes at the jurisdictional level, it may be a potential pathway to support upscaling ACM from the local to the subnational level; this has been noted as a challenge by ACM proponents (Colfer 2011). The potential for this pathway is reinforced by the fact that the MSFs that took part in tool development were among the few multi-actor coordination spaces in their landscapes, and included participants representing governmental and non-governmental organizations from the local, subnational, and national levels. In fact, the lessons learned from research on MSFs summarized in this chapter and that informed How are we doing? are in close conversation with other ACM proponents. These improvements to MSFs are a potentially rich field in which to continue to develop ACM. 
It is premature to assess the results that How are we doing? will have on MSFs, but early results and the sorts of conversations that MSF participants had during the first set of implementations of the tool are promising. Most conversations were set around the need to create strategies for the more effective participation of women in their forums, collaboratively developing ways to adapt their work based on what they had learned from their reflections. The research team will continue to implement the tool, developing different versions of the same reflexive and adaptive method that seeks to bring the key objectives of ACM into MSFs (CIFOR and SERNANP 2020) and territorial governance (CIFOR and ONAMIAP 2020), and publishing their results as they are available.

\section{Acknowledgements}

The author thanks CIFOR's research team on multi-stakeholder forums for their participation in the work that led to this chapter. Led by Anne M. Larson and the author, the team was composed of: Shintia Arwida, Natalia Cisneros, Deborah Delgado, Jazmin Gonzales, Nicole Heise, Christopher Hewlett, Nining Liswanti, Marina Londres, Harlem Mariño, Diego Palacios, Aditio Ramadian, Mayte Benicio Rizek, Daniel Rodriguez, Ade Tamara, and Mastewal Yami. Research funding support was provided by the Norwegian Agency for Development Cooperation, the European Commission, the International Climate Initiative of the German Federal Ministry for the Environment, Nature Conservation and Nuclear Safety, and the United Kingdom's Department for International Development. It was undertaken as part of the CGIAR Research Programs on Policies, Institutions and Markets (PIM), led by the International Food Policy Research Institute (IFPRI) and on Forest, Trees and Agroforestry (FTA), led by CIFOR. The opinions expressed here belong to the author and do not necessarily reflect those of CIFOR, IFPRI, or CGIAR.

\section{Notes}

1 The Realist Synthesis Review method allows for the systematic and comparative analysis of how contexts affect an initiative's outcome, revealing "what works, for whom, in what circumstances, and why" (Pawson 2013). The method allowed the reviewing team to consider how contextual factors affected the transition from theory (design) to practice (implementation) in each MSF case study (see Sarmiento Barletti et al. [2019] for the research protocol).

2 https://sustainabledevelopment.un.org/sdg17.

\section{References}

Atmadja, Stibniati, Christopher Martius, Stephen Leonard, and Maria Sanz Sanchez. Forthcoming. "Transformational Change for Reducing Deforestation and Climate Change Impact: A Review of Definitions, Concepts and Drivers in Scientific and Grey Literature." CIFOR Working Paper. Washington, DC: CIFOR. 
Avritzer, Leonardo. 2002. Democracy and the Public Space in Latin America. Princeton, NJ: Princeton University Press.

Barnes, Grenville, and Brian Child (eds). 2014. Adaptive Cross-Scalar Governance of Natural Resources. London: Routledge.

Bastakoti, Rishi, and Conny Davidsen. 2015. "Nepal's REDD+ Readiness Preparation and Multi-Stakeholder Consultation Challenges." Journal of Forest and Livelihood 13 (1): 30-43. https://doi.org/10.3126/jfl.v13i1.15364

Bastos-Lima, Mairon, Ingrid Visseren-Hamakers, Josefina Braña-Varela, and Aarti Gupta. 2017. "A Reality Check on the Landscape Approach to REDD+: Lessons from Latin America." Forest Policy and Economics 78 (May): 10-20. https://doi.org/10.1016/j.forp ol.2016.12.013.

Buchy, Marlene, and Suzanne Hoverman. 2000. "Understanding Public Participation in Forest Planning: A Review." Forest Policy and Economics 1 (1) (May): 15-25. https://doi .org/10.1016/S1389-9341(00)00006-X

Butler, William, and Courtney Schultz, eds. 2019. A New Era for Collaborative Forest Management: Policy and Practice Insights from the Collaborative Forest Landscape Restoration Program. London: Earthscan/Routledge.

Castro, Alfonso P., and Erik Nielsen. 2001. "Indigenous People and Co-management: Implications for Conflict Management." Environmental Science and Policy 4(4-5): 229-239.

Chambers, Robert. 1983. Rural Development: Putting the Last First. New York: John Wiley.

Chambers Robert, Arnold Pacey, and Lori Thrupp, eds. 1989. Farmer First: Farmer Innovation and Agricultural Research. London: Intermediate Technology Publications.

CIFOR. 2008. "Adaptive Collaborative Management Can Help us Cope with Climate Change." CIFOR Infobrief 13. Bogor: CIFOR.

CIFOR and [ONAMIAP] Organización Nacional de Mujeres Indígenas de los Andes y Amazonía del Perú. 2020. ¿Cómo vamos? Una herramienta para reflexionar sobre la participación de las mujeres indígenas $u$ originarias en la gestión y gobernanza de sus territorios. Lima: CIFOR.

CIFOR and SERNANP. 2020. ¿Cómo Vamos? Una Herramienta para Reflexionar Sobre los Procesos, los Avances y las Prioridades en los Comités de Gestión de las Áreas Naturales Protegidas. Lima: SERNANP.

Cohen, Joshua, and Charles Sabel. 1997. "Directly-deliberative Polyarchy." European Law Journal 3 (4) (December): 313-342. https://doi.org/10.1111/1468-0386.00034.

Colfer, Carol J. Pierce. 1983. "On Communication among 'Unequals'." International Journal of Intercultural Communication 7 (3): 263-283. https://doi.org/10.1016/0147-1767(8 3) $90033-0$.

Colfer, Carol J. Pierce. 2005. The Complex Forest: Communities, Uncertainty, and Adaptive Collaborative Management. Washington, DC: Resources for the Future/CIFOR.

Colfer, Carol J. Pierce, E Andriamampandry, Stella Asaha, Emmanuel Lyimo, Endri Martini, Jean-Laurent Pfund and John Watts. 2011. "Participatory Action Research for Catalyzing Adaptive Management: Analysis of a 'Fits and Starts' Process." Journal of Environmental Science and Engineering 5(1): 28-43.

Cooke, Bill and Uma Kothari, eds. 2001. Participation: The New Tyranny? New York: Zed Books.

Cornwall, Andrea. 2008. "Unpacking 'Participation:' Models, Meanings and Practices." Community Development Journal 43(3) (July): 269-283. https://doi.org/10.1093/cdj/bsn010

Danielsen, Finn, Neil D. Burgess, Per M. Jensen, and Karin Pirhofer-Walzl. 2010. "Environmental Monitoring: The Scale and Speed of Implementation Varies According to the Degree of People's Involvement.” Journal of Applied Ecology 47: 1166-1168. 
De Sy, Veronique, Martin Herold, Christopher Martius, Hannes Bottcher, Steffen Fritz, David Gaveau, Stephen Leonard, Erika Romijn, and Rosa Maria Roman-Cuesta. 2016. "Enhancing transparency in the land-use Sector: Exploring the role of independent monitoring approaches." CIFOR Infobrief 156.

Dougill, Andrew, Evan Fraser, John Holden, Klaus Hubacek, Christina Prell, Mark Reed, Sigrid Stagl, and Lindsay Stringer. 2006. "Learning from Doing Participatory Rural Research: Lessons from the Peak District National Park." Journal of Agricultural Economics 57 (2) (July): 259-275. https://doi.org/10.1111/j.1477-9552.2006.00051.x.

Escobar, Arturo. 1995. Encountering Development: The Making and Unmaking of the Third World. Princeton, NJ: Princeton University Press.

Espinoza Llanos, Roberto, and Conrad Feather. 2011. The Reality of REDD+ in Peru: Between Theory and Practice. Lima: AIDESEP and Forest Peoples Program.

Estrada-Carmona, Natalia, Abigail Hart, Fabrice DeClerck, and Jeffrey Milder. 2014. "Integrated Landscape Management for Agriculture, Rural Livelihoods, and Ecosystem Conservation." Landscape and Urban Planning 129 (September): 1-11. https://doi.org/10 .1016/j.landurbplan.2014.05.001

Evans, Kristen, Selmira Flores, and Anne M. Larson. 2019. "Participatory Monitoring in Forest Communities to Improve Governance, Accountability and Women's Participation." Small-scale Forestry 18: 165-187.

Evans, Kristen, and Manuel Guariguata. 2016. "Success from the Ground Up: Participatory Monitoring and Forest Restoration.” CIFOR Occasional Paper 159. Bogor: CIFOR.

Evans, Kristen, Anne M. Larson, Esther Mwangi, Peter Cronkleton, Tendayi Maravanyika, Xochilt Hernandez, Pilar Müller, Alejandro Pikitle, Roberto Marchena, Concepta Mukasa, Alice Tibazalika, and Abwoli Banana. 2014. Field Guide to Adaptive Collaborative Management and Improving Women's Participation. Bogor, Indonesia: Center for International Forestry Research (CIFOR).

Evans, Kristen, Anne M. Larson, and Selmira Flores. 2020. "Learning to Learn in Tropical Forests: Training Field Teams in Adaptive Collaborative Management, Monitoring and Gender." International Forestry Review 22 (2) (June): 189-198. https://doi.org/10.1505 $/ 146554820829403504$

Faysse, Nicolas. 2006. "Troubles on the Way: An Analysis of the Challenges Faced by Multi-Stakeholder Platforms." Natural Resources Forum 30 (3) (September): 219-229. https://doi.org/10.1111/j.1477-8947.2006.00112.x

Ferguson, James. 1995. The Anti-Politics Machine: 'Development,' Depoliticization and Bureaucratic Power in Lesotho. Minneapolis, MN: University of Minnesota Press.

Fernandez-Gimenez, Maria E., Heidi L. Ballard, and Victoria E. Sturtevant. 2008. "Adaptive Management and Social Learning in Collaborative and Community-Based Monitoring: A Study of Five Community-Based Forestry Organizations in the Western USA.” Ecology and Society 13(2): 4.

Fisher, Micah, Timothy Workman, Agus Mulyana, Moira Moeliono, Linda Yuliani, Carol J. Pierce Colfer, and Urban El Faith Bani Adam. 2017. "Striving for PAR Excellence in Land Use Planning: Multi-Stakeholder Collaboration on Customary Forest Recognition in Bulukumba, South Sulawesi." Land Use Policy 99 (December). https://doi.org/10.1 016/j.landusepol.2017.09.057.

Fishman, Akiva, Edegar Oliveira, and Lloyd Gamble. 2017. Tackling Deforestation Through a Jurisdictional Approach: Lessons from the Field. Washington, DC: Worldwide Fund for Nature.

Franco, Isabel, and Masato Abe. 2020. "SDG 17 Partnerships for the Goals." In Actioning the Global Goals for Local Impact, edited by Isabel Franco, Tathagata Chatterji, Ellen Derbyshire, and James Tracey, 275-293. Singapore: Springer. 
Friedman, Rachel, Angela Guerrero, Ryan McAllister, Jonathan Rhodes, Truly Santika, Sugeng Budiharta, Tito Indrawan et al. 2020. "Beyond the Community in Participatory Forest Management: A Governance Network Perspective." Land Use Policy 97. https:// doi.org/10.1016/j.landusepol.2020.104738

Funder, Mikkel, Finn Danielsen, Yonika Ngaga, Martin R. Nielsen, and Michael K. Poulsen. 2013. "Reshaping Conservation: The Social Dynamics of Participatory Monitoring in Tanzania's Community-managed Forests." Conservation and Society 11: 218-232.

Gallina, Ambra. 2010. Gender Aware Approaches in Agricultural Programmes: International Literature Review. UTV Working Paper 3. Stockholm, Sweden: SIDA.

Gardner, Katy, and David Lewis. 2015. Anthropology and Development: Challenges for the Twenty-First Century. London: Pluto Press.

Gonsalves, Julian, Thomas Becker, Ann Braun, Dindo Campilan, Hidelisa de Chavez, Elizabeth Fajber, Monica Kapiriri, Joy Rivaca-Caminade, and Ronnie Vernooy, eds. 2005. Participatory Research and Development for Sustainable Agriculture and Natural Resource Management: A Sourcebook. Understanding Participatory Research and Development. Lima, Peru: International Potato Center.

Gonzales Tovar, Jazmin, Anne M. Larson, Juan Pablo Sarmiento Barletti, and Grenville Barnes. 2021a. "Politics, Power and the Search for Sustainability in Multi-Stakeholder Territorial Planning: A Comparative Study of Two Contrasting Cases in the Brazilian Amazon." International Forestry Review 23 (S1): 59-75.

Gonzales Tovar, Jazmin, Juan Pablo Sarmiento Barletti, Anne M. Larson, Grenville Barnes, and Catherine Tucker. 2021b. "Can Multi-Stakeholder Forums Empower Indigenous and Local Communities and Promote Forest Conservation? A Comparative Analysis of Territorial Planning in Two Brazilian States with Contrasting Contexts." Conservation Science and Practice 3(1). https://doi.org/10.1111/csp2.326.

Guijt, Irene. 2007. Negotiated Learning: Collaborative Monitoring for Forest Resource Management. Washington, DC: RFF/CIFOR.

Hauser, Oliver, Christian Hilbe, Krishnendu Chatterjee, and Martin Nowak. 2019. "Social Dilemmas among Unequals." Nature 572 (7770): 524-527. https://doi.org/10.1038/s 41586-019-1488-5

Hemmati, Minu. 2002. Multi-Stakeholder Processes for Governance and Sustainability: Beyond Deadlock and Conflict. London: Earthscan.

Klenk, Nicole Lisa, Maureen Reed, Gun Lidestav and Julia Carlsson. 2013. "Models of Representation and Participation in Model Forests." Environmental Policy and Governance 23 (3): 161-176. https://doi.org/10.1002/eet.1611

Larson, Anne M., Juan Pablo Sarmiento Barletti, and Ashwin Ravikumar. 2018. "The Challenge of Coordination in REDD+ Policy and Practice." In Transforming REDD+: Lessons and New Directions, edited by Arild Angelsen. Christopher Martius, Veronique De Sy, Amy Duchelle, Anne M. Larson, and Thuy Pham, 81-91. Bogor, Indonesia: CIFOR.

Larson, Anne M., and Juan Pablo Sarmiento Barletti. 2020. "Designing for Engagement: Insights for More Equitable and Resilient Multi-Stakeholder Forums." CIFOR Infobrief 280. Bogor: CIFOR.

Larson, Anne M., Juan Pablo Sarmiento Barletti, and Nicole Heise Vigil. n.d. "A place at the Table is Not Enough: Multi-Stakeholder Platforms from the Perspective of Indigenous Peoples and Local Communities." Unpublished manuscript. CIFOR.

Lyons, Colleen, Maria DiGiano, Jason Gray, Javier Kinney, Magaly Medeiros, and Francisca Oliveira de Lima Costa. 2019. "Negotiating Climate Justice at the Subnational Scale." In Routledge Handbook of Climate Justice, edited by Tahseen Jafry, 431-448. Oxford: Routledge. 
McDougall, Cynthia, Hemant Ojha, Mani Ram Banjade, Bishnu Hari Pandit, Tara Bhattarai, Manik Maharjan, and Sushila Rana. 2008. Forests of Learning: Experiences from Research on an Adaptive Collaborative Approach to Community Forestry in Nepal. Bogor, Indonesia: CIFOR.

McDougall, Cynthia, Janice Jiggins, Bishnu Hari Pandit, Sushila Thapa Magar Rana, and Cees Leeuwis. 2013. "Does Adaptive Collaborative Forest Governance Affect Poverty? Participatory Action Research in Nepal's Community Forests." Society and Natural Resources 26 (11): 1235-1251. https://doi.org/10.1080/08941920.2013.779344

Mosse, David. 2014. "Knowledge as Relational: Reflections on Knowledge in International Development." Forum for Development Studies 41 (3): 513-523.

Mutimukuru-Maravanyika, Tendayi, and Frank Matose. 2013. "Learning in Contested Landscapes: Applying Adaptive Collaborative Management in Forested Landscapes of Zimbabwe." In Adaptive Collaborative Approaches in Natural Resource Governance, edited by Hemant Ojha, Andy Hall, and Rasheed Sulaiman, 177-215. London: Earthscan/ Routledge.

Nayak, Prateep, and Fikret Berkes. 2008. "Politics of Co-optation: Community Forest Management Versus Joint Forest Management in Orissa, India." Environmental Management 41 (5): 707-18. https://doi.org/10.1007/s00267-008-9088-4.

Nikolakis, William, and Ngaio Hotte. 2019. "How Law Shapes Collaborative Forest Governance: A Focus on Indigenous Peoples." Society \& Natural Resources 33 (1): 1-19. https://doi.org/10.1080/08941920.2019.1605433.

Nyirenda, Richard, and Witness Kozanayi. 2007. "Tracking Broom Grass Resources for Equity in Zimbabwe." In Negotiated Learning: Collaborative Monitoring in Forest Resource Management, edited by Irene Guijt, 66-72. Washington, DC: Resources for the Future.

Palacios Llaque, Diego, and Juan Pablo Sarmiento Barletti. 2021. "The Challenges of Multiple Governmentalities and Forms of Participation in Protected Natural Areas: The Amarakaeri Communal Reserve.” International Forestry Review 23 (S1) : 90-102.

Parkins, John, Michael Dunn, Maureen Reed, and John Sinclair. 2016. "Forest Governance as Neoliberal Strategy: A Comparative Case Study of the Model Forest Program in Canada." Journal of Rural Studies 45: 270-278. https://doi.org/10.1016/j.jrurstud.2016.04.006.

Pawson, Ray. 2013. The Science of Evaluation: A Realist Manifesto. London: SAGE.

Pinkerton, Evelyn. 2019. "Benefits of Collaboration Between Indigenous and nonIndigenous Communities Through Community Forests in British Columbia." Canadian Journal of Forest Research 49(4): 387-394.

Pinto, Severino R., Felipe Melo, Marcelo Tabarelli, Aurélio Padovesi, Carlos A. Mesquita, Carlos Alberto de Mattos Scaramuzza, Pedro Castro, Helena Carrascosa, Miguel Calmon, Ricardo Rodrigues, Ricardo Gomes César, and Pedro H. S. Brancalion. 2014. "Governing and Delivering a Biome-wide Restoration Initiative: The Case of Atlantic Forest Restoration Pact in Brazil." Forests 5(9): 2212-2229

Reed, Mark. 2008. "Stakeholder Participation for Environmental Management: A Literature Review." Biological Conservation 141 (10): 2417-2431. https://doi.org/10.1016/j.biocon .2008.07.014.

Rodriguez, Daniel, and Juan Pablo Sarmiento Barletti. 2021. "Can Multi-Stakeholder Forums Mediate Rights and Development Priorities? Insights from the Peruvian Amazon." International Forestry Review 23 (S1): 103-115.

Reed, James, Josh Van Vianen, Elizabeth L. Deakin, Jos Barlow, and Terry Sunderland. 2016. "Integrated Landscape Approaches to Managing Social and Environmental Issues in the Tropics: Learning from the Past to Guide the Future." Global Change Biology 22(7): 2540-2554. 
Robbins, Paul. 2012. Political Ecology: A Critical Introduction. Oxford: Wiley-Blackwell.

Sarmiento Barletti, Juan Pablo, and Anne M. Larson. 2019a. "The Role of Multi-Stakeholder Forums in Subnational Jurisdictions: Framing Literature Review for In-Depth Field Research." CIFOR Occasional Paper 194. Bogor: CIFOR.

Sarmiento Barletti, Juan Pablo, and Anne M. Larson. 2020. "Paradigms for Participation in Multi-stakeholder Forums: Lessons from a Realist Synthesis Review." CIFOR Infobrief 281.

Sarmiento Barletti, Juan Pablo, and Anne M. Larson. 2019b. The Role of Multi-Stakeholder Forums in Subnational Jurisdictions: Methods Training Manual and Tools for In-Depth Research. Bogor, Indonesia: CIFOR.

Sarmiento Barletti, Juan Pablo, and Anne M. Larson. 2020a. "How are Land-Use MultiStakeholder Forums Affected by their Contexts? Perspectives from Two Regions of the Peruvian Amazon." In The Wicked Problem of Forest Policy, edited by John Innes and William Nikolakis, 301-327. Cambridge: Cambridge University Press.

Sarmiento Barletti, Juan Pablo, and Anne M. Larson. 2020b. "Paradigms for Participation in Multi-Stakeholder Forums: Lessons from a Realist Synthesis Review.” CIFOR Infobrief 281. Bogor: CIFOR.

Sarmiento Barletti, Juan Pablo, Christopher Hewlett, and Anne M. Larson. 2019. "Protocol for a Realist Synthesis Review: How Does Context Affect the Outcomes of Subnational Multi-Stakeholder Forums on Land-Use/Land-Use Change?” Bogor: CIFOR.

Sarmiento Barletti, Juan Pablo, Anne M. Larson, Christopher Hewlett, and Deborah Delgado. 2020a. "Designing for Engagement: A Realist Synthesis Review of How Context Affects the Outcomes of Multi-Stakeholder Forums on Land Use and/or Land-Use Change." World Development 127: 1-19.

Sarmiento Barletti, Juan Pablo, Anne M. Larson, Natalia Cisneros, Nicole Heise, Nining Liswanti, Harlem Mariño, and Ade Tamara. 2020b. How Are We Doing? A Reflexive Tool to Learn About our Multi-Stakeholder Forum's Process, Progress and Priorities. Bogor, Indonesia: CIFOR.

Sarmiento Barletti, Juan Pablo, Anne M. Larson, and Nicole Heise. 2021. "Organizing for Transformation? How and Why Organizers Plan their Multi-Stakeholder Forums.“ International Forestry Review 23 (S1): 9-23.

Sarmiento Barletti, Juan Pablo, Nicole Heise, and Natalia Cisneros. Forthcoming. "Designing for Engagement: Lessons from Multi-stakeholder Forums for More Equitable Community Forest Management Initiatives." In The Routledge Handbook of Community Forest Management. Oxford: Routledge.

Sayer, Jeffrey, Terry Sunderland, Jaboury Ghazoul, Jean-Laurent Pfund, Douglas Sheil, Erik Meijaard, Michelle Venter, Agni Klintuni Boedhihartono, Michael Day, Claude Garcia, Cora van Oosten, and Louise E. Buck. 2013. "Ten principles for a landscape approach to reconciling agriculture, conservation, and other competing land uses." Proceedings of the National Academy of Sciences of the United States of America 110(21): 8349-8356.

Søreide, Tina, and Rory Truex. 2011. "Collaboration Against Corruption? Multistakeholder Groups in Natural Resource Management." Anti-Corruption Resource Centre U4 5: 1-25.

Stanturf, John, Stephanie Mansourian, and Michael Kleine (eds). 2017. Implementing Forest Landscape Restoration: A Practitioner's Guide. Vienna: IUFRO.

Stringer, Lindsay C., Andrew J. Dougill, Evan Fraser, Klaus Hubacek, Christina Prell, and Mark S. Reed. 2006. "Unpacking "Participation" in the Adaptive Management of Social-ecological Systems: A Critical Review.” Ecology and Society 11(2): 39.

Tamara, Ade, Nicole Heise Vigil, Nining Liswanti, Shintia Arwida, Anne M. Larson, and Juan Pablo Sarmiento Barletti. 2021. "Trust Building and Leadership in Multi-Stakeholder Forums: Lessons from Indonesia.” International Forestry Review 23 (S1): 43-58. 


\section{Juan Pablo Sarmiento Barletti}

Taitelbaum, Sara. 2016. "Introduction: A Shared Framework for the Analysis of Community Forestry in Canada." In Community Forestry in Canada: Lessons from Policy and Practice, edited by Sara Taitelbaum, pp. 3-30. Vancouver: University of British Columbia Press.

Tippett, Joanne, John F. Handley, and Joe Ravetz. 2007. "Meeting the Challenges of Sustainable Development: A Conceptual Appraisal of a New Methodology for Participatory Ecological Planning." Progress in Planning 67(1): 9-98.

United Nations Development Programme (UNDP). 2017. Institutional and Context Analysis for the Sustainable Development Goals: Guidance Note. New York: UNDP.

Wampler, Brian. 2010. Participatory Budgeting in Brazil: Contestation, Cooperation, and Accountability. University Park, Pennsylvania: Penn State Press.

Warner, Jeroen. 2006. "More Sustainable Participation? Multi-Stakeholder Platforms for Integrated Catchment Management." Water Resources Development 22 (1): 15-35. https:/ /doi.org/10.1080/07900620500404992.

Yami, Mastewal, Juan Pablo Sarmiento Barletti, and Anne M. Larson. 2021. "Can MultiStakeholder Forums Influence Good Governance in Communal Forest Management? Lessons from Two Case Studies in Ethiopia." International Forestry Review 23 (S1): 24-42. 


\section{Introduction to Chapter 8}

Chapter 8 shifts gears, providing a much more theoretical interpretation of ACM processes. In some ways, it takes up where Chapter 1 left off - providing a theoretical update. Whereas Chapter 1 began from the mainly anthropological theories and practices with which we began ACM, Chapter 8 draws on political science, governance, feminist and other more recent social theories to tackle continuing challenges of power asymmetry in community-based natural resources management. The authors emphasis is on understanding the persistence of power imbalances and how ACM can help to shift such imbalances, so common in local resource management institutions.

McDougall and Ojha apply a theoretical lens to their own long-term engagement in Nepal's community forestry to highlight mechanisms underlying the positive shifts in power in that ACM case. They look at three concepts that help to unpack and explain power imbalances: (i) culturally rooted social and gender identities (unmarked categories); (ii) dominant beliefs that are internalized and thus taken-for-granted and unnoticed (doxa); and (iii) political representation (delegation). They then discuss the interplay between structure and agency, an interface that can offer clues to how and when ACM can contribute to changing power relations. In thinking about what actually allows empowerment to occur, they emphasize reflexivity (as emphasized in Chapters 2, 3, 6 and 7) and how it links with deliberative decision making and social learning. They conclude that employing these processes in theoretically grounded ways can greatly enhance ACM's effectiveness in empowerment.

Although this chapter will be more of a struggle for biophysical scientists, given the theoretical orientation and social science language, it provides a very useful understanding of processes that have not been examined in this way or in this detail before. With growing global recognition of the importance of more successful collaborations with communities in a variety of fields - REDD+, forest restoration, climate change mitigation and adaptation, etc. - this chapter provides some excellent theoretical building blocks from which to work. 


\title{
8 How does adaptive collaborative management leverage changes in power Insights from social theory
}

\author{
Cynthia McDougall and Hemant Ojha
}

\section{Introduction}

As community-based natural resources management (CBNRM) initiatives proliferate in low-income country contexts - from forestry through fisheries, marine protected areas, to REDD+ investments and beyond - power imbalances in CBNRM emerge as a major concern (Colfer 2005; Berkes 2006; Ojha, Cameron and Kumar 2009; Adams, Juran and Ajibade 2018). Even in CBNRM cases considered "successful," power imbalances persist, leading to inequitable decision making and distributional outcomes (Arts and Visseren-Hamakers 2012; Basnyat et al. 2020). Addressing these dynamics has become pressing, even more so in recent times with the COVID-19 pandemic's exacerbation of structural inequities along the intersecting lines of gender, wealth, ethnicity, migrant status and more (see Kabeer, Razavi, and van der Meulen Rodgers 2021).

While power can be understood as a phenomenon within and across multiple scales, in this chapter, we focus on the local (community and intra-community) scale in CBNRM. Here, power imbalances - especially relating to gender and intersecting socio-economic dimensions of inequality - frequently play out in terms of the marginalization of some people from decision-making processes (Mahanty et al. 2006; Nightingale 2011; Cassidy 2021). In terms of everyday experiences of people from marginalized groups, the effects of this marginalization include less access, amount or quality of natural resources, lower-income opportunities or returns, and potentially higher burdens and risks such as challenges in meeting resource-related fees, distances, or restrictions. Power asymmetries compound climate risks and vulnerabilities of marginalized actors, as well as weaken resource governance due to limited input, buy-in and conflict (Colfer 2005). Consequently, these power dynamics and inequities limit conservation and development outcomes, including women's empowerment and poverty reduction (Lachapelle, Smith and McCool 2004; Charnley and Poe 2007; Baynes et al. 2016). As such, unaddressed power imbalances limit CBNRM's potential to contribute to pressing Sustainable Development Goals (SDGs), in particular, SDGs 1 (poverty reduction), 5 (gender equality), 8 (decent work), 10 (inequity) and 13 (climate resilience), as well as 14 (life below water) and 15 (land). 
Amidst a variety of initiatives in CBNRM, adaptive collaborative management (ACM) has emerged as one potentially promising approach (Colfer 2005). ACM is "an approach in which shared learning, experimentation, and adaptation are key principles, as are inclusivity and shared decision-making at various levels" (Box 8.1). The approach has emerged in various forms in response to the complexity of socio-ecological systems and the challenges of enhancing collaborative decision making among multiple actors in such systems, which are often under top-down governance or varying stages of devolution (Folke et al. 2005; Colfer 2005; Olsson et al. 2006; see also Plummer, Armitage and de Loë 2013). While on the one hand, ACM has been criticized for not explicitly or effectively acknowledging or engaging with power and related risks (Colfer 2005; Plummer and Armitage 2007; Nadasdy 2007; Mutimukuru-Maravanyika and Matose 2013; Ojha, Hall and Sulaiman 2013), on the other hand, there are some promising examples evidencing ACM's ability to engage and contribute to shifting power towards greater equity (McDougall et al. 2013b; McDougall and Banjade 2015; Chapters 4 and 5, this volume; Colfer 2005). The latter, however, have been mainly in empirical, descriptive terms (i.e., what interventions contributed to what observed effects). What is lacking is a theoretically nuanced explanation of how ACM engages with and addresses power imbalances in the latter at a deeper level. Without an understanding of underlying phenomena and mechanisms at play, we are left with the fundamental question: "Yes, in some cases ACM shifts power and reduces inequities, but how?"

This dearth of theoretical exploration into power leaves ACM and CBNRM at an impasse. This morass is in urgent need of addressing given the policy and development investments in CBNRM and ACM in the past decade. It is this knowledge gap and risk that animates our motivation for this chapter. In line with Lewin's maxim that "There is nothing as practical as a good theory," we turn to social theory to ultimately enable more effective engagement with power in practice. We propose that a theory-based inquiry can elucidate the underlying mechanisms of persistence and change in power relations, thus sharpening the edge of ACM and its ability to improve CBNRM policy and practice. This theoretical exploration thus seeks to tackle two main questions:

1) Why do power imbalances persist in CBNRM contexts?

2) When ACM does constructively shift power imbalances, how can this be explained? In other words, what are the underlying mechanisms at play?

In addressing these questions, we do not seek to explore the depths of any single theoretical perspective on power, nor do we present a comprehensive review of the literature. Rather, following Kemp (2010), we aim to build bridges across ontological divides (around the nature and dynamics of power imbalances). Specifically, we integrate formative social theory-related insights (from the work of Bourdieu, Giddens, Archer and Habermas), enriched with feminist theory from various arenas (drawing in particular on Kabeer's foundational inputs as well as more recent insights of Mackay and Ackerly). The 
feminist theory's specific value is through its critique regarding the need for theory to engage without blinders with an imperfect and unequal world, and its contributions regarding what is needed to create a more level playing field given these imperfections. While this wide cross-fertilization may be academically unconventional, we see it as worthwhile to help create a richer and more coherent picture for CBNRM and ACM policymakers and practitioners alike.

The chapter's aim is thus to generate a theoretical explanation of why power imbalances persist in local scale CBNRM and how an ACM approach interacts with power-reproducing dynamics to enable shifts in them. First, we ground the chapter by briefly presenting an example of ACM in Nepal that demonstrates persistent power imbalances and evidence that they shifted with ACM. Next, we unpack concepts: defining power and exploring relevant conceptions of power. Following that, we explore theoretical underpinnings explaining why power imbalances persist, in particular using concepts of unmarked categories, doxa, delegation and the interface between structure and agency. This is followed by an exploration of how ACM may contribute to transforming these power imbalances (i.e., what mechanisms underlie changes). In particular, here we unpack and explain the potential for shifting power through the concepts of reflexivity, deliberative decision making and social learning. The interplay of these concepts is graphically summarized in Figure 8.1. The chapter wraps up by highlighting insights developed through this exploration, including regarding a relatively unique role ACM may be able to play in relation to one form of power (power over) and speculating on the application of this learning.

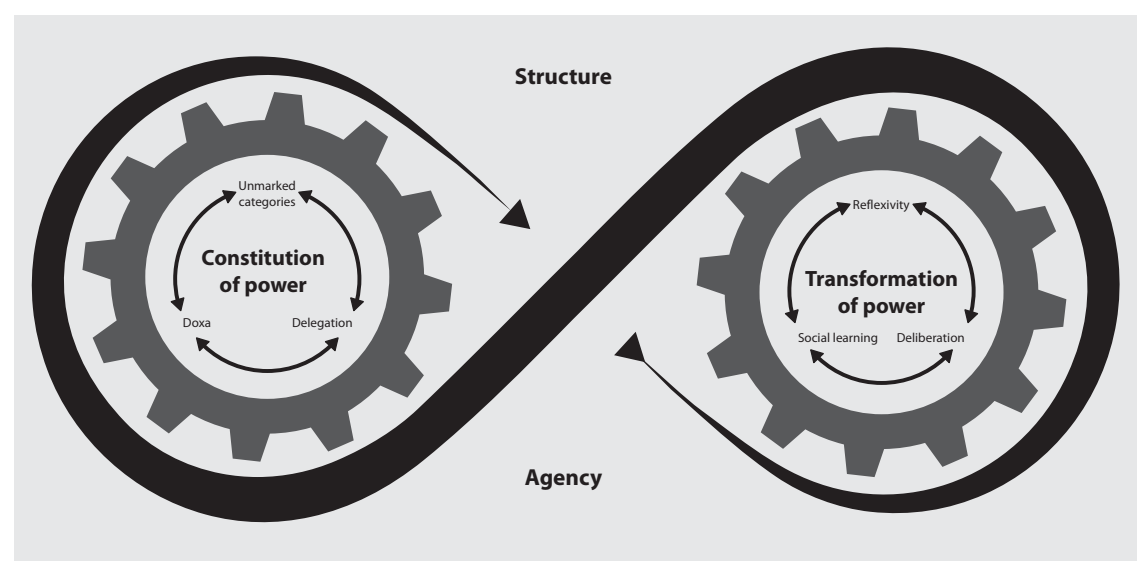

Figure 8.1 Indicating perpetual evolution.

\section{Power and ACM: An empirical example from community forestry in Nepal}

The case presented here draws on a six-year collaborative research initiative focused on catalysing and assessing ACM and its effects in community forestry 
in Nepal (see McDougall et al. 2013a, b; McDougall and Banjade 2015). ${ }^{2}$ In this case, ACM was understood as an approach in which actors "intentionally use social learning as the basis for decision making (see Leeuwis and Pyburn 2002), emphasize inclusion and equity in processes and outcomes, and seek to engender effective connections amongst actors and/or groups of actors" (McDougall and Banjade 2015). This initiative emerged in response to recognition by government, civil society, development agencies and research groups that community forestry - framed as a form of "pro-poor and inclusive CBNRM" - was not delivering on its social and poverty reduction goals. While it had been extensively (and "successfully") scaled out in Nepal by 1999 (at the time of project start) through the establishment of over 10,000 community forest user groups (CFUGs) (Kanel and Kandel 2004) and had led to some conservation outcomes, it was evident that the CFUGs were replicating the pre-existing gender and social inequalities. Not only were decision making and benefit sharing biased systematically towards more powerful (wealthy, male, higher caste) local actors, but in some cases, marginalized actors were being made worse off (Agarwal 2001; Bhattarai and Ojha 2001; Buchy and Subba 2003).

While this ACM study engaged from sub-local through national scales, here we focus on the local scale, within and up to the level of CFUGs. These groups hold legal use rights over community forests and have significant institutional autonomy to plan and manage forests for the benefit of local households. The research used in-depth multi-year case studies, using mixed methods involving qualitative and quantitative assessment. The transition to ACM took place through participatory action research (PAR), which is a well-established, people-centred, integrated strategy to learning and action for catalysing ACM (see Selener 1997; Chevalier and Buckles 2013). In this study, PAR was oriented to the CFUGs seeking to improve their own, self-identified, site-specific community forestry-related issues (including internal relations and conflict, equity and livelihood outcomes; see more on PAR in Chapter 9). They operationalized this through shared, iterative, learning-based efforts to enhance the internal adaptiveness of their CFUG governance as well as strengthen the CFUGs' collaboration with other stakeholders. The first phase (1999-2002) involved four CFUG case studies (i.e., long-term sites). While these continued through the second phase, an additional seven sites were added in 2004-2007 ( $\mathrm{n}=11$ groups). A final field visit to each site took place in 2008.

Through participatory action research, the groups shifted from "business as usual" to varying degrees of ACM-based decision making. (In fact, the case team came to refer to it as adaptive collaborative governance, as opposed to adaptive collaborative management, because of the strong emphasis on applying learning and collaborative strategies primarily to the decision making (governance) itself, not to technical management.) In terms of processes, the groups shifted away from operational and annual plans being based on standard local "blueprints" or interests of more powerful committee members to participatory visioning and self-monitoring-based planning. This involved cycles of shared visioning, collaborative assessment of strengths and weaknesses using the CFUG's own 
indicators, and participatory reflection leading to the adjustment and implementation of processes and management plans. A central part of this was the self-analysis of equity (in governance and of outcomes) by CFUG members. Equity-tracking processes involved strategies such as participatory wealth ranking and gender data as the basis for CFUGs' monitoring of their diverse members' involvement in, and distribution of benefits from, the CFUG, crosschecked against agreed aims and indicators. In terms of institutional arrangements, CFUGs shifted from executive committees as the single decision making bodies to multi-level, multi-node (i.e., nested) arrangements, with toles (hamlets) as the base. The approach was catalysed and backstopped by facilitators - first external, then a combination of local and extension actors, backstopped periodically by research team members. The facilitators' role was not only to lead processes but also to take on the role of a supportive "critical questioner," raising queries to spark reflection and self-awareness, helping the group members to "hold up a mirror" on their own assumptions, practices and resultant outcomes. Facilitators also supported groups in recognizing and addressing conflicts in a transparent way as a part of the ACM approach (McDougall and Banjade 2015).

In terms of effects, although the progress was not linear, the case evidenced recognizable changes in power imbalances and a shift towards greater gender and social equity across all sites. At the outset, women, Dalit (a highly marginalized caste group) and poorest members were largely marginalized from CFUG decision making, including being driven away from general assemblies, and accessed relatively few benefits. In some cases, they reported being persecuted and accused as "destroyers" for pursuing what they saw as their only livelihood option (fuelwood selling). In all CFUGs, there was resource-related conflict, most of which had persisted over many years. The primary areas of this persistent conflict were identified as related to equity in: decision making, especially the de facto exclusion of members along the lines of class, caste, ethnicity or gender hierarchies and corruption and transparency issues relating to executive committees; distributional rights and resources, especially forest product distribution and benefit sharing; "illegal" collection and sale of firewood by low caste and poor members (mostly women); and "encroachment" issues.

The assessments during and at the end of the participatory action research found that ACM contributed to shifts in relation to the above power issues. In terms of decision making, not only were there quantitative increases in previously marginalized members attending CFUG assemblies, but researchers noted shifts in "voice," including that women increasingly challenged power imbalances as individuals and collectively. For example, in one site, a Mothers' Group - led by a Dalit woman - successfully removed the CFUG chairperson who had been misappropriating CFUG funds. In terms of leadership, the representation of women and poor members in executive committees almost doubled across sites. The selfmonitoring records of all CFUGs indicated that members perceived their engagement to have increased in 27 of the 28 self-assessed indicators (in total, all sites) relating to participation and/or "voice." As one tole representative noted: "In the past our [women's] voice was not considered but nowadays our sayings also are counted and we are asked as well" (McDougall and Banjade 2015). 
Finally, in terms of the extent to which the user groups' priorities and actions reflect the marginalized members' interests and needs (as a proxy for distributional equity), the case also found a shift in all sites towards CFUG priorities better reflecting women's and poor and low caste members' priorities than at the outset of ACM. For example, the number of sites with incomegeneration initiatives targeted to women and/or poor members increased from two to ten (of 11), with the eleventh site planning one for the post-research period. Similarly, the number of sites with pro-poor small loan programmes grew from five to nine of 11 sites, with the remaining two having plans to start in the post-project period. As one poor member explained, "After...tole-level reflection and discussion, the real poor have accessed the community forest fund for income-generation activities in an equitable manner and increased [the participation of the] poor" (McDougall et al. 2013a, 9).

\section{Understanding power: Key concepts}

Power is a multidimensional concept and is interpreted in diverse ways. At a basic level, power can be understood as relating to the capacity of individuals or groups to exercise their will. As such, is a condition for the potential for (social) action (Rupert 2004). In other words, "power is the production, in and through social relations, of effects that shape the capacities of actors to determine their own circumstances and fate" (Barnett and Duvall 2004, 9).

A central feature of power is that it is relational - one actor's power cannot be specified except in relation to that of other parties. This is illustrated in Weber's contributions, in which power is understood as "the probability that one actor within a social relationship will be in a position to carry out his [sic] own will despite resistance" (Weber 1978, 53). While shedding the masculine language, the relational understanding is a central driver in Kabeer's approach in gender and development: ${ }^{3}$ the "concept of gender relations sought to shift attention away from looking at women and men as isolated categories to looking at the social relationships through which they were mutually constituted as unequal social categories" (Whitehead 1979; Elson 1991) (Kabeer and Subrahmanian 1996, 17). As CBNRM represents multiple actors and/or groups negotiating the management of shared resources, power relations of one form or another are manifest in CBNRM. Power relations underpin how and the extent to which different actors control, use and benefit or bear risks related to resources and thus shape equity (Box 8.1; Sikor and Lund 2009).

\section{BOX 8.1 EQUITY AND CBNRM}

Equity, a cornerstone concept bridging social justice and development, refers here to the perception of fairness and relates to procedural and distributional domains. Procedural equity in natural resources encompasses not only recognition of rights, but also spans actors' inclusion, and power 
and ability to engage without discrimination, to make views clearly understood and appreciated by others and to negotiate and influence (including enabling processes; see Agarwal 2001; Österblom et al. 2020; Bennett et al. 2019; Ribot and Peluso 2003; Ojha 2008; McDougall et al. 2013a). Procedural equity, however, is mediated by a multitude of factors. For example, in many parts of the Global South, cultural and colonial assumptions about CBNRM being a male domain, normative constraints about men - not women - being "leaders," compounded by associated unequal gender divisions of unpaid labour. These have contributed to patterns of women's engagement in CBNRM decision making being token (attending versus influencing; Kleiber, Harris and Vincent 2018). In this sense, recognitional justice (see Bennett et al.2019) can be considered a foundation for procedural equity.

Equity in CBNRM outcomes - distributional equity - relates to the proportioning of benefits and burdens of all kinds. This includes distribution of benefits such as amount or quality of natural resources, related income or opportunities and also burdens such as resource-related fees, distances walked or restrictions on harvesting. Those whose interests are marginalized by power imbalances, whether they are themselves present or absent in governance (low procedural equity), are less likely to get their resource needs met and may bear a relatively larger portion of the burdens (low distributional equity).

Power relations are also nuanced and complex in multiple ways. First, they do not exist in the abstract; rather, they are embedded in specific socio-economic, political and ecological contexts. Moreover, they are negotiated and change over time. Second, however, there is a tension between this embeddedness and dynamism: across contexts and over time in CBNRM - and development more broadly - certain markers of identity (socio-economic characteristics), show up as consistently correlated to lower power. These patterns of actors with lower power relate (but are not limited) to gender (women), wealth (low income) and low social status groups (such as low caste groups in South Asia and ethnic minorities). Third, power is not uni-dimensionally constituted. Rather, power is nuanced in that it reflects multifaceted identities or intersectionalities: one actor is never fully embodied by a single identity (McDougall 2001; Sen 2006; Nightingale 2011). Different markers of identity, in different combinations, such as gender, ethnicity, caste and wealth have varying and contextdependent implications. Thus, while gender is a significant marker of power differences throughout the world, the relative power of different women or groups of women is shaped by many other factors such as wealth, marital status and age. For instance, in contexts such as Nepal and India, Indigenous women may be less subject to the dominant cultural norms that discourage 
otherwise more privileged Brahmin women from speaking out in public meetings. Overall, the above patterns elucidate that while power is dynamic and can be context-specific, it is rooted in various structural regularities in the society, hence is neither neutrally nor randomly expressed.

Additionally, development and CBNRM literatures have increasingly recognized that power needs to be understood in relation to systemic aspects of society or its formal and informal rules. Specifically, and of relevance to CBNRM and equity, is the fact that power relations are embedded within institutions. ${ }^{4}$ Feminist theory in particular adds depth here to institutional theory relating to power, unpacking the "complex ways in which organizational rules, cultural norms and routinized practices from different institutional sites intersect to produce and sustain such inequality across society" (Kabeer and Subrahmanian 1996, 21). As elucidated by Kabeer and Subrahmanian (1996, 17):

Gender relations are an aspect of broader social relations and, like all social relations, are constituted through the rules, norms and practices by which resources are allocated, tasks and responsibilities are assigned, value is given and power is mobilized. In other words, gender relations do not operate in a social vacuum but are products of the ways in which institutions are organized and reconstituted over time.

Decades later, Mackay, Kenny and Chappell (2010) flag the same as they underscore the continuing need for and value-added of a feminist lens to otherwise often power-light or gender-blind institutional theory. ${ }^{5}$

Sources of power have been distinguished in a multitude of ways. Galbraith, for instance, frames power as "condign" (based on force), "compensatory" (based on the use of resources) or "conditioned," and sources of power as "personality" (individuals), "property" (resources) and "organizational" (Galbraith 1983). In a broader social commentary, Toffler emphasizes the transformative and amplifying role of knowledge vis-a-vis power: "Knowledge itself... turns out to be not only the source of the highest-quality power, but also the most important ingredient of [the other sources of power:] force and wealth" (Toffler 1990, 18). Linking to CBNRM, it is useful to recognize the focus on capital brought in by livelihood frameworks (Ellis and Freeman 2004), such as human capital (including knowledge, ability to labour, language skills, persuasive ability and ability to speak in public assemblies), symbolic capital (respect, honour and so forth) and social capital (in terms of positive linkages to others and/or to powerful actors). It is critical to note that "power is most likely to be exercised by those who are able to mobilize these resources over a range of organizational domains" (Kabeer and Subrahmanian 1996, 21). Connecting to the gendered patterns noted earlier:

It is precisely because men from any given social class are more able in general than women from the same social class to mobilize resources from 
a broader range of organizational domains - the intimate and personalized organizations of family and kinship to the increasingly more distant and apparently impersonal organizations, community, market and state - that gender relations are constituted as relations of power.

Institutional theory concurs that there are power differentials between institutional actors and offers further that these arise from access to resources that are tied to "rules and worldviews" that differentially constrain or empower different actors (Olsen 2009, 9). Mackay et al. $(2010,581)$ underscore that feminist institutional analysis adds value here by highlighting that

access to these resources, and the power they create, has a gender bias... While constructions of masculinity and femininity are both present in political institutions, the masculine ideal underpins institutional structures, practices and norms, shaping "ways of valuing things, ways of behaving and ways of being" (Duerst-Lahti and Kelly 1995, 20), as well as constraining the expression and articulation of marginalized perspectives. With a few exceptions, women are... thereby disadvantaged in the power play over which ideas matter and who accumulates institutional resources.

Finally, power can be unpacked into forms of power: i) influence on or control over resources or over other actors ("power over"); ii) actors being socially empowered with capacities and practices that influence their ability to perform or achieve socially meaningful action ("power to"); iii) internal sense of selfworth and confidence ("power within"); and iv) relation or connection with others ("power with") (see Hillenbrand et al. 2015). ${ }^{6}$ While not necessarily explicitly identified, a review of the relevant literature for this chapter suggests that much CBNRM (as well as empowerment-focused development) work is implicitly oriented towards the latter three. Specifically, there are considerable investments in three kinds of social capital (see McDougall and Banjade 2015), all contributing to "power with": the bonding (within groups), bridging (connecting between similar groups) and linking (between community groups and NGOs, government or other agencies) social capital. Similarly, there is considerable investment in capacity building aspects of CBNRM, aimed at building "power within" and enhancing the ability to act based on greater information, resources or networks ("power to").

In line with the feminist critique that this may embody "empowerment lite" (Cornwall 2018), what is notably less clear in the literature is reference to how "power over" (other actors) can be shifted - in particular, the power imbalances between more and less powerful groups. This leaves a gap in knowledge for CBNRM - and in particular for ACM - regarding how policy and practice can effectively address the pervasive and persistent multifaceted social (including gender, caste and class) hierarchies that shape engagement and outcomes of management. This missing thread in the literature is the entry point for our analysis. 


\section{Why power imbalances persist}

In the previous section, we defined and unpacked the concept of power. Here we use social theory, including feminist thinking, to explore and explain the persistence of power imbalances. We begin by exploring three concepts that help to unpack and explain power imbalances: i) privileged and marginalized social and gender identities (unmarked categories); ii) dominant beliefs that are internalized and thus taken for granted and unnoticed, dominant beliefs (doxa); and iii) political representation (delegation). Together, these cover a broad swath of social theory on structural forms of power. We then consider the persistence of these imbalances through the application of the more encompassing and interconnected concepts of structure and agency. As noted, here we draw on an array of political and institutional theory including feminist critiques that address earlier gender blindness and wrestle with these issues in an imperfect (power-imbalanced) world. Together, these conceptual lenses offer an explanation of the internalized and structural aspects that contribute to stasis in power imbalances, while also indicating the potential for transformation. We conclude each subsection with a question; we gather and return to these in the next section of the chapter.

\section{Unmarked categories}

Bucholtz and Hall $(2004,372)$ describe the phenomenon of unmarked categories as "an ideological process of erasure." The concept, with its roots in feminism and linguistics, offers a lens into power imbalances by highlighting the phenomenon of more dominant, powerful categories of actors being (unconsciously) understood as constituting the standard for all categories of social actors. As dominant actors are taken to constitute the norm (the "unmarked category"), other identities are implicitly delegated to outlier status (the "marked" categories) - "the Other" (as per de Beauvoir [1953]). ${ }^{7}$ Buchholtz and Hall (2004) describe it thus:

When one category is elevated as an unmarked norm, its power is more pervasive because it is masked. By being construed as both powerful and normative, its special status is naturalized and the effort required to achieve this status is rendered invisible...Because markedness implies hierarchy, differences between groups become socially evaluated as deviations from a norm and, indeed, as failures to measure up to an implied or explicit standard. Hence such differences are used as a justification for social inequality.

(Bucholtz and Hall 2004, 373)

The construct of unmarked categories is illustrated in local CBNRM contexts in terms of dominant, visible and powerful actors - such as wealthier, nonminority men in the Nepal forestry case - embodying the norm or unmarked category. Other actors - women, poor, Dalit people and especially those for 
whom such markers of identity overlap - constitute the marked categories who are "less than" the norm. Being perceived as outliers, these (non-dominant) "marked" actors have tended to be implicitly overlooked (erased) while more dominant, visible and powerful actors can claim to or are perceived by government, extension, NGO and other actors to be "the community" and legitimate (Chambers 1995; Guijt and Shah 1998; see also Criado Perez 2019 for how this translates to data gaps and gender-blind innovation and policy). We suggest this also plays into the positioning of marginalized actors as "deviants" (such as the Dalit members in the case above, being driven away from assemblies and framed as "destroyers"). If this aspect of power imbalances is considered in terms of systemic erasure - or a form of myopia - then the question emerges: What shifts in process or otherwise would contribute to making less powerful groups seen and, moreover, recognized on their own terms?

\section{Doxa}

Doxa is another important concept in understanding power imbalances. Here we shift from (non-dominant) actors being unnoticed (above) to underlying beliefs or assumptions being unnoticed. In the words of social theorist Bourdieu, doxa refers to "a particular point of view, the point of view of the dominant, which presents and imposes itself as a universal point of view" (Bourdieu 1998, 57). As main aspects of the social order are naturalized, they become taken for granted and go unnoticed specifically because they become perceived as part of the "natural" order (doxa). Regardless of the actor's intentions, practices thus tend to reinforce the claims of the powerful (Bourdieu 1977). In this way, doxa reinforces the dominant discourse, values, standards, procedures or beliefs that are taken for granted and 'go without saying.' In doing so, doxa simultaneously does two things: it legitimates otherwise potentially illegitimate practices (such as unequal rights, or inequitable access to natural resources) and reduces the perceived need for deliberation and critical thought (Ojha 2006).

The concept of doxa sheds light on how power imbalances are perceived - or more accurately not perceived (unnoticed) in CBNRM, as in development more broadly. As noted by Kabeer and Subrahmanian (1996, 25), "Few institutions profess explicitly to ideologies of inequality; where inequalities are observed, they tend to be explained in terms of natural difference, divine will or culture and tradition." The widespread internalization of unequal and constraining gender norms in CBNRM (and agriculture) is a potent example (see McDougall et al. 2021). This includes the framing of men as decision makers, leaders and "real" farmers and fishers - in contrast to women as followers, caregivers and "helpers." Women and men alike are so deeply immersed in these norms that they may be largely unaware of them and how they affect all aspects of decision making and outcomes. This is akin to McLuhan and Fiore's (1968) metaphor of fish being unaware of the water they swim in - actors in CBNRM (and agriculture) may not recognize the gender norms within which they are immersed and that shape their own thinking and behaviours. 
We suggest that the lens of doxa can also be helpful to elucidate the phenomenon in which less powerful actors are present (attend) natural resource governance processes, and yet are in effect excluded. Specifically, it can help to flag that CBNRM governance arrangements and processes themselves tend to accommodate and serve the needs of more dominant actors. For example, in the Nepal case, as in many cases, the use of assemblies or other large meetings was standard and unquestioned as a forum. Yet, in these types of forums, members need to effectively communicate with and in front of large, heterogeneous, mixed-gender groups, sometimes in a language other than their mother tongue and sometimes in relation to written information. These factors inhibited the participation of women, people from minority language groups, those who were not literate and other less powerful actors. And yet, the fact that the arrangements and processes themselves reinforce inequitable opportunities to engage, went without notice and was unquestioned. As such, we flag that decision-making processes and arrangements themselves can be doxic. Widely normalized "participatory or community-based" decision-making processes and arrangements are assumed to be inclusive or power neutral (see Agarwal 2001). Because they are assumed to be or experienced that way by dominant actors, the processes and arrangements may go unquestioned and unchallenged.

The above concept of doxa underscores how dominant views, discourse or even processes can go unnoticed because they are so naturalized. If doxa reinforces power imbalances in these ways, then the question emerges: What, if anything, can allow actors to take a cognitive step back and perceive doxa become aware of "the water we swim in" - and thus become more conscious of its implications and alternatives?

\section{Delegation}

Power imbalances are also produced and reproduced through the processes of political expressions and representations - processes that we frame here as "delegation." This relates to the vital social processes regarding "who makes decisions." The question of power delegation is particularly critical in CBNRM contexts because, despite the expansion of participatory discourse in natural resource governance, the historical legacy of centralized bureaucratic systems of control over natural resources persists ( $\mathrm{Li} 1999,2002)$. Within these systems, the responsibility for informed (policy) decisions has been delegated from "citizens" to "experts," either in the form of scientists, bureaucrats or politicians (Ojha 2006). This occurs at many scales, for example, the delegation of resource decision making to "politicians" (as experts) in the form of local leaders, including local resource group leaders.

Two considerations arise in relation to our reflection on power. The first is regarding representation. Building broadly on critiques of representation and delegation (Foucault and Deleuze 1977; Radhakrishnan 1990), we note that representative governance grows from an assumption of people being able to be categorized into groups based on shared interests - an assumption that fails 
to acknowledge the multifaceted (intersectional) nature of identities. As such, there is an underlying dilemma in terms of a representative being able to represent the interests of a group when each member of the group him or herself embodies multiple categories. In relation to CBNRM, Ribot (2012) and others similarly challenge deficits in representation in the context of decentralization of natural resources on the basis that

the potential of decentralization to be efficient and equitable depends on the representativeness of local institutions. But there are few cases where democratically accountable local institutions are being chosen and given discretionary powers.

(Ribot 2012, xix)

Instead, political space available for the community in its internal governance and external dealings tends to be made accessible to and claimed by members of dominant groups (see above). The needs of marginalized groups (if considered) are assumed to be represented by the dominant groups. For example, in CBNRM, poor members' interests are assumed to be represented by wealthier members, women's by men, and nuancing further, less powerful women by more powerful women. In this way, pre-existing power relations - and failures to challenge the "myth of community" (Guijt and Shah 1998) and to engage with multifaceted difference - legitimize the power and authority of dominant actors as representatives (Nightingale and Ojha 2013), resulting in "participatory exclusions" (Agarwal 2001) in CBNRM.

Second, in broad terms, following critical theorist Habermas (1996), "any use of coercion and power (such as the constitution of a small group or legislature of a state) is legitimate only when it is constituted through reasoned debate among citizens" (Ojha, Timsina and Khanal 2007, 2). In practice, however, this is rarely the case. For example, as part of a larger techno-bureaucratic system and embedded in existing socio-cultural contexts, the Nepal case (above) demonstrated the opposite. The decision-making groups were not being constituted through reasoned debate among citizens; rather, executive committees were created by external actors (who tended to have stronger ties to more powerful community members) or based on appointments through doxic processes (see earlier). In terms of decision-making, as described above, CFUG decisions were not made through "reasoned debate through citizens," but rather were taken by the committee chair or one or two committee members based on their interests or on "blueprints." Even in the de facto openings for "debate" (such as assemblies), not noted in the case, less powerful actors' "voice was not counted."

As well as delegation reducing meaningful engagement in decision making, it also may prioritize one type of (and one social group's) knowledge over another. As flagged by Bäckstrand (2004), delegation enables scientific over traditional and local knowledge. Broadly speaking, in CBNRM contexts, this is played out and exacerbated through the tendency for there to be closer ties between local elite and externally valued technical and bureaucratic forms of 
knowledge, while marginalized actors may have a higher reliance on and connection to experiential knowledge.

The above considerations raise two important questions. First, if the delegation of decision making potentially disempowers by misrepresenting or excluding the interests of marginalized people, what is a constructive alternative? Second, can CBNRM decision-making processes (in an imperfect, power-imbalanced world) engender decision making based on local "reasoned debate" rather than settling issues through delegation?

\section{Structure and agency}

To better understand the persistence and reproduction of power imbalances over time, we draw on ideas regarding the shaping of social systems from philosopher Bourdieu, sociologist Giddens and social theorist Archer, and link to feminist and new institutional theory through Kabeer and Mackay. While these are divergent - even opposing perspectives - in many ways (Kemp 2010), taken together, they shed light on both the stickiness of and the potential for change in power imbalances. Their differences notwithstanding, these theorists share common ground insofar as they highlight social structure and human agency as forces that jointly reinforce and mutually re-create social systems (Jones 2005). While each theoretical approach has its own view, structure here refers to patterns of social relationships that are enacted in practice consciously or without notice. Agency, as used here, is the human actor's ability to learn, reflect and choose actions, even in the face of structural constraints. Cutting across the debate on structure and agency is the question of reproduction or change in practice, including the role of agency-led initiatives or the emergence of any crisis in structure.

Within his larger social theory, Bourdieu sees social structure as propelled by people who take action - and yet people are locked within existing patterns of identification and cognition, in compliance with the social order (see Jones 2005). For Bourdieu, a social institution tends to reproduce itself through existing forms of doxa and entrenched relations of power that go "mis-recognised" by both the more and less powerful. As Bourdieu argues:

The practical acts of knowledge and recognition of the magical frontier between the dominant and the dominated that are triggered by the magic of symbolic power and through which the dominated, often unwittingly, sometimes unwillingly, contribute to their own domination by tacitly accepting the limits imposed, often take the form of bodily emotions - shame, humiliation, timidity, anxiety, guilt - or passions and sentiments - love, admiration, respect.

(Bourdieu 2001, 39)

This implies that power imbalances are related to beliefs, practices and knowledge that have been produced and reproduced over time (in their particular 
contexts as well as through the influence of broader supra-local fields). In this framing, one possibility of change - rather than reproduction - lies in the prospect of "crisis" that can unsettle underlying doxa, mindsets and habituated practices (Ojha, Cameron and Kumar 2009).

Giddens (1984), in his theory of structuration, describes social relations as shaped by what he calls the duality of structure. He suggests that "social structures are both constituted by human agency, and yet at the same time are the very medium of this constitution" (Giddens 1993,128-129). Agency and structure are seen as connected in

a never ending recursive process...each agent draws upon structure (that is, stocks of knowledge) to reproduce sets of spatially and temporally specific practices which in turn contribute to the total constitution of society at any one point in time in any one spatial location.

(Thrift 1985, 612)

Giddens acknowledges emergent changes in social patterns, but frames these as largely unintended effects, as agents generally act without consciousness (Jones 2005).

Archer's approach to structure and agency also emphasizes their mutual influence. However, she re-conceptualizes them to be less "instantly and simultaneously" co-generated than Giddens (Jones 2005, 4). She instead proposes them as interrelated, but separate entities. Archer suggests transcending both structure and agency by considering them to be two faces of a single coin. She suggests that transcending this "divide rests upon conceptualising 'structures' and 'agents' as ontologically inseparable because each enters into the other's constitution and therefore they should be examined as one mutually constitutive amalgam" (Archer 2007a, 18). Her focus on the interplay between the two (and with cultural systems), creates greater scope for (conscious) causal power to create change (Jones 2005; Vandenberghe 2005).

The potential for change is also underscored in new institutional theory's contributions. Mackay, Kenny and Chappell $(2010,578)$ argue that current work

has shifted the focus to the dynamics of endogenous institutional change, highlighting the ways in which "institutions organically evolve (or are intentionally designed) through changing, introducing or manipulating institutional elements while supplementing existing elements (or responding to their failure to generate desired behaviour)."

(Greif and Laitin, 2004, 640)

Mackay, Kenny and Chappell (2010) flag that new institutional theory represents a convergence around views of institutional change as incremental and bounded. They signal that more nuanced attention is needed regarding which elements of particular institutional arrangements are renegotiable (or not), and why some forms of change are more forthcoming than others. 
Finally, we underscore a dimension of effective analysis of structure and agency that is critical for CBNRM: that structure and agency in institutions are (intersectionally) gendered (Mackay, Kenny and Chappell 2010). Feminist theory in development, in fact, has drawn on and advanced earlier thinking. As well as elucidating the interconnections of structure and agency in relation to women's empowerment (e.g., Eerdewijk et al. 2017), feminist contributions have underscored that a focus on agency alone is limited (and may place development burdens on women). Underlying structural barriers need to be addressed if gender equality is to be achieved (Cornwall 2018; McDougall et al. 2021). As Kabeer (forthcoming, 1), for example, articulates "Unlike neo-classical understandings of agency as the free-floating capacity for rational choice, therefore, feminist approaches conceptualize agency as inextricably bound up with structure." This unpins the shift in development towards gender transformative approaches that seek to engage with underlying structural barriers, including constraining gender norms in CBNRM and beyond (McDougall et al. 2021).

With the recursive - yet potentially evolving - nature of structure and agency in mind, the potential transformation of persistent power imbalances hinges around these questions: What can create a "break" in these reinforcing patterns of (gendered) structure and agency? How can CBNRM enable (constructive) cognitive "crisis" that can unsettle underlying doxa, mindsets and habituated practices? How can actors build coalitions of action and learning to trigger changes in individuals' behaviours, group dynamics and institutional practices?

\section{How ACM may shift power}

As noted in the Introduction, some forms of ACM in some contexts have contributed to shifting power imbalances. In the Nepal case presented earlier, we highlighted that - while imperfect and not without its challenges - in practice, ACM's combination of learning and inclusion-oriented processes, structures and facilitation and the focus on equity in decision making itself (versus ACM as a technical management strategy), contributed to shifts towards equity (see McDougall and Banjade 2015; McDougall et al. 2013a, b). In particular, ACM appeared to enable more equitable engagement of women, the poor and low caste members, as well as greater distributional equity and a concomitant increase in social capital. These all reflect renegotiations of power imbalances within the local CBNRM institutions. In other words, it illustrated shifts in "power over," not only increases in power "to," "with," or "within." As noted earlier, however, insights into how ACM contributes to these changes in this case and others remain descriptive. For example, such shifts have been illustrated with practical reference to the following: the self-monitoring processes developed by the community forestry group involved (Dangol 2005); and facilitators identifying and addressing local power imbalances and this leading to overall improvements in decision making and planning (Ojha et 
al. 2010). To date, the underlying mechanisms with which such shifts in power imbalances occur with ACM remain murky. Here we unpack how ACM practices contribute to shifting power relations through the concepts of reflexivity, deliberative decision making and social learning.

\section{Reflexivity as an opening for change}

We begin with a broad question about the potential for change within potentially recursive systems of structure and agency. In particular, we highlight reflexivity - in terms of the potential for learning as a foundation for change. In this framing, reflexivity offers a means of going beyond established rules or routines that underpin particular relations of power. Reflexivity (in Giddens' terms "reflexive monitoring of actions") refers to conscious self-consideration or monitoring of one's own actions and behaviours in relation to the social context or others' actions. Reflexivity is critically important in that it enables "agents to design and determine their responses to the structured circumstances in which they find themselves" (Archer 2007a, 20; see also Chapters 6 and 7). Kemp builds on Archer here with the suggestion of reflexivity as "an inherent ability that all social actors possess" (Kemp 2010, 8). One strength in this view is that it encourages (all) actors to map out possibilities regarding what they can do to enable change, rather than waiting for structural forces to cause change.

Reflexivity thus emerges as a principally important concept here. It embodies specific potential to unsettle habituated thinking and practices, including Bourdieu's notion of doxa as culturally embedded views (Ojha 2008, 45). As such, reflexivity enables change by dynamically bridging structure and agency, "mediating deliberatively between the objective structural opportunities confronted by different groups and the nature of people's subjectively defined concerns" (Archer 2007b, 61).

And yet, while reflexivity is recognized for its potential to enable social systems to change rather than conform to history, even reflexivity itself is a construct of the social system (Giddens 1984). This is a line of thinking pushed further by Bourdieu in his notion of doxa, which is seen as structurally reproduced in diverse fields of social practices. In other words, the structural constraints to reflexivity themselves need to be recognized as a substantial impediment to the process of change. CBNRM actors may be so deeply embedded in the system that although the inequity is experienced, it is difficult for it to be critically perceived, reflected upon and addressed, even by those adversely affected by it. In other words, from within a self-reinforcing system with relations of power fully naturalized at the level of culture, it is difficult for actors to spontaneously or independently step entirely outside of that system and achieve an alternate view (i.e., cognitive distance or outsider perspective, see Syed 2019) that would enable a break in the reinforcing social feedback loops of structure and agency. In view of the entrenched nature of power imbalance in CBNRM contexts, how is reflexivity to be enabled when it involves actors who are 
themselves part of the structure and who tacitly accept doxic forms of knowledge that have historically sustained such relations?

\section{Deliberative decision making}

Here we turn from the broader notions of agency and reflexivity as openings for change to the question of decision making. One way to understand how ACM may shift power imbalances (when it is effective) is that ACM represents a transition from a delegative towards a deliberative approach to decision making. In contrast to delegative decision making, deliberation theoretically emphasizes space for debate and for the bringing together of diverse forms of knowledge (hence it embodies social learning). The concept of deliberation also reflects the notion of democratically legitimate decision making involving the communicative power of citizens being translated into administrative power (Habermas 1996; Ojha, Timsina and Khanal 2007; Dryzek 2010). As a foundation of collaboration, deliberation is an implicit element of adaptive collaborative management. This is significant for CBNRM in that CBNRM often de facto relies on delegation and representation-based arrangements and processes (Ojha 2006; Ojha et al 2007; Ojha, Cameron and Kumar 2009).

And yet the notion of deliberative democracy has been widely critiqued (e.g., Young 2003; Cornwall and Goetz 2005), especially by feminist theory, for its foundational assumptions that deliberation takes place in a power neutral context. As highlighted previously, CBNRM does not take place in power neutral contexts or on "level playing fields," but rather in contexts in which power imbalances are the norm and deeply entrenched. Feminist theory notes of liberal democratic, critical and postmodern theoretical perspectives, that:

because they presume equality where substantive equality is lacking, they fail to provide a satisfactory account of how individual and group rights can be respected in a democratic model, and they fail to consider as political those issues and interests that have been historically considered private...In the real world, coercion impedes argument, social criticism, social decision making, and social change. People with more power are able to prevent social change or to influence the process to their advantage and to the detriment of others. Third World feminist social criticism shows how, despite power inequalities, the views of the less powerful can be heard and can influence social decision making. How can society hear the arguments of those who do not argue because they are coerced in their environment, living metaphorically in crocodile-infested water?

(Ackerly 2000, 30-31)

As this is the case, how is it that in some instances, ACM has been able to contribute to shifting power within a deliberative approach? First, we suggest that when ACM has contributed to power shifts (such as in the Nepal and Uganda cases, Chapters 4 and 5), then it is likely that the approach to 
ACM used as a starting point the rejection of assumptions of neutrality of deliberative democracy, and instead took as a starting point a critical view that the playing field is most likely uneven. Taking this one step further, when this is a starting assumption in ACM and ACM has equity as a goal, then it seems likely that the form of deliberation enacted reflects "de-centred notions of authority." By this, we suggest ACM, when it shifts power, reflects what Carey, Dickinson and Olney $(2017,9)$ describe from a post-structural feminist perspective, highlighting

the ways in which the diverse groups drawn into the policy process can and should challenge authoritative ways of working on the basis of positionality. Thus, post-structuralist feminist theories and ways of working have de-centred notions of authority, that is, single ways of knowing or doing (Gavey 1989; St. Pierre, 2000)...Recognising that de-centred power can be productive allows for and enables a great diversity of perspectives, as well as assisting to negotiate diverse perspectives.

This de-centred authority is visible in the Nepal case, for example, through ACM catalysing the shift from centralized (committee and chairperson-based) to decentralized (hamlet-based) and nested visioning, planning, monitoring and decision making. This likely helped to address the challenge of less powerful people not being heard because of discrimination or "because they are unable to present their views according to the terms of appropriate content of deliberative fora" (Ackerly 2000, 179). The smaller, more familiar and casual spaces in which experiential knowledge was valued - which ultimately fed into overall decision making - reflect one response to feminist theorists' call for expanding what are considered "acceptable arguments" and language as a means of more inclusive deliberative democracy (see Carey, Dickinson and Olney 2017; Ackerly 2000).

An additional mechanism from the ACM Nepal case emerges as a feminist element for inclusive deliberative institutions: social criticism. In the ACM Nepal case, facilitators (external and internal to the communities), used critical questioning to routinely and explicitly spark reflexivity, including about equity. Unpacking this through a theory lens, the facilitator plays the role of the "social critic," which is framed as essential in Ackerly's Third World feminist social criticism. Social critics (internal and external)

draw society's attention to those exploitative or potentially exploitative inequalities that are perpetuated through its values, practices, and norms... social critics must follow a methodology intended to be sensitive to the reality of an imperfect world where power inequalities enable coercion and potential exploitation to silence some within a society and to impede social criticism and social change... The social critic must criticize the values, practices, and norms of a society. This may require being a critical voice as a representative of silent voices, facilitating the social criticism 
of others (possibly by creating a safe place for those who are excluded or exploited), or contributing to social criticism directly.

(Ackerly 2000, 28)

Contrasting with the neutral assumption of deliberative theory, Ackerly (2000, 18) further underscores the significance of the feminist method of social criticism as the "critical bridge between the ideal and the reality of social change."

\section{Social learning as a catalyst for reshaping power imbalances}

While reflexivity is concerned with agency, and deliberative democracy with institutions, the related concept of social learning takes us closer to mechanisms relating to processes. Specifically to how groups of (diverse) actors engage in the process of challenging beliefs, behaviours and culture that underpin and sustain power imbalance. We propose that, while complex and multifaceted, here social learning as a concept and mechanism are particularly salient. Social learning, in relation to CBNRM, is a multifaceted process in which multiple stakeholders bring together their different knowledge, experiences, perspectives, values and capacities in social spaces where communication, joint deliberation, critical reflection and analysis are facilitated as a means of identifying ways forward in relation to a shared issue (Prabhu, McDougall and Fisher 2007; see also Leeuwis and Pyburn 2002). An emphasis is placed on shared or co-learning and facilitation involves negotiation of power relations, including conflict management (Leeuwis 2000; Edmunds and Wollenberg 2001; Prabhu, McDougall and Fisher 2007). As such, while learning occurs naturally in society, social learning as framed here is a way to harness learning potential more consciously. While ACM-related literature has already engaged with social learning as a key element (Armitage, Berkes and Doubleday 2007; Ojha, Hall and Sulaiman 2013), it has not yet fully recognized it or fleshed it out in relation to the forces underlying power imbalances outlined in the previous sections. Of particular interest here is the productive dialogue that emerges when we consider the above challenges and questions (unmarked categories, doxa, how to enable reflexivity) through social learning and feminist lenses.

First, referring to the challenge of unmarked categories, a key observation relates to the question of what may make less powerful actors more visible and shift their outlier status. What can theory tell us about the underlying mechanisms that distinguished ACM from business as usual "participation?" We propose that the social learning foundation of $A C M$ was an underlying mechanism. Specifically, social learning relies on the pooling of diverse knowledge and perspectives (Pahl-Wostl, Mostert and Tàbara 2008; Reed et al. 2010). It is helped along by facilitators - in the mode of feminist social critics - enabling forums to expand on what is understood to be "accepted" forms of expression and knowledge (Ackerly 2000).

Yet to be effectively brought together, first the value of diverse knowledge and perspectives needs to be acknowledged. For this to occur, diverse 
actors must themselves be recognized and acknowledged. Here, a feminist lens articulates why this is a prerequisite. As posited by Carey, Dickinson and Olney $(2017,9)$ in relation to policy processes:

Feminist theories can enable deeper analysis of why different actors need to be brought together to solve problems. As noted above, groups have different and partial knowledge of policy problems. Accessing this different knowledge is the gain that offsets the heightened complexity of working across boundaries... Rather than merely acknowledging complexity, poststructural feminist theory pushes us forward to actively challenge orthodoxies and make space for competing views inside... We can be more open to dissenting views...It enables us to shift from vague concepts of plurality to more concrete notions of diversity (deLeon 1999). We argue that there is a need to actively seek out different, and particularly underrepresented, voices and make space for them. This is important because alone complexity can seem daunting and impenetrable (deLeon 1999). ${ }^{9}$

Through its recognition of the value of cognitive diversity, ACM being anchored in social learning and a feminist grounding may thus contribute to the shifting of power imbalances by serving as a potential opening counterforce to unmarked categories.

A second observation relates to the question of what can help actors "step back" (gain cognitive distance) and experience a "break in thinking." In practical terms, the Nepal case suggests that change is related to inquiry-based facilitation over time, prompting reflection on people's own views and assumptions, combined with process and arrangement changes, such as participatory monitoring. What can theory tell us about underlying mechanisms at play here? First, we note the link between social learning and Bourdieu's notion of "crisis" as an inducement of reflexivity. In particular, we signal cognitive crisis: when there is a lack of synchrony in subjective expectations and objective conditions (or feedback about conditions). The nature of social learning as oriented to problem-solving across diverse views means that it is oriented towards the potential to create such a "cognitive crisis." When well done, social learning thoughtfully confronts people with information and experiences and knowledge different from their own, but in spaces and processes designed to enable listening and reflection ("safe spaces"), rather than setting up for zero-sum outcomes. We propose that Bourdieu's "breaks in thinking" may relate to what practitioners refer to as "ah ha moments" of transformative learning. Recognizing that social and institutional change is a slow process, it is likely that these "moments" are most effective if they occur over time, rather than in a one-off event. In the Nepal cases, for example, the self-monitoring processes over time involved marginalized members feeding back their diverse experiences and perceptions of equity in opportunity, combined with data (who actually received the opportunities) compared against equity goals (women, Dalit and poor members were to have been prioritized). This "new information" about (lack of equity), in 
the context of a facilitated process with equity as an agreed goal (and including conflict management), likely enabled cognitive distance and a "break" in thinking in the previous perception of the committee that the forestry groups were de facto inclusive and pro-poor (McDougall et al. 2007, 2013a, b).

The third and closely related point relates to the question of making doxa more explicit. In particular, it relates to Giddens' suggestion that even reflexivity is a construct of the social system. The question thus arises: how can doxa be made more explicit if the tool to surface doxa - i.e., reflexivity - is itself embroiled in the constructs and biases of the system? We speculate that when this happens it may be through social learning bringing into question not only material inequities in the context but also facilitating the critical questioning of the underlying factors at play: actors' own individual and collective perceptions, norms and values in relation to social hierarchies and power relations. Gender transformative approaches offer a current example of this in development. These approaches have been increasingly recognized in development for their catalysing shifts in unequal power relations. Similar to ACM cases that make explicit power relations, assumptions and outcomes in CBNRM, gender transformative approaches operate by engaging women and men together in explicitly reflexive, experiential processes about (previously "hidden") constraining gender norms, surfacing endogenous insights into how these shape the wellbeing of women, men, households and communities (McDougall et al. 2021). In other words, the mechanism at play here is likely the surfacing and bringing into conscious awareness the previously unseen doxa underpinning power imbalances - combined with endogenously identified alternative ways of knowing and being.

Extending this to the notion above that decision-making processes (and associated outcomes) themselves may be doxic flags an important structural barrier to change. The Nepal case's success here elucidates an important entry point: the mechanism at play was not only illuminating doxa in relation to individuals' or groups' norms or attitudes - it was about collective reflexivity about doxa within the group's formal structures (the processes and arrangements of decision making). Thus, ACM - applied to governance - can facilitate critical questioning of the decision-making processes and practices themselves, such as who decides and how decisions are made about what constitutes equitable access to natural resources in a given context. This suggests that a key means by which ACM may contribute to power shifts is through using social learning as a mechanism to purposively surface and make explicit the (previously implicit) doxa embedded in decision-making processes and arrangements. In doing so, ACM has likely created opportunities for embedded doxa and inequities to both be noticed and questioned (e.g., Dalit members previously being driven out of assemblies). This is in line with the proposition that facilitated social learning can enable shared critical reflection on and deconstruction of "the existing structures and value systems that hinder the transformation of society" (Banjade et al. 2006, 24). While institutional change also entails deliberation and contestation, as well as consensus-building (Mackay, 
Kenny and Chappell 2010), this surfacing of doxic arrangements and processes is a start. It, along with the above other mechanisms, creates openings and momentum for change. Linking back to theory, Wacquant $(2004,97)$ argued that "knowledge of the social determinants of thought is indispensable to liberating thought." We suggest that liberating thought within CBNRM - at the level of individuals, groups and in relation to institutional processes and arrangements - in turn, may be indispensable to enabling purposeful, constructive evolution in structure and agency towards more equitable power relations in CBNRM.

\section{Conclusions}

At a time when CBNRM has become a key strategy for environmental sustainability, climate resilience and human wellbeing across the developing world, a growing body of research warns that the persistence of power imbalances has hampered CBNRM's potential to deliver expected outcomes. In this context, questions around why imbalances persist and what can enable transformative change are paramount. These questions have remained, even as innovations such as ACM grow, with claims of varying levels of success. This chapter was animated by our concern that the ability of ACM and CBNRM to respond meaningfully to these questions - especially as they go to scale in multiple sectors - will remain limited or be at risk unless there is a deeper understanding of the underlying mechanisms at play. In response, in this chapter, we have aimed to help address this gap by drawing on a range of insights from social and feminist theory.

Using the concepts of unmarked categories, doxa, delegation and structure and agency, we demonstrated the tension and opportunities between stasis and change. Our exploration surfaced several insights into the questions: How can new configurations emerge? And, in particular, how can ACM's potential influence in shifting power imbalances be understood? A convergence of emphasis in social and feminist theory suggests that purposeful, critically reflexive thinking and strategies may contribute to transformative change in power imbalances. At the crux of this theoretical exploration is the link between the concepts of reflexivity, deliberation and social learning, which are ideally, central elements of ACM. These embody purposeful efforts to introduce a "break" in recursive patterns of unrecognized power imbalances (as explained through concepts of doxa, unmarked categories and delegation). In other words, these sticky, recursive aspects of power imbalances may be unsettled and tackled through reflexivity - and in particular, through feminist-informed deliberation and social learning. The nature of social learning as engendering reflexivity, including with regard to unquestioned assumptions and beliefs, stands out as particularly compelling as long as practitioners are aware of and oriented to social and gender equity. In connection to this, the learning focus on equity and improvements in decision-making processes and arrangements (governance itself) appears centrally important. If equity and power shifts are the aim, 
CBNRM actors may even want to consider re-framing ACM as "adaptive collaborative governance" to keep this in focus.

These theory-based insights have implications for more effective ACM in forested landscapes (as per this case and volume), as well as for other sectors such as fisheries and wetlands management and climate resilience. The insights can also be applied in gender and development more broadly, as they help to explain why women's empowerment in mainstream development may have led to limited or unsustained efforts to date and how gender transformative approaches (that engage with underlying normative constraints) seem to have a greater effect (McDougall et al. 2021). Moreover, this exploration sparks us to speculate that it is worth CBNRM and development design returning to Toffler's proposition that knowledge is the most important source of power: specifically, it suggests the potency of actors in CBNRM and development more broadly mobilizing the "counter power" of questioning of our implicit perspectives and understanding - as a potent source of transformation.

Finally, our theoretical exploration suggests a clear conceptual basis for linking ACM with theories of power, and in particular feminist theory, in order to better understand the potential transformation of power imbalances in community-based natural resource contexts. Looking ahead, we hope that this theoretical exploration may enrich future ACM and CBNRM design and scaling so that these may move more effectively and consistently in their contributions towards a more inclusive, equitable and just future.

\section{Acknowledgements}

The authors would like to thank Carol J. Pierce Colfer as well as the anonymous reviewers for their excellent input and Carol, Ravi Prabhu and Anne Larson for their extraordinary patience in this endeavour. In connection to and for fisheries, aquatic foods and CBNRM, this work was undertaken as part of the CGIAR Research Program on Fish Agri-Food Systems (FISH) led by WorldFish. The programme is supported by contributors to the CGIAR Trust Fund. We also kindly acknowledge Wageningen University and Research (WUR) as a result of publishing a much earlier version of this work as part of Cynthia's $\mathrm{PhD}$ thesis.

\section{Notes}

1 See, for example, Lewin $(1943,1945)$ or McCain's (2015) analysis.

2 We select this case not only as one of the few published ACM studies that evidence changes in power and equity (see also Colfer 2005; and Chapters 4 and 5, this volume), but also because we (the authors) were involved in the case and thus have a high level of trust in the evidence and first-hand knowledge of the involved factors. In line with Lincoln and Guba (1985) on rigour in qualitative research, this engagement is useful even necessary - to support meaningful in-depth interpretation of change mechanisms.

3 Gender refers not to biological differences (sex), but rather is "understood as a constitutive element of social relations based upon perceived (socially constructed and culturally 
variable) differences between women and men, and as a primary way of signifying (and naturalizing) relationships of power and hierarchy (Hawkesworth 2005; Scott 1986). Gender, therefore, not only operates at the level of the subjective/interpersonal (through which humans identify themselves and organize their relations with others); but is also a feature of institutions and social structures, and a part of the symbolic realm of meaningmaking, within which individual actors are 'nested"' (Mackay, Kenny and Chappell 2010, 580).

4 Kabeer and Subrahmanian (1996) define institutions thus: "A simple definition of institutions is as a framework of rules for achieving certain social or economic goals; organizations refer to the specific structural forms that institutions take (North 1990). For analytical purposes, it is useful to think of four key institutional sites - the state, the market, the community and the domain of family/kinship" (Kabeer and Subrahmanian 1996, 17).

5 Mackay, Kenny and Chappell (2010, 584):

"Although operating across the variants of NI [new institutionalism], feminist approaches to institutionalism have many central concerns in common: they are pluralistic in approach; pay attention to both formal and informal institutional environments; see institutional change (and stability) as driven by gendered processes from within and without and consider actors as having agency, albeit bounded by various constraints. These core features are, we argue, enough to suggest that there exists an emergent feminist institutionalism. While it is obviously still a work in progress, the synthesis of institutionally focused feminist scholarship and NI into a feminist institutionalism has considerable potential to enhance our understanding and analyses of institutional dynamics, gender power and the patterning of gendered inequalities in political life."

6 Galiè and Farnworth (2019) have flagged a fifth form - power through - in relation to gender and development.

7 De Beauvoir observes:

"man represents both the positive and the neutral, as is indicated by the common use of man to designate human beings in general; whereas woman represents only the negative, defined by limiting criteria, without reciprocity... A man is in the right in being a man; it is the woman who is in the wrong. It amounts to this: ...there is an absolute human type, the masculine... She is defined and differentiated with reference to man and not he with reference to her; she is the incidental, the inessential as opposed to the essential. He is the Subject, he is the Absolute - she is the Other" (de Beauvoir 1953, xviii-xix.).

8 Ackerly notes:

"Where inequalities are pervasive, the less powerful may not express their wishes even though existing values, practices, and norms inhibit their ability to live the life they desire. Where there are people who live according to values, practices, and norms they are unable to affect, social decision making is not informed, collective, and uncoerced. Where social decision making is not informed, collective, and uncoerced, social criticism plays important roles in promoting social decision making that is. In contexts of coercion and disagreement, social criticism is in part responsible for enabling those who live in the crocodile-infested water to participate in social decision making and to influence social change through the feminist method, critics encourage the silent to speak for themselves and represent the silent when they don't" (Ackerly 2000, 28).

9 See also Syed's (2019) relevant argument for the value of cognitive diversity in decision making for complex problems in the workplace and beyond. Moreover, while beyond 
the scope of this chapter, we acknowledge the important cross-scale - or endogenousexogenous interdependencies - influences in path dependency and change trajectories (see also Mackay, Kenny and Chappell 2010).

\section{References}

Ackerly, B. A. 2000. Political Theory and Feminist Social Criticism. Cambridge: Cambridge University Press.

Adams, E. A., L. Juran and I. Ajibade. 2018. "Spaces of Exclusion' in Community Water Governance: A Feminist Political Ecology of Gender and Participation in Malawi's Urban Water User Associations." Geoforum 95:133-142.

Agarwal, B. 2001. "Participatory Exclusions, Community Forestry, and Gender: An Analysis for South Asia and a Conceptual Framework." World Development 29 (10):1623-1648.

Archer, M. S. 2007b. Making our Way Through the World: Human Reflexivity and Social Mobility. Cambridge, UK: Cambridge University Press.

Archer, M. S. 2007a. "The Ontological Status of Subjectivity: The Missing Link Between Structure and Agency." In Contributions to Social Ontology, edited by C. Lawson, J. Latsis and N. Martins, 17-31. New York: Routledge.

Armitage, D., F. Berkes and N. Doubleday, eds. 2007. Adaptive Co-Management: Collaboration, Learning, and Multi-Level Governance. Vancouver: UBC Press.

Arts, B. and I. J. Visseren-Hamakers. 2012. "Forest Governance: Mainstream and Critical Views." ETFRN News 53:3-10.

Bäckstrand, K. 2004. "Scientisation vs. Civic Expertise in Environmental Governance: Eco-Feminist, Eco-Modern and Post-Modern Responses." Environmental Politics 13(4):695-714.

Banjade, M. R., N. P. Timsina,, H. R. Neupane, K. Bhandarai, T. Bhattarai, and S. K. Rana. 2006. "Transforming Agency and Structure for Facilitating Pro-Poor Governance in Community Forestry." Journal of Forests and Livelihood 5(1):22-33.

Barnett, M., and R. Duvall. 2004. "Power in Global Governance." In Power in Global Governance, edited by M. Barnett and R. Duvall, 1-32. Cambridge, UK: Cambridge University Press.

Basnyat, B., T. Treue, R. K. Pokharel, S. Baral, and Y. B. Rumba. 2020. "Re-Centralisation through Fake Scientificness: The Case of Community Forestry in Nepal." Forest Policy and Economics 115:102147.

Baynes, J., J. Herbohn and W. Dressler. 2016. "Power Relationships: Their Effect on the Governance of Community Forestry in the Philippines. Land Use Policy 54:169-176.

Beauvoir, de, S. 1953. The Second Sex. Translated by H. M. Parshley. New York: Knopf.

Bennett, N. J., J. Blythe, A. M. Cisneros-Montemayor, G. G. Singh and U. R. Sumaila, 2019. "Just Transformations to Sustainability." Sustainability 11(14):3881.

Berkes, F. 2006. "From Community-Based Resource Management to Complex Systems: The Scale Issue and Marine Commons." Ecology and Society 11(1):45.

Bhattarai, B. and H. Ojha. 2001. Distributional Impact of Community Forestry: Who is Benefiting from Nepal's Community Forests. Kathmandu: ForestAction.

Bourdieu, P. [1972] 1977. Outline of a Theory of Practice. Translated by R. Nice. Cambridge: Cambridge University Press.

Bourdieu, P. 1998. Practical Reason: On the Theory of Action. Stanford: Stanford University Press.

Bourdieu, P. 2001. Masculine Domination. Cambridge: Polity Press. 
Bucholtz, M. and K. Hall. 2004. "Language and Identity." In A Companion to Linguistic Anthropology, edited by A. A. Duranti, 369-394. Oxford, UK: Blackwell.

Buchy, M. and S. Subba. 2003. "Why is Community Forestry a Social and Gender-blind Technology? The Case of Nepal." Gender, Technology and Development 7(3):313-332.

Carey, G, H. Dickinson and S. Olney. 2017. "What Can Feminist Theory Offer Policy Implementation Challenges?" Evidence and Policy: A Journal of Research, Debate and Practice 15(1):143-59.

Cassidy, L. 2021. "Power Dynamics and New Directions in the Recent Evolution of CBNRM in Botswana." Conservation Science and Practice 3(1): e205.

Charnley, S. and M. R. Poe. 2007. "Community Forestry in Theory and Practice: Where are We Now?” Annual Review of Anthropology 36:301-336.

Chambers, R. 1995. "Poverty and Livelihoods: Whose Reality Counts?" Environment and Urbanization 7(1):173-204.

Chevalier, J. M., \& Buckles, D. J. 2013. Handbook for Participatory Action Research, Planning and Evaluation, 155. Ottawa: SAS2 Dialogue.

Colfer, C. J. P., ed. 2005. The Equitable Forest: Diversity, Community and Resource Management. Washington, DC: Resources for the Future.

Cornwall, A. 2018. "Beyond 'Empowerment Lite': Women's Empowerment, Neoliberal Development and Global Justice.” Cadernos Pagu 52. https://doi.org/10.1590/180944 49201800520002

Cornwall, A., and Goetz, A. M. 2005. "Democratizing Democracy: Feminist Perspectives." Democratisation 12(5):783-800.

Criado-Perez, C. 2019. Invisible Women: Data Bias in a World Designed for Men. New York: Random House.

Dangol, S. 2005. "Participation and Decision Making in Nepal." In The Equitable Forest: Diversity, Community and Resource Management, edited by C. J. P. Colfer, 54-71. Washington, DC: Resources for the Future.

deLeon, P. 1999. "The Stages Approach to the Policy Process: What has it Done? Where is it Going?" In Theories of the Policy Process, edited by P. A. Sabatier. Boulder, CO: Westview Press.

Dryzek, J. S. 2010. Foundations and Frontiers of Deliberative Governance. Oxford: Oxford University Press.

Duerst-Lahti, G., \& R. M. Kelly. (Eds.). 1995. Gender Power, Leadership, and Governance. Anne Arbor: University of Michigan Press.

Edmunds, D. and E. Wollenberg. 2001. "A Strategic Approach to Multistakeholder Negotiations." Development and Change 32(2):231-253.

van Eerdewijk, A., F. Wong, C. Vaast, J. Newton, M. Tyszler and A. Pennington. 2017. White Paper: A Conceptual Model of Women and Girls' Empowerment. Amsterdam: Royal Tropical Institute (KIT).

Ellis, F. and H. A. Freeman. 2004. "Rural Livelihoods and Poverty Reduction Strategies in Four African Countries." Journal of Development Studies 40(4):1-30.

Elson, D. 1991. Male Bias in Macro-Economics: The Case of Structural Adjustment. In Male Bias in the Development Process, edited by D. Elson, 164-190. Manchester, UK: Manchester University Press.

Folke, C., T. Hahn, P. Olsson and J. Norberg. 2005. "Adaptive Governance of SocialEcological Systems." Annual Review of Environmental Resources 30:441-473.

Foucault, M. and G. Deleuze. 1977. "Intellectuals and Power." In Language, Countermemory, Practice: Selected Essays and Interviews, edited by D. F. Bouchard, 205-217. Ithaca, NY: Cornell University Press. 
Galbraith, J. K. 1983. The Anatomy of Power. Boston: Houghton Mifflin.

Galiè, A. and C. R. Farnworth. 2019. "Power Through: A New Concept in the Empowerment Discourse." Global Food Security 21:13-17.

Gavey, N. 1989. "Feminist Poststructuralism and Discourse Analysis: Contributions to Feminist Psychology." Psychology of Women Quarterly 13(4): 459-475.

Giddens, A. 1984. The Constitution of Society. Berkeley, CA: University of California Press.

Giddens, A. 1993. New Rules of Sociological Method (2nd ed.). Stanford, CA: Stanford University Press.

Greif, A., and D. Laitin. 2004. "A Theory of Endogenous Institutional Change." American Political Science Review 98(4): 633-652.

Guijt, I. and M. K. Shah. 1998. The Myth of Community: Gender Issues in Participatory Development. London: Intermediate Technology Publications.

Habermas, J. 1996. Between Facts and Norms: Contributions to a Discourse Theory of Law and Democracy. Cambridge, MA: MIT Press.

Hawkesworth, M. 2005. "Engendering Political Science: An Immodest Proposal.” Politics and Gender 1(1): 141.

Hillenbrand E., N. Karim, P. Mohanraj and D. Wu. 2015. Measuring Gender Transformative Change: A Review of Literature and Promising Practices. Working Paper. Atlanta: CARE USA.

Jones, G. 2005. The Consequences of Flexibility for Structure. In Proceedings of the 4th International Critical Management Studies Conference, July 4-6, Cambridge, UK: University of Cambridge.

Kabeer, N. 2021, Forthcoming. "Three Faces of Agency in Feminist Economics: Capabilities, Empowerment and Citizenship." In The Handbook of Feminist Economics, edited by Günseli Berik and Ebru Kongar. New York: Routledge.

Kabeer, N. and R. Subrahmanian. 1996. Institutions, Relations and Outcomes: Framework and Tools for Gender-Aware Planning. Brighton: Institute of Development Studies.

Kabeer, N., S. Razavi and Y. van der Meulen Rodgers. 2021. "Feminist Economic Perspectives on the COVID-19 Pandemic." Feminist Economics 27(1-2):1-29. DOI: 10.1080/13545701.2021.1876906

Kanel, K. R. and B. R. Kandel. 2004. "Community Forestry in Nepal: Achievements and Challenges." Forest and Livelihood 4(4):55-63.

Kemp, C. 2010. "Building Bridges between Structure and Agency: Exploring the Theoretical Potential for a Synthesis between Habitus and Reflexivity." Essex Graduate Journal of Sociology 10:4-12.

Kleiber, D., L. Harris and A. C. J. Vincent. 2018. "Gender and Marine Protected Areas: A Case Study of Danajon Bank, Philippines.” Maritime Studies 17(2):163-175. https://doi .org/10.1007/s40152-018-0107-7

Lachapelle, P. R., P. D. Smith and S. F. McCool. 2004. "Access to Power or Genuine Empowerment? An Analysis of Three Community Forest Groups in Nepal." Human Ecology Review 11(1):1-12.

Leeuwis, C. 2000. "Reconceptualizing Participation for Sustainable Rural Development: Towards a Negotiation Approach.” Development and Change 31:931-959.

Leeuwis, C., and R. Pyburn, eds. 2002. Wheelbarrows Full of Frogs: Social Learning in Rural Resource Management. Assen, the Netherlands: Koninklijke Van Gorcum.

Lewin, K. 1943. Psychology and the Process of Group Living. Journal of Social Psychology 17:113-131.

Lewin, K. 1945. The Research Centre for Group Dynamics at Massachusetts Institute of Technology. Sociometrics 8:128-135. 
Li, T. M. 1999. "Compromising Power: Development, Culture, and Rule in Indonesia." Cultural Anthropology 14(3):295-322.

Li, T. M. 2002. "Engaging Simplifications: Community-Based Resource Management, Market Processes and State Agendas in Upland Southeast Asia." World Development 30(2):265-283.

Lincoln, Y. S. and E. G. Guba. 1985. Naturalistic Inquiry. Newbury Park CA: Sage Publications.

Mackay, F., M. Kenny and L. Chappell. 2010. "New Institutionalism Through a Gender Lens: Towards a Feminist Institutionalism?" International Political Science Review 31(5):573-88.

Mahanty, S., J. Fox, M. Nurse, P. Stephen, and L. McLees. 2006. Hanging in the Balance: Equity in Community-Based Natural Resource Management in Asia. Bangkok and Honolulu: RECOFTC and East-West Center.

McCain, K. W. 2015. “'Nothing as Practical as a Good Theory': Does Lewin's Maxim Still have Salience in the Applied Social Sciences?" Proceedings of the Association for Information Science and Technology 52(1):1-4.

McDougall, C. 2001. "Gender and Diversity in Assessing Sustainable Forest Management and Human Well-Being: Reflections on Assessment Methods Tests Conducted in Bulungan, East Kalimantan, Indonesia." In People Managing Forests: The Links Between Human Well-Being and Sustainability, edited by C. J. P. Colfer and Y. Byron, 50-71. Washington, DC: Resources for the Future.

McDougall, C., L. Badstue, A. Mulema, G. Fischer, D. Najar, R. Pyburn, M. Elias, D. Joshi, A. Vos. Forthcoming in 2021. "Toward Structural Change: Gender Transformative Approaches." In Advancing Gender Equality through Agricultural and Environmental Research: Past, Present and Future, edited by R. Pyburn and A. van Eerdewjk. Washington, DC: IFPRI.

McDougall, C. and M. R. Banjade. 2015. "Social Capital, Conflict and Adaptive Collaborative Governance: Exploring the Dialectic." Ecology and Society 20(1):44. http:/ /dx.doi.org/10.5751/ES-07071-200144

McDougall, C., H. Ojha, R. K. Pandey, M. R. Banjade and B. H. Pandit. 2007. "Enhancing Adaptiveness and Collaboration in Community Forestry in Nepal: Reflections from Participatory Action Research." In Adaptive Collaborative Management of Community Forests in Asia: Experiences from Nepal, Indonesia and the Philippines, edited by R. Fisher, R. Prabhu and C. McDougall, 52-92. Bogor, Indonesia: CIFOR.

McDougall, C., J. Jiggins, B. H. Pandit, S. K. Thapa Magar Rana and C. Leeuwis. 2013 a. "Does Adaptive Collaborative Forest Governance Affect Poverty? Participatory Action Research in Nepal's Community Forests." Society \& Natural Resources 26(1):1235-1251. http://www.tandfonline.com/eprint/wZXN4UXu9ewgi7ugW23w/full

McDougall, C. L., C. Leeuwis, T. Bhattarai, M. R. Maharjan and J. Jiggins. 2013b. "Engaging Women and the Poor: Adaptive Collaborative Governance of Community Forests in Nepal." Agriculture and Human Values 30(4):569-585. [online] URL: http:// link.springer.com/article/10.1007/s10460-013-9434-x

McLuhan, M. and Q. Fiore. 1968. War and Peace in the Global Village: An Inventory of Some of the Current Spastic Situations that Could be Eliminated by More Feedforward. New York: Bantam Books.

Mutimukuru-Maravanyika, T. and F. Matose. 2013. "Learning in the Contested Landscapes: Applying Adaptive Collaborative Management in Forested Landscapes of Zimbabwe." In Adaptive Collaborative Approaches in Natural Resource Governance: Rethinking Participation, Learning and Innovation, edited by H. Ojha, D. Hall and R. Sulaiman V, 177-215. London: Routledge. 
Nadasdy, P. 2007. "Adaptive Co-Management and the Gospel of Resilience." In Adaptive Co-Management: Collaboration, Learning and Multi-Level Governance, edited by D. Armitage, F. Berkes and N. Doubleday, 208-227. Vancouver: UBC Press.

Nightingale, A. J. 2011. "Bounding Difference: Intersectionality and the Material Production of Gender, Caste, Class and Environment in Nepal." Geoforum 42(2):153-162.

Nightingale, A. J., and H. R. Ojha. 2013. "Rethinking Power and Authority: Symbolic Violence and Subjectivity in Nepal's Terai Forests." Development and Change 44(1):29-51.

North, D. C. 1990. "A Transaction Cost Theory of Politics." Journal of Theoretical Politics 2(4): 355-367.

Ojha, H. 2006. "Techno-Bureaucratic Doxa and the Challenges of Deliberative Governance: The Case of Community Forestry Policy and Practice in Nepal." Policy and Society 25(2):131-175.

Ojha, H. 2008. Reframing Governance: Understanding Deliberative Politics in Nepal's Terai Forestry. New Delhi: Androit.

Ojha, H., N. Timsina and D. Khanal. 2007. "How are Forest Policy Decisions Made in Nepal?" Journal of Forest and Livelihood 6(1):1-17.

Ojha, H. R., J. Cameron and C. Kumar. 2009. "Deliberation or Symbolic Violence? The Governance of Community Forestry in Nepal." Forest Policy and Economics 11(5-6):365-374.

Ojha, H. R., N. S. Paudel, M. R. Banjade, C. McDougall and J. Cameron. 2010. "The Deliberative Scientist: Integrating Science and Politics in Forest Resource Governance in Nepal." In Beyond the Biophysical: Knowledge, Culture, and Politics in Agriculture and Natural Resource Management, edited by L. German, J. J. Ramisch and R. Verma, 167191. New York: Springer.

Ojha, H. R., A. Hall and R. Sulaiman, eds. 2013. Adaptive Collaborative Approaches in Natural Resource Governance: Rethinking Participation, Learning and Innovation. London: Routledge.

Olsen, J. P. 2009. Change and Continuity: An Institutional Approach to Institutions of Democratic Government. European Political Science Review 1(1):3-32.

Olsson, P., L. H. Gunderson, S. R. Carpenter, P. Ryan, L. Lebel, C. Folke, and C. S. Holling. 2006. "Shooting the Rapids: Navigating Transitions to Adaptive Governance of Social-Ecological Systems.” Ecology and Society 11(1):18. [online] URL: http://www .ecologyandsociety.org/vol11/iss1/art18/

Österblom, H., C. C. C. Wabnitz, D. Tladi et al. 2020. Towards Ocean Equity. Washington, DC: World Resources Institute. Available online at www.oceanpanel.org/how-distrib ute-benefits-ocean-equitably.

Pahl-Wostl, C., E. Mostert and D. Tàbara. 2008. "The Growing Importance of Social Learning in Water Resources Management and Sustainability Science." Ecology and Society 13(1):24.

Plummer, R., and D. R. Armitage. 2007. "Charting the New Territory of Adaptive Co-Management: A Delphi Study. Ecology and Society 12(2):10.

Plummer, R., D. R. Armitage and R. C. de Loë. 2013. "Adaptive Co-Management and its Relationship to Environmental Governance." Ecology and Society 18(1):21. http://dx.doi .org/10.5751/ES-05383-180121.

Prabhu, R., C. McDougall and R. Fisher. 2007. "Adaptive Collaborative Management: A Conceptual Model." In Adaptive Collaborative Management of Community Forests in Asia: Experiences from Nepal, Indonesia and the Philippines, edited by R. Fisher, R. Prabhu, and C. McDougall, 16-49. Bogor, Indonesia: CIFOR. 
Radhakrishnan, R. 1990. "Towards an Effective Intellectual." In Intellectuals: Aesthetics, Politics, Academics, edited by B. Robbins, 57-100. Minneapolis, MN: University of Minnesota.

Reed, M., A. C. Evely, G. Cundill, I. R. A. Fazey, J. Glass, A. Laing, J. Newig, B. Parrish, C. Prell and C. Raymond. 2010. "What is Social Learning?" Ecology and Society 15(4) [online] URL: http://www.ecologyandsociety.org/vol15/iss4/resp1/

Ribot, J. C. 2012. "Choosing Representation: Institutions and Powers for Decentralized Natural Resource Management." In The Politics of Decentralization: Forests, Power and People, edited by C. J. P. Colfer and D. Capistrano, 86-106. London: Earthscan.

Ribot, J. C. and N. L. Peluso. 2003. "A Theory of Access." Rural Sociology 68(2):153-181. Rupert, M. 2004. "Class Powers and the Politics of Global Governance." In Power in Global Governance, edited by M. Barnett and R. Duvall, 205-228. Cambridge: Cambridge University Press.

Scott, J.W. 1986. "Gender as a Useful Category of Historical Analysis." American Historical Review 91: 1053-1075.

Selener, D. 1997. Participatory Action Research and Social Change (No. Ed. 2). Ithaca, New York: The Cornell Participatory Action Research Network, Cornell University.

Sen, A. 2006. Identity and Violence: The Illusion of Destiny. London: W. W. Norton.

Sikor, T. and C. Lund. 2009. "Access and Property: A Question of Power and Authority." Development and Change 40(1):1-22.

St. Pierre, E. A. 2000. "Poststructural Feminism in Education: An overview". International Journal of Qualitative Studies in Education 13(5): 477-515.

Syed, M. 2019. Rebel Ideas: The Power of Diverse Thinking. London: John Murray.

Thrift, N. 1985. "Bear and Mouse or Bear and Tree? Anthony Giddens' Reconstitution of Social Theory." Sociology 19(4):609-623.

Toffler, A. 1990. Powershift. New York: Bantam.

Vandenberghe, F. 2005. "Book Review: The Archers: A Tale of Folk (Final Episode?)." European Journal of Social Theory 8(2):227-237.

Wacquant, L. 2004. "Critical Thought as Solvent of Doxa." Constellations 11(1):97-101.

Weber, M. 1978. Economy and Society. Berkeley, CA: University of California Press.

Whitehead, A. 1979. "Some Preliminary Notes on the Subordination of Women". IDS Bulletin 10(3): 10-13.

Young, I. M. 2003. “Activist Challenges to Deliberative Democracy.” In Debating Deliberative Democracy, edited by J. S. Fishkin and P. Laaslett, 102-120. Oxford: Blackwell. 


\section{Introduction to Chapter 9}

This chapter returns to a focus on a more personal writing style, documenting the experience of the authors over the past three to four decades with the different iterations and manifestations of action research, participatory action research and adaptive collaborative management. These authors are modest in their interpretations of their early experiences with these approaches, neglecting to mention that they were themselves part of the approaches' development. They describe the imprecise differentiation among AR, PAR and ACM as reflecting similarities in the three approaches.

This chapter also provides a good historical summary of the very influential approach taken in Nepal in the early years, an approach that influenced global ideas about participation and contributed to the development of global interest in community forestry and the value of forest user groups. Its emphasis on restoration/reforestation has good (and needed) lessons for current efforts in this arena.

The diversity of examples provided, from agriculture to water management, animal husbandry (nomadism) and forestry in a wide variety of locales and at various scales, is further testament to the flexibility and broad applicability of such approaches.

Fisher and Jackson also emphasize the importance of paying serious attention to understanding a context before diving into an ACM-like process. Specifically, they emphasize the value of ethnographic approaches for gaining such understanding.

We remember Fisher's suggestion, when we struggled with CIFOR's initial scepticism about ACM in the early 2000s, that we should focus on "plausible causal connections". Although we valued it as a "response" to critiques about lack of generalizability, Fisher suggested it to address our difficulties providing 'proof' of what we saw as demonstrable links between actions and impacts. 


\title{
9 Can activist engagements have research outcomes?
}

\author{
The case of ACM and \\ participatory action research
}

\author{
Robert Fisher and William Jackson
}

\section{Introduction}

Adaptive learning approaches involving affected stakeholders are often advocated as an appropriate way to deal with complex and evolving situations in natural resource and environmental management or social development. Recognising that natural resource and environmental management involve social change, which experimental and reductionist science cannot easily address, some research institutions have introduced adaptive collaborative management (ACM), action research (AR) or particularly participatory action research (PAR) within their programmes. While the need for interdisciplinary research that involves mixed stakeholders is recognised, experience in applying such approaches shows that the scientific validity of the methods is often regarded with considerable scepticism within research institutions.

This chapter reflects on the experiences of the two authors in action research and, to a lesser extent, in ACM in a variety of institutions and contexts over more than three decades. ${ }^{1}$ Both authors first became involved in action research while working with the then Nepal-Australia Forestry Project (NAFP) in the late 1980s and early 1990s. Subsequently, RF taught in the School of Agriculture and Rural Development at the University of Western Sydney, Hawkesbury (UWS-H), from 1991 to 1996. At that time, most master's and $\mathrm{PhD}$ research in the School was undertaken as action research. RF supervised a number of action research-based master's and $\mathrm{PhD}$ theses, including the thesis by WJ (Jackson 1999). When Colfer, Prabhu and others at CIFOR began to develop CIFOR's ACM programme, RF became involved as an external partner engaged in action research training and subsequently with an ACM related writing workshop and editing a book on ACM with CIFOR researchers (Fisher, Prabhu and McDougall 2007). Finally, both RF and WJ were involved in the Livelihoods and Landscapes Strategy (LLS), a global programme of the International Union for Conservation of Nature (IUCN), which applied elements of action research methodology.

The chapter is very much about reflections on personal experiences. For the most part, we were both involved in what we understood as and referred to as action research, although our understanding of the method developed 
over time, as described later. Although our chapter title refers to participatory action research, the explicitly participatory version did not develop until later in our experience. When RF became involved with ACM, he continued to see AR, PAR and ACM as essentially cyclical and exploratory approaches that combined action and research to progressively work through complex and changing contexts in order to both learn about and improve them. This differed somewhat with the understanding within CIFOR which differentiated AR/PAR from ACM:

Our differentiation between adaptive collaborative management (ACM, an umbrella framework or approach) and participatory action research (PAR, a method) needs clarification. PAR shares with ACM the emphasis on facilitated and shared social learning in iterative cycles and on human resource development. But, unlike ACM, it can take place within a single group and address any topic of importance to the participants. CIFOR's version of ACM, on the other hand, requires attention to improving human well being, inter-group equity, health of forests (or other natural resources), to policy concerns, and collaborative work with other stakeholders or actors (at other levels or in other communities).

(Colfer 2013, 55)

While we acknowledge this distinction, our focus in this chapter is on the common features of ACM and AR/PAR as being concerned with both achieving research and interventionist outcomes. In particular, we want to show that both ACM and AR/PAR can produce research outputs while also leading to change.

\section{What were the concerns about ACM and action research?}

Colfer (2013; see also Chapter 1) discusses the experiences in developing and conducting ACM in CIFOR over an extended period. She is quite explicit about the early bias against ACM due to the reductionist preference among CIFOR's researchers. ACM was criticised as being unscientific for a variety of reasons, including the difficulty of scaling up from individual cases, and the replicability and generalisability of the research. It was later criticised because many of the publications from the ACM group did not fit CIFOR's "institutional preference for refereed journals in English" (Colfer 2013, 70), and there were even concerns about the non-standard format of social science publications compared with biophysical journals. Another issue

pertained to the general acceptance within forestry of the institutional and political status quo. Many scientists saw their roles as technical and decidedly not political... Yet within ACM there was broad recognition that a central goal was empowerment... of the women and men in forest communities, in their interactions with others.

(Colfer 2013, 51; see Chapter 8) 
Criticism of the ACM programme was explicit, often coming in meetings with the CIFOR board and from the director-general.

The trigger for this chapter came from the experiences of one of the authors (RF) who advised the ACM group from time to time and was a member of their international steering committee. RF did not directly observe the interactions between the ACM group and CIFOR management and other staff. He heard about the concerns and discussed them with the ACM team. $\mathrm{He}$ also observed negative attitudes from others at CIFOR, essentially in the context of "comments in the corridor" rather than public criticism. The criticisms faced by Colfer and other team members were much more explicit and direct.

The concerns about ACM described by Colfer are similar to concerns we have heard in the context of our work in action research outside CIFOR, although the concerns were generally less vehement. The main criticisms from scientists at CIFOR and other institutions were along the line that action research is not real science. The findings are not replicable or generalisable. In other words, AR misses some of the "hallmarks" of scientific processes. Such criticisms were often linked to scepticism about qualitative research generally. Colfer (2013) mentions this in the case of ACM at CIFOR.

As in the case of CIFOR, we were also exposed - in other contexts - to some discomfort about the combination of activism/intervention and research. However, this was not necessarily the same type of concern as that among the scientists at CIFOR. While researchers/scientists at CIFOR questioned ACM in terms of its research outcomes and the activist objectives, we have observed the reverse problem. Some activists were uncomfortable with combining social action/activism with research. Their concerns were twofold: the ideas that 1) research combined with development is exploitative, and 2) it is not the role of agencies concerned with development or sustainable development (see the later discussion of IUCN'S LLS).

This chapter deals with the problem of legitimacy in terms of both the concerns of scientists and activists. As it deals with our experiences, it focuses on action research, although we believe that the findings are relevant to ACM, which we see as essentially equivalent. The chapter will identify practical social and environmentally related outcomes from action research as well as research (knowledge) outcomes. It aims to show how action research (and ACM) can have multiple outcomes:

- Practical outcomes (such as improved practices or improved overall management);

- Social change outcomes (such as recognising existing local social organisations in forest management, acknowledgement of use rights and empowerment of women);

- Research outcomes (such as publications and dissemination including research publications). The research outcomes can include findings on useful methods and process documentation. 
The chapter will also briefly address questions about replicability and generalisability.

\section{What is action research?}

Kurt Lewin (1946) is generally regarded as being the first author to articulate action research as a method. He saw action research as a form of community experiment aimed at addressing social problems through collective action by a group. Even in this very early formulation of action research, Lewin talks of "circles" of "planning, executing, and reconnaissance or fact-finding" (Lewin 1946, 38) as the basis of planning subsequent steps:

Rational social management...proceeds in a spiral of steps each of which is composed of a circle of planning, action and fact-finding about the result of the action.

(Lewin 1946, 38)

As is evident from Lewin's work, the origins of action research are deeply rooted in social action and social change. Sometimes having social change objectives is seen as an essential element in definitions of action research. Greenwood and Levin $(1998,4)$ define action research as

social research carried out by a team encompassing a professional action researcher and members of an organisation or community seeking to improve their situation. AR promotes broad participation in the research process and supports action leading to a more just or satisfying situation for the stakeholders.

Greenwood and Levin specifically define action research as a type of social research. Fisher $(2002,41)$, in a positive review of Greenwood and Levin, has one "quibble." He suggests that " $[\mathrm{t}]$ he strong emphasis on $\mathrm{AR}$ as a form of social science may mask its potential relevance in the application of physical sciences." As we discuss in this chapter, AR can be and has been applied to environmental and resource management issues. We pursue the potential of action research's relevance to biophysical sciences in the context of community forestry and natural resource management, often in combination with action research as research for social change.

We see the key elements of action research as those identified by Kemmis and McTaggart (1988). ${ }^{2}$ Their book addresses AR specifically in the context of educational practices, but the elements are relevant more broadly. The key concepts link closely with the ideas of Lewin's seminal paper, particularly in the idea that the process is cyclical.

A key concept is the idea of a thematic concern, which is an "issue, or broad concern," rather than a specific research question. This is important in the examples of action research that we discuss later. For example, the work of 
NAFP in Nepal was not based on a specific research question, but a broad concern with a theme - such as the recognition that forest use and management needed to be handled better. The understanding of what specifically needed to be addressed evolved progressively through the project. More specific "research questions" could be defined for specific AR cycles.

Two of the other key elements of AR, as presented by Kemmis and McTaggart, are that it is a group activity in which group members participate in collectively addressing the thematic concern and that the process it follows involves a cyclical process of planning, acting, observing the results of action and reflection on the results and process. As a result of this reflection, a new cycle begins.

We suggest that Kemmis and McTaggart's approach is a useful way to conceptualise AR. However, we also suggest that it is useful to avoid being overly purist in applying it in different contexts.

In regard to the need to avoid being overly purist, we emphasise that the nature of participation and collaboration varies. It might involve a small core group of researchers and stakeholders tightly engaged in all aspects of a particular action research activity, including planning and evaluating action research cycles. Where the stakeholders consist of a large, dispersed population, it might involve some sort of representative structure. In other cases, there might be a core group, with other satellite groups being engaged at different levels in different aspects of a project. An example of this is an action research project on improving livelihoods and the performance of a government extension project in Papua New Guinea (Sriskandarajah and Fisher 1992). That project had a core group consisting of the researchers and national stakeholders in the project, with separate overlapping groups at district and sub-district levels.

We understand action research as a form of applied research (Fisher 2013). The essential differences between AR and other forms of applied research are the focus on exploratory, reflective and iterative inquiry and the participatory/ collaborative aspect.

Broadly speaking, applied research aims to address a situation or problem from a practical point of view, looking for a solution. The problem is often, but not always, defined by the owners of the problem rather than the scientist (which often makes it different from conventional research). Once the problem is defined, applied research can be implemented through more conventional approaches to science including the use of controlled experiments.

Action research differs from the more common linear approach to applied research in that it combines action and research and involves a group of people around an issue or concern. It involves consciously and systematically, moving through a series of repeated cycles of action, observation, reflection and planning. While more conventional applied research often involves the scientists going away to solve a research problem on behalf of a client, action research involves investigating issues at the same time as attempting to address them learning by doing and learning from doing. The solutions are tested and modified as the research proceeds. 
Action research is a process of learning in order to act more effectively in a particular situation. In this sense, it is first and foremost a methodology for implementation and action (Fisher and Jackson 1999). PAR is a form of action research that involves collaboration between researchers and people who are concerned with the need to solve a problem.

ACM has similar logic. It is about addressing problems collaboratively in a manner that adapts as the nature of the "problem" changes or as new problems emerge.

We suggest that it is important to differentiate between action learning and action research (Fisher 2013). Action learning is about learning approaches to problem solving. Like action learning, action research is about learning approaches to problem solving, but also about contributing to public knowledge by publication or other methods of dissemination of ideas/information. Unlike action learning

action research is... a type of research, in the sense that it contributes to "public" knowledge. Experience in a specific situation generates insights and understanding which can inform actions in similar situations. The word inform is important here. The intention is not to provide recipes for implementation, but rather to provide insights which others may find useful in other contexts. This aspect of generalising from learning in a specific situation is the research element.

(Fisher and Jackson 1999)

Both action learning and action research are useful when:

- a situation or issue is complex with many unknowns (and therefore not suitable to a reductionist approach);

- a situation is changing;

- the starting point is not clear;

- there are multiple stakeholders involved.

These situations commonly apply in cases involving the management of environmental and natural resources by humans.

\section{Our experiences with action research}

In the following section, we discuss our experiences with AR/PAR as we progressively became aware of the approach. The progression is from a naive stage when we were first exposed to some general ideas, through more informed stages as we were exposed to literature and wider experience. With our colleagues from the NAFP we started "by making it up as we went along," before becoming involved in a university programme where action research was central and later we took part in a more developed approach in the context of the IUCN LLS programme. 


\section{Nepal-Australia Forestry Project}

Australia has a lengthy history of involvement in forestry in Nepal, beginning in 1966 with a technical focus on forest nurseries and plantation establishment. By the late 1970s, the geographic focus of NAFP had shifted to the middle hills districts of Sindhu Palchok and Kabhre Palanchok, east of Kathmandu, and while the concern of the project remained largely on afforestation, it also began to widen to include community forestry.

In his description of the project in the late 1970s, David Griffin writes:

Forestation was said to be necessary to provide fuelwood, mainly for the Kathmandu Valley towns, and to arrest erosion on the surrounding hills. The initial solution was thought to be to plant fast growing, quick rotation exotic species in areas protected from the local populace by fences and guards. The very first advisor saw the weakness in such an assessment but for years the project remained in a largely technocratic mould.

(Griffin 1988, 23)

By the time we began working with NAFP in the late 1980s (we both joined in 1987), the thematic concern had shifted to a broader concern with improving both forest restoration and livelihoods. There was an increased focus on social questions, but this coexisted with the need to address other technical issues such as silviculture of natural forests and shrublands. Early efforts to develop forest management plans for communities failed when community consultations involved groups that were not traditional users of particular forests - the wrong people were identified (Gilmour and Fisher 1991). This led, progressively, to cycles of investigation (Lewin's "fact-finding") of developing methods for working with different "interest groups" within communities, ${ }^{3}$ identification of traditional users and studies of "indigenous" organisations and institutions of forest management. In parallel, cycles of more technical research took place on silvicultural issues related to meeting local needs and developing appropriate silvicultural techniques for communities. It is worth noting that the technical AR also involved collaboration with local forest users in terms of identifying the problems, undertaking technical interventions such as thinning of dense shrublands to promote the growth of locally preferred species and monitoring results.

These parallel and interlinked cycles were essentially action research cycles, illustrating the possibility that multiple AR cycles can occur at one time and that AR can usefully be applied to more conventional biophysical research.

By 1987, project staff, led by Project Director David Griffin and the Team Leader Don Gilmour, had begun talking about action research, but the discussion was barely informed by much, if any, of the literature or theory specifically related to action research. In fact, we were not exposed to the theoretical literature on action research until RF joined UWS-H in 1991. We did not consciously follow an action research cycle and there was no formal group of participants. 
In a brief paper, David Griffin (1987), the project director, questioned the meaning of intensified forestry in the context of mountain regions, arguing that the meaning of intensification needed to take account of linkages between forests and local communities. He then went on to suggest the relevance of participatory action research. In the same year, a conference paper by project staff (Gilmour, King and Fisher 1998) also argued the case for action research based on the inadequacy of traditional forestry research. Again, despite the use of the term, there was no specific reference to theoretical literature on action research. In fact, the case for action research was related to the work of Chambers (1986) on the "new professionalism" in development.

It appears that the origin of these publications and the concern with action research was in the movement that had been rethinking Himalayan mountain issues in the 1980s. In the context of increasing concerns by researchers about the high level of uncertainty about the real causes and effects of environmental degradation in the Himalaya, despite the commonly accepted view of a Himalayan mountain crisis, considerable work had been done calling the consensus into question. This questioning led to the Mohonk Conference in April 1986 in New York. The proceedings of the conference, which cover the findings of the critical research on the supposed crisis, are in an issue of Mountain Research and Development in 1987 (vol 7 no 3). Ives and Messerli (1989) also deal with the conference outcomes and show just how many of the common assumptions about the Himalayan environment added up to a myth.

Thus, it seems that the emergence of AR in NAFP was a consequence of the recognition that there were many unknowns about the Himalayan environment and development and recognition that scientific forestry was inadequate for addressing forestry in the Himalaya, specifically Nepal in the case of NAFP. The AR approach used in NAFP shifted progressively from focusing on improving awareness and capacity of local communities to restore and manage degraded forests using conventional forestry approaches, to working more closely with local people to identify challenges and potential solutions.

At the time we joined NAFP, concerns about the high level of uncertainty of data and information influenced our discussions within the project and with Department of Forest (DoF) colleagues. Given the social and environmental heterogeneity within the middle hills, the lack of reliable data and information meant that we had to constantly adapt the project as we learned. Although project staff did not widely use the term action research, and indeed much of the published literature on action research was not available to us at that time, we were engaged in what may be thought of as a naive form of action research. Nevertheless, almost intuitively, we engaged as a research team in a cyclical process of planning, acting, learning and reflecting. This process involved DoF staff and, informally, local forest users. We should stress here that, at this stage, there was no formal and ongoing involvement of local people as participants in the reflection process, but there was very active discussion with local people by staff as we trekked from village to village throughout the districts, staying in 
villages. We had not, at that time, developed a clear model for participation in PAR. In fact, we generally referred to the method as action research.

An essential feature of the process of engaging with local communities was the importance of identifying issues, stakeholders and conflicts before forming groups to plan community forest management. The risk of forming groups (community assemblies or committees) made up of the "wrong people" without legitimate interests in the form of recognised use rights was recognised very early, based on lessons from an abortive effort to set up a forest management plan at Chaap al Danda Forest through formal meetings (Gilmour and Fisher 1991). Following this abortive effort, participatory principles were applied without the project consciously practising PAR. The idea that forming a committee was not the first step contrasted with the usual bureaucratic practice of forest officers. They typically began community interventions by contacting local leaders and asking them to call a meeting without preliminary familiarisation with issues and stakeholders. This lesson could usefully be applied in contemporary programmes such as Forest Landscape Restoration and REDD+.

Had we, as part of the project team, not been afforded the flexibility of adapting the project as we learned, it is highly unlikely the project would have achieved the results that it did.

The exploratory approach adopted by the project enabled project staff to consider the validity of the generalisations and question the appropriateness of project interventions. One area of particular interest was indigenous ${ }^{4}$ management of forests. Gilmour and Fisher $(1991,17)$ note that:

The professional culture of foresters includes assumptions about the priority of technical knowledge about trees in all forestry activities. Such assumptions lead to a tendency to ignore the relevance of indigenous knowledge. They also lead to great difficulties in recognising the genuine multi-disciplinary nature of the activity we call community forestry.

The project began to explore the nature of indigenous forest management, and this revealed that a wide variety of indigenous systems and organisations existed, often in parallel with the formal government community forestry programme (at that time, the responsibility for forests was being handed over from the DoF to local governments, panchayats). We began to recognise that most hill forests had a set of users that were mutually recognised, that many had some form of indigenous forest management and that, in some cases, the panchayat approach to community forestry was leading to conflict when traditional users were disenfranchised from using a local forest or non-traditional users were empowered to use a forest. This revelation helped inform the shift to the user group approach to community forestry.

The research about indigenous forest management, undertaken as an outcome of the reflection in the action research process that this was an important knowledge gap, has been described in Gilmour and Fisher (1991) as well as in more conventional ethnographic literature (Fisher 1989, 1994). This 
emphasises that AR can include cycles of research in other modes and that it can contribute to more "conventional" literature.

It is important to stress here that, while the project was exploring social change through action research, a range of technical forestry issues, including silviculture of shrublands and harvesting of pine plantations to produce timber, were also explored through action research cycles. These simultaneous "action research" cycles interacted with each other as most project interventions had elements of social change and technical improvement.

\section{Outcomes of action research in the project}

NAFP was considered to be successful in several respects:

- In its early period, it was very successful in promoting and enabling reforestation with communities;

- The research into social aspects of forest management, including traditional or indigenous forest management, contributed to the development of community forestry policy and practice in the late 1980s and 1990s through close collaboration with senior DoF officials and policymakers - the approaches developed and community-level organisational models were incorporated in official guidelines and laws;

- The approaches to working with communities to collaboratively negotiate and plan community forestry activities were used as the basis of training activities and materials for DoF staff and were also published in a book (Gilmour and Fisher 1991) and a training manual (Jackson et al. 1996).

- The social aspects of research were published (including Gilmour and Fisher 1991; Fisher 1989, 1994). An important aspect of the published research is the process documentation of the social experiments (e.g., Gilmour and Fisher 1991).

- In terms of more conventional research, the project produced and disseminated a significant number of publications (including distributed reports and working papers) on social and biophysical topics as well as publications on the process of project intervention.

The experiences within NAFP certainly involved a relatively simple (even naïe) understanding of $A R$, and certainly, one in which participation was not formalised. The point that needs to be emphasised is that exploratory and cyclical research led to successful (and published or otherwise disseminated) research outcomes, as well as contributing to changes to community forestry policy and practice. The fundamental changes in policy and practice were 1) to support the separation of existing user groups from official political-administrative units that did not reflect use rights and 2) to contribute to the guidelines for forest department staff in implementing user group-based forestry. 


\section{Action research at the University of Western Sydney, Hawkesbury}

In the 1990s, AR was used in most, if not all, $\mathrm{PhD}$ and master's projects in the then School of Agriculture and Rural Development at UWS-H. ${ }^{5}$ The School was experimenting with quite radical new approaches to university teaching, at both the undergraduate and postgraduate levels. For postgraduate research (understood as master's or $\mathrm{PhD}$ level research in Australia), the emphasis was on combining social research with agriculture and natural resource concerns through action research. The field of social research is not synonymous with action research. The innovation at UWS-H was applying action research to social research.

The resulting theses dealt with a variety of problems. Some dealt with general development or rural development issues without being directly concerned with natural resource management. For example, Avorn Sansak (1996) applied what she called "collaborative action research" in the context of empowerment of women in a village in northern Thailand. She undertook her research as a facilitator of a core group of women who followed the cyclical action research process to improve their impact on decision making about village development. This was specifically concerned with social change but was not related to biophysical research.

Other theses addressed natural resource management or sustainable development issues, combining social and biophysical research. Solieng Mak (1997) explored agricultural innovation in rural Cambodia. Her initial focus was examining barriers to the adoption of green manuring in rainfed dryland rice farming. Promoters of green manuring had been puzzled by the poor level of uptake of the technology that demonstrably improved productivity. Solieng's work showed that the lack of "adoption" was due to a shortage of labour availability during the key period when the plants were maturing prior to being mixed with the soil. During this time, the growing plants were susceptible to free grazing cattle. Labour to guard the fields was not available. Men were busy during this time harvesting palm sugar, which was virtually the only available source of cash income. Women were occupied at home processing the raw material into palm sugar and looking after young children. A contributing problem was that the demographic structure was very biased towards small families with very few older adults to look after children. This was a result of the drastic demographic changes resulting from the Khmer Rouge period.

The emphasis further shifted to participatory research with villagers to address some of the identified issues, such as different ways of protecting rice plots in the context of shortages of labour and developing water supplies. One possibility was the use of collaborative groups to share labour. Initially, people were reluctant to become involved in working groups, a result of very negative experiences with agricultural working groups during the then-recent Khmer Rouge period. Later phases involved collaborative work digging ponds to store water for irrigation.

The research included a preliminary stage or cycle of what was essentially ethnographic research and then moved to further cycles of AR/PAR. The 
ethnographic work provided important findings on factors affecting the adoption of new technologies in post-conflict dryland Cambodia.

Mohammad Emadi's PhD (1995, further described in Emadi 2005) dealt with the frequently negative relationships between pastoral nomads and government officials in Iran. His research also began with an essentially ethnographic phase and moved to group meetings in which the different stakeholders discussed issues and conflicts and attempted to address them. A major finding of the ethnographic phase was that the problems facing nomads were perceived differently by nomads and officials. For officials, the key issue was damage to grasslands due to overgrazing. For nomads, key issues were the need to access services such as health and education for their families and the reduced access to grazing land due to spreading agriculture.

The action responding to these research findings focused on assisting government officials and academics to examine their assumptions and rethink their attitudes in a facilitated learning workshop (cf. Chapters 3 and 6, this volume, for more recent attempts to accomplish such goals). The practical outcomes were improved relationships and mutual understanding (i.e., social change).

Other theses addressed issues related to natural resources or agriculture, each involving PAR methodology in various ways.

Helen Ritchie (1998) worked with private landowners to address the problem of controlling water contamination from private land in Waikato, New Zealand. This was a complex practical problem involving collective action by individuals with strong commitments to private rights. The process involved the establishment of PAR groups. The research contributed to the theoretical literature on environmental governance.

Finally, Tevita Toafa (1994) carried out an action research project working with actors from the pumpkin industry in an effort to address the importance of the specific needs of the pumpkin market in Japan. Requirements included needs for reliable supplies in a narrow time window and pumpkin products to meet specified quality standards. The market was a niche market aimed to fill a gap in supply during a season when the supply could not be met from the main source - New Zealand. Like Ritchie's thesis, this involved encouraging people who were market competitors to collaborate through a participatory action research group in order to achieve common goals. From a research point of view, important findings involved improved understanding of group processes. The thesis also built upon and contributed to research on market chains.

It is important that all of these theses combined forms of PAR with a first phase in which the researcher(s) familiarised themselves with the context, including the physical and social landscapes (we think of this as an ethnographic phase). In particular, they identified the stakeholders who would need to be involved in planning and decision making. All of this was preliminary and was subject to further exploration. Additional stakeholders could be identified and added to the relevant PAR group. The essential element was that the process starts with an understanding of the, sometimes competing, interests of various stakeholders. PAR group formation is not a first step and must be informed. 
All of these theses had practical outcomes in terms of social change. They also contributed to knowledge in social fields and provided insights into action research methodology.

It is interesting to note here that, while this chapter accepts the premise that the scientific integrity of action research is often challenged, none of the external examiners of any of these theses criticised them as being "unscientific." In Australia, master's and $\mathrm{PhD}$ theses are examined by independent researchers rather than by the thesis advisors, so this indicates a level of openness to nonconventional research.

\section{The Livelihoods and Landscapes Strategy}

LLS was a five-year programme (2007-2011) implemented by IUCN and funded by the DGIS (Ministry of Foreign Affairs of the Netherlands). The Strategy focused on four main themes: poverty reduction, natural resourcebased markets and incentives, forest governance and landscape transformation (IUCN 2012).

LLS operated in a range of complex situations in 23 countries involving a wide variety of activities and a learning strategy focused on translating learning into policy-relevant messages. IUCN (2012) describes LLS as something of a laboratory to test widely held assumptions about the linkages between forest landscapes and livelihoods, for which limited, or only anecdotal evidence had been available. The LLS team included IUCN staff and consultants and more than 60 partner organisations in the countries involved.

The contexts of LLS activities in the 23 countries differed greatly. However, in each case, the context was complex, meaning there were many unknowns, and achieving collaboration with multiple partners with sometimes widely differing agendas and perspectives was challenging, to say the least. Action research was identified as one way of dealing with the need for collaborative problem solving. This led to an action learning and action research training workshop, involving participants from most of the LLS national teams, held in Tanzania in 2008.

Individual country teams had different approaches to implementing LLS. Several countries included action research in their activities. Examples from Ghana and China are discussed below.

The Wassa Amenfi West landscape (Nyame, Okai, Adeleke and Fisher 2012) forms part of the cocoa-producing area in southwest Ghana. In this area, there is a mix of land uses of which the principal agricultural activity is smallscale cocoa production by farmers who are mainly leaseholders. There are also often areas of degraded forests.

The LLS actions in the landscape were guided by a small team that consisted of LLS staff and relevant government officers. This group met regularly to review and evaluate activities. The PAR cycle was explicitly followed. This group was a structured group acting collaboratively to plan and implement action and research. 
As the project was operating in separate and dispersed communities, a single PAR group covering all sites and communities was not practical or desirable. In what can be understood as a sort of satellite structure, action research was also used at the community level in a less formal way, with community-level meetings. In these contexts, it again involved cycles of reflection and planning.

One important outcome involved addressing the reluctance of farmers to plant trees on their land, which was generally leased from local traditional leaders ("chiefs"). According to a Forestry Commission Directive, farmers had ownership of trees they planted provided the land was registered for the purpose of tree ownership - and not as certificates of land ownership or tenure. However, even when the land was registered, registration certificates were not provided, and farmers lacked confidence about their rights in the absence of evidence of registration. LLS designed a simple form, with details of registration, to be kept by farmers, thus increasing confidence through an informal innovation. The tenure innovation was reported in a publication on experiences in informal tenure reform in LLS (Fisher, Barrow, de Silva and Ingles 2012).

In China, the Miyun watershed ( $\mathrm{Li}$ and Emerton 2012) was one of the focal areas of the LLS programme. The watershed is an important source of water for Beijing. Occupancy and some use of the land were accepted by the government, but communities had no formal tenure rights. The government's emphasis on afforestation and protecting the watershed meant that community access for livelihood benefits in the watershed was restricted, and a logging ban prohibited most forest harvesting. To meet their fuelwood needs, local communities cut young undergrowth. This stopped the forests from naturally regenerating and halted ecological succession.

The protectionist emphasis on the management of the watershed was not achieving the balance of environmental and social outcomes that the government desired. The government, with the support of LLS, developed a villagebased participatory planning approach that led to the development of new local forest management plans. Use and management zones were agreed between government forest officers and local people for water protection, tourism and forest exploitation, informed both by community needs and the technical surveys carried out by the government and LLS staff, which documented forest status, resource availability and biodiversity. The PAR style approach taken to restoration in the Miyun watershed helped government staff to harmonise technical information with local interests and knowledge. The approach provided a better means for local people to use the forests at a sustainable level to meet their fuelwood needs while supporting watershed protection and conservation. It also contributed to the government exploring opportunities to integrate Forest Landscape Restoration into the activities of State Forest Farms, as demonstrated in an ongoing Global Environment Facility (GEF) supported project. $^{6}$

The practical results of activities in both landscapes were improved management of aspects of conservation and livelihoods. Most of the documentation 
of the activities provided insights on processes and problems that are relevant to people working on similar issues in other contexts rather than more broadly generalisable "research results." However, we would argue that such insights are research results (Fisher and Jackson 1999). The case studies were published in working papers. Such results are not peer-reviewed, but we argue that research outcomes are about "findings" or "lessons" that are disseminated in some way and may be useful in other similar contexts. This point is developed later.

For LLS, which was motivated and funded by donors to develop lessons about landscape approaches to conservation and livelihoods, research results were essential in order to enable lessons to be tried more broadly. Several regional writing workshops were held to support reflective report writing. There were several IUCN publications on specific issues and results from numerous countries, as well as a small number of papers published in journals. The work of LLS provided IUCN with knowledge that was used by the Government of Germany and IUCN to encourage governments to sign up to the Bonn Challenge to bring 150 million hectares of degraded and deforested landscapes into restoration by 2020 and 350 million hectares by 2030. The findings of LLS are also being used in the GEF project mentioned previously.

However, there was resistance from some of the LLS staff to the idea of action research and to efforts to encourage writing for publication. We believe that action learning (learning to improve action) was accepted, but some of the LLS team members were uncomfortable about combining activist concerns with research. They saw research as "exploitative" and both inappropriate and unnecessary in community-based conservation and development activities. They also asked why research was needed in LLS. This became a focus of disagreement at one global team meeting. Such concerns are the reverse of concerns by some scientists (as already discussed) that research should not be combined with activism.

\section{Discussion and conclusions}

We hope that the examples and experiences presented in this chapter contribute to addressing two apparently opposing concerns: the idea that ACM and $\mathrm{AR} / \mathrm{PAR}$ are poor methods for producing useful research on the one hand, and the idea that research cannot produce practical results in terms of social change or improved management on the other.

We have focused on AR rather than ACM because that is where we have had the most relevant experience. However, we believe that there is not much difference in practice because each aims for changes in practice as well as lessons that are useful beyond the immediate activity involved.

The examples given clearly show that AR can contribute to practical social or management changes and we do not intend to belabour that point. The key question here is to what extent there have been research outcomes. 
There are some clear examples of action research leading to the understanding of social phenomena. Examples from the chapter studies include:

- Solieng Mak's research finding explaining that Cambodian dryland rice farmers were unable or unwilling to adopt green-manuring technology because of labour shortages and the wariness of agricultural groups (learned during the Pol Pot period).

- Mohammad Emadi's finding that the concerns of nomads were more about accessing sedentary social services than access to pasture.

- Action research in Nepal leading to an increased understanding of indigenous forest management organisations (Gilmour and Fisher 1991; Fisher 1989, 1994).

However, demonstrating that action research may have concrete findings may not address the more general concern of quantitative/reductionist scientists that action research, like qualitative research in general, does not produce replicable or generalisable results. We suggest that the problem with that is that action research deals with cases that are context and time specific. The data cannot be confirmed by subsequent researchers because the situation has changed. ACM and PAR are meant to be applied to specific contexts in space and time. Nevertheless, insights gained through the processes may be useful in understanding and intervening in different cases.

Another point to consider is that action research is not necessarily or essentially about gathering information, such as information about numbers of trees, survival rate of trees, population numbers and so on. It is generally about increasing understanding of interactions between people, understanding implementation processes or understanding decision making. As Fisher and Jackson (1999) state "Action research focuses more on increasing understanding than on collecting facts (although these can be collected under the rubric of action research when necessary)."

In action research, much of what is learned is in the form of insights about causes and effects in a specific situation. The insights are not generalisable in the same way the results of laboratory experiments are, but they may be useful for understanding other situations where some similar conditions exist. For example, understanding why people do not adopt technology in one situation (because of risk or labour shortage) may not be universal, but it is an insight that may be helpful in other cases.

Most programme/project interventions in natural resource management still tend to favour approaches that are based on available evidence using a theory of change or a results-based approach that makes assumptions about the social and socio-ecological situation, which then the programme/project proceeds to try and improve. Often, the complexity of the situation is not well understood at the start of a programme/project but emerges with time. Programmes/projects are often not well equipped to adapt to an emerging understanding of a situation but are driven by a need to deliver agreed results that were (often 
incorrectly) identified at the start of a programme/project. PAR and ACM were meant to help address this problem.

Based on our experiences, and many others documented, we suggest that action research, following an exploratory cyclical approach, is of great value in contributing to contemporary programmes such as Forest Landscape Restoration and REDD+. In both of these programmes, implementation occurs in the context of many unknowns - social, political and biophysical. There are often, if not usually, major unknowns that can affect results, including different tenure systems, different types of local institutions and different policies. Action research allows action to start without a full understanding of the situation and to be modified as more becomes known or as the situation changes. We also suggest that a hybrid approach to action research, which encompasses both social research and biophysical research is ideally suited to these programmes.

\section{Acknowledgements}

We would like to thank Dr Don Gilmour, who was the Team Leader of NAFP when we first experienced action research, and the late Emeritus Professor David Griffin, who was the project director. Both led the way with action research in those days and our experience in Nepal would have been much reduced if not for their leadership and willingness to question. We would also like to thank our colleagues in NAFP, both Nepali and expatriate as well as our colleagues within the Department of Forests. We also acknowledge Professor Richard Bawden, Dr Nadarajah Sriskandarajah, Dr Mohammad Emadi and other colleagues at the University of Western Sydney, Hawkesbury, as well as our colleagues in IUCN for sharing their knowledge and experience in action research.

\section{Notes}

$1 \mathrm{RF}$ is an anthropologist. WJ was trained as a forester but has also worked in a wide range of conservation roles.

2 There is a more recent edition of Kemmis and McTaggart. We refer to the 1988 edition as that was the edition to which we were first initiated at UWS-H and which influenced all of our subsequent work.

3 The application of methods such as focus groups was introduced in parallel with training workshops for Department of Forests field staff, led by Dr Kaji Shrestha (a Nepali adult education specialist) and activist and Jane Gronow, a British volunteer.

4 In project documentation and publications, the term indigenous referred to locally initiated management arrangements and local knowledge. It did not refer to the institutions or knowledge of "indigenous" groups (i.e., minority ethnicities). Retrospectively, the better word might have been "endogenous." but we use the term as it was used in our documents at the time.

5 As is common in universities that have the endless tendency to reorganise, the name and organisational structure of the unit changed several times in the period 1991-1996, although what we refer to as the School remained a recognisable entity. 
6 See the GEF project - Building Climate Resilient Green Infrastructure: Enhancing Ecosystem Services of Planted Forests in China through Forest Landscape Restoration and Governance Innovation. Accessed 7 March 2021. https://www.thegef.org/project /building-climate-resilient-green-infrastructure-enhancing-ecosystem-services-planted -forests.

\section{References}

Chambers, Robert. 1986. "Normal Professionalism, New Paradigms and Development." Discussion Paper 227, Institute of Development Studies, University of Sussex.

Colfer, Carol J. Pierce. 2013. "The Ups and Downs of Institutional Learning: Reflections on the Emergence of Adaptive Collaborative Management at the Center for International Forestry Research." In Adaptive Collaborative Approaches in Natural Resource Governance: Rethinking Participation, Learning and Innovation, edited by Hemant R. Ojha, Andy Hall and Rasheed Sulaiman V., 48-102. London and New York: Earthscan.

Emadi, Mohammad H. 1995. "Pastoralists, Participation and Policy: An Action Oriented, Systemic and Participatory Approach to Improve the Relationships Between Pastoralist Nomads, Government and Natural Resources in Iran." PhD Thesis, University of Western Sydney, Hawkesbury, Australia.

Emadi, Mohammad Hossein. 2005. "Research Through Action with Nomadic Pastoralists in Iran." In Participatory Research and Development for Sustainable Agriculture and Natural Resource Management: A Sourcebook. Volume 1. Doing Participatory Research and Development, edited by Julian Gonsalves, Thomas Becker, Ann Braun, Dindo Campilan, Hidelisa de Chavez, Elizabeth Fajber, Monica Kapiriri, Joy Rivaca-Caminade and Ronnie Vernooy. Ottawa, Ontario, Canada: International Development Research Centre.

Fisher, Robert. 1989. "Indigenous Systems of Common Property Forest Management in Nepal." Working Paper 18. Honolulu: East-West Environment and Policy Institute, EastWest Center.

Fisher, Robert. 1994. "Indigenous Forest Management in Nepal: Why Common Property is Not a Problem." In Anthropology of Nepal: People, Problems and Processes, edited by Michael Allen, 64-81. Kathmandu: Mandala Book Point.

Fisher, Robert. 2013. "Learning through Action: Reflections on Action Research in Natural Resource Management." In Adaptive Collaborative Approaches in Natural Resource Governance: Rethinking Participation, Learning and Innovation, edited by Hemant R. Ojha, Andy Hall and Rasheed Sulaiman V, 257-286. London and New York: Earthscan.

Fisher, Robert, Edmund Barrow, Janaka de Silva, Andrew Ingles and Gill Shepherd. 2012. "Improved Access to Forest Resources: Experiences in Informal Tenure Reform from IUCN's Livelihoods and Landscapes Strategy." Working Paper 3, Livelihoods and Landscapes Strategy. Gland, Switzerland: IUCN.

Fisher, R.J. 2002 "Review of Introduction to Action Research: Social Research for Social Change (Davydd J. Greenwood and Morten Levin).” Practicing Anthropology 24 (1): 41.

Fisher, R.J. and W.J. Jackson. 1999. "Action Research for Collaborative Management of Protected Areas." In Collaborative Management of Protected Areas in the Asian Region, edited by Krishna Prasad Oli, 235-243. Kathmandu: IUCN Nepal. Proceedings of a Workshop held at Royal Chitwan National Park, Sauraha, Nepal, May 25-28, 1998.

Fisher, Robert J., Ravi Prabhu and C. McDougall, eds. 2007. Adaptive Collaborative Management of Community Forests in Asia: Experience from Nepal, Indonesia and the Philippines (ACM Series). Bogor, Indonesia: CIFOR. 
Gilmour, D. A. and R. J. Fisher. 1991. Villagers, Forests and Foresters. Kathmandu, Nepal: Sahayogi Press.

Gilmour, D.A., G.C. King and R.J. Fisher. 1998. "Action Research into Socioeconomic Aspects of Forest Management." In Role of Forest Research in Solving Socioeconomic Problems in the Himalayan Region. Proceedings of IUFRO Symposium, Peshawar, Pakistan, 1727 October 1987.

Greenwood, Davydd J. and Morten Levin. 1998. Introduction to Action Research. Social Research for Social Change. Thousand Oaks, London and New Delhi: Sage Publications.

Griffin, David. 1987. "Intensified Forestry in Mountain Regions." Mountain Research and Development 7 (3): 254-255. Proceedings of the Mohonk Mountain Conference: the Himalaya-Ganges Problem.

Griffin, David. 1988. Innocents Abroad in the Forests of Nepal. An Account of Australian Aid to Nepalese Forestry. Canberra: ANUTECH Pty Ltd.

IUCN. 2012. Livelihoods and Landscapes Strategy: Results and Reflections. Gland, Switzerland: IUCN.

Ives, J. D. and B. Messerli. 1989. The Himalayan Dilemma: Reconciling Development and Conservation. London and New York: The United Nations University-Routledge.

Jackson William, Y. B. Malla, A. W. Ingles, H. B. Singh and D. A. Bond. 1996. Community Forestry for Rural Development in Nepal. A Training Manual. Kathmandu, Nepal: NACFP.

Jackson W.J. 1999. “The Dynamics of Lekh Forest Use in the Middle Hills of Nepal.” PhD Thesis, University of Western Sydney, Hawkesbury.

Kemmis, Stephen and Robin McTaggart, eds. 1988. The Action Research Planner. Australia: Deakin University, Deakin University Press (3rd edition).

Lewin, Kurt. 1946. "Action Research and Minority Problems.” Journal of Social Issues 2 (4): 34-46.

Li, J. and L. Emerton. (2012) Moving Closer to Nature: Lessons for Landscapes and Livelihoods from the Miyun Landscape, China. Strategy Working Paper 1. Gland, Switzerland: IUCN (LLS).

Mak, Solieng. 1997. "Rainfed Lowland Rice Farming in Cambodia: A Study of Agricultural Change." PhD Thesis, University of Western Sydney, Hawkesbury.

Nyame, Samuel Kofi, Michael Okai, Adewale Adeleke and Bob Fisher. 2012. Small Changes for Big Impacts: Lessons for Landscapes and Livelihoods from the Wassa Amenfi West Landscape, Ghana. Landscape Paper 4. Gland, Switzerland: IUCN (LLS).

Ritchie, Helen. 1998. "Beyond the Fences: Co-ordinating Individual Action in Rural Resource Management through Landcare. A Case Study of Managing Non-point Source Discharges to Water in Waikato, New Zealand." PhD Thesis, University of Western Sydney, Hawkesbury, Australia.

Sansak, Avorn. 1996. "Empowering Women in Rural Development: A Collaborative Action Research Project in Northern Thailand." PhD Thesis, University of Western Sydney, Hawkesbury, Australia.

Sriskandarajah, N. and R.J. Fisher. 1992. "A Participatory Approach to Improving Rural Livelihoods of People in the Goilala District of Papua New Guinea." Report on a research project funded by the Australian International Development Assistance Bureau under the Development Research Grants Scheme.

Toafa, Tevita. 1994. "Action Research to Improve the Pumpkin Industry in Tonga." MSc Thesis, University of Western Sydney, Hawkesbury, Australia. 


\section{Introduction to Chapter 10}

As we move from Chapter 9, which focused on the varying iterations and uses of approaches like ACM, PAR and AR, we return to their use in the ACM programme generally. PAR was used as a tool to encourage the development of (or strengthen existing) adaptive collaborative management, primarily in communities, although with tentacles reaching up and out to other levels as needed.

In Chapter 10, Prabhu, Larson and Colfer begin by referring to a Greek differentiation: between relatively static ouroboros cycles and the forward movement involved in the also-cyclic Greek triskelion. The latter we see as parallel to a PAR process (as shown in Figure 5.1, which has formed consistent guidance for ACM teams in interaction with communities and other stakeholders), ideally moving ever-forward in terms of human and ecological improvements.

These authors provide two African examples where others have drawn on ACM principles, in trying to upscale, to extend ACM processes to work with a wider range of actors over larger geographic areas. These examples clearly show some of the differences in working at the local level and trying to incorporate ACM principles at broader scales. But they also give some excellent suggestions for new and adapted approaches that appear to be working at the moment (SHARED and Regreening Africa).

They conclude this chapter and the book by looking forward to encouraging further adoption of ACM-like approaches in the many global efforts to improve natural resource management - so many of which still ignore the needs and capabilities of local communities. We also acknowledge in passing that a second volume, tentatively entitled Adaptive Collaborative Management for Forests and People: Past, Present and future, is in the works with continued attention to assessing the longevity and effectiveness of ACM and its uses at broader scales and in different sectors. 


\title{
10 Circles and spirals
}

\author{
Ravi Prabhu, Anne M. Larson \\ and Carol J. Pierce Colfer
}

\section{Introduction}

Here we are, nominally at the end, but really only at the beginning. It should be clear by now that we have entered the histories of people and forests somewhere in the middle, their beginnings lost in time, their futures beyond our compass. The ancient Greeks visualized this as ouroboros, the snake that eats its own tail, and understood it as a loop, a cycle, the depiction of the neverending story. This may be the story of the people and their forests, but the story of ACM is a little different.

That story would best be depicted by yet another ancient symbol, the spiral. The Greeks, always to be relied on in such circumstances, have a triple, interconnected spiral called the triskelion, which, in many ways, captures the essence of what we hope ACM will lead to - a spiralling out and up, one of collaborative, structured learning, with improved outcomes for people and their environments.

The ACM process spirals out from co-created and shared evidence, from a shared vision of a better future and from collective actions to achieve it, seeking to make collective sense of what is happening and to enhance it. Within a shared framework of history, preferences and aspirations, ACM participants act within and upon this shared framework in the awareness that outcomes may not match expectations. Better said, ACM embodies the ambition of making an improved collective sense of what is happening within a shared framework of aspirations for better and more sustainable outcomes.

A number of the authors of the preceding chapters have tried to look under the hood of these ambitions, to describe and analyse the practical steps that make up ACM in order to determine whether they actually led to improved outcomes. They analysed roles of proximate actors - primarily those in their communities - and distant ones, the government for example. The focus was on actors who matter or "count," although this is not always immediately knowable. We are led to wonder, does ACM successfully harness the power of the "adaptive learning and action" spiral and lead to improvements? And if so, how does it do that? This is the central question we address in this chapter as we look across the landscape traversed earlier. 
Before that, however, we examine this book's chapters to convey our present understanding of ACM in "Revisiting adaptive collaborative management: What it is," distinguishing it, for example, from the participatory action research used to catalyse and investigate the emergence or consolidation of ACM processes. We carry forward Fisher and Jackson's (Chapter 9) discussion of the distinction and overlaps between ACM's "research," "action" and/or a combination of the two. That ACM is not a technocratic solution is clear from the previous chapters. Rather, it is a body of knowledge, a framework for a principled approach that helps locate and finetune interventions that connect and optimize existing processes of social interaction and exploration into collective endeavours for social enterprise and change. We spend some time here on understanding how differences - power, gender, endowments, training seem to have affected both the pragmatic course of ACM and the outcomes we aspire to ("From cycle to spiral: Does ACM actually help?"). We also take a shot at laying to rest one of our epistemological conundrums - does ACM exist in the world like a rough gem waiting to be polished, or only in its foundational components? Is it, as a rough gem, already on the spiral of adaptive improvement and simply in need of better traction to get further up? Or does it emerge, as a result of being coaxed out of its component processes - processes that already exist in some not well-connected form - to deliver an iterative improvement spiral and escape from ouroboros circularity?

Does our understanding of ACM processes and outcomes still hold true if we leave forested landscapes ("Spiralling out: ACM beyond the forest")? We pursue this question into non-forested contexts only briefly here in order to better understand ACM and its potential. Our journey here departs from ouroboros, leaving it behind almost immediately, to spend most time with what happens on the collective learning and action spiral before stepping back to see whether ACM leads to such spiralling out - the triskelion.

\section{Revisiting adaptive collaborative management: What it is}

We draw on the book chapters to explore most fundamentally what $A C M$ is. However, as such a broad concept, we have found that different individuals see it and various projects use it somewhat differently - partly because we are dealing with "wicked problems" (both complex and ever-changing). Here, we briefly return to ACM's history. In this book (and others), there have been multiple uses of the terms participatory action research and adaptive collaborative management. Initially, in our ACM programme at CIFOR, we were focused on the ACM process as an iterative one of improving management in an equitable manner, and we saw PAR as a means to do that, as a tool. We saw ACM as an umbrella approach, encompassing numerous tools (like criteria and indicators, reflexivity, biophysical experimentation, social networking, gender analysis and more).

PAR, as used by others, has not always focused on forests, or even natural resources. PAR, though central to ACM in its iterative quality, was not 
inherently focused on forest management and human well-being, unlike our version of ACM. ACM's initial forest focus allowed us to integrate this social science approach within a CGIAR centre in a way that was unusual within that network. The approach served as an entrée for the use of methods that addressed human factors (termed "human well-being" in our early days), which we deemed much needed but at that time under-utilized.

Others have seen and used PAR as the more comprehensive umbrella. The PAR process has been used in a wide range of settings, far beyond forestry, as shown in Chapters 2 and 9 particularly. Those who have begun with PAR are likely to consider ACM as a special case, focused on forests and their management. Most of our ACM team members over the years have focused on forests and begun with ACM, thus seeing PAR as a subset of tools or approaches of use in the management thereof.

Another element of the "confusion" about ACM and PAR derives from the fact that both recognize the holistic nature of cultural and biological systems. Both address a wide range of concerns. Within ACM, for instance, diverse topics have at various times and with various individuals taken centre stage, within any particular project situating that topic within the system of which it was a part. Examples include:

- Gender and inclusivity (Colfer 2005; Indriatmoko et al. 2007; Evans et al. 2017)

- $\quad$ Social learning (Wollenberg et al. 2001a; McDougall et al. 2009, 2010; Evans, Larson and Flores 2020)

- Monitoring (the collection by Guijt 2007 or CIFOR 1999)

- Governance (Cronkleton et al. 2010; Colfer and Pfund 2011; Flores et al. 2016)

- Equity (Colfer 2005; Wollenberg, Anderson and Edmunds 2001b; McDougall et al. 2013)

- Modelling (Vanclay, Prabhu and Sinclair 2003; Vanclay, Prabhu and Sinclair 2006)

- The future (Evans et al. 2006; Wollenberg, Edmunds and Buck 2000) and

- Collective action (Komarudin et al. 2012)

This diversity also characterizes PAR. The iterative, cycling triskelion process is also central to both.

Another differentiation that has bedevilled our attempts at conceptual specificity and clarity with regard to concepts - more related to ACM than PAR - is that between management and governance. ACM, of course, includes management in its very name; and forest management has been a central pillar of our concerns. However, our initial recognition that ACM processes would have to span levels, from the local "up" to higher levels or "out" to broader scales, quickly brought us into questions of governance - an involvement that has only strengthened. McDougall and Ojha and others have written of "adaptive collaborative governance" (McDougall et al. 2013); see also Chapter 8). 
Colfer once opined that "One could say that management is to a defined organization or sector, such as forestry, what governance is to society at large" (Colfer et al. 2011, p. 26). In early 2021, she carefully read the book Forest Governance and Management Across Time (Marald et al. 2017), seeking a clear differentiation between the two; she found none. One could construct a Venn diagram showing the overlap, with ACM in the intersecting arcs - the overlap perhaps contracting or expanding depending on the varying topics addressed and analyses conducted.

Fisher and Jackson (Chapter 9) focus on whether the action research components of PAR and ACM constitute a legitimate approach to research. They counter a common scientific bias that research needs to be replicable, and perhaps also more quantitative, to be reliable and legitimate. They also discuss their experience of NGO disapproval of PAR as too focused on "research" - a very different complaint from those of scientists but showing the sometimes difficult battle for legitimacy for such participatory methods. In Fisher and Jackson's formulation, ACM does not always have research objectives, but when it does, it has revealed important scientific findings in multiple contexts, as well as leading to important social and practical outcomes. Its distinctive feature is that it permits much better engagement with the specificities of context, which can make or break any project intervention. It permits project organizers to admit that they do not (and perhaps cannot) have the full a priori knowledge required for a successful intervention.

Considering ACM, Johnson and Pokorny (Chapter 2) recognize:

the need to carefully take into account the capacities and agendas of all involved actors, the researchers, technicians, their supervisors, and local research partners. ... It is also clear that collaboration requires more than the simple application of participatory techniques and methods. It requires a true interest in and understanding of the perceptions and susceptibilities of the community and the inequalities related to logistics, lifestyles, expectations and priorities. Adequate training and intensive supervision are mandatory but may sometimes be insufficient.

Further, Cronkleton, Evans and Larson (Chapter 6) also point to the importance of scaling "learning to the needs, interests and capacities of the participants." They go on to point out that these processes can be uncomfortable, particularly when such experiences challenge the assumptions and identities of those involved. Nevertheless, in order to work in and engage with the complex environments of forest communities, everyone has to "learn how to learn" more effectively. Their chapter lays out in detail how this was accomplished.

Learning is integrally related to participation in decision making regarding natural resource management. Mukasa et al. (in Chapter 5) identify the ACM approach as an intervention "designed to enhance participation by all stakeholders (especially marginalized groups) in deliberate community efforts including decision making and benefit sharing." As Bomuhangi et al. (Chapter 4) point 
out, this process can be formalized: ACM can be an approach "where decision making by forest adjacent communities in making rules related to enforcement and benefit sharing has been formally acknowledged by the state," as it seeks to improve management with improved outcomes. Or it can remain informal. In the early ACM sites, several teams opted for the former (e.g., Nepal, Zimbabwe, Malawi), others for the latter (e.g., Brazil, Indonesia). Sites like Bolivia, Cameroon and the Philippines opted for intermediate structures, tying in closely with government policies and institutions, but forming loose local groups.

As Cronkleton, Evans and Larson (Chapter 6) put it, ACM requires that everyone adopt the "learning way," that is, despite the fact that a part of what makes us humans is our ability to communicate, collaborate, learn and adapt, this is a process that benefits from active support, engagement and capability strengthening. Collaborating, learning and adapting through collective action - in a way that is equitable, and with outcomes that are both sustainable and beneficial - is clearly not a trivial task. Seen this way, ACM is a capability strengthening approach as much as it is a management approach.

McDougall and Ojha (Chapter 8) highlight another pervasive dimension to this collaborative learning environment: unequal power relations. One of the reasons that communication and collaboration do not "naturally" emerge is because people are not bringing the same resources to negotiations. As these authors suggest, through their deep theoretical inquiry, assuming a level playing field is unlikely to bring about a successful learning process that promotes the kind of critical inquiry and reflection required to challenge inequalities. Thus, we return to the importance, as emphasized in so many of the chapters, of capacity building at all levels, from the researchers to community participants: it takes considerable understanding, skill and tact to surface implicit assumptions and enable their questioning in "safe spaces."

In Chapter 9, Fisher and Jackson take us through a repertoire of ways that action research has been used - sometimes emphasizing action, sometimes research. Where we (the editors) have focused rather clearly on the use of participatory action research, they write more about "action research," which does not necessarily have to be collaborative, in their view. They discuss action research that has been conducted in several sectors and at varying scales emphasizing its versatility and broad utility.

In our experience, borne out also by the chapters of this book, ACM has to emerge out of strengthening and connecting capabilities that exist in every social grouping - local communities, multi-stakeholder forums, forms of governance. To the extent that it already exists (our unpolished gem), it may mainly need coaxing in contexts where there is already a spirit of collaboration. But unequal power relations can not only keep it from emerging but take it in untoward directions. It thus requires strengthening processes of reflection, based on gathering and analysing evidence that can challenge confirmation biases and entrenched views - including those that underlie unequal power relations. It requires an ability to share and communicate collective insights in 
ways that are equitable and constructive. It involves learning as well as being open to unlearning. Only when the resulting social learning is transformative can we say that $\mathrm{ACM}^{1}$ has emerged. Whether this results in better outcomes or not is the question we turn to next.

\section{From cycle to spiral: Does ACM actually help?}

We turn now to understanding what ACM has achieved. Has it actually helped or not, and if so, how? What made this possible?

In Chapter 9, Fisher and Jackson report a number of action research findings that were essential for understanding local contexts, and which at times led to important changes in policies and approaches. For example, in Nepal, the revelation of indigenous forest management systems and organizations informed the shift from the panchayat (subnational government) model of community forests to the current community forest user group (CFUG) model, one of the most successful community forestry experiences in the world (Gnych et al. 2020).

In Chapter 5, Mukasa et al. document the clearest evidence of the kinds of local management outcomes that ACM processes have helped to deliver: "with the coming of ACM, [previous adverse conditions] have been reversed. The forest has been restored and there are alternative income-generating projects that are not forest based," says one interviewee in possibly the strongest statement of a positive outcome from ACM processes recorded here. But despite seeing changes to "sticky" social norms after six years of ACM, the evidence remains at best mixed (Table 5.7). Changing attitudes, behaviours and norms is clearly what ACM sets out to do on a path to delivering positive outcomes that can be sustained. But we have long known that this is not a quick process in forested contexts, as results from other chapters indicate as well. Indeed, such change rarely happens quickly in any context. ${ }^{2}$

Bomuhangi et al. (Chapter 4) record that "More women in ACM sites reported enhanced participation and quality of participation in forestry management activities as compared with women in non-ACM sites." Mukasa et al. (Chapter 5), using in-depth evidence from their ACM cases, also record evidence for women's empowerment and greater equity in decision making. They note that one woman member of a group participating in ACM was "chosen as a chief in the Buganda Kingdom, a cultural institution, after demonstrating her leadership skills." But they, like other ACM researchers, also note that this requires focused building of capabilities if gender transformative outcomes are to ensue, consistent with what Cronkleton, Evans and Larson (Chapter 6) also show. It must be added that these ACM efforts did focus on women's empowerment, rather than, say, economic empowerment as a whole. They provide evidence for legally recognized ACM groups accessing new opportunities, with improved farming practices and income generation as the result. Self-empowerment through ACM intertwined with legal recognition, mutually reinforcing the groups' forward movement. The mixed results 


\section{Ravi Prabhu et al.}

in Table 5.7 suggest that positive outcomes from ACM processes were more likely if they were able to successfully engage at multiple levels of governance, authority and power, rather than being only locally focused.

Cronkleton, Evans and Larson (Chapter 6) saw in ACM "a way to generate a culture of transparent information sharing and learning in an environment where examples of good governance were rare, and where logging historically had been conducted through bribery, conflict, and clientelism." They too note positive impacts on women's participation and greater acceptance of their views in discussions and reflections. Mukasa et al. (Chapter 5) warn of challenges to the implementation of ACM from power imbalances and elite capture on the one hand or elite resistance on the other when power begins to shift and dependencies may arise, especially from disadvantaged groups - issues that arose (and were dealt with) routinely in ACM sites. McDougal and Ojha (Chapter 8) show how the approach to ACM in Nepal successfully overcame such underlying power imbalances, improving the participation of previously excluded Dalits (marginalized groups) and women in decision making, and the central role that social learning plays in mediating responses and outcomes. ${ }^{3}$

It seems clear that ACM has led to consequential, if mixed, outcomes in all these cases (as well as most others about which researchers have published). In our experience here and elsewhere, we have been able to see examples of improved trust among stakeholders, better negotiation and self-analytical skills, conflict management, bonding social capital and greater self-confidence, in addition to important research contributions to understanding local contexts. Nevertheless, the evidence for outcomes is patchy and responses are variable - though how could they not be, given the diversity of contexts, of locally determined goals, of facilitation skills, as well as the inherent ACM responsiveness to evolving local conditions? All "successes" are notoriously difficult to "prove." This persistent difficulty of measuring success across sites remains a dilemma for donors and management and governance institutions considering an ACM approach.

Fundamental to ACM successes has been their consistent attention to the context where change is being encouraged. All of these (and any genuine ACM) are firmly grounded in knowledge of and interaction with the cultural and ecological realities encountered. Success also appears contingent on how well the ACM approach addresses the distribution of power and authority at any particular level (mostly the local, in these case studies) and across scales within which that level was nested. The clearest indication of successful outcomes reported here were shifts in gender roles. Where these were directly linked to resource utilization outcomes, there were also positive economic outcomes.

Nevertheless, we remain dissatisfied with our abilities to assess the effectiveness of the approach. Our personal experience tells us that enormous changes - of uncertain duration -- have occurred in individuals and communities. We believe that many of the shortcomings of more conventional approaches to "development" are addressed and overcome within ACM - particularly as it 
functions on a small scale. Our efforts at higher levels began later; and we have struggled more at these levels, where we confront power more equivalent to our own (informal power); where trained and committed individuals can be relocated by their bureaucratic superiors and thus lost to the endeavour; where desirable local funding can be withdrawn; and so on. ${ }^{4}$

We also recognize that expecting truly substantive success, long-lasting beneficial change, has been illusive no matter what approach has been used. Our sense is that holistic and multi-scale efforts, like ACM or PAR, are needed, approaches that recognize the systemic and dynamic nature of societies and environments. These qualities and their inevitable variation from place to place and time to time suggest that logically we cannot use conventional experimental scientific methods alone ${ }^{5}$ (seeking generalizability and replicability) as the overarching umbrella approach. These fly in the face of the variability on the ground.

Still, as noted previously, our ability to measure and prove the impacts of our efforts, especially at larger scales, have been limited. In fact, any approach that is embedded in reality is challenging to implement in large, complex socio-political landscapes. The decisions made at local scales, especially in forests, which are rarely locally owned, are deeply influenced by multiple actors (e.g., government, investors) and drivers (e.g., regulations, markets) that originate far from local forests and farms. The effects of ACM, as noted, have so far been mostly local - at least those are the effects we have found easier to document. Shifting the underlying power structures at larger scales, with an ever larger and increasingly diverse - and likely more powerful - set of actors becomes increasingly difficult. The cases presented here and in other research (e.g., Sarmiento Barletti et al. 2020) suggest that efforts in larger political landscapes need to be not only bottom-up but also top-down, with a clear analysis of power and interests and an engaged and theoretically grounded strategy for change (see also Chapter 8).

Although we recognize the need for better measurement of impacts at various levels, one constraint has been that the changes we seek take time; return visits are costly and rare. As we put together this book, we learned of some multi-level successes beyond those highlighted in Nepal in Chapters 8 and 9:

1. In Indonesia, the levels of trust, established among diverse stakeholders in Jambi's ACM programme around 2000, have continued for years after the program ended (Liswanti, Tamara and Arwida 2021, in draft).

2. The Jambi community-based effort to secure rights to manage a protected area was secured, after a decade of effort by the community, an NGO and various bureaucratic levels up to national (thereby contributing to the national experience of effective local management; Yuliani et al. 2021, in draft).

3. In Zimbabwe, where national crises have been recurrent since ACM days (2000-2006), the human resources trained within the Ministry of Forestry have disappeared, though it seems likely that the ACM capabilities they 
acquired may be usefully applied elsewhere. Kozanayi et al. (2021, in draft) document the continued activity of some of the community ACM groups who continue managing as they did during the funded ACM years. ${ }^{6}$

More anecdotal evidence of impacts includes, for example,

1. The meshing of the ACM results in Cameroon with the Canadian Model Forest Program for Central Africa, under the guidance of Chimere Diaw, an early ACM proponent.

2. The network of early ACM researchers in Nepal has continued to work on related forest management issues.

3. Ravi Prabhu's continued use of the approach, as he's shepherded the projects discussed below in Africa.

Sadly, we do not know what may have occurred in several of the original ACM sites (e.g., Malawi, Brazil, the Philippines). ${ }^{7}$

In summary, ACM, in the cases we have discussed here, clearly has helped to improve equity, especially gender equity, especially locally. In some cases, this led to changes in the way forest resources and forests were managed, as men's interests in and needs for these resources were confronted constructively with women's. There remains little doubt that those researchers/facilitators involved gained valuable experience, which no doubt many have continued to use to facilitate similar processes subsequently (e.g., Cronkleton et al., Chapter 6; Yuliani et al. 2015, in West Kalimantan; Colfer et al. 2015a, b, in Sulawesi; and many more). But as with any complex adaptive system, progress evolves in unpredictable directions, is seldom linear and can take varying amounts of time. All this is likely to require changes in beliefs, behaviour and institutions, and rarely happens quickly. And it wreaks havoc with attempts to assess progress.

Ultimately, in forest communities, the capability to adapt collectively to changing circumstances will be of paramount importance to forest stakeholders and their resources. The evidence that ACM improves such adaptive capacity, and therefore lives up to its name, is clearer. It will take longer-term, more consistent and possibly more ambitious engagement to understand whether cultures, conditions and ecosystems at broader scales are also changing for the better.

\section{Spiralling out: ACM beyond the forest}

Looking beyond the forests, and the work presented in the previous nine chapters, we, the three authors of this chapter, take a peek at what is happening with ACM outside the canopy of the trees. We turn to agriculture and the management of common property resources in two short excursions to get a sense of ACM from "outside" its birthplace in the forest. The first of these deals with SHARED, an approach that has been successfully used to support 
subnational decision making in Turkana County, Kenya. We turn then to the wildly ambitious Regreening Africa project that seeks to improve the lives of 500,000 households across eight countries by "regreening" a million hectares of degraded agriculture, essentially by supporting local communities to naturally regenerate or plant trees in their crop and pastoral lands. In these cases, we wanted to open a small window of insight into how multiple, often nested, scales of intervention can be connected through social learning processes with some roots in ACM, nurtured in part from the rich intellectual soils of the forest.

\section{SHARED}

SHARED represents an attempt to move beyond the village or forest management unit level, in addressing agricultural improvements over a broader scale, in an iterative process that retains ACM's responsiveness to local conditions. SHARED incorporates the social learning deemed so important in ACM; and emphasizes previously more latent aspects of communication and decision making. The need to alter attitudes, as discussed particularly in Chapters 6 and 7 , was evident at this intermediate scale (a county), as the county sought to enhance its resilience. The successes to date are impressive.

About one year after Prabhu began engaging with the challenges of agroforestry - integrating trees more effectively into agriculture with crops and livestock - it became apparent to him that there were significant disconnects in the information that flowed between those involved in making decisions about investments in agriculture and the farmers who actually managed the land. The frames of reference and the data and evidence these farmers and broader decision makers used differed. Power, authority and hierarchy further confounded communication, learning and decision making. This was not a particularly new or original insight; but for someone with a history of working in forests and with ACM, it suggested an opportunity. Better connections among the various people and groups operating at different scales could bridge the disconnects, allow new evidence to be considered and improve the nature of decisions based on the social learning that ensued.

In Constance Neely, he found a collaborator with an intuitive understanding for creating connections where gaps existed and a much deeper understanding of agriculture than his own, especially the agriculture of pastoralists: very different because in the management of rangelands and the pasture they provide, water and soil are so dependent on herd size and the movement of these herds through these landscapes. Neely had been charged with helping the county government of Turkana (see Figure 10.1) to improve their development plans as part of a USAID and UN funded effort. She, Sabrina Chesterman and Minu Limbu from UNICEF began looking together at the challenges of opening up entrenched positions and views, including among the technocrats charged with helping to improve the situation. New ways of seeing the evidence would be needed. This was when Tor Vagen joined the efforts with his superlative 


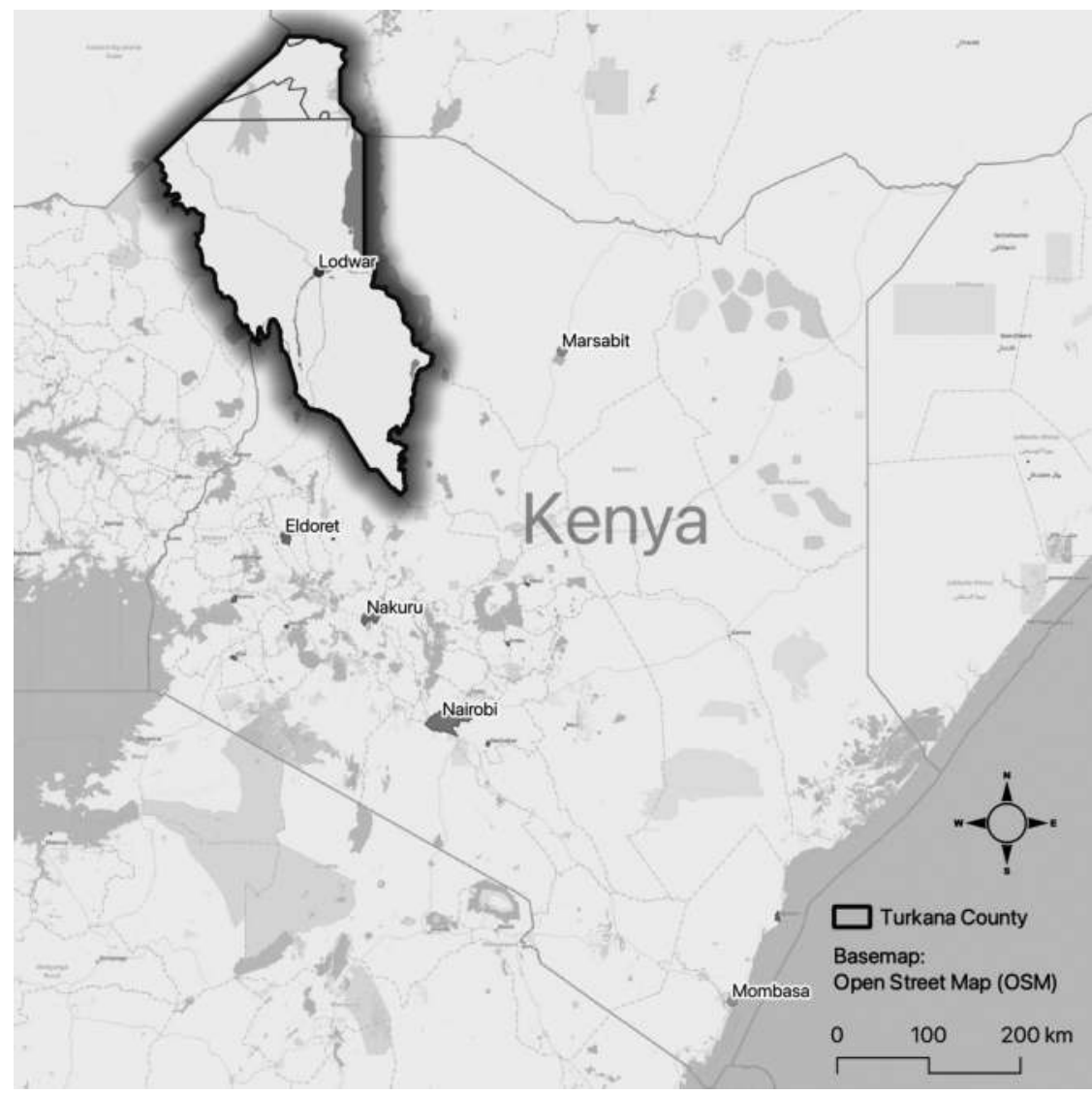

Figure 10.1 Map of Kenya, showing Turkana County.

spatial modelling skills and his deep personal history in the arid counties of Kenya. The result of the evolving ACM was the Stakeholder Approach to Risk-Informed and Evidence-Based Decision Making (SHARED). What follows is drawn from the description by Neely et al. (2021), who reach the conclusion that ACM and multiple loop learning are essential for the kind of institutional learning that leads to better understanding and values, which in turn are essential for organizational change. Essentially, SHARED is a process that enables the co-construction of bridges between different kinds of data and evidence and among different kinds of people, at different levels of hierarchy or disciplinary background. The intent is to facilitate joint understanding, gain insight and make decisions about the group's shared environment.

Key phases in the SHARED framework (see Figure 10.2) ${ }^{8}$ consist of: Context, Integrating Evidence, Prioritizing, Planning and Learning and Responding. The phases are designed to support institutional learning and 


\section{SHARED framework}

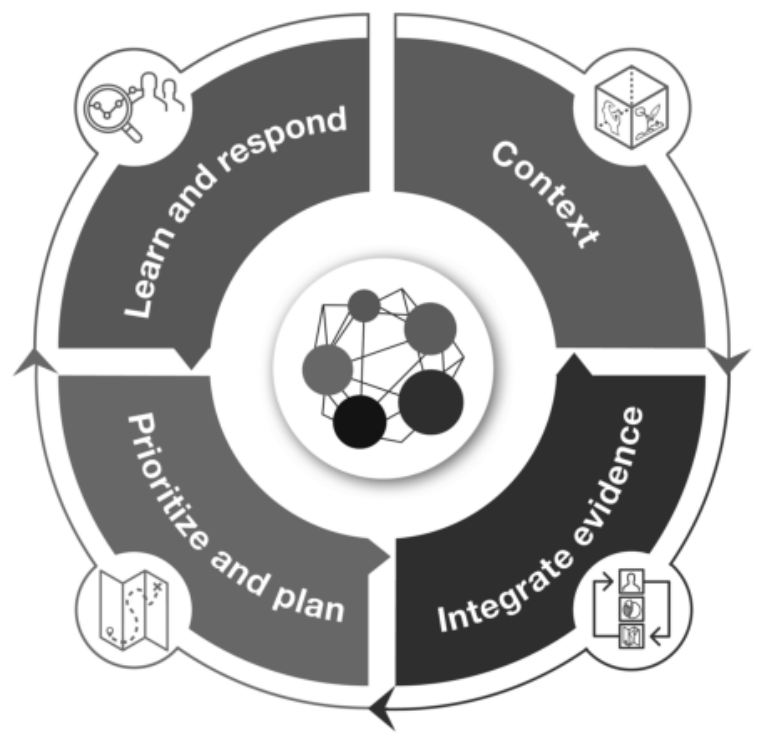

Figure 10.2 The phases of the SHARED Framework.

understanding, shift institutional values and promote organizational change. Neely et al. describe SHARED at length and its impact on decision making in Turkana County. It has since been used in other counties in Kenya and in about ten other countries around the world, with outcomes that varied from changing development plans to the identification of policy gaps. It almost always resulted in better insights into the complex agricultural systems that people were seeking to influence in order to improve their livelihoods (see e.g., Hughes et al. 2020; Vågen et al. 2018; Winowiecki et al. 2021).

Turkana County opted to use the SHARED approach, ${ }^{9}$ with SHARED scientists, collaborators and partners facilitating events with and for a variety of stakeholders. These included local and international civil society, development partner agencies, intergovernmental organizations, sectoral executives and technical staff, county assembly members, national government representatives and scientific and academic partners. Community consultations took place in each of the $30 \mathrm{Sub}-$ County Wards to incorporate local priorities fully in county-level plans.

Based in ACM, the way the SHARED approach was applied in Turkana County in Kenya intentionally integrated multiple loop learning. The results corresponded to institutional learning that contributes to a shift in understanding and values (a form of double-loop learning) and organizational change in the form of changes in norms and policies (corresponding to triple-loop 
learning). The initial policy goal was to enhance the resilience of the Turkana County Government. The actors sought to "make decisions that will have an impact on outcomes - despite the risks Turkana faces." By imbedding institutional learning, they hoped to shift the decision-making culture, as a prerequisite to changing how decisions would be made in the future and formally imbed such decision making in the development of a five-year integrated development plan.

With an aim to shift understanding and values, something that Turkana County officials saw as important for the county's future, the SHARED approach evolved, as represented in Box 10.1. Although functioning on a broader level than many ACM programmes, one can recognize the progression of steps, for the most part, similar.

\section{BOX 10.1 ELEMENTS OF THE SHARED APPROACH}

SHARED evolved towards

a) supporting an understanding of how decisions are taken, based on behavioural and structural influences and self-awareness of the existing decision-making process used by the Turkana County government;

b) co-developing a compelling and commonly held vision, framed in resilience, among a broad set of government sectors, partners and stakeholders;

c) introducing systems thinking and causal analyses for addressing development challenges;

d) creating an evidence culture to motivate securing, managing and using socio-ecological evidence; and

e) facilitating an appreciation for the insights of diverse actors and the advantage of functioning partnerships and collaboration from the community to county level with responsibility for adaptively managing resources.

Though building on ACM, this was a process that emerged out of several workshops that Neely, Chesterman and Limbu facilitated, with active and constructive engagement of Turkana County government officials. Vagen's creativity also proved influential, as he helped to visualize complex data and evidence in ways meaningful to the participants. It was an iterative process of improvement, with SHARED emerging as co-constructed by those involved. Prabhu moved to the back seat and took on the role of a sounding board for the team's thinking - a team that had expanded to include all the authors of the Neely et al. paper (2021). 
Integrating accessible and actionable high-quality evidence into decision making was seen as critical by the participants in the process from the Turkana County Government. They radically changed the way they developed their "County Integrated Development Plan," a plan required of all counties by the central government in Nairobi. They emerged with a sense that they had truly managed to integrate thinking and decision making across various government departments and with local stakeholders. They had overcome skills barriers, adapted the culture of gathering, organizing and storing data, and improved their ability to interpret it, particularly socio-ecological data. They overcame problems of defensiveness associated with displaying data that might reflect negatively on a sector's performance. Their appreciation for the importance of grounded and credible evidence led to the creation of a county data management strategy, a co-designed central web-based and transparent platform for sharing data, the requirement of evidence to support resource allocation proposals, the integration of statistics into the planning department and a monitoring and evaluation framework, department and policy. Ultimately, these changes involved opening them up to information coming from sources other than the bureaucratic channels they had used hitherto. In McDougall's terms, this was a transition to adaptive collaborative governance (2013; or Chapter 8).

Purposeful, structured and continuous stakeholder engagement resulted in more meaningful community participation and deepened cross-sectoral and multi-stakeholder linkages and relationships. This in conjunction with working hand in hand with the pivotal Department of Finance and Economic Planning led to the promotion of coordination and finance mechanisms that foster synergies, cross-sectoral and multi-stakeholder partnerships and transformative pathways.

\section{Regreening Africa}

Regreening Africa, a more recent effort, which began in 2017, takes ACMstyle efforts to an even grander scale (https://regreeningafrica.org/). Again, the project strives for communication, co-creation of knowledge and social learning as central features; and it has negotiated unusually flexible funding (so valuable in a responsive ACM process). The emphasis on restoration - one of the world's foci at the moment - makes this a particularly timely contribution.

About the time the SHARED team in Turkana was winding up its first phase with encouraging outcomes, the European Commission was discussing a major restoration project with ICRAF (World Agroforestry Center). The idea was to use mainly farmer-managed natural regeneration to "regreen" about a million hectares of farm and pastoral land across eight African countries. Involving development-oriented non-governmental organizations like World Vision International, Catholic Relief Services, CARE International and Oxfam, the project would be led by ICRAF- a research organization - intended to benefit 500,000 households. Apart from farmer-managed natural regeneration, the 
Regreening Africa project as it has come to be called, involves tree planting and other forms of agroforestry, complementary sustainable land management interventions along with community mobilization, the formation of multistakeholder advisory groups in addition to teams focused on research and the delivery of knowledge and technical support.

The project was initially conceived as a standard development project where ICRAF, as the "knowledge partner," would provide technical inputs and NGO partners would deliver and implement these with local communities through their teams in the eight countries. However, based on past experience with other projects, success with ACM approaches and the coming of age of SHARED, Prabhu was able to convince a very open-minded, farsighted and engaged team at the European Commission (Bernard Crabbe and Alexandru Ghiurca) to consider modifying the design. His proposed changes were intended to make the project more flexible, integrated and based around adaptive management principles, where it could "learn to improve" as it moved forwards, a rather radical departure from business as usual.

The European Commission team enshrined these ideas in the grant agreement signed with ICRAF; it was then possible for Prabhu to structure this project using principles of collaborative learning. Establishing trust and a basis for collaboration among the research and delivery partners was essential, but a challenge as the integration of research into development in this way was seen as novel there and participants had no real experience of working together. Susan Chomba joined the team as its project manager several months later and instituted a culture of trust, high standards and negotiated agreements that allowed congenial and productive working relationships to emerge and collaborative processes to take root. Institutionally, these were based in the committees, teams, workshops, sharing events and continuous outreach that Chomba and her team led, modelling behaviours that engendered trust.

Just as essential as the collaborative engagement among the project participants was the means to learn effectively together. This meant stepping back from a standard technology transfer model to one where knowledge was cocreated based on the analysis of credible evidence. This meant structuring the project so that evidence and related learning loops would be "hard wired" into it. This was done in two ways - dedicated teams would deliver evidence, some of it co-created, into soft-institutional platforms (informal structures, where rules of engagement are agreed though not formally) where participants could analyse and learn from it. A monitoring, evaluation and learning team (MEL) was designed into the project, and it developed an approach to measuring change based on modifications to standard, mostly extractive techniques of establishing baselines and endlines.

ICRAF has some of the best remote sensing tools for assessing change over time to soil and biomass, and a land degradation dynamics (LDD) team (Leigh Winowiecki and Tor Vagen) was charged with providing this layer of information. The SHARED team, led by Mieke Bourne and Neely, would deliver information from interactive meetings that considered what people understood 
to be happening in the project landscapes; the MEL and LDD teams also provided relevant information. The transfer of the technology team (design techniques implementation - DTI) responded to all three and to information they received from their own meetings with communities and partners, surveys and other assessments. Two further soft institutional platforms were designed into the project at the outset: First, a steering committee that involved the European Commission and all the project implementing partners. This assessed progress against the targets and helped to make adaptive changes to structures, shift funding or even deploy additional funding. This last change became an option as the European Commission and the European Parliament gained faith in the project and what it was achieving. Second, in each of the eight countries, a national stakeholder committee (NOCC) was constituted to guide implementation and adaptation in that country. ${ }^{10}$

Three and a half years into the implementation of this project, learning and adaptation are firmly established in its DNA. So much so that the team has continued to innovate and develop additional collaborative learning mechanisms and opportunities. At the end of the first year, they developed and successfully carried out "joint reflection and learning missions" (JRLMs, see Neely and Bourne 2021); and when the COVID-19 pandemic hit in 2020, they successfully took these missions into cyberspace. Approaches such as "planned comparisons" that promoted experiential learning with the farming communities were introduced, so that new technologies or tree species could be adopted (or not) and adapted to farmers' needs. Throughout the process, an "options by context" approach has been applied to ensure proposed changes and solutions suit the intended beneficiaries and were fit for the social and ecological contexts within which they were being applied. The communications team worked to ensure that information generated in one location could be shared across all. This involved using multiple channels including social media and especially WhatsApp groups, which have proved enormously popular among project participants.

A more recent innovation is a new mobile application (created by Vagen, Ahmad and Winowiecki) that helps lead farmers, government extension agents and project officers to collect data on key indicators of land restoration such as the number and type of species of trees planted; those that survived over different time periods; the GPS location of tree nurseries and the type of tree species they stock; the polygons and management practices in farmer-managed natural regeneration (FMNR) sites; the trainings offered to farmer groups, including women and youth beneficiaries; among other variables. It has become an additional way of monitoring their progress, with data they have generated and which is accessible to them on their own smartphones through a user-friendly online data-reporting system.

While the project has paid great attention to collaboration, learning and adaptation among project investors and implementors, it is less clear how all of this has impacted the communities concerned. ${ }^{11}$ It will not be enough to simply assume that because of discernible changes on the ground in terms 
of tree cover, adoption of new techniques or new tree or shrub species that communities have internalized the kinds of social learning approaches we have identified as ACM or have gained the benefits that have accrued at lower scales. At the same time, a project that had the aim of regreening Africa at 20 euros per hectare would have no hope of meeting its targets if there were no collaborations from the communities concerned and if they were unable or unwilling to adapt. Indeed, current assessments of adoption, innovation and adaptation are very encouraging. While it is still unclear that the ambitious targets will be met, benefits to communities from their endeavours and changes in attitudes and behaviours of development partners are being recorded.

Olaf Westermann of Catholic Relief Services has noted that the nature of the project's structure forced a paradigm shift. "The idea of different international NGOs, who otherwise would be competitors, working together to deliver a common goal is, in itself, a great paradigm shift," he said.

\section{Beyond the horizon: Last thoughts}

There's little doubt that over the last 20 years, there's been a significant global paradigm shift about development, conservation and natural resource management (see Box 10.2).

\section{BOX 10.2 A GLOBAL PARADIGM SHIFT}

Many have recognized that we need:

- new approaches based on systems thinking;

- involvement of a variety of stakeholders in management and governance;

- better interaction between the local scale - such a central focus in the earliest ACM work $^{12}$ - and broader scales;

- recognition that farmers and other rural dwellers have key contextual information, experience and knowledge warranting respect;

- acknowledgement that marginalized groups exist within communities and vis-à-vis other national and international actors, and that the views of such people deserve attention; and

- $\quad$ understanding how power differentials can have devastating results as policies are developed and implemented (or not).

Still, more traditional approaches tend to prevail, particularly in global responses to climate change and biodiversity loss, which are still based largely on topdown visions (e.g., REDD+, zero deforestation commitments, nature-based 
solutions, forest landscape restoration). Local peoples are still an afterthought, or a group to be "safeguarded," or perhaps convinced to change their practices, rather than being seen as equal partners in change.

In addition, our continuing perusal of NRM literature convinces us of a global shortage of needed skills - to conduct research, facilitate collaboration and learning loops, formalize plans and develop policies that respect the above observations. Awareness of this shortcoming has been one of our motivations for pulling together the analyses in this book (and a forthcoming collection on the same topic). We have introduced some tools and procedures we found useful in conducting ACM; shown how these have evolved; and considered how such approaches can be used beyond the forest.

In Chapters 2, 4 and 5, we looked at the details of ACM and PAR processes (processes which can most usefully be seen as an overlapping part of a Venn diagram). Within our own (the editors') work, we have seen PAR as a tool to help bring about ACM, though not everyone sees it that way. Both concepts, however, include iterative learning cycles, one of ACM's most central attributes. All three of these chapters, using different methods and styles, convey the process of ACM as well as some evaluation of its functioning (in Bolivia and Uganda).

We then discussed more specific issues that need addressing in any ACM project: ensuring good interdisciplinary collaboration (Chapter 3); training participants in the approach itself (Chapter 6); and one way groups can monitor their interactions to ensure inclusivity (Chapter 7).

In Chapters 1, 8 and 9, we delve into first the theoretical background of the original conceptualization of ACM, along with reflections on the editors' varied perspectives and backgrounds (1); then more recent theories and considerations as ACM has evolved, focusing particularly on issues of power (8); and finally, an overview of the use of action research in various sectors and contexts, demonstrating its versatility and broad applicability, a topic we have continued in this chapter (10), emphasizing attempts to move up and outwards with ACM-style approaches.

Meanwhile, we will make other efforts to encourage the development of the skills needed to conduct research and action that attend to issues like those listed in Box 10.1. Colfer and Larson are both also working, for instance, on forest landscape restoration, where the lack of attention to local level realities is striking (also identified, e.g., in collections by Mansourian and Parrotta 2018 or Butler and Schultz 2019). They and their colleagues are working to rectify this situation (e.g., in this volume and in one by Katila et al. under development). Larson and her team continue to work on multi-stakeholder platforms and processes, not simply to support their existence but also their quality, with regard to equity and social inclusion (see https://www.cifor.org/toolboxes/tools-for-managing-land scapes-inclusively/). Prabhu's work in agroforestry has identified shortcomings in their research as well, much of it captured in the agricultural cases in this chapter.

About the time this book appears, the global community will be preparing to meet to discuss the critical contributions that smallholder agriculture, forest-dependent people and those involved in the supply chains that originate 
in the forested and treed landscapes of our small planet, as well as discussions on preventing - or exacerbating - forest and biodiversity loss, greenhouse gas emissions and losses of soil fertility. If there is anything we can offer the global community it is this: these people are both exploiters and stewards of the land. How we view them, and how they view themselves, will determine which trajectory or spiral of change emerges - towards improvement or towards further degradation. The triskelion is agnostic about its direction - it can devour or protect. ACM offers a spiral of improvement and empowerment, where people are viewed and treated, and view themselves, as inter-generational stewards of all that the land produces, tangible and intangible.

\section{Notes}

1 A clear use of "ACM" as the desired endpoint as well as the process of getting there.

2 Three draft chapters for our second ACM volume document changes over time (since the early 2000s): two in Indonesia, where national conflict levels have been low and success substantial (e.g., successful formalization of local management rights in a local forest, widespread trust among stakeholders at different levels, and continuing collective action locally; Yuliani et al. 2021 (in draft form), Liswanti, Tamara, and Arwida 2021 (in draft)); one in Zimbabwe, where some local capabilities linger, but efforts to institutionalize triskelion style processes at higher levels stalled due to national crises, political and economic implosion and the disappearance of trained personnel in the Ministry of Forestry (Kozanayi et al. 2021 (in draft)).

3 For examples from earlier work, see e.g., Wiliam-deVries (2006) for an approach that successfully overcame Islamic concerns about ACM, feared to be trying to negate women's "legitimate fate" as submissive homemakers in Indonesia; or Bolaños and Schmink (2005) for community antagonism to women's involvement in logging enterprises in Bolivia.

4 See e.g., Colfer and Pfund (2011) for a CIFOR-based comparative study; or Butler and Schultz (2019) for a rather similar, US-based collaborative programme operating at a larger landscape level (also Colfer and Prabhu 2021 (in draft)).

5 Clearly, we can and often do use them for specific purposes within the umbrella of ACM.

6 That these authors from Jambi and Zimbabwe respectively, conducted these return visits without any financial incentives is evidence of their continuing interest in the approach and its impacts. Indeed, we provided no funding for the participation of any of the authors of this book (though some have been able to consider it part of their normal job).

7 Two initial sites had trouble nearly from the beginning (Ghana, Kyrgyzstan).

8 Unfortunately, this image does not fully capture the evolving and responsive aspect of the process.

9 The researchers worked with an inter-institutional working group in developing the second Turkana County Integrated Development Plan (CIDP), led by the Department of Finance and Economic Planning.

10 These two kinds of committees were extremely helpful in the original ACM programme as well.

11 CIFOR's Landscape Mosaics programme, in five countries, had similarly worded planning documents; but the learning and empowerment processes were never truly implemented in the field, so the anticipated community benefits were unlikely to have been forthcoming. Hopefully, Regreening Africa has learned from such shortcomings elsewhere. 
12 This was partly because of the dearth of information about life at local scales being taken into account in forest policymaking at the time (a similar rationale to that of Women in Development specialists in the 1970s who were filling a gap before attending to gender dynamics).

\section{References}

Bolaños, Omaira, and Marianne Schmink. 2005. "Women's Place is Not in the Forest: Gender Issues in a Timber Management Project in Bolivia.” In The Equitable Forest: Diversity, Community and Resource Management, edited by Carol J. Pierce Colfer. Washington, DC: Resources for the Future/CIFOR.

Butler, William H., and Courtney A. Schultz, eds. 2019. A New Era for Collaborative Forest Management: Policy and Practice Insights from the Collaborative Forest Landscape Restoration Program. London: Earthscan/Routledge.

CIFOR. 1999. CEI Toolbox. 9 vols. Bogor, Indonesia: CIFOR.

Colfer, Carol J. Pierce, ed. 2005. The Equitable Forest: Diversity, Community and Resource Management. Washington, DC: RFF/CIFOR.

Colfer, Carol J. Pierce, and Jean-Laurent Pfund, eds. 2011. Collaborative Governance of Tropical Landscapes. London: Earthscan, CIFOR.

Colfer, Carol J. Pierce, and Ravi Prabhu. 2021 (in draft). "From Sustainable Forest Management to Forest Landscape Restoration: Comparison of Two Participatory Approaches." In ACM Volume 2, edited by C. Colfer, R. Prabhu and A. Larson.

Colfer, Carol J. Pierce, Jean-Laurent Pfund, with Etienne Andriamampandry, Stella Asaha, Amandine Boucard, Manuel Boissière, Laurène Feintrenie, Verina Ingram, Emmanuel Lyimo, Endri Martini, Salla Rantala, Michelle Roberts, Terry Sunderland, Zora Lea Urech, Heini Vihemaki, Vongvilai Vongkhamsao, and John Daniel Watts. 2011. "An Introduction to Five Tropical Landscapes, their People and their Governance." In Collaborative Governance of Tropical Landscapes, edited by Carol J. Pierce Colfer and Jean Laurent Pfund, 1-34. London: Earthscan.

Colfer, Carol J. Pierce, Ramadhani Achdiawan, Hasantoha Adnan, Moira Moeliono, Agus Mulyana, Elok Mulyoutami, James R. Roshetko, E. Linda Yuliani, with Balang, and LepMil. 2015a. "Preparing the Ground for Better Landscape Governance: Gendered Realities in Southern Sulawesi." Forests, Trees and Livelihoods 24 (1): 59-83. http://dx. doi.org/10.1080/14728028.2014.951002.

Colfer, Carol J. Pierce, Ramadhani Achdiawan, James M. Roshetko, Elok Mulyoutami, E. Linda Yuliani, Agus Mulyana, Moira Moeliono, Hasantoha Adnan, and Erni. 2015b. "The Balance of Power in Household Decision-Making: Encouraging News on Gender in Southern Sulawesi." World Development 76: 147-164.

Cronkleton, Peter, Deborah Barry, Juan M. Pulhin, and Sushil Saigal. 2010. "The Devolution of Management Rights and the Co-Management of Community Forests." In Forests for People: Community Rights and Forest Tenure Reform, edited by Anne Larson, Deborah Barry, Ganga Ram Dahal and Carol J. Pierce Colfer, 43-68. London: Earthscan/CIFOR.

Evans, Kristen, Sandra J. Velarde, Rocio P. Prieto, Sheila N. Rao, Sandra Sertzen, Karina Dávila, Peter Cronkleton, and Wil De Jong, eds. 2006. Field Guide to the Future: Four Ways for Communities to Think Ahead. Nairobi, Kenya: CIFOR, ASB, ICRAF.

Evans, Kristen, Selmira Flores, Anne M. Larson, Roberto Marchena, Pilar Müller, and Alejandro Pikitle. 2017. "Challenges for Women's Participation in Communal Forests: 
Experience from Nicaragua's Indigenous Territories." Women's Studies International Forum 65: 37-46.

Evans, Kristen, Anne M. Larson, and S. Flores. 2020. "Learning to Learn in Tropical Forests: Training Field Teams in Adaptive Collaborative Management, Monitoring and Gender." International Forestry Research 22 (2): 189-198.

Fisher, Micah R., Timothy Workman, Agus Mulyana, Balang Institute, Moira Moeliono, E. Linda Yuliani, Carol J. Pierce Colfer, and Urban El Fatih Bani Adam. 2020. "Striving for PAR Excellence in Land Use Planning: Multi-stakeholder Collaboration on Customary Forest Recognition in Bulukumba, South Sulawesi." Land Use Policy 99: 102997.

Flores, Selmira, Kristen Evans, Anne M. Larson, Alejandro Pikitle, and Roberto Marchena. 2016. "Participation of Rural Indigenous Women in Community Governance." CIFOR InfoBrief 151: 4.

Gnych, Sophia, Steven Lawry, Rebecca McLain, Iliana Monterroso, and Anukram Adhikary. 2020. "Is Community Tenure Facilitating Investment in the Commons for Inclusive and Sustainable Development?" Forest Policy and Economics 111.

Guijt, Irene. 2007. Negotiated Learning: Collaborative Monitoring for Forest Resource Management. Washington, DC: RFF/CIFOR.

Hughes K., Oduol J., Kegode H., Ouattara I., Vagen T., Winowiecki L. A., Bourne M., Neely C., Ademonla D. A., Carsan S., Van Schoubroeck F., and Chomba S. 2020. Regreening Africa Consolidated Baseline Survey Report. Nairobi, Kenya: World Agroforestry. Indriatmoko, Yayan, Linda Yuliani, Yunety Tarigan, Farid Gaban, Firkan Maulana, Dani Wahyu Munggoro, Dicky Lopulalan, and Hasantoha Adnan, eds. 2007. Dari Desa ke Desa: Dinamika Gender dan Pengeloalaan Kekayaan Alam [From Village to Village: Gender Dynamics and the Management of Nature's Wealth]. Bogor, Indonesia: CIFOR.

Katila, Pia, Carol J. Pierce Colfer, Wil Dejong, Glenn Galloway, Pablo Pacheco, and Georg Winkel, eds. n.d. under development. Restoring Forests and Trees for Sustainable Development: Policies, Practices, Impacts and Ways Forward.

Komarudin, Heru, Yuliana L. Siagian, Carol J. Pierce Colfer, with Neldysavrino, Yentirizal, Syamsuddin, and Deddy Irawan. 2012. "The Role of Collective Action in Securing Property Rights for the Poor: A Case Study in Jambi Province, Indonesia." In Collective Action and Property Rights for Poverty Reduction, edited by Esther Mwangi, Helen Markelova and Ruth Meinzen-Dick, 235-269. Philadelphia, PA: University of Pennsylvania Press.

Kozanayi, W., R. Nyirenda, T. Mutimukuru, F. Matose, M. Ngwenya, and L. Sibanda. n.d. under development. Sustaining ACM Processes: Challenges and Opportunities from Mafungautsi State Forest, Gokwe, Zimbabwe.

Liswanti, Nining, Ade Tamara, and Shintia Arwida. 2021 (in draft). n.d. under development. Trust Building in a Multi-stakeholder Forum in Jambi, Indonesia.

Mansourian, Stephanie, and John Parrotta, eds. 2018. Forest Landscape Restoration: Integrated Approaches to Support Effective Implementation. New York: Routledge/Earthscan.

Marald, Erland, Camilla Sandstrom, Annika Nordin, and others. 2017. Forest Governance and Management Across Time: Developing a New Forest Social Contract. London: Routledge/ Earthscan.

McDougall, Cynthia, Bishnu Hari Pandit, Mani Ram Banjade, Krishna Prasad Paudel, Hemant Ojha, Manik Maharjan, Sushila Rana, Tara Bhattarai, and Sushma Dangol. 2009. Facilitating Forests of Learning: Enabling an Adaptive Collaborative Approach in Community Forest User Groups: A Guidebook. Bogor, Indonesia: CIFOR.

McDougall, C., H. Ojha, M. Banjade, B.H. Pandit, T. Bhattarai, M. Maharjan, and S. Rana. 2010. Forests of Learning: Experiences from Research on an Adaptive Collaborative Approach to Community Forestry in Nepal. Bogor, Indonesia: CIFOR. 
McDougall, Cynthia L., Cees Leeuwis, Tara Bhattarai, Manik R. Maharjan, and Janice Jiggins. 2013. "Engaging Women and the Poor: Adaptive Collaborative Governance of Community Forests in Nepal." Agriculture and Human Values 30: 569-585.

Neely, C. and M. Bourne. 2021. "Regreening Africa Joint Reflective Learning Missions 2020." Nairobi: ICRAF. https://regreeningafrica.org/wp-content/uploads/2021/04 /2020_Regreening-Africa-JRLM-Summary_ONLINE_31_03_21.pdf

Neely, C.L., M. Bourne, S. Chesterman, T-G. Vågen, V. Lekaram, L.A. Winowiecki, and R. Prabhu. 2021. Inclusive, Cross-sectoral and Evidence-based Decision Making for Resilience Planning and Decision Making in a Devolved Context. European Journal of Development Research 33 (40): 1115-1140.

Barletti Sarmiento, Juan Pablo, and Anne M. Larson. 2020. "Paradigms for Participation in Multi-stakeholder Forums: Lessons from a Realist Synthesis Review." CIFOR Infobrief 281.

Vågen, T.-G., L. A. Winowiecki, C. Neely, S. Chesterman, and M. Bourne. 2018. "Spatial Assessments of Soil Organic Carbon for Stakeholder Decision-making: A Case Study from Kenya." Soil 4: 259-266.

Vanclay, Jerome K., Ravi Prabhu, and Fergus Sinclair. 2003. "Special Issue on Participatory Modelling of Community Forest Landscapes." Small-Scale Forest Economics, Management and Policy 2 (2): 117-326.

Vanclay, Jerry, Ravi Prabhu, and Fergus Sinclair. 2006. Realizing Community Futures: A Practical Guide to Harnessing Natural Resources. London: Earthscan.

Wiliam-deVries, Dede. 2006. Gender Bukan Tabu: Catatan Perjalanan Fasilitasi Kelompok Perempuan di Jambi [Gender is not Taboo: Field Notes on Facilitating Women's Groups in Jambi. Bogor, Indonesia: CIFOR.

Winowiecki, Leigh Ann, Mieke Bourne, Christine Magaju, Constance Neely, Boniface Massawe, Patricia Masikati, Tor-Gunnar Vågen, Faith Musili, Muhammad Nabi, Anthony Nguyo, Hadia Seid, Kiros Hadgu, Aikande Shoo, Howard Tembo, Floyd Chipatela, Sabrina Chesterman, Karl Hughes, Emmanuel Temu, Anthony Anderson Kimaro, and Fergus Sinclair. 2021. "Bringing Evidence to Bear for Negotiating Tradeoffs in Sustainable Agricultural Intensification Using a Structured Stakeholder Engagement Process." International Journal of Agricultural Sustainability: 1-23. doi:10.1080/14735903. 2021.1897297.

Wollenberg, Eva, David Edmunds, and Louise Buck. 2000. Anticipating Change: Scenarios as a Tool for Adaptive Forest Management (a Guide). Bogor, Indonesia: CIFOR.

Wollenberg, Eva, David Edmunds, Louise Buck, Jefferson Fox, and S. Broch, eds. 2001a. Social Learning in Community Forests. Bogor, Indonesia: CIFOR.

Wollenberg, Eva, Jon Anderson, and David Edmunds. 2001b. "Pluralism and the Less Powerful: Accommodating Multiple Interests in Local Forest Management." International Journal of Agricultural Resources, Governance and Ecology 1 (3/4): 199-222.

Yuliani, Elizabeth Linda, Hasantoha Adnan, Carol J. Pierce Colfer, and Yayan Indriatmoko. 2015. "Problem-solving Versus Appreciative Inquiry Approaches in Community-based Conservation." Forests, Trees and Livelihoods: 97-111. doi: 10.1080/14728028.2014.954638.

Yuliani, Linda, Moira Moeliono, Yanti Kusumanto, Marzoni, Effi Permatasari, Hasantoha Adnan, Yayan Indriatmoko, and Carol J. Pierce Colfer. 2021. n.d. in preparation. "Revisiting Baru Pelepat: Life after ACM." 


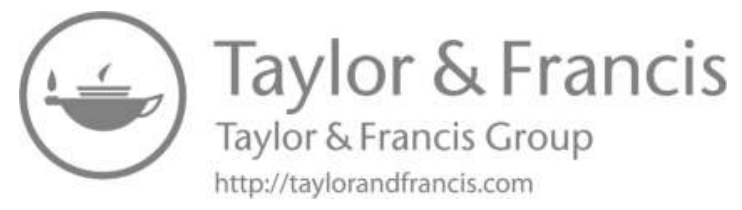




\section{Index}

Note: Page numbers in italics indicate figures and bold indicate tables in the text.

Achagituni, Vitus 154

Acholi ethnic group 91

ACM training process see capacity building for ACM

ACM Zim News 82n5

action learning 31-60; chaco visit 40; chronological overview of 34 ; Cobija visit 45-46; community visit 38 ; contextualization 31-33; council meeting 35-44, 57; delivery of chicks 49; Dr Rodríguez 50; Martinez, Pedro 33-35; meeting of council directors 36; meeting of men's local research group 49-50; meeting of women's local research group 47-48; practical course on chicken keeping with Dr Emilio 55-56; PROMETE offices in Cobija 36-37; radio message 44-45; surviving chicks collection 54-55; town hall visit in Puerto Rico 46-47; visit of an inspector from INRA 56; visit of Ing. Rosmery to Nuevo Horizonte 52-54; visit of Ing. Rosmery with Dr Emilio 55; visit of INRA survey team 56; Walter's visit to the Federation Offices and INRA in Cobija 50-52; women's leadership roles in $\mathbf{1 2 1}$

action research 19, 31-32, 35, 39-42, 44, 54, 57, 219-221; defined 221-223; experiences with 223-232; livelihoods and landscapes strategy 230-232; NepalAustralia Forestry Project 224-227; outcomes of 227; at University of Western Sydney, Hawkesbury 228-230; see also participatory action research (PAR) adaptive collaborative governance 14 , 19, 209 adaptive collaborative management (ACM) 1-20, 111, 170-171, 218234, 239-243; capacity building for 134-154; concerns about 219-221; from cycle to spiral 243-246; decision making 87; defined 2, 239-243; group activities 125-126; impact on gender equity 107 ; implementation groups 113; implementation of activities 115; initial rollout of 13-16; intellectual forebears 8-16; intellectual influences 13-16; justification for approach $2-3$; key element of 111 ; leadership in groups 120; learning from 159-178; leverage changes in power 186-210; in Nepal 188; versus non-ACM sites 93-99, 94; overview 1-2; paths to 4-8; performance of forest user groups 122-127; potentially promising approach 187; power-reproducing dynamics 188 ; principles of 3, 160; sites $\mathbf{9 1}$; spiralling out 246-247; in Uganda 88; version of $3,20 \mathrm{n} 4$

adaptive co-management 5

Addoah, Thomas 153

advancing gender inclusion in forest management 115-122

Afagachie, Kenneth 154

Agarwal, Bina 16

agency 199-201

Agrawal, Arun 15 agriculture: ACM 148-149, 246; aquatic 72, 82n1; Aquatic Agricultural Systems (AAS) Program 61; disciplines within 11; factors role in $\mathbf{6 3}$; floodplain 64-65; improvements 247; innovation in rural Cambodia 228; international agricultural 


\section{Index}

research institutions 68; land for production 110; land intensification 124; natural resource systems and 62; poor productivity 82n3; processes in 150-151; professional technicians $60 \mathrm{n} 1$; social research with 228; in southwest Ghana 230; swidden 9 agro-ecological zones 88, 91, 109 agroforestry 31, 110, 113, 117, 129n4, 165, 247, 252, 255

Alto Mayo Protected Forest 171-172

Amarakaeri Communal Reserve 168, 171-172

analysis: componential 9; data analysis 92; power and communication 12; principal component analysis (PCA) 92; taxonomic 9

Anderson, Jon 12

"aquarium" (fishbowl) method 139

Aquatic Agricultural Systems (AAS) Program 61, 63, 66, 74, 82n1

Archer, M. S. 199, 200, 202

Ardener, Shirley 13

Armitage, Derek R. 20n4

Arora-Jonsson, S. 106

Asian Development Bank 5

Aswa river plain 88, 91

Atmadja, Stibniati 161

Austrian Development Agency (ADA) 103, 129,153

authoritative knowledge 12

availability/abundance of forest resources $\mathbf{1 0 0}$

Axelrod, R. 13

Bäckstrand, K. 198

Baganda 110

Bakonzo ethnic group 91

Bardhan, P. 15

Barletti, Sarmiento 18, 19, 158

Barotse Floodplain PAR process 61, 63, 64, 64, 66, 68, 70-72

Barotse Royal Establishment 65

Basefeli, Stella 154

benefit distribution mechanisms in

Guarayos, Bolivia 136-141

Berry, Sara 15

Bioversity 68

Bolivia 17, 18, 60n3, 136-141

Bolivian Sustainable Forest Management Project (BOLFOR) 136-138, 141

Bomuhangi, Allan 17-18, 86, 241, 243

Bourdieu, P. 196, 199, 202, 206

Brahmin women 192-193

Brazil 5, 7, 17, 18, 163
Bucholtz, M. 195

Buck, Louise 5, 6, 14

Bulozi Plain see Barotse Floodplain

Cambodia 19

Cameroon 7

capacity building for ACM 134-154; case study 136-149; experimentation processes 135; "learning by doing" 149-150; learning from cases 149-152; methods 135-136; overview 134-135

Carey, G. 204, 206

case study: benefit distribution mechanisms in Guarayos, Bolivia 136-141; encouraging farmers in northern Ghana 146-149; Indigenous women in territorial and forest governance in Nicaragua 141-146; multi-stakeholder forums (MSF) 164-165

Cedro 41, 60n3

Center for International Forestry Research (CIFOR) 4-7, 9, 11-13, 80, 88, 103n1, 137, 142, 154n1, 160, 220

central forest reserves (CFR) 110, 111, 113, 116-118, 117, 123

Chambers, Robert 12, 225

Chapman, E. C. 9-10

Chappell, L. 193, 200, 210n5

China 19

coca $38,60 \mathrm{n} 2$

Cohen, M. D. 13

Colfer, Carol J. Pierce 4-15, 80, 209, 219

collaboration level $\mathbf{6 7}$

Collaborative Adaptive Management (CAM) group 20n4

collaborative forest management (CFM) $87,103,116,123$

collective action 10

Collective Action and Property Rights (CAPRI) 3, 10, 12

communication system 78

community-based natural resources management (CBNRM) 186, 188, 191, 194, 196-197, 201; development 192; equity and 191-192; literatures 193; pro-poor and inclusive 189; variety of initiatives in 187

Community Based Organizations (CBO) 122

community decision-making forums 142 community dream $72-73,73$ community forestry in Nepal 188-191 community forestry organization (CFO) 137-141 
community forest user groups (CFUG) 189-190

community-level plans 73

Compass and Gyroscope (Lee) 5-6

componential analysis 9

Conklin, Harold C. 9

Consultative Group of International Agricultural Research (CGIAR) 6, 10,63

Cornell University 20n4

Côte d'Ivoire 5

Cedrela odorata $60 \mathrm{n} 3$

criteria and indicators (C\&I) 4-5, 13

Cronkleton, Peter 7, 18, 133

Cropper, Angela 13

cultural coherence 16

cultural imperialism 16

cultural norms 93, 102, 107, 110, 115, 117, 128, 130n2, 192-193

Cururú 136-138

Dalit 190, 195-196

delegation 197-199

deliberative decision making 203-205

dependence on forest products $99-100$

De Sy, Veronique 177

Dickinson, H. 204, 206

disciplinary collaboration 66; see also interand trans-disciplinary collaboration; multi-disciplinary collaboration; transdisciplinary research

Djoudi, Houria 153

Dove, Michael R. 10

doxa 196-197

Dudley, Richard 13

East Kalimantan's Provincial Council on Climate Change 172

Ecuador 17

Edmunds, David 12, 14

Emadi, Mohammad 7, 10, 229

encouraging farmers in northern Ghana 146-149

Environment and Natural Resources Subsector Gender Mainstreaming Strategy 87,88

equity 2, 191-192

Escobar, Arturo 12

Ethiopia 18, 163

Eucalyptus 117-118

Evans, Kristen 14, 18, 133

factors for participation in forest management 95-99, 96, 99 farmer-managed natural regeneration (FMNR) 253

Farmers of the Forest (Kunstadter, Chapman, and Sanga) 10

Farming Systems Research and Development (FSR \&D) 11

Farnworth, C. R. 210n6

feminist theory 15, 187-188, 193, 201, 203, 206, 208-209

Ferguson, James 11

Ficus natalensis 116-117

Fiore, Q. 196

Fisher, R. J. 7, 10, 19, 217, 221, 226

floodplain: aquatic agricultural systems and 82n1; Barotse Floodplain 61, 63, 64, 64, 66, 68, 70-72, 82n1; cultural significance to Lozi people 65; designated a Ramsar site 64 ; heavy reliance by 65 ; potential for agricultural and ecosystem services 64; tidal variations of 65; Zambezi Floodplain 64

flood risk management 73

forest-based activities 113

forest-dependent communities 161

Forest Land Oriented Resource Envisioning System (FLORES) 13

forest management 106; advancing gender inclusion in 115-122; collaborative 87; men's and women's participation in 93-99; public vs. private 86; sustainable 87; women in Mafungautsi Forest Reserve 108; women's involvement in 86, 88, 91-92, 106; World Bank forestry strategy 106

forest products in ACM and non-ACM sites 99

Forest Sector Support Department (FSSD) 87,88

forest user groups: conflict resolution 124; improved formalization of 122-123; income-generating activities 124-127; participation in CFM activities 123; performance of, using ACM 122-127; relationship between local communities and other stakeholders 123-124

ForLive project 29, 33-35, 39, 51, 53, 59

Fox, Jefferson 15

FPIC (Free, Prior, and Informed Consent) 15

Freire, Paulo 12, 21n24

Friction (Tsing) 11

Galiè, A. 210n6

Gaventa, John 15 


\section{Index}

gender: collaborative resource governance and 107-109; concept of 191; dimension of forest product and income use 101, 101-102; efforts 16; equality 106, 113, 128, 186, 201; institutional concerns about 16; issues 13 ; literature 16; relations 193; significant masculine dominance 16 ; training 120 ; transformation 73

gender and ACM in Uganda 87-103; data analysis 92 ; dependence on forest products 99-100; factors for participation in forest management 95-99, 96, 99; gender dimension of forest product and income use 101-102; household characteristics 92-93; men's and women's perceptions in ACM versus non-ACM sites 93, 95; methodology 88-92; results and discussion 92-102; study area and sampling 88-92, 89, 90

generalizability 5

Ghana 7, 18, 19; northern 146-149

Giddens, A. 199-200, 207

Gilmour, Don 224, 226

global paradigm shift 254

Greenwood, Davydd J. 221

Grevillea 118

Griffin, David 224-225

Guarayo Indigenous community 136-141

Guijt, Irene 14

Guyana 13

Habermas, J. 198

Haggith, Mandy 13

Hall, K. 195

Hartanto, Herlina 13

Hildebrand, Peter E. 11

Hollings, Buzz 5

hub development challenge 72

"imagined" farmer 29

Indigenous community forestry organizations 136-141

Indigenous women in territorial and forest governance in Nicaragua 141-146

Indonesia 3, 5, 7, 9, 18, 163, 172

Indunas 76

ingeniero agronomo $37,60 \mathrm{n} 1$

institutional reluctance 15

inter- and trans-disciplinary collaboration 11

interdisciplinary research 65

interlinked scales 10-11

International Fund for Agriculture and Development (IFAD) 154
International Labour Organisation Covenant 162

International Livestock Research Institute (ILRI) 68

International Steering Committee 12

International Union for Conservation of Nature (IUCN) 218

International Water Management Institute (IWMI) 68, 82n1

Iran 12, 19

iterative process $12-13$

iterative reflection 134

Ives, J. D. 225

Jackson, W. J. 19, 217

Japan 19

Johnson, James 16

Kabeer, N. 191, 193, 196

Kaiser, H. 92

Kelly, George Alexander 9

Kemmis, Stephen 221-222, 234n2

Kemp, C. 187, 202

Kenny, M. 193, 200, 210n5

Kibanja 129n2

knowledge and rationality of forest peoples 9-10

knowledge vis-a-vis power 193

Kunstadter, Peter 9-10

Kuomboka 65

lack of coordination and understanding 79-80

lack of data-sharing mechanisms 80

lack of understanding by researchers $\mathbf{7 1 - 7 2}$

Lake Victoria agro-ecological zone 109, 109

Lake Victoria basin 88-89

land degradation dynamics (LDD) 252

Landscape Mosaics projects/programme 3,12

Larson, Anne M. 7-9, 14-16, 18, 21n23, 133

Latin American movements 15

learning from ACM 159-178; adaptive, context-responsive approach to MSF 168-171; jurisdictional multi-stakeholder forums 163-168; multi-stakeholder forums (MSF) 161-163; tool 171-177

Lee, Kai 5

leverage changes in power 186-210; community forestry in Nepal 188-191; concepts 191-194; imbalances persist 195-201; power shifting 201-208 
Levin, Morten 221

Lewin, Kurt 187, 209n1, 221

Li, Tania 16

Lise, Wietze 97

Livelihoods and Landscapes project (IUCN) 19

Lopez, Citlalli 12

Lozi people 65

Lusaka 68-70

Mabira Forest 91

Mackay, F. 193, 194, 199, 200, 210n5

Madre de Dios 167

Madzudzo, E. 17, 66

Maesopsis 117

Mafungautsi State Forest, Zimbabwe 66, 108

mailo $129 \mathrm{n} 2$

Malawi 7

Mallon, F. 15

management by objectives (MBO) 79, 80

Marald, Erland 10

Maruyama, Magoroh 11

McDougall, Cynthia 6, 13-14, 19, 242

McLuhan, M. 196

McTaggart, Robin 221-222, 234n2

Mead, Margaret 10

Meinzen-Dick, Ruth 10

memoranda of understanding

(MOU) 78

Messerli, B. 225

mestizos 142

Metzger, Duane G. 9

Miskitu Indigenous people 142

Mountain Research and Development 225

muddling 14

Mukasa, Concepta 18, 88, 105, 241, 243-244

multi-disciplinary collaboration 65, 66-67

multi-stakeholder forums (MSF) 159, 161-163; adaptive, context-responsive approach to 168-171; Amarakaeri Communal Reserve 168; annual work plan 174; in Brazil 160; case studies in CIFOR's research 164-165; comparative research project 163-168; fashionable 159; fieldwork findings 160; jurisdictional 163168; "local" indicators 174; participatory processes 161-162; potential limitations of 168; research-based indicators $\mathbf{1 7 3}$; research participants 163-164; role of 159; sustainable land and resource 161; tool 171-177; transformational potential of 159-160, 161-163 multi-stakeholder platforms 159

multi-stakeholder processes 12

Mutimukuru-Maravanyika, Tendayi 14, 17, 19, 61, 66

Mwangi, Esther 7-8, 21n23, 129n1

myth of community 198

Naaba, Jonathan 154

National Forest Authority (NFA) 87, 88, 110, 113, 114, 116, 123

National Forestry and Tree Planting (NFTP) Act 87

National Institute of Agrarian Reform $60 \mathrm{n} 4$

natural resource/agriculture managers factors 62,63

Neely, C. 247-250

Nepal 7, 14, 19, 108, 188-191, 204

Nepal-Australia Forestry Project (NAFP) 218, 222, 224-227

New Zealand 19, 229

Nicaragua 8, 18, 133, 151, 152, 153; ACM project in 8; Caribbean coast of 141 ; decentralization in 141; Indigenous women in 136, 141-146; Northern Caribbean Autonomous Region (RACCN) 142; training for ACM 18

No Condition Is Permanent (Berry) 15 non-ACM sites $\mathbf{9 1}$

Norman, David W. 11

Northern Caribbean Autonomous Region (RACCN) 142

Ojha, Hemant R. 3, 19

Olney, S. 204, 206

Ostrom, Elinor 10

Owubah, Charles E. 97

Panarchy (Gunderson and Holling) 14

participation 87; of women in forest management activities 93-99, 94, 95, 96

participatory action research (PAR) 6-7, 10, 16-17, 61, 62, 65-66, 74, 108, 147-148, 189

participatory exclusions 198

participatory indicators 92

Pearson chisquare $\left(\chi^{2}\right)$ values 92

Peet, R. 15

perceptions on availability/abundance of forest resources $\mathbf{1 0 0}$

Peru 17, 18, 163

Peru's Protected Areas Service (SERNANP) 173

Philippines 7, 9 


\section{Index}

Phillip, P. F. 11

Piggot-Irvine, E. 67

Pine 117

Pokorny, Benno 16

political ecology 8,15

"poor people" 12

power: compound climate risks 186 ;

feature of 191; forms of 194; imbalances 186, 195-201; institutional theory

194; knowledge vis-a-vis 193;

multidimensional concept 191; shifting

201-208; sources of 193; see also leverage changes in power

Power and Powerlessness (Gaventa) 15

Prabhu, Ravi 4-9, 12-15, 20n3, 246

practical outcomes 220

principal component analysis (PCA) 92

productivity 73

progressive contextualization 11

property-rights regimes 110

Psychology of Personal Constructs (Kelly) 9

Purnomo, Herry 13

qualitative research 68, 209n2, 220, 233

quantified impact assessment 5

Realist Synthesis Review method 169, 171, 178n1

reflexivity $68,133-134,185,202-203$, 205, 207

regimes: property-rights 110 ; tree tenure 110

regreening Africa 251-254

researcher collaboration complexities

62-82; Barotse Floodplain PAR process

70-72; collaborative research challenges

65-68; methodology 68-70; overview

62-64; research initiatives in Barotse

73-75; shared visions and planning

72-73; study area 64-65

researcher conflicts 80

research initiatives in Barotse 73-75

research outcomes 220

Ribot, J. C. 198

Ritchie, Helen 229

Roe, Emery 11

Rwenzori Forest National Park 91

Sanga, Sabhasri 9-10

San Martin 167

Saxena, N. C. 5

Schmehl, W. R. 11

second/third class citizens 15

self-determination 15
Sen, Amartya 12

Senanga Safaris in Barotse 70, 75

Shaner, W. W. 11

SHARED 247-251, 249, 250

shared understanding of PAR 77-78

Smith-Dumont, Emilie 153

social change outcomes 220

social justice literature 15

social learning 151-152, 205-208

social movements and revolution 15

social scientific theories 9-13

socio-ecological systems 187

sondeos $11,21 \mathrm{n} 20$

Songe, M. M. 17

Spain 163

Sri Lanka 14

strengthening women's tenure rights

in Uganda 106-130; gender and

collaborative resource governance

107-109; implementation of ACM

activities 115; methodology 110-115;

results and discussion 115-127; study

area 109-110, 111

Subrahmanian, R. 193, 196, 210n4

Sunderland, Terry 100

Sustainable Development Goal 88, 161, 186

sustainable forest management 87,128 , $136,137,144$

systems thinking $12-13$

Taungya $130 \mathrm{n} 6$

taungya system 113

taxonomic analysis 9

team building 77

Thailand 19

Toafa, Tevita 229

Toffler, A. 193, 209

trans-disciplinary research 65

transforming partnership engagement approaches 78

transtemporality 10

travel and subsistence $(\mathrm{T} \& \mathrm{~S})$ allowance 74

tree tenure regimes 110

triadic sorting 9

Tsing, Anna Lowenhaupt 3, 11

Uganda 8, 17, 87; agro-ecological zones 88, 91, 109; girls in 93; Lake Victoria agro-ecological zone 109, 109; natural resources policies 112; see also gender and ACM in Uganda

Uganda Forestry Act 107

United Nations Declaration for the Rights of Indigenous Peoples 162 
United States 5, 12, 163

University of Hawaii (UH) 11

University of Western Sydney,

Hawkesbury (UWS-H) 218, 228-230

unmarked categories 195-196

Uphoff, Norm 14

US Collaborative Forest Landscape

Restoration Program 3

value chains 73

Vanclay, Jerry 13

Vayda, Andrew P. 10

Vayda, A. P. 3, 10-11

von Bertalanffy, Ludwig 13

Wacquant, L. 208

Waldrop, M. M. 13

Walters, Carl 5

Watts, M. 15

Weber, M. 191

West African Forest-Farm Interface

(WAFFI) project 146, 148

wicked problems 1, 14, 239

Williams, Gerald E. 9

Wollenberg, Eva 5-6, 12, 14

Wollenberg, Lini 5, 14 women: attendance and participation in formal meetings 108; in attending community meetings 113; Brahmin 192-193; contributing actively during discussions 113; controlling income/ benefits 113, 118; cultural norms 107; Dalit 190; decision making 121, 121-122, 145; in leadership 113, 121, 121-122, 145; in Mafungautsi Forest Reserve 108; in Nepal 108; ownership of tree resources 114; owning trees 113; participation in forest-related decisions 144; participation in leadership and decision making 119-121; participation in tree planting 115-119; rights and access to forest and tree resources 107 Women in Development (WID) $21 \mathrm{n} 21$ workshop rules $\mathbf{7 6}$

World Bank forestry strategy 106

WorldFish 68-69, 71, 82n1

Zambezi Floodplain see Barotse Floodplain Zambezi River Basin 64

Zambia 61, 64, 68, 71

Zida, Mathurin 153

Zimbabwe 7, 14, 19, 66, 108 


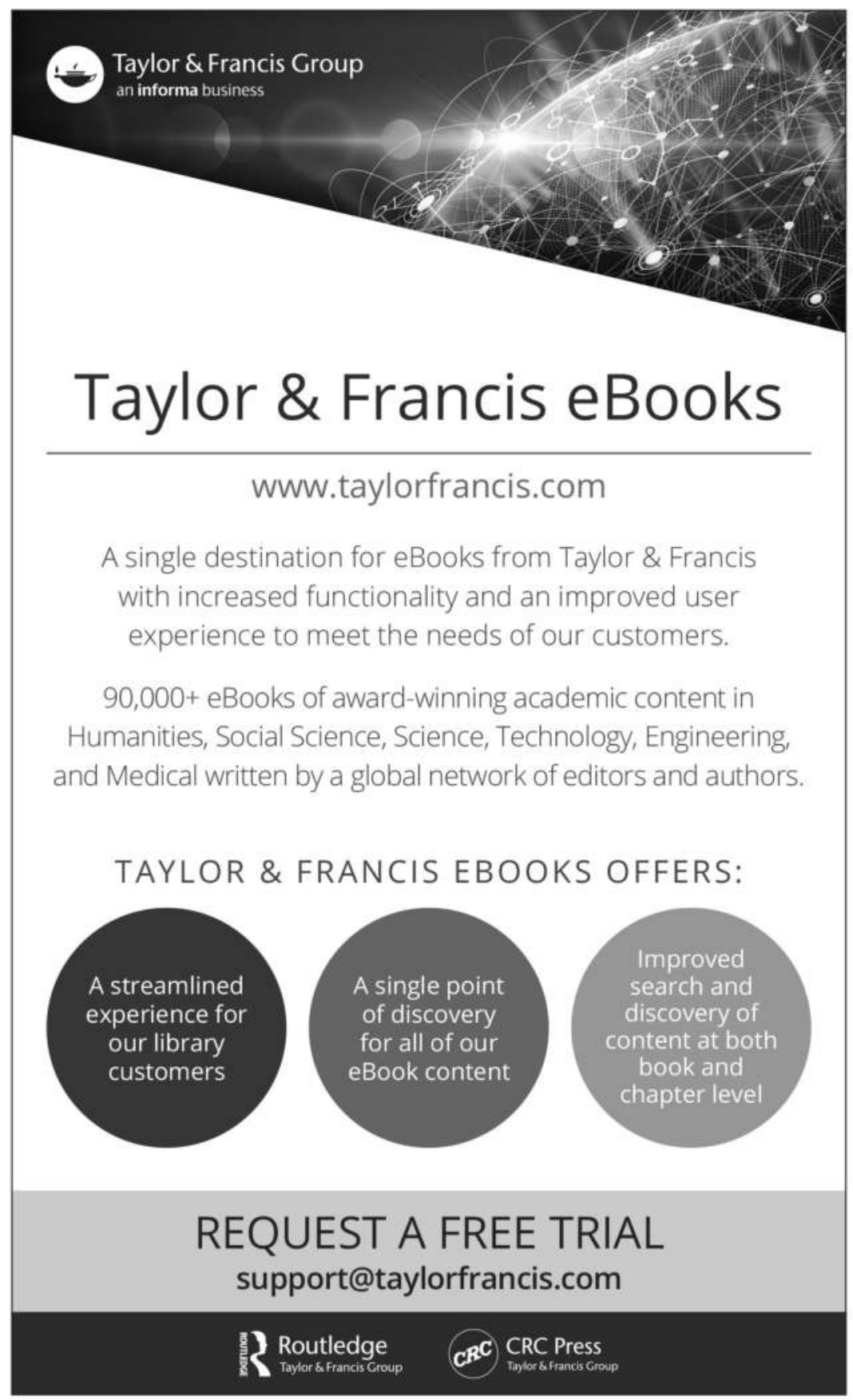

